Uma plataforma para ensino e treinamento em desenvolvimento de sistemas operacionais 

SERVIÇO DE PÓS-GRADUAÇÃO DO ICMC-USP

Data de Depósito: 27 de agosto de 2012

Assinatura:

\title{
Uma plataforma para ensino e treinamento em desenvolvimento de sistemas operacionais
}

\author{
Renê de Souza Pinto
}

Orientador: Prof. Dr. Francisco José Monaco

Dissertação apresentada ao Instituto de Ciências Matemáticas e de Computação - ICMC-USP, como parte dos requisitos para obtenção do título de Mestre em Ciências - Ciências de Computação e Matemática Computacional. VERSÃO REVISADA 
Ficha catalográfica elaborada pela Biblioteca Prof. Achille Bassi e Seção Técnica de Informática, ICMC/USP, com os dados fornecidos pelo(a) autor(a)

\begin{tabular}{|c|c|}
\hline \multirow[t]{3}{*}{ S659p } & $\begin{array}{l}\text { Souza Pinto, Renê } \\
\text { Uma plataforma para ensino e treinamento em } \\
\text { desenvolvimento de sistemas operacionais / Renê } \\
\text { Souza Pinto; orientador Francisco Jose Monaco. -- } \\
\text { São Carlos, } 2012 \text {. } \\
\quad 103 \text { p. }\end{array}$ \\
\hline & $\begin{array}{l}\text { Dissertação (Mestrado - Programa de Pós-Graduação en } \\
\text { Ciências de Computação e Matemática Computacional) -- } \\
\text { Instituto de Ciências Matemáticas e de Computação, } \\
\text { Universidade de São Paulo, } 2012 \text {. }\end{array}$ \\
\hline & $\begin{array}{l}\text { 1. Sistemas Operacionais. 2. Arquitetura e } \\
\text { Organização de Computadores. } 3 \text {. Ensino e } \\
\text { Aprendizagem. I. Jose Monaco, Francisco, orient. II. } \\
\text { Título. }\end{array}$ \\
\hline
\end{tabular}


Feliz aquele que transfere o que sabe e aprende o que ensina.

Cora Coralina 

A minha namorada Juliana, pela companhia em todos os momentos, e aos meus pais Walkmar e Lurdinha, por brindar-me os mais valiosos presentes: a vida e a educação. 



\section{Agradecimentos}

Aos meus pais Walkmar e Lurdinha, e meus irmãos Mirela, Walker e Eneida, pelo eterno apoio e por serem a minha família.

Ao prof. Dr. Francisco José Monaco, pela orientação e pela incalculável ajuda antes e durante a execução deste trabalho, como orientador e como amigo.

A minha namorada Juliana, pelo carinho, amor, e principalmente por me acompanhar com paciência e compreensão nessa longa jornada.

Ao meu inseparável amigo canino Astolfo, sempre ao meu lado durante muitas noites de escrita e programação.

Aos amigos da República Eskória, pelo convívio e pelos momentos felizes.

A todos os amigos, alunos ou professores, do Laboratório de Sistemas Distribuídos e Programação Concorrente (LaSDPC), pelas preciosas sugestões e críticas, sempre construtivas.

A todas as pessoas que nobremente colaboram direta ou indiretamente em projetos livres.

Ao Instituto de Ciências Matemáticas e de Computação (ICMC) e todos seus funcionários, e a Universidade de São Paulo, por sua excelência em ensino e pesquisa.

A Coordenação de Aperfeiçoamento de Pessoal de Nível Superior (CAPES) pelo apoio financeiro.

E a todos que colaboraram direta ou indiretamente para a realização deste projeto. 

Ste trabalho tem como objetivo propor e desenvolver uma plataforma para ensino e treinamento em técnicas de projeto e implementação de sistemas operacionais. Após mais de uma década de hegemonia de alguns poucos produtos comerciais, o estabelecimento do paradigma do software livre e a proliferação de arquiteturas embarcadas capazes de executar um sistema operacional (SO) implicam em demanda de especialistas para atuarem diretamente no desenvolvimento de novos SOs, adequados a novos requisitos das aplicações emergentes. Assim, para além de disciplina de formação teórica, o conhecimento em sistemas operacionais tem reforçado seu caráter prático como competência técnica - perspectiva que este trabalho atende mediante uma abordagem de aprendizado baseado em projetos. A principal contribuição para o estado da arte nesse domínio é um roteiro de instrução que associa teoria e prática por meio do processo de desenvolvimento integral de um sistema operacional funcional. 

DHis work aims at proposing and developing a learning and training platform on design and implementation of operating systems. After more than a decade of hegemony of a few commercial products, the establishment of free software paradigm and the proliferation of embedded architectures capable of running an operating system (OS) increase the demand for specialists to work directly on the development of new operating systems suited to the new requirements of novel applications. Therefore, beyond its function as theoretical background discipline, the area of operating systems has its practical importance highlighted as a technical competence - a perspective which this work meets by means of a project-based learning approach. The main contribution to the state of the art in this domain is an instruction program which associates theory and practice through the process of developing integrally a functional operating system. 

Resumo

$\begin{array}{lll}\text { Abstract } & \text { iii }\end{array}$

Lista de Siglas $\quad$ xi

1 Introdução $\quad 1$

1.1 Contextualização e Motivação . . . . . . . . . . . . . . . . . . . . . . . . . . . . . . .

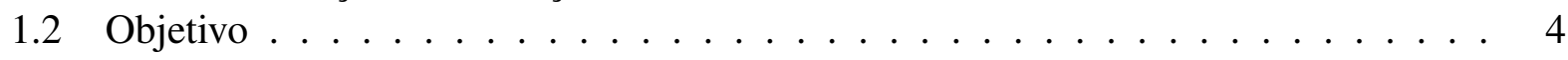

1.3 Organização da Monografia . . . . . . . . . . . . . . . . 4

2 Revisão $\quad 5$

2.1 Trabalhos Relacionados . . . . . . . . . . . . . . . . . . . 6

2.2 Abordagens Baseadas em Projetos . . . . . . . . . . . . . . . . 6

3 Metodologia 9

3.1 Resultados esperados e forma de avaliação . . . . . . . . . . . . . . . . . 11

3.2 Material Didático . . . . . . . . . . . . . . . . . . 13

4 Desenvolvimento $\quad 15$

4.1 Sistemas Operacionais . . . . . . . . . . . . . . . . . . 15

4.2 A Plataforma de Ensino . . . . . . . . . . . . . . . . . . . . . . 19

4.2.1 Visão geral do Sistema Operacional . . . . . . . . . . . . . . . 20

4.2 .2 Arquitetura do Kernel . . . . . . . . . . . . . . . . . 24

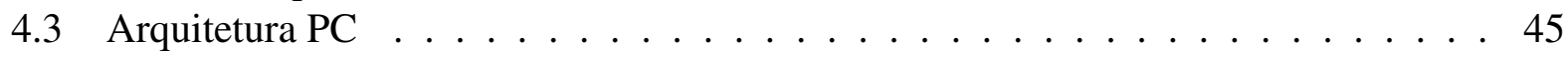

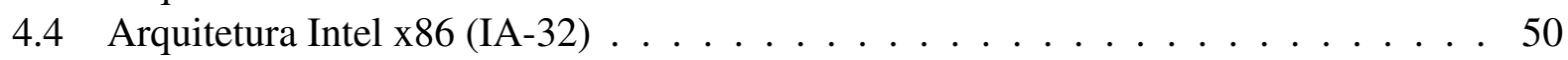

4.4 .1 Visão geral . . . . . . . . . . . . . . . . . 50

4.4 Ambiente Básico . . . . . . . . . . . . . . . . . . 55

4.4 .3 Organização da Memória . . . . . . . . . . . . . . . . 55

4.4 Registradores . . . . . . . . . . . . . . . . . . . . . . 57

4.4 .5 Tabelas GDT, LDT e IDT . . . . . . . . . . . . . . . . 59

4.4.6 Sistema de Paginamento de Memória . . . . . . . . . . . . . . . . 62

4.5 Roteiro passo a passo . . . . . . . . . . . . . . . . . . . 64

4.5.1 Preparação das ferramentas . . . . . . . . . . . . . . . 64

4.5 .2 Sistema de boot . . . . . . . . . . . . . 65 
4.5.3 Funções internas do kernel . . . . . . . . . . . . . . . . . . . . . 69

4.5.4 Controle e configuração de interrupções . . . . . . . . . . . . . . . . 71

4.5.5 Gerenciamento de memória . . . . . . . . . . . . . . . . . . 74

4.5.6 Threads de kernel e o escalonador . . . . . . . . . . . . . . . . 78

4.5.7 Drivers de dispositivos . . . . . . . . . . . . . . . 80

4.5.8 Cache de blocos . . . . . . . . . . . . . . . . 82

4.5.9 Camada VFS e driver para sistema de arquivo . . . . . . . . . . . . . 83

4.5.10 Chamadas ao sistema . . . . . . . . . . . . . . . 85

4.5.11 Execução de aplicativos do usuário . . . . . . . . . . . . . . . . . 86

4.5.12 Notas finais . . . . . . . . . . . . . . . . . . . 88

5 Resultados $\quad 89$

6 Conclusões $\quad 99$

$\begin{array}{ll}\text { Referências } & 101\end{array}$

$\begin{array}{ll}\text { Anexos } & 105\end{array}$ 


\section{Lista de Figuras}

3.1 Alta interdependência na implementação dos conceitos teóricos. . . . . . . . . . . 10

3.2 Relação direta do código implementado com os conceitos teóricos (baixa interdependência). . . . . . . . . . . . . . . . . . . 10

4.1 Arquitetura Microkernel. Fonte (Machado e Maia, 2007). . . . . . . . . . . . . . . 16

4.2 Sistema Operacional: Arquitetura Monolítica. . . . . . . . . . . . . . . . . . 17

4.3 Visão geral do SO, mostrando as camadas envolvidas desde o usuário até o kernel. . 20

4.4 Organização em árvore do sistema de arquivo. Fonte: (Tanenbaum, 2000) . . . . . 21

4.5 Código exemplo para criação de um novo processo. . . . . . . . . . . . . . . . . 24

4.6 Arquitetura do kernel da plataforma TempOS. Figura adaptada de (Bach, 1986). . . 25

4.7 Código assembly (IA-32) para execução de chamadas ao sistema no Linux. . . . . 27

4.8 Código $\mathrm{C}$ usando as chamadas ao sistema open() e close () . . . . . . . . . . . . 28

4.9 Aplicativo efetuando chamada ao sistema open(). . . . . . . . . . . . . . . . 28

4.10 Tabela HASH para os blocos em cache no TempOS. . . . . . . . . . . . . . 31

4.11 Ilustração de um $i$-node apontando para blocos de dados e de endereços (que apontam para blocos de dados) e seus respectivos encadeamentos. . . . . . . . . . . . 33

4.12 TempOS VFS: Estrutura do Superbloco. . . . . . . . . . . . . . . . . . 35

4.13 TempOS VFS: Estrutura do $i$-node . . . . . . . . . . . . . . . . . . . . . . . . . . . . . . . .

4.14 TempOS VFS: Estrutura da tabela de montagem. . . . . . . . . . . . . . . 37

4.15 Mecanismo de montagem feito pelo VFS. . . . . . . . . . . . . . . 38

4.16 Tabelas utilizadas pelo SO para gerenciamento de arquivos e i-nodes. . . . . . . . 40

4.17 Abstração do acesso aos dispositivos de entrada e saídas padrão do processo. . . . 40

4.18 Modelos de gerenciamento de memória: Mapa de bits e pilha. . . . . . . . . . . . . 42

4.19 Filas de processos bloqueados. . . . . . . . . . . . . . . . . . 44

4.20 Uso das rotinas sleep () e wakeup (). . . . . . . . . . . . . . . . . . . . . . 44

4.21 Arquitetura PC . . . . . . . . . . . . . . . . . . . 46

4.22 Esquema de ligação dos PICs Mestre e Escravo à entrada de interrupção da CPU . 47

4.23 Mapeamento do primeiro 1MB de memória na Arquitetura PC. Adaptado de (Intel, 2009). . . . . . . . . . . . . . . . . . 49

4.24 Segmentação de Memória. . . . . . . . . . . . . . . . . . . . . . 51

4.25 Anéis de privilégio na Arquitetura x86. Adaptado de (Intel, 1999a). . . . . . . . . 52

4.26 Ordem dos bits e bytes na memória . . . . . . . . . . . . . . . . . . 54

4.27 Os três modelos de organização da memória na Arquitetura x86. Fonte: (Intel,

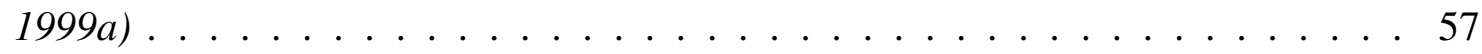

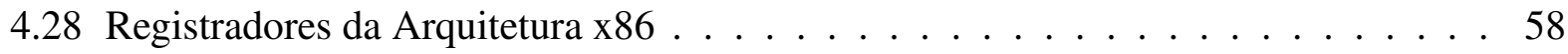


4.29 Estrutura do Descritor de Segmento. Fonte: (Intel, 1999b). . . . . . . . . . . . . . 60

4.30 Estrutura do Descritor de Interrupção. Fonte: (Intel, 1999b). . . . . . . . . . . . . . 61

4.31 Tradução de endereço no Sistema de Paginamento. Fonte: (Intel, 1999b) . . . . . . 63

4.32 Código de boot. . . . . . . . . . . . . . . . . . . . 66

4.33 Esquema de mapeamento da memória de vídeo CGA . . . . . . . . . . . . . . 67

4.34 Script do ld que defina os endereços das seções do arquivo ELF. . . . . . . . . . 68

4.35 Função para escrever um caractere no vídeo. . . . . . . . . . . . . . . . . . 71

4.36 Bloco de memória alocado pela função kmalloc() . . . . . . . . . . . . . . . . 75

4.37 Tradução para o endereço linear, a base do segmento é somada. Fonte: (Intel, 1999a) 76

4.38 Estrutura com informações de uma tarefa no TempOS. . . . . . . . . . . . . . 78

4.39 Layout da partição de um sistema de arquivo EXT2 . . . . . . . . . . . . . . . . . 84

4.40 Programa de usuário que faz uma chamada ao sistema no TempOS . . . . . . . . . 86

5.1 Associação do código do TempOS com os módulos da arquitetura do kernel. . . . . 90

5.2 Exemplo da documentação do código do kernel do TempOS. . . . . . . . . . . . . 91

5.3 Total de linhas de código e de comentários. . . . . . . . . . . . . . . . . . 97 


\section{Lista de Tabelas}

4.1 Esquema para arquivos de dispositivos representando as portas seriais de uma má-

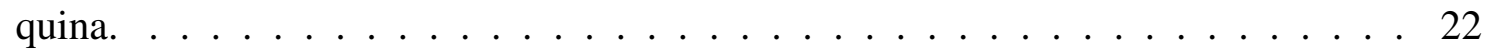

4.2 Arquivos de dispositivo representando um disco IDE com três partições. . . . . . . . 22

4.3 Estrutura básica da raiz do sistema segundo o padrão FHS versão 2.3. . . . . . . . . 23

4.4 Tipos de entrada de diretório no EXT2. Fonte: (Bovet e Cesati, 2006). . . . . . . . 34

4.5 Funções implementadas por um driver de sistema de arquivo. . . . . . . . . . . . . 38

4.6 Funções implementadas pela camada VFS. . . . . . . . . . . . . . . . . . . . 39

4.7 Exceções geradas pelo processador . . . . . . . . . . . . . . . . . . . 59

4.8 Preparação das ferramentas: Tabela de referências. . . . . . . . . . . . . . . 65

4.9 Sistema de boot: Tabela de referências. . . . . . . . . . . . . . . . . . . . . . 69

4.10 Tipos de dados utilizados pelo TempOS. . . . . . . . . . . . . . . . . 70

4.11 Funções internas do kernel: Tabela de referências. . . . . . . . . . . . . . . . 71

4.12 Controle e configuração de interrupções: Tabela de referências. . . . . . . . . . . . 74

4.13 Entradas da tabela GDT configurada pelo TempOS . . . . . . . . . . . . . 77

4.14 Gerenciamento de memória: Tabela de referências. . . . . . . . . . . . . . . 77

4.15 Threads de kernel e o escalonador: Tabela de referências. . . . . . . . . . . . . . 80

4.16 Drivers de dispositivos: Tabela de referências. . . . . . . . . . . . . . . . . 82

4.17 Cache de blocos: Tabela de referências. . . . . . . . . . . . . . . . . 83

4.18 Camada VFS e driver para sistema de arquivo: Tabela de referências. . . . . . . . . 85

4.19 Chamadas ao sistema: Tabela de referências. . . . . . . . . . . . . . . . 86

4.20 Execução de aplicativos do usuário: Tabela de referências. . . . . . . . . . . . . 87 

AGP - Accelerated Graphics Port

API - Application Programming Interface

BSS - Block Started by Symbol

BIOS - Basic Input/Output System

ELF - Executable and Linking Format

FOSS - Free and Open Source Software

GDT - Global Descriptor Table

GNU - GNU's Not Unix

IDE - Integrated Development Environment

IDT - Interrupt Descriptor Table

IPC - Inter-process communication

IRQ - Interrupt ReQuest

ISA - Industry Standard Architecture

LDT - Local Descriptor Table

PAE - Physical Address Extension

PC - Personal Computer

PCIe - PCI-Express

PCI - Peripheral Component Interconnect

PIC - Programmable Interrupt Controller

POSIX - Portable Operating System Interface

SMP - Symmetric multiprocessing

TSS - Task State Segment 


\section{CAPÍTULO \\ 1 \\ Introdução}

\subsection{Contextualização e Motivação}

Há apenas algumas décadas, no início da era dos microcomputadores, a simplicidade do hardware e do software de então caracterizavam uma realidade contrastante com a maturidade tecnológica dos dias de hoje. Naquele contexto, para o interessado em estudar o funcionamento de um computador e adquirir uma compreensão geral da arquitetura do sistema, e dos processos que têm lugar através dela para executar uma aplicação, era tarefa bem ao alcance do aprendiz. O estudante não encontrava muita dificuldade em abarcar os conhecimentos que lhe permitissem uma visão em diversos níveis, do lógico ao eletrônico, e entender, de maneira sistêmica e consistente, como suas interações se processam, pois o nível de abstração era mínimo, ou quase nenhum. Essa abrangência e profundidade de compreensão facilitava entender diversos aspectos práticos do sistema computacional, tais como, por exemplo, como determinada escolha arquitetural do software tem impacto em propriedades funcionais e não funcionais (p.ex. desempenho, confiabilidade, escalabilidade, etc.) da aplicação, em função das características do hardware, ou como certo detalhe da organização do equipamento limita ou amplia as opções de projeto do software.

O cenário de hoje é bastante diverso. Os recursos e facilidades oferecidos pelos sistemas computacionais modernos alcançam níveis dificilmente imagináveis há 20 ou 30 anos. Interfaces avançadas, multimídia, mobilidade, conectividade e outras capacidades cada vez mais avançadas superam-se constantemente. Tal evolução, entretanto, é acompanhada de um correspondente aumento da complexidade dos sistemas computacionais, e é conseguida por meio de abstrações cada vez mais sofisticadas, as quais, se por um lado tornam-se mais poderosas, por outro encobrem mais fortemente os mecanismos de hardware e software subjacentes, que de fato suportam essas 
funcionalidades. Enquanto isso seja desejável em benefício da usabilidade para o usuário final, o mesmo não se aplica ao especialista aprendiz que tem como objetivo compreender os aspectos teóricos e práticos da tecnologia de computação. Obscurecidos por níveis intermediários de crescente complexidade, os fundamentos que se aplicam aos equipamentos computacionais nem sempre são devidamente compreendidos pelos profissionais em formação.

A disciplina de Sistemas Operacionais (SO), básica na estrutura curricular de graduação em cursos na área de computação, tem importância de destaque nesse aspecto. É em seu escopo que o estudante aprende a interface entre o software e o hardware, e compreende como são fisicamente realizados conceitos abstratos de sistemas de computação. A despeito dessa importância, contudo, o obscurecimento da visão da plataforma computacional em nível de sistema, decorrente da crescente complexidade, acontece historicamente em concomitância à diminuição relativa da relevância da disciplina de SO como função de habilitação para o mercado de trabalho. Depois da emergência dos SOs nos anos 60 e 70, a hegemonia de algumas poucas plataformas de hardware e seus sistemas operacionais proprietários, por mais de uma década, relegou o escopo da disciplina a um significado mais ligado à formação teórica básica, e menos à capacitação para atuação profissional no campo específico. Tal realidade, todavia, está rapidamente se alterando. A criação e formalização dos modelos de Software Livre/FOSS (Free and Open Source Software) na década de 1980/1990 e seus estabelecimentos na década de 1990, trazendo em evidência o sistema GNU/Linux, e a proliferação de uma miríade de novas arquiteturas embarcadas capazes de executar um $\mathrm{SO}$, criam novas demandas de especialistas para atuarem diretamente no desenvolvimento de sistemas operacionais. A introdução dessas aplicações em sistemas críticos coloca novamente em evidência o papel da disciplina de sistemas operacionais como competência técnica para atuação profissional na área de desenvolvimento.

Sob o ponto de vista de abordagem pedagógica, enquanto a disciplina reúne tópicos teóricos importantes, a efetiva apreensão dos aspectos práticos é buscada em cursos na área através de atividades de laboratórios onde o estudante tem a oportunidade de exercitar os conceitos teóricos. Ao lado de bons livros textos e software de apoio didático, um recurso que vem sendo utilizado em cursos mais avançados é o de oferecer ao aluno a oportunidade de atingir esse objetivo através de um desafio, concreto e estimulante, de efetuar alterações e incluir novas funções em um sistema operacional real.

Existem alguns exemplos de implementações dessas práticas de laboratório que exploram exercícios onde o aprendiz é convidado a estudar, manipular, alterar e ampliar diretamente o códigofonte de um sistemas operacional, tendo a oportunidade de consolidar suas noções teóricas e entender aspectos técnicos que as complementam. Exemplos amplamente conhecidos dessa abordagem incluem o sistemas operacionais MINIX (Tanenbaum, 2000), originariamente desenvolvido com finalidades didáticas, e GNU/Linux, crescentemente utilizado como estudo de caso em função de sua relevância e licença Livre.

Embora vantajosamente empregada nesse contexto, todavia, a experiência de alterar partes de um sistema operacional é ainda assim limitada, à medida em que corresponde a uma visão 
fragmentada do tema, não ressaltando as relações e interdependências entre os tópicos estudados. Especificamente na matéria em questão, tal compreensão sistêmica do conjunto de conceitos e técnicas relacionadas, bem como a engenharia envolvida na sua integração, são inerentes aos objetivos da disciplina de sistemas operacionais.

Sob essa perspectiva, este trabalho tem em vista ampliar as possibilidades desse tipo de prática didática, propondo ao aluno o desafio de construir passo-a-passo um sistema operacional completo, desde as primeiras linhas de código até os módulos mais complexos incluindo subsistemas de carregamento (boot), acionadores de dispositivos (device drivers), gerenciamento de memória e demais funções de alto nível. Existem exemplos de cursos mais elaborados na área que experimentam algumas iniciativas parciais nessa direção, porém propondo implementação de apenas partes do SO ou mediante o uso de simuladores ou toolkits que fornecem módulos pré-preparados. Embora um ganho em relação à prática tradicional do estudo de códigos prontos, a alternativa é ainda fragmentada e não propicia ao aluno uma experiência integral e efetiva sobre os conceitos e técnicas pertinentes ao assunto, essencial para a aquisição da segurança e auto-confiança com respeito ao domínio do tema. Nesse âmbito, o objetivo deste trabalho distingue-se do estado da arte em avançar nessa direção, propondo a implementação completa do sistema, enfatizando a experiência multidisciplinar e contextualizada em condições do mundo real.

Uma das dificuldades para a elaboração de um programa de disciplina baseado na proposta de construção de um SO passo-a-passo, sem o uso de partes pré-fabricadas, é o amplo escopo de aspectos técnicos específicos envolvidos, o qual deve ser compreendido em profundidade suficiente para viabilizar o empreendimento. A construção das diversas funções de um sistema operacional básico requer um sólido conhecimento multidisciplinar que engloba desde a arquitetura do hardware e especificidades eletrônicas até técnicas de programação em baixo nível e abordagens práticas para os problemas algorítmicos típicos da aplicação.

Existe vasto material na Internet com informações úteis à condução desse projeto, incluindo abundante bibliografia sobre sistemas operacionais, que fornece riquíssima referência para consulta. Essas fontes, todavia, encontram-se em sua maior parte esparsas em artigos, tutoriais, relatos informais e códigos fonte de inúmeros exemplos. Um bom material didático reunindo essa informação de maneira sistematizada e que possa servir de roteiro para elaboração de um programa de disciplina é um recurso importante para viabilizar a abordagem proposta e facilitar a sua reprodução em disciplinas de sistemas operacionais, tanto teóricas como de laboratório.

Com relação ao Minix, especificamente educacional, este tem sido empregado com sucesso como objeto de estudo em livros textos consagrados da área de computação. Sua abordagem, entretanto, como afirma o autor (Tanenbaum, 1987), não se destina a servir de modelo para implementação integral passo a passo, a medida que não sacrifica sofisticação em prol desse objetivo. 


\subsection{Objetivo}

Este projeto tem como objetivo elaborar uma plataforma para ensino e treinamento em desenvolvimento de Sistemas Operacionais fundada na abordagem de aprendizado baseado em projeto (project-based learning). A plataforma será constituída de uma especificação de arquitetura de SO cuja estrutura em nível de implementação mapeie uma correspondência simples e coerente com um roteiro de conteúdo instrucional baseado em módulos teóricos sequencialmente conectados. A arquitetura de SO, portanto, deve minimizar o acoplamento funcional entre módulos e orientar-se pela construção/desenvolvimento incremental do código seguindo uma sequência intuitivamente ligada ao material didático. Dentre os requisitos do sistema proposto devem constar facilidades para desenvolvimento de sistemas portáveis entre arquiteturas e reduzida curva de aprendizado para que seja viável sua utilização como recurso de ensino para práticas de laboratório em cursos de graduação na área de computação. Fazem parte da plataforma uma clara documentação que explica a utilização e construção passo-a-passo, na forma de um tutorial e documentos de referência, de um Sistema Operacional básico para Arquitetura Intel IA-32 (x86 32 bits), além de todo software de suporte para configuração, compilação e edição do código-fonte.

\subsection{Organização da Monografia}

O capítulo 2 faz uma revisão sobre trabalhos relacionados ao ensino de Sistemas Operacionais e algumas abordagens baseadas em projeto. O capítulo 3 descreve a metodologia aplicada no desenvolvimento da plataforma assim como a forma de avaliação e os resultados esperados. O capítulo 4 apresenta a plataforma, incluindo toda especificação das arquiteturas, o roteiro passo a passo e o Sistema Operacional desenvolvido. O capítulo 5 apresenta os resultados da análise de complexidade do código do SO da plataforma. Por fim, o capítulo 6 apresenta as conclusões e sugestões para trabalhos futuros. 


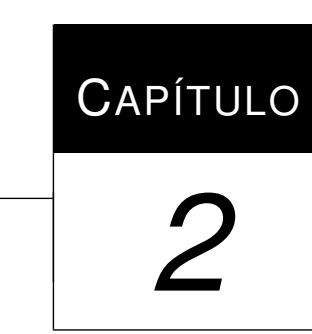

Revisão

O desenvolvimento de um SO implica em um vasto conhecimento não só relacionado a Sistemas Operacionais, mas também a vários outros ramos da computação, e mesmo de outras áreas, como noções de eletrônica digital. Projetar e implementar um SO básico requer o domínio de pelo menos alguns tópicos, como Organização de Computadores Digitais, Algoritmos e Estruturas de Dados, Arquitetura de Computadores, Programação C e Assembly e Compiladores. Estes tópicos são básicos para os cursos de Ciência/Engenharia de Computação, de modo que vem a ser perfeitamente plausível uma disciplina prática nesse contexto.

Existem atualmente alguns poucos projetos de grandes dimensões que produzem Sistemas Operacionais livres, destacando-se: Linux(Linux, 2012), FreeBSD(FreeBSD, 2012) e OpenSolaris(OpenSolaris, 2012). Outros projetos de menor porte estão listados no sítio http: / / wiki . osdev.org/Projects, tais como DexOS(DexOS, 2012) e DremOs(DreamOS, 2012). Há também projetos de materiais didático para ensino e desenvolvimento de Sistemas Operacionais, dentre eles OSDev(OSDev, 2012), BonaFide(BonaFide, 2012), SO Numa Boa(SO Numa Boa, 2012) e The Operating System resource center(The Operating System resource center, 2012), em geral orientados a amadores (hobby) e interessados de maneira geral.

Além desses há também os projetos acadêmicos voltados ao ensino de graduação e pós-graduação, como MIT Open Course: Operating System Engineering(MIT Open Course: Operating System Engineering, 2012), aiorOS(aiorOS, 2012), KeyOS(KeyOS, 2012) e Fiasco(Fiasco, 2012). 


\subsection{Trabalhos Relacionados}

Em uma pesquisa feita sobre as ementas dos cursos de diversas universidades no Brasil e no exterior, dentre elas USP(USP - IME, 2012), PUCPR(PUCPR, 2012), UECE(Universidade Estadual do Ceará, 2012), UFES(UFES, 2012), PUC-RS(PUC Rio Grande do Sul, 2012), UFSCAR(Ufscar, 2012), UFRGS(UFRGS, 2012), MIT(MIT Open Course: Operating System Engineering, 2012) e Berkeley(nac, 2010), constata-se que o curso de Sistemas Operacionais, em cursos de computação, costuma ser dividido em duas disciplinas, Sistemas Operacionais I e II, aonde a primeira tem com foco a teoria e a segunda visa um curso mais prático.

No âmbito nacional, ementas para a disciplina de Sistemas Operacionais I em geral cobrem os conceitos mais importantes da área, incluindo as noções de processo (threads, multiprogramação), sistemas de arquivos, entrada e saída E/S, gerenciamento de memória, métodos de sincronismo, etc. Já em Sistemas Operacionais II costuma-se abordar as chamadas ao sistema através do desenvolvimento de shell e aplicativos diversos. Algumas ementas, como a da Universidade de São Paulo (USP) também fazem um introdução a arquiteturas convencionais, paralelas, multiprocessadores, abrangendo o conteúdo abordado pelo curso. Já as ementas dos cursos de Berkeley e do MIT apresentam a teoria com um nível maior de profundidade, abordando a arquitetura x86 e sua programação, arquitetura PC, sistemas de arquivos de alto desempenho, Multics e o UNIX, Minix, máquinas virtuais, etc. A parte prática também é mais abrangente, focalizando kernels (núcleos) de sistemas operacionais reais como o Minix e sistemas/simuladores de intuito educacional como o Nachos(nac, 2010), que foi desenvolvido em Berkeley especificamente para ser utilizado nas disciplinas de Sistemas Operacionais.

O Minix é o tema do livro-texto clássico em cursos de computação "Operating System Design and Implementation"(Tanenbaum, 2000) (primeira edição em 1987). Além desse exemplo, já há alguns anos existem livros de teoria de SO que elaboram os tópicos com base no código-fonte do sistema Linux(O'Gorman, 2001). Alguns outros livros utilizam simuladores de arquiteturas de hardware em conjunto com rotinas menores.

\subsection{Abordagens Baseadas em Projetos}

Abordagens teóricas são muito mais frequentes no ensino de Sistemas Operacionais. Já as experiências práticas, descritas na literatura, são realizadas com o auxílio de Sistemas Operacionais de intuito educativo. Diversos desses exemplos são baseados em simulação, i.e. em algoritmos que são avaliados em um emulador de arquitetura de hardware.

É o caso, por exemplo, do Nachos(Christopher et al., 1993), um Sistema Operacional educacional desenvolvido na Universidade da Califórnia, Berkeley. O núcleo do Nachos executa em cima de outro Sistema Operacional, simulando uma arquitetura MIPS R2000/3000. Na utilização descrita, os estudantes recebem apenas um esqueleto do código, e durante as práticas vão desen- 
volvendo as funcionalidades não implementadas. O OS/161(Holland et al., 2002) é um Sistema Operacional educacional desenvolvido na Universidade Harvard baseado nas experiências da utilização do Nachos, visando superar algumas de suas limitações. O OS/161 é executado em um simulador chamado System/161, que emula um processador MIPS R2000 e mais alguns dispositivos de hardware tais como discos e portas seriais. Os alunos desenvolvem práticas que incluem sincronização, chamadas ao sistema e sistema de arquivos.

Dentre os sistemas operacionais educativos não-emulados, i.e., que são executados diretamente pelo hardware real, encontram-se diversos exemplos de SO para arquiteturas embarcadas. O Xinu(Carissimo, 1995) foi desenvolvido na década de 1980 na Purdue University; apesar de ser tema de dois livros textos, atualmente não esta mais em desenvolvimento(Anderson e Nguyen, 2005). O Topsy(Fankhauser et al., 1996) é um Sistema Operacional baseado em microkernel desenvolvido no Swiss Federal Institute of Technology in the Computer Engineering and Networks Laboratory. Segundo (Anderson e Nguyen, 2005), seu uso parece estar restrito apenas alguns campi europeus. O Topsy executa em um processador MIPS R3000, tanto no hardware físico quanto em simuladores.

Para plataformas mais elaboradas, como a da arquitetura PC convencional existe um dos mais famosos projetos de Sistemas Operacionais educacionais: o Minix(Tanenbaum, 1987), um clone do Unix escrito por Andrew S. Tanenbaum entre 1984 e 1897. Naquela época, o Unix, então aberto, era utilizado como objeto de estudo em cursos universitários. A partir da versão 7 a AT\&T mudou a licença do software, inviabilizando o estudo do seu código fonte, e o Minix tornou-se uma alternativa relevante. O Minix possui uma arquitetura robusta baseada em microkernel, o que significa que vários serviços providos pelo Sistema Operacional são na verdade providos por processos executando em nível de usuário através do paradigma cliente servidor, sendo a comunicação com o núcleo feita através de passagem de mensagens. Embora arquiteturalmente mais moderno e bastante complexo e sofisticado, isso faz do Minix um exemplo mais acadêmico que real, sendo tema de famoso debate Minix vs. Linux(DiBona et al., 1999), este último, monolítico e de sucesso na indústria.

Linux é hoje um sistema operacional bastante conhecido, desenvolvido por programadores espalhados por todo mundo e por diversas empresas, como IBM, Intel, HP, e instituições, como a Linux Foundation(Yaghmour et al., 2008). Utilizado tanto em servidores de grande porte quanto em desktops caseiros, o Linux foi criado em 1991 pelo finlandês Linus Torvalds, então estudante de graduação da Universidade de Helsink, na Finlândia. Naquela época o projeto GNU (Projet, 2012), fundado por Richard Stallman, já possuía um conjunto de ferramentas livres (FOSS) utilizáveis mas carecia de um kernel funcional, que estava sendo desenvolvido e foi denominado Hurd (GNU/Hurd, 2012). O Hurd era baseado em microkernel e seu desenvolvimento foi muito lento - em boa parte em virtude da sua enorme complexidade arquitetural — deixando o caminho livre para que kernel do Linux o substituísse no sistema GNU. Milhares de programadores ao redor do mundo começaram a participar voluntariamente no desenvolvimento do Linux, que unido ao conjunto de ferramentas GNU passou a crescer rapidamente. Várias distribuições foram lançadas 
(Debian, Slackware, Red Hat) e o Linux é hoje um dos sistemas operacionais mais importantes, forte concorrente no mercado corporativo (servidores, clusters) e que vem ganhando lugar no mercado de desktops e notebooks. Projetos como o OLPC (One Laptop per Child) (OPLC, 2012) e o Programa de Inclusão Digital brasileiro também apóiam-se nesse sistema. O Linux é um relevante exemplo das possibilidades do envolvimento de estudantes em aprendizagem baseada em projetos, desafios, visto que foi criado por um estudante de computação e acabou tornando-se um importante sistema utilizado mundialmente, em grande parte, por contribuição de estudantes e pesquisadores. A relativa simplicidade do Linux em relação ao Minix é frequentemente citada como a razão de seu sucesso na medida em que facilita a curva de aprendizado necessário para habilitar a participação em seu desenvolvimento. Essa hipótese está de acordo com os argumentos de motivação para este projeto.

No conjunto dos casos estudados, a utilização de sistemas operacionais em cursos de graduação baseia-se ou em simulação, ou na modificação de SOs existentes, ou na implementação pontual de funções específicas, atendo-se atualmente ao desenvolvimento de aplicativos que rodam acima do sistema operacional, utilizando as chamadas ao sistema para estudar suas capacidades. Detalhes internos do kernel, principalmente sobre implementações, acabam não sendo abordados. Não foram identificados relatos de práticas de laboratório ou abordagens de estudo baseado em projeto que proponham a construção de um protótipo de sistema operacional completo, ainda que simplificado, mas abrangendo suas principais partes e com enfoque nos problemas e restrições do mundo real e realidade da indústria. 
Existem diversos exemplos da utilização de código de sistemas operacionais em atividades de ensino de graduação. Os sistemas Minix e GNU/Linux incluem-se dentre os mais conhecidos. Em geral, estuda-se a implementação ou executa-se modificações em trechos do software como exercício de aprendizado. Uma das dificuldades em utilizar esses dois exemplos como modelo para o desenvolvimento de um SO durante o curso é que se tratam de sistemas de grandes dimensões em termos de implementação e cuja complexidade torna pouco praticável. Outros sistemas eventualmente utilizados como alternativa são com frequência simplificados em termos de funcionalidade à medida que não correspondem às arquiteturas de interesse em aplicações reais, ou são apresentados como componentes isolados, funcionais, porém destacados da visão sistêmica em termos de implementação.

A característica principal buscada no sistema proposto é um balanço entre esses extremos ao propor um sistema completo do ponto de vista das partes essenciais de um SO, mas ao mesmo tempo suficientemente simples para que possa ser integralmente compreendido pelo estudante. Objetiva-se assim que o modelo possa ser estudado e tomado como exemplo para a reconstrução do SO, com possíveis extensões a critério do projetista.

Uma dificuldade em conduzir-se um curso de Sistemas Operacionais através de programação passo-a-passo de um código completo é que as instanciações das diversas funcionalidades, em um sistema complexo, podem ser realizadas de modo "fragmentado" em diversas partes do código fonte, ao invés de serem implementadas de modo coeso dentro de módulos bem distintos em termos construtivos. Questões referentes ao desempenho, aspecto essencial aos SOs, podem recomendar decisões arquiteturais que resultem em uma forte interdependência de diferentes componentes, de maneira que determinada função é realizada por interações complexas entre muitos procedimentos 
e funções que compartilham estados. Se por um lado é possível aplicar conceitos de modelagem orientada a objetos no projeto arquitetônico, a implementação real ainda tem de ser mapeada na visão de sistema em baixo nível, o que significa interagir com a arquitetura de hardware e suas próprias abstrações - nem sempre bem encapsuladas. Assim, é em geral difícil elaborar um roteiro de aulas que mapeie conceitos às respectivas implementações de modo simples e que refiram o conteúdo abordado a partes auto-contidas do código fonte (Figura 3.1).

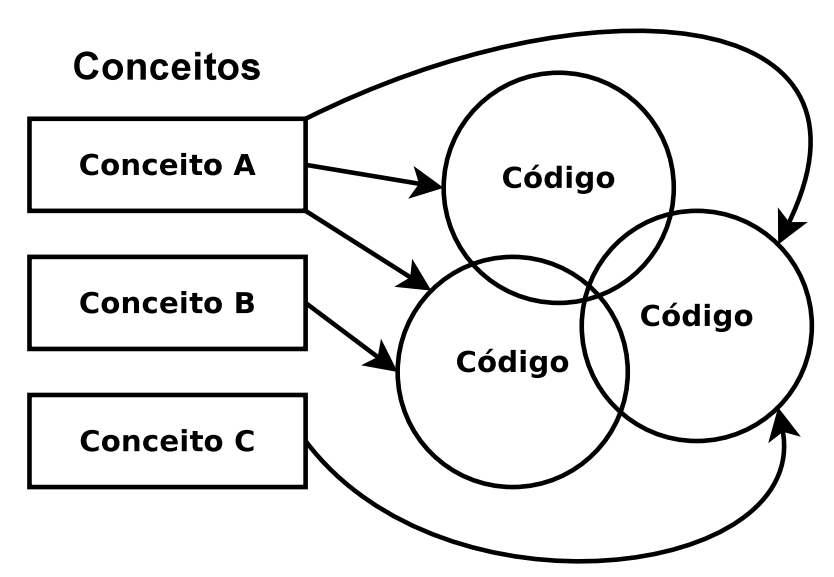

Figura 3.1: Alta interdependência na implementação dos conceitos teóricos.

A estratégia da plataforma de ensino proposta, na qual consiste o diferencial de modelo adotado, baseia-se na concepção e especificação de uma arquitetura de SO em nível de implementação na qual os módulos componentes são projetados de modo a minimizar o acoplamento de código fonte, e a apresentar uma correspondência simples e direta com os tópicos conceituais destacadas (Figura 3.2).

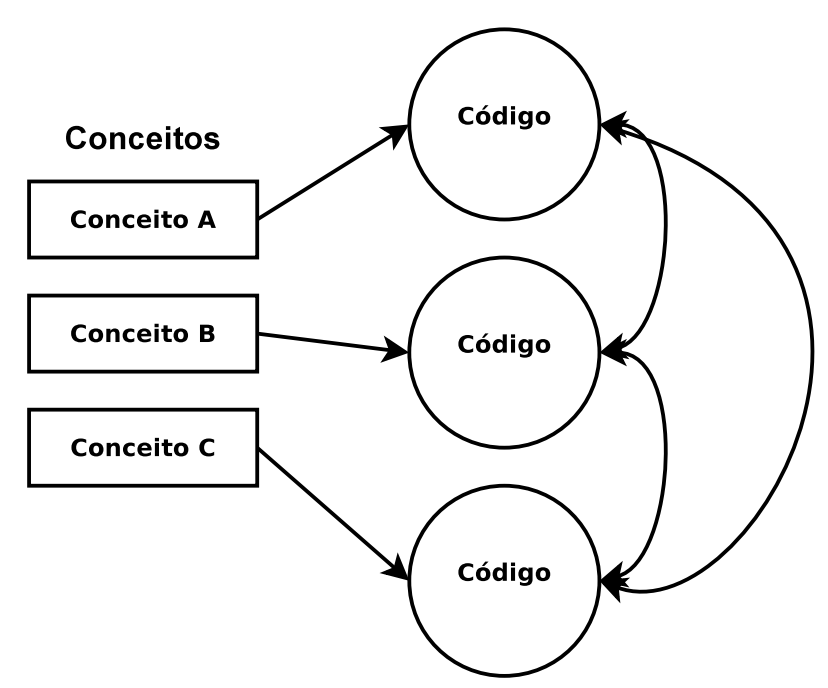

Figura 3.2: Relação direta do código implementado com os conceitos teóricos (baixa interdependência).

Idealmente seguindo um programa institucional com tópicos sequenciais, esse princípio facilita o estudo do código fonte em trechos concisos e de menor interação com outras partes, especial- 
mente com aquelas a serem abordadas em etapas posteriores do roteiro de estudo. Isso também é verdade para a tarefa de implementação se a arquitetura completa puder ser construída incrementalmente, a partir de partes que se agregam ao sistema, minimizando o esforço de recorrer à fragmentos de código espalhados pelo programa todo, e não intuitivamente conexos. Este é o princípio geral para a especificação da plataforma de ensino.

A plataforma proposta compõe-se do sistema-modelo, das especificações e da descrição do método de ensino e treinamento aplicáveis a seu uso na prática.

De posse desse recursos, o aluno deve ser capaz de reimplementar ele mesmo toda arquitetura, tendo a possibilidade de exercitar seus conhecimentos incorporando modificações e extensões de funcionalidade. São requisitos gerais dos módulos acima relacionados o desenho arquitetural simples e compreensivo, código legível e didático, documentação precisa e completa.

\subsection{Resultados esperados e forma de avaliação}

A plataforma proposta neste projeto deve ser composta pelos seguintes componentes:

- Especificação de uma arquitetura completa de um sistema operacional funcional, baseado no Unix, compondo-se de suas diversas partes:

- Kernel (núcleo) do sistema, que irá fornecer a API interna para os drivers e externa (chamadas ao sistema), além de gerenciar todos os recursos da máquina.

- Gerenciadores de dispositivos (device drivers), incluindo dispositivos de teclado, mouse, discos IDE, e periféricos específicos, como o temporizador e controlador de interrupções.

- Código fonte, extensivamente documentado, detalhando o uso de cada função e estrutura de dados presentes no código.

- Ambiente de desenvolvimento, configurado e otimizado, incluindo software de edição de código e depuração (debugging), emulador, ferramentas de teste e avaliação de desempenho.

- Roteiro na forma de tutorial passo a passo dividido em distintas práticas que, recorrendo ao modelo, conduza o aluno através do processo de construção de um sistema operacional completo e funcional, desde as primeiras linhas de código até os módulos mais complexos incluindo subsistemas de carregamento, acesso ao hardware, gerenciamento de memória e demais funções de alto nível. A sequência de aula deve ser projetada de modo a servir como base para um programa de disciplina de graduação em cursos de computação.

O modelo está inicialmente baseado na plataforma PC, mas tendo em mente a portabilidade para outras arquiteturas de hardware, em vista da crescente relevância das arquiteturas embarcadas e a demanda por profissionais capacitados ao desenvolvimento de sistemas operacionais para tecnologias de hardware emergentes. 
Os resultados são avaliados mediante a comparação de casos de usos em que se analisa a utilização do sistema proposto em confronto a alternativas tradicionalmente empregadas como Linux e Minix. O objetivo dessa comparação não é de medir a qualidade do projeto entre os sistemas, mas de avaliar a simplificidade do seu uso em um programa de ensino e treinamento em técnicas de desenvolvimento, com ênfase na correlação entre conceitos teórico-práticos e complexidade da implementação.

Para a implementação do sistema proposto os recursos básicos necessários são ferramentas de desenvolvimento de software. Foram utilizados exclusivamente programas disponíveis na forma de software livre / open source. O conjunto essencial de ferramentas inclui o compilador gcc (para Linguagem C) e gas (GNU Assembler, para a linguagem Assembly), utilitário make para auxiliar na compilação, e o shell bash para executar os scripts que também compõem o sistema de compilação. Para auxiliar no desenvolvimento foi utilizado o emulador QEMU, que permite depurar e testar rapidamente o sistema em desenvolvimento sem a necessidade de reiniciar a máquina e inicializar o sistema em questão. O QEMU possui um monitor que pode fornecer diversas informações em tempo de execução, tais como valores de registradores e mapa da memória, extremamente úteis para o desenvolvedor.

O desenvolvimento foi executado em ambiente Linux, embora visto que todas as ferramentas empregadas são livres e também portadas para outros ambientes, como Open Solaris e FreeBSD, não impedindo que a plataforma seja executada em outros ambientes. Todo artefato de software produzido foi disponibilizado sob uma licença de uso, modificação e distribuição livres, na forma open source.

É utilizado como o Sistema Operacional integrante da plataforma o TempOS (TempOS is an educational and multi purpose Operating System). O SO é escrito para a arquitetura IA-32 (x86 32 bits), com maior parte do código em Linguagem C, sendo o Assembly (sintaxe AT\&T) utilizado para partes dependentes de arquitetura. Com um robusto sistema de compilação (desenvolvido através de scripts atuando em conjunto com o utilitário make), o TempOS pode ser compilado e testado muito facilmente a partir do Linux juntamente com o emulador QEMU ou executando-o diretamente em um PC comum. O código está extensivamente comentado possuindo documentação gerada automaticamente com o software doxygen ${ }^{1}$, que descreve todas as funções e seus respectivos parâmetros, contem referências para que o usuário possa pesquisar e correlacionar conceitos teóricos com a implementação em código, incluindo referências para os manuais da arquitetura IA32 (disponibilizados na internet gratuitamente pela Intel). O código-fonte está disponível no sítio http: / / tempos-project . org sob a licença GPL e foi totalmente modularizado, isolandose a parte dependente da Arquitetura x86, de modo a permitir que o TempOS seja portado para outras arquiteturas sem grande dificuldade. Dentre suas características o TempOS possui um sistema de boot multiestágio, implementação de funções da biblioteca $\mathrm{C}$, realocação dinâmica no kernel, organização plana de memória, paginamento via hardware, chamadas ao sistema POSIX, driver para discos PATA (IDE) e demais recursos fundamentais em SOs.

\footnotetext{
${ }^{1}$ Disponível em http://www.stack.nl/ dimitri/doxygen/
} 


\subsection{Material Didático}

O TempOS tem função como referência para a especificação da arquitetura do SO modelo. A partir desta, foi elaborado o material de instrução que descreve o processo pelo qual um SOexemplo poderá ser desenvolvido integralmente pelo aluno. O roteiro foi elaborado como uma sequência de tópicos conceituais logicamente encadeados, referenciando os exercícios de implementação. Seguindo esses passos, o aluno será guiado pelo processo iterativo de desenvolvimento do SO, evoluindo incrementalmente o projeto.

O material instrucional foi confeccionado na forma de uma apostila para uso em ministração de aulas e práticas de laboratório. O código do TempOS, exemplo de instâncias da arquitetura especificada, é utilizado também como exemplo. A estrutura geral da arquitetura está consistentemente baseada na arquitetura Unix e no padrão POSIX. 

Este capítulo aborda a plataforma TempOS de ensino. São detalhadas a especificação da arquitetura do Sistema Operacional e da plataforma e cada um de seus módulos, o material que aborda os principais tópicos teóricos envolvidos na implementação, o roteiro passo a passo para desenvolvimento e o TempOS, Sistema Operacional implementado seguindo a plataforma.

\subsection{Sistemas Operacionais}

Segundo Tanenbaum (Tanenbaum, 2000) um Sistema Operacional pode ser visto de duas maneiras: como um Gerenciador de Recursos e como uma Máquina Estendida. Os computadores são compostos por processador(es), memória, e um conjunto de dispositivos que necessitam ser controlados de maneira ordenada. Imagine o que aconteceria se três programas tentassem gravar uma mesma área do disco ao mesmo tempo! Seria impossível manter a consistência dos dados. O SO deve controlar todos os dispositivos presentes na máquina: discos, placa de som, teclado, mouse, monitor, deve também gerenciar toda a memória, não permitindo que um programa utilize a área de memória destinada a outro e alocar os recursos necessários para a execução. O SO também deve prover serviços que possibilitam e facilitam (através de abstrações) o acesso ao hardware pelos aplicativos. Assim, se determinada aplicação deseja ler um arquivo, basta fazer uma chamada ao SO pedindo pela leitura do arquivo, não importando se o mesmo encontra-se em um disco IDE ou SCSI, em um sistema de arquivo EXT2 ou FAT, é dever do SO gerenciar o acesso em baixo nível. 
Um Sistema Operacional é composto basicamente por um kernel (do inglês, núcleo) de sistema, que unido a uma biblioteca básica e a um conjunto de aplicativos dão completa funcionalidade ao SO, permitindo a interação entre usuário e hardware.

Existem diferentes arquiteturas de kernel, sendo as principais Monolítica e Microkernel.

$\mathrm{Na}$ arquitetura de Microkernel o núcleo do SO é composto por um micronúcleo e diversos serviços que executam em um nível de privilégio menor. Estes serviços por sua vez, provêm as chamadas para os aplicativos de usuário. O micronúcleo executa em Modo Kernel (máximo privilégio) fazendo acesso direto ao hardware e provê serviços básicos e mecanismos de passagem de mensagens, meio pelo qual é feita a comunicação com os demais serviços. Portanto, drivers de rede, sistemas de arquivos e diversos outros serviços são executados como processos normais do sistema, podendo executar no mesmo nível de privilégio que aplicativos do usuário ou em um nível maior, mas sempre em um nível de menor privilégio que o micronúcleo. A grande vantagem desta arquitetura é a confiabilidade, pois a falha de um driver de dispositivo não compromete a execução do micronúcleo, e o serviço pode ser reiniciado apenas finalizando e iniciando novamente o processo. A principal desvantagem é o overhead gerado pela comunicação com o micronúcleo (via passagem de mensagens), pois como os drivers deixam de ter acesso direto ao hardware, o acesso deve ser feito através do micronúcleo.

O Mac OS X, Minix, QNX e Hurd são SOs que seguem esta arquitetura, já o Windows ${ }^{\circledast}$ possui um kernel híbrido, partes funcionam como serviços e outras partes estão integradas diretamente no kernel.

A figura 4.1 ilustra a arquitetura Microkernel.

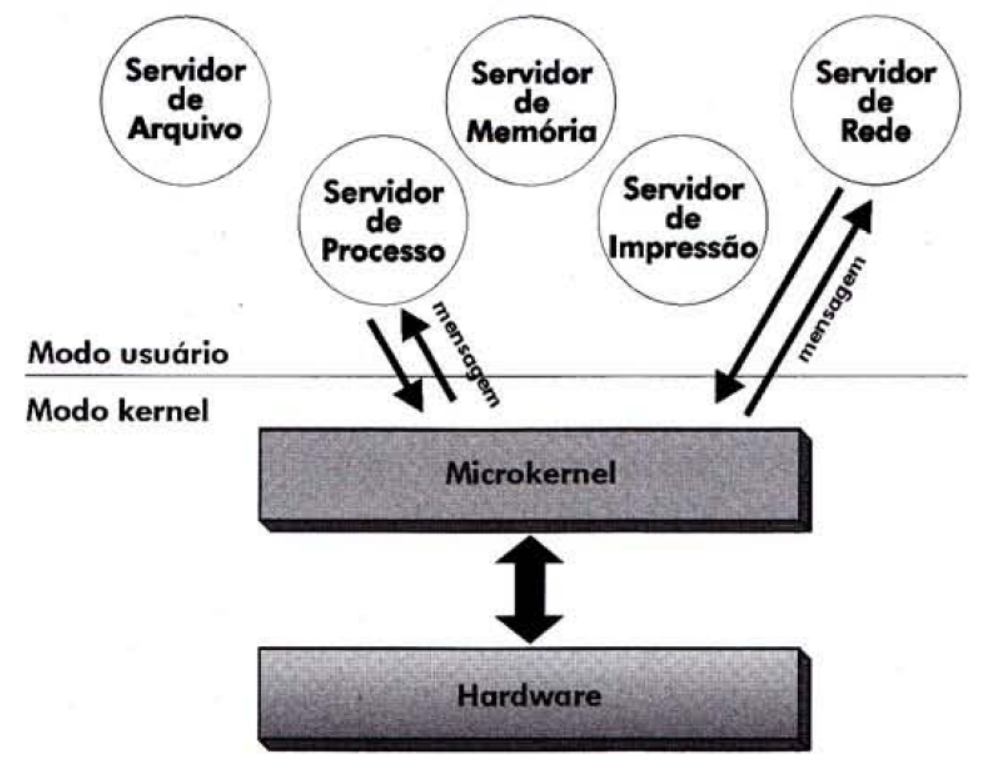

Figura 4.1: Arquitetura Microkernel. Fonte (Machado e Maia, 2007).

Já a arquitetura monolítica integra todos os drivers de dispositivos e serviços (gerenciador de memória, sistema de arquivos, etc) diretamente em um só kernel que é executado em um nível 
de máximo privilégio (Modo Kernel). A grande vantagem desta arquitetura é a performance e maior facilidade na implementação, pois como todos os drivers possuem acesso direto ao hardware não há necessidade de passagens de mensagens assim como toda implementação de comunicação Serviço-Micronúcleo, características do Microkernel. Entretanto, a grande desvantagem é que se um driver ou subsistema travar durante seu funcionamento, todo o kernel pode ser comprometido culminando no travamento de todo sistema.

A figura 4.2 ilustra a arquitetura Monolítica.

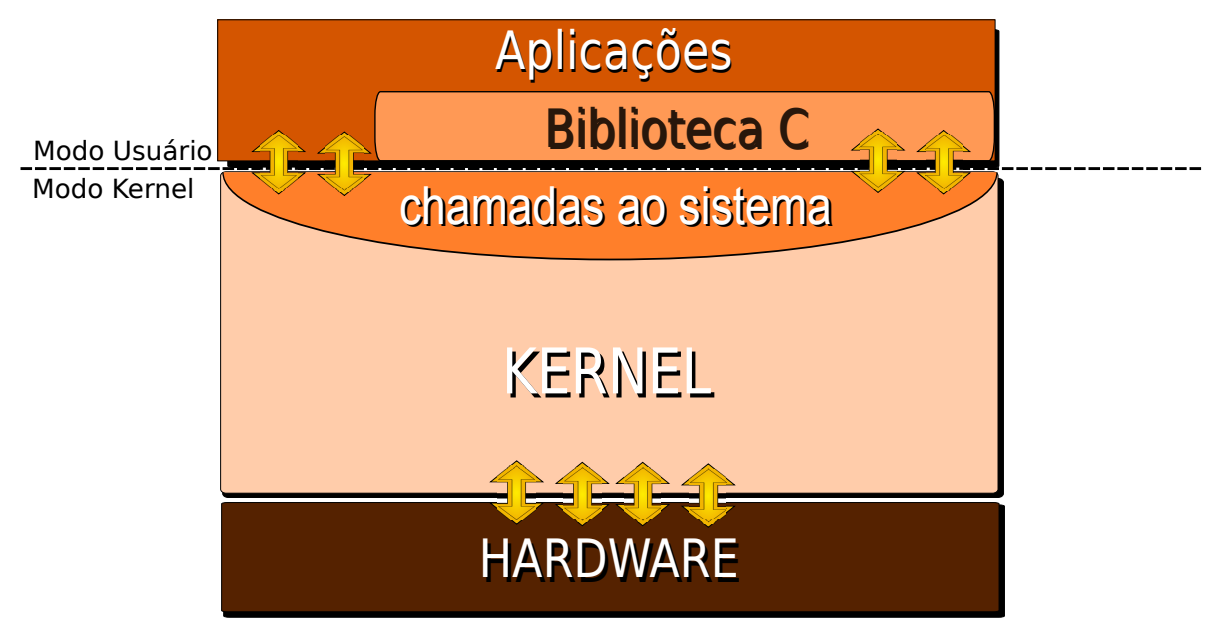

Figura 4.2: Sistema Operacional: Arquitetura Monolítica.

O Sistema Operacional atua na máquina (sobre o hardware), fornecendo uma interface de programação através de chamadas ao sistema (system calls), ou syscalls. É através das syscalls que os aplicativos irão se comunicar com o SO e utilizar todo o hardware gerenciado pelo mesmo. Para facilitar ainda mais a programação e permitir portabilidade dos aplicativos de usuário, existem bibliotecas (como a biblioteca C) que podem atuar sobre o SO (através das syscalls) e fornecer uma abstração ainda maior para os aplicativos.

O padrão POSIX(IEEE, 2004) (Portable Operating System Interface) define uma série de especificações, dentre elas o conjunto de syscalls, que um Sistema Operacional baseado em Unix deve seguir. Assim, todos os aplicativos desenvolvidos para o padrão POSIX serão compatíveis com todo SO que segue este padrão. Por exemplo, Linux(Locke, 2005) e FreeBSD ${ }^{1}$ seguem em grande parte o POSIX. AIX ${ }^{2}$ e Minix ${ }^{3}$, seguem em sua totalidade.

\section{A história do UNIX e LinuX}

Dado o crescimento de sistemas baseados no POSIX faz-se ainda mais necessário que Sistemas Operacionais derivados do Unix (chamados de sistemas Unix ou Unix-like) sejam abordados nos

\footnotetext{
${ }^{1}$ http://people.freebsd.org/ schweikh/posix-utilities.html

${ }^{2} \mathrm{http} / / / \mathrm{www}-03 . \mathrm{ibm} . \mathrm{com} / \mathrm{systems/power/software/aix/standards/index.html}$

${ }^{3} \mathrm{http}: / / \mathrm{www} . \operatorname{minix} 3$. org
} 
cursos universitários. A vasta gama de softwares que seguem este padrão também permite ao aluno testar facilmente aplicativos no seu próprio SO, economizando tempo de desenvolvimento.

A história do Unix (detalhadamente contada no artigo de Dennis M. Ritchie (Ritchie, 1980)) começou no ano de 1969 nos laboratórios da Bell. Em 1965 a Bell, o MIT (Massachusetts Institute of Techology) e a General Eletric (GE) uniram-se para desenvolver um Sistema Operacional, chamado Multics (MULTiplexed Information and Computing Service), de tempo compartilhado, que seria utilizado por uma grande comunidade de usuários, executando num computador GE645. Era um projeto custoso e que não apresentava bons resultados. No ano de 1969 a Bell retirou-se do projeto. Mais tarde, ainda no mesmo ano, um dos programadores do Multics, Ken Thompson, iniciou o desenvolvimento do jogo "Space Travel", inicialmente escrito para o Multics e mais tarde traduzido em Fortran para executar no GECOS (o Sistema Operacional do computador Honeywell 635). O jogo era basicamente um simulador onde o jogador navegava pelo sistema solar através de uma nave. Os gráficos da versão para o GECOS eram insatisfatórios, além do jogo custar U\$75 pelo tempo de uso de CPU em um computador de grande porte. Pouco tempo depois Thompson encontrou um computador PDP-7 com excelente processador gráfico. Com a ajuda de seu amigo Dennis M. Ritchie, Thompson reescreveu o jogo em assembly para executar no PDP-7. Não era uma tarefa fácil, já que os programadores decidiram se desfazer de todo software existente no PDP-7. Para executar o "Space Travel" era preciso desenvolver um sistema com as funções para aritmética de ponto flutuante, um sistema de debug e o driver para o display. Tudo escrito em assembly para executar em um montador cruzado que rodava no GECOS e produzia fitas em papel para o PDP-7 até que um montador para o próprio PDP-7 fosse escrito. Os trabalhos continuaram com a organização do sistema de arquivos, processos e interpretador de comandos (shell), que foram incorporados ao novo sistema. Em 1970 Brian Kernighan sugeriu o nome Unix, uma paródia ao nome Multics.

Em 1972 Ritchie desenvolveu uma nova linguagem de programação, nada menos do que a Linguagem $C$, baseada na linguagem B (criada por Thompson), que por sua vez era baseada na linguagem BCPL. Em 1973 o Unix foi reescrito em C para executar em um computador PDP-11, sendo apresentado a comunidade científica em 1974 no clássico artigo de Thompson e Ritchie (Ritchie e Thompson, 1974). A partir de 1976 o Unix começou a ser amplamente distribuído fora dos laboratórios da Bell. Seu código era disponibilizado, permitindo que vários setores (acadêmicos e privados) começassem a modificá-lo e lançassem variantes do sistema. Essas variantes começaram a gerar incompatibilidade até que o IEEE definiu o padrão POSIX (Portable Operating System Interface, o X vem de Unix), que define uma série de padrões e principalmente as syscalls para Sistemas Operacionais Unix (e seus variantes) (IEEE, 2004). O POSIX é atualmente um padrão maduro e responsável por permitir que um vasto conjunto de aplicativos, principalmente os aplicativos do projeto GNU, executem transparentemente em vários Sistemas Operacionais, como o Linux, FreeBSD, AIX, HP-UX, Solaris, Minix, etc.

A AT\&T foi responsável pelo lançamento de várias versões do Unix, dentre elas o Unix System $V$, que tornou-se padrão internacional no mercado. No meio acadêmico, o Unix era amplamente es- 
tudado, principalmente em disciplinas de Sistemas Operacionais, percebendo a preciosidade deste sistema, a AT\&T lançou a versão 7 com uma licença restritiva: O código-fonte não poderia ser estudado em cursos, assim, muitas universidades tiveram de conformar-se em terminar com os estudos de Unix, ensinando apenas a teoria de Sistemas Operacionais.

Para contornar este problema, Andrew S. Tanenbaum, professor da universidade de Vrije, Amsterdã, escreveu um novo sistema operacional a partir do zero destinado a fins educacionais, compatível com o Unix, mas completamente diferente internamente, ou seja, sem nenhuma linha de código dos Unix da AT\&T. Sugestivamente, este sistema foi denominado MINIX (mini-UNIX).

No dia 5 de Outubro de 1991 uma mensagem publicada via Usenet na lista comp.os.minix marcaria a história da computação. Linus Torvalds, um estudante finlandês de ciências da computação da Universidade de Helsinki trouxe ao mundo a notícia de que estava trabalhando no projeto de um sistema operacional baseado no Minix, a versão 0.02 estava pronta e seria distribuida com seu código-fonte. Nascia assim o Linux.

Naquela época o projeto GNU, fundado por Richard Stallman, já possuia um conjunto de ferramentas utilizáveis mas carecia de um kernel, que estava sendo desenvolvido e se chamava Hurd. O Hurd era baseado em microkernel e seu desenvolvimento acabou estacionando, deixando o caminho livre para o kernel do Linux integrar o sistema GNU. Milhares de programadores ao redor do mundo começaram a ajudar no desenvolvimento do Linux, que unido ao conjunto de ferramentas GNU passou a crescer cada vez mais e suportar cada vez mais dispositivos. Várias distribuições foram lançadas (Debian, Slackware, Red Hat) e o Linux é hoje um Sistema Operacional de peso, forte concorrente no mercado corporativo (servidores, clusters) e que vem consolidando-se cada vez mais no mercado de desktops, notebooks e principalmente dispositivos móveis, através de sistemas como o Android ${ }^{4}$.

\subsection{A Plataforma de Ensino}

Esta seção apresenta a arquitetura e os componentes da Plataforma de Ensino, denominada TempOS (pronuncia-se tem-pôs). A Plataforma TempOS especifica a arquitetura de um Sistema Operacional Unix, ou seja, composta por um kernel monolítico que fornece chamadas ao sistema POSIX e que pode executar aplicativos em Modo de Usuário, como o Shell, compiladores, etc. Esta arquitetura foi escolhida por ser a base de diversos Sistemas Operacionais e por ser monolítica, possibilitando uma implementação mais simplificada. Portanto, a arquitetura da Plataforma TempOS é compatível com o Unix e sistemas mais atuais, como Linux e FreeBSD. Logo, seus componentes aplicam-se também a estes sistemas e outras variantes do Unix. A partir de agora, será referenciado apenas como a arquitetura e componentes da plataforma.

\footnotetext{
${ }^{4}$ Plataforma aberta para dispositivos móveis, baseada em Linux e desenvolvido pela Google. http://android.com
} 


\subsubsection{Visão geral do Sistema Operacional}

O Sistema Operacional da Arquitetura TempOS corresponde a um clone do Unix, possuindo um kernel monolítico, cuja função é prover chamadas ao sistema POSIX, ou seja, que permitam acesso ao hardware de maneira controlada e abstraída, assim como a criação, execução de processos e todas as operações com arquivos: criação, remoção, atribuição de permissões, manutenção da consistência e acesso dos dados. A funcionalidade do SO para o usuário se dá através da execução de programas (utilitários) do sistema, cada utilitário é responsável por um comando em específico, como listar arquivos e diretórios, setar/exibir data, exibir ou editar o conteúdo de um arquivo, enfim, estes utilitários utilizam as funções das bibliotecas ou chamam diretamente as chamadas ao sistema do kernel para efetuarem determinada operação. A interface com o usuário é feita através de um utilitário gráfico ou através de um Shell (interpretador de comandos), que fornece uma linha de comando ao usuário, permitindo que comandos sejam inseridos e os programas desejados sejam executados. A Figura mostra a arquitetura geral e as camadas envolvidas desde o usuário até o kernel.

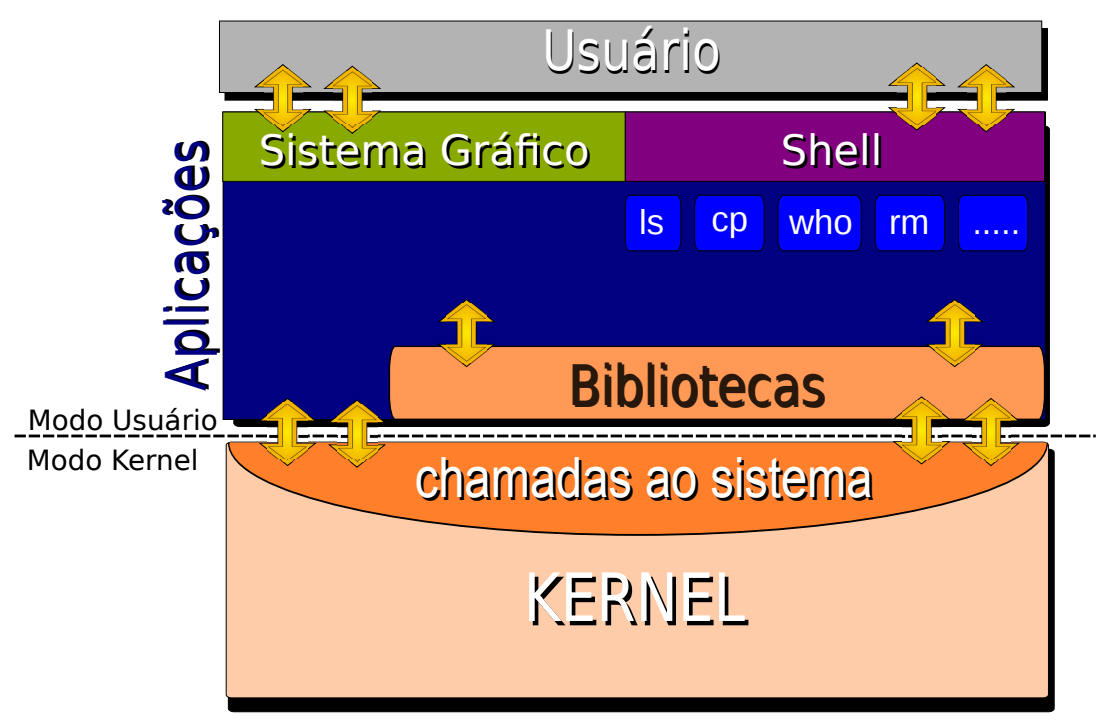

Figura 4.3: Visão geral do SO, mostrando as camadas envolvidas desde o usuário até o kernel.

É importante explanar que na literatura o termo Sistema Operacional é utilizado para indicar tão somente o kernel quanto o conjunto kernel + Aplicações (o que inclui bibliotecas, utilitários, etc). De fato, o kernel gerencia os recursos da máquina e provê a abstração do hardware, atuando como uma máquina estendida. Porém sua integração com o conjunto de aplicativos e bibliotecas é que promovem a interação homem-máquina, compondo o Sistema Operacional.

As entidades Arquivo e Processo correspondem ao elementos principais do sistema. O sistema de arquivo é caracterizado por uma estrutura hierárquica (em árvore, como mostra a Figura 4.4), que pode conter diversos diretórios e/ou arquivos. Cada arquivo/diretório possui permissões de acesso para o usuário dono do arquivo e para um grupo de usuários. As permissões são leitura, escrita ou execução. 


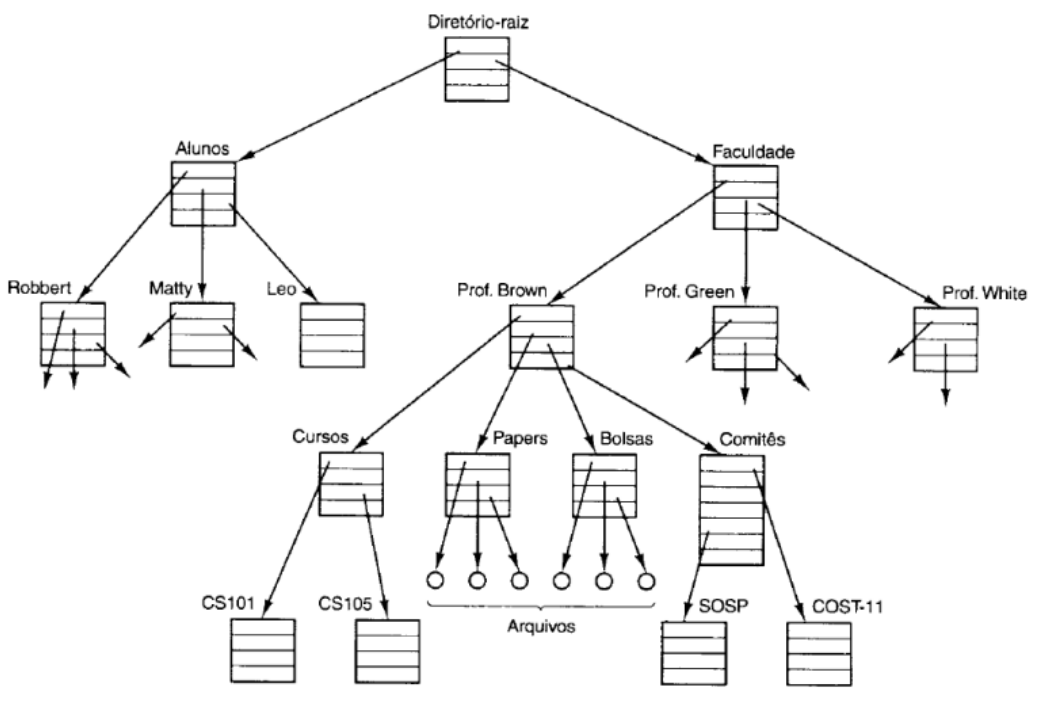

Figura 4.4: Organização em árvore do sistema de arquivo. Fonte: (Tanenbaum, 2000)

A raiz do sistema (representada por /) corresponde ao diretório principal, que contém todos os utilitários de sistema, arquivos de configurações, do carregador de boot, etc.

Os recursos da máquina são abstraídos em arquivos, assim, qualquer dispositivo é acessado pelos aplicativos através de arquivos denominados arquivos de dispositivos. Existem três tipos de arquivos de dispositivos:

- Arquivos de Bloco: Representam os dispositivos que podem ser acessados por blocos, como o disco rígido. Leitura e Escrita podem ser executadas em qualquer parte do dispositivo, sem uma sequência específica.

- Arquivos de Caractere: Representam os dispositivos que só podem ser acessados sequencialmente, como Modems e terminais de texto, onde a comunicação é feita de maneira serial, enviando e recebendo caracteres.

- Arquivos de Pseudo-Dispositivos: Representam os dispositivos que não se classificam como dispositivos de bloco ou caractere. Podem ser dispositivos como o relógio do sistema (RTC), dispositivo nulo (/dev/null), etc.

Estes arquivos contém dois números que estão associados ao driver que irá manipular o dispositivo representado pelo arquivo. Estes números são denominados Número Maior (major number) e Número Menor (minor number). O major number determina qual é o driver que irá manipular o dispositivo. O kernel mantém uma tabela para cada tipo de dispositivo (caractere e bloco, sendo os pseudo-dispositivos geralmente considerados dispositivos de caractere) onde cada entrada está associada a um driver. Logo, se o driver para o controlador de portas seriais estiver na entrada 4, então o major number dos arquivos que representam portas seriais será 4. Já o minor number 
representa cada dispositivo de uma mesma categoria. No exemplo anterior, considerando uma máquina com duas portas seriais, cada arquivo de determinada porta teria um minor number diferente. A tabela 4.1 ilustra o exemplo.

Tabela 4.1: Esquema para arquivos de dispositivos representando as portas seriais de uma máquina.

\begin{tabular}{|c|c|c|l|}
\hline Porta Serial & major number & minor number & Arquivo de dispositivo \\
\hline 1 & 4 & 0 & $/ \mathrm{dev} /$ ttyS0 \\
\hline 2 & 4 & 1 & $/ \mathrm{dev} /$ ttyS 1 \\
\hline
\end{tabular}

O minor number também pode ser utilizado para outras finalidades, como diferenciar partições de um determinado disco. Como exemplo, considere um disco IDE (major number 8) instalado no canal primário e atuando como mestre, contendo 3 partições. O disco todo e cada partição serão representados por um determinado arquivo de dispositivo, listados na tabela 4.2.

Tabela 4.2: Arquivos de dispositivo representando um disco IDE com três partições.

\begin{tabular}{|c|c|c|l|}
\hline Partição & major number & minor number & Arquivo de dispositivo \\
\hline Disco todo & 8 & 0 & $/ \mathrm{dev} / \mathrm{hda}$ \\
\hline 1 & 8 & 1 & $/ \mathrm{dev} / \mathrm{hda} 1$ \\
\hline 2 & 8 & 2 & $/ \mathrm{dev} / \mathrm{hda} 2$ \\
\hline 3 & 8 & 3 & $/ \mathrm{dev} / \mathrm{hda} 3$ \\
\hline
\end{tabular}

É importante notar que o nome do arquivo de dispositivo não influencia de fato em qual dispositivo será manipulado, as únicas informações necessárias, e que estão contidas dentro do arquivo, são os números major e minor e o tipo do dispositivo. Todavia, existem padrões para definir os nomes dos arquivos de dispositivos de forma a torná-lo intuitivos. No exemplo abordado, o arquivo de nome hda foi utilizado para indicar o disco rígido (hd = hard disk) instalado no canal IDE primário e atuando como mestre (representado pela letra a), sendo as partições indicadas pelos seus respectivos números $(\mathbf{h d a 1}=$ partição $1, \mathbf{h d a} 2=$ partição 2 e hda3 $=$ partição 3$)$. Se o disco rígido estivesse instalado no canal primário, mas atuando como escravo, a nomenclatura para o arquivo seria hdb.

No Linux, o documento "Linux Allocated Devices (2.6+ version)" (Cox, 2009), distribuído junto com o código fonte do kernel, contém a lista oficial dos números major e minor para os dispositivos, assim como os nomes dos arquivos. Este documento faz parte do FHS (Filesystem Hierarchy Standard), padrão que define diretrizes e requisitos para a composição da raiz de arquivos e diretórios de um sistema $\operatorname{Unix}^{5}$ (Kraft, 2005).

\footnotetext{
${ }^{5} \mathrm{~A}$ especificação completa do FHS pode ser obtida em http://www.pathname.com/fhs
} 
$\mathrm{Na}$ arquitetura TempOS tanto os arquivos de dispositivo quanto a organização da raiz do sistema também devem seguir o padrão FHS. A tabela 4.3 apresenta a estrutura geral da raiz do sistema segundo a ultima versão (2.3) do FHS(Filesystem Hierarchy Standard Group, 2004).

Tabela 4.3: Estrutura básica da raiz do sistema segundo o padrão FHS versão 2.3.

\begin{tabular}{|l|l|}
\hline Diretório & Descrição \\
\hline / & Raiz do sistema \\
\hline /bin & Utilitários (comandos) essenciais do sistema \\
\hline /boot & Arquivos estáticos do carregador de boot (bootloader) \\
\hline /dev & Arquivos de dispositivo \\
\hline /etc & Arquivos de configuração do sistema \\
\hline /home & Diretório dos usuários \\
\hline /lib & Bibliotecas compartilhadas essenciais e módulos do kernel \\
\hline /media & Ponto de montagem para mídias removíveis \\
\hline /mnt & Utilizado como ponto de montagem temporário \\
\hline /opt & Reservado para complementos de pacotes de software \\
\hline /root & Diretório home do usuário root \\
\hline /sbin & Arquivos binários do sistema \\
\hline /usr & Dados compartilhados \\
\hline /srv & Dados de serviços providos pelo sistema \\
\hline /tmp & Diretório de arquivos temporários \\
\hline
\end{tabular}

O diretório /usr compõe a segunda maior seção do sistema de arquivo. Segue uma hierarquia semelhante a raiz e pode ser compartilhado entre sistemas. Contém comandos do usuário, bibliotecas, utilitários não "vitais" para o sistema, sistema gráfico, códigos fonte e diversos outros itens especificados pelo FHS.

\section{Processos}

Um processo é a instância de um programa em execução. Quando o kernel é iniciado, após efetuar todas as operações de carregamento do sistema, o programa /sbin/init é executado. O init é responsável por preparar o ambiente do usuário, como configurar terminais, iniciar outros programas, como serviços de rede e o gerenciador de login do sistema.

A criação de um novo processo se dá através da chamada ao sistema fork(). Esta chamada duplica o processo que a chamou. As regiões de memória do processo atual (memória alocada, pilha, segmentos de código e dados) são copiadas e associadas a um novo processo. O processo pai (aquele que efetuou a chamada) e o processo filho (o novo processo criado) executarão exatamente a partir do ponto de retorno da chamada fork(). Entretanto, o valor de retorno para o processo filho será 0 (zero), e para o pai será o PID (Process Identifier), um número associado unicamente ao processo filho. 
É importante notar que a chamada ao sistema $f o r k()$ apenas duplica o processo que efetuou a chamada em uma nova instância, fazendo apenas uma cópia do processo pai. A instanciação de um programa (geralmente armazenado em disco) em um novo processo ocorre através do uso em conjunto das chamadas fork() e execve(). A chamada ao sistema execve() substitui o processo que a chamou por uma nova instância de um programa, geralmente carregado a partir do disco. O novo processo será executado a partir de um endereço de início, que pode ser pré-definido ou ser informado no cabeçalho do arquivo executável, como é permitido, por exemplo, no formato ELF (Executable and Linkable Format) (The Santa Cruz Operation, 1996). A figura 4.5 mostra um código de exemplo para a execução do programa /bin/ls a partir de um processo em execução. A chamada waitpid() é utilizada pelo pai para aguardar o término do processo filho. Enquanto o filho está em execução, waitpid() permanece bloqueada. Esta função é utilizada para evitar que o processo pai termine antes de seu filho, pois quando o processo pai é finalizado, todos os filhos existentes também são finalizados.

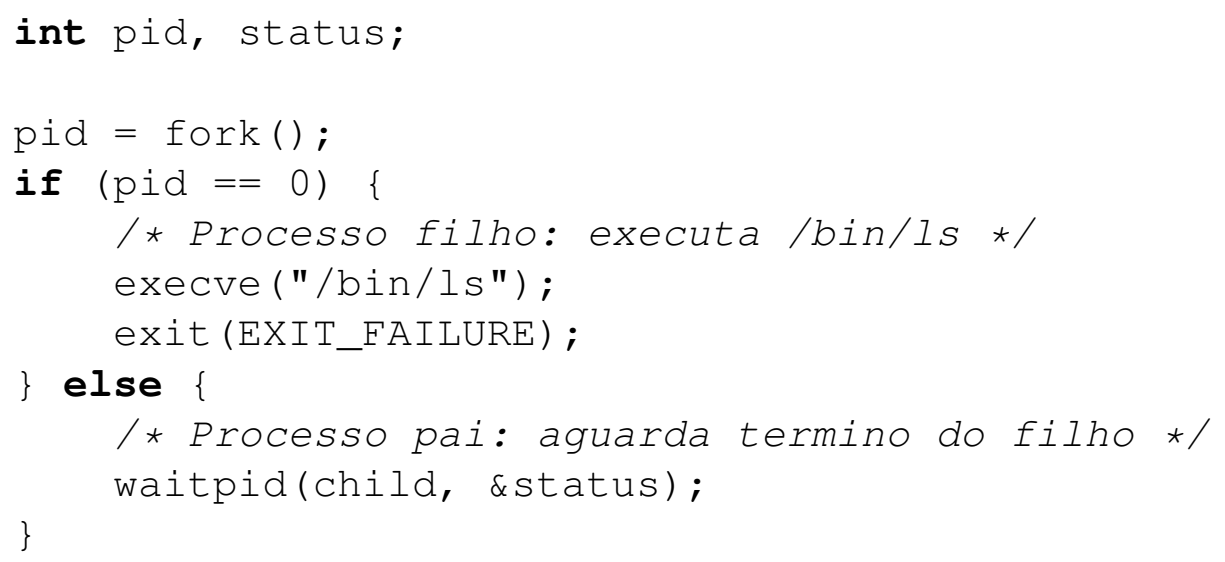

Figura 4.5: Código exemplo para criação de um novo processo.

A variável pid contém o valor de retorno da chamada fork(). Ambos os processos (pai e filho) continuarão a execução a partir do retorno da chamada. Cada processo verifica sua identidade (pai ou filho) simplesmente checando o valor de pid. No filho, pid será igual a 0 (zero), e portanto a chamada execve() será executada. Já no pai, pid será diferente de zero, fazendo com que a chamada waitpid() seja executada, bloqueando a execução do processo pai até o término do filho.

A finalização voluntária de um processo, ou seja, quando todas as tarefas já foram executadas e o processo deseja ser finalizado, é feita a través da chamada ao sistema exit(). O valor de retorno do processo é passado como argumento para a chamada. Este valor pode ser obtido pelo processo pai através da chamada waitpid().

\subsubsection{Arquitetura do Kernel}

O kernel é a parte central da arquitetura TempOS. Segue a arquitetura do Unix mostrada em Bach(Bach, 1986) e por isso muitas de suas funções internas também seguem o mesmo nome e 
algoritmo das funções do Unix. É monolítico e implementa chamadas ao sistema POSIX que permitem criação de processos, gerenciamento de arquivos, como leitura, escrita, criação, remoção e modificação de atributos, comunicação entre processos e acesso ao dispositivos de hardware (através de drivers de dispositivo). O kernel é composto por seis principais módulos: Interface de chamadas ao sistema, Camada Virtual de Sistema de Arquivo, Cache de Blocos, Drivers de Dispositivos, Controle de Hardware e Subsistema de Controle de Processos, que contém o escalonador, o gerenciador de memória e os mecanismos para comunicação entre processos. A figura 4.6 mostra a arquitetura e seus módulos.

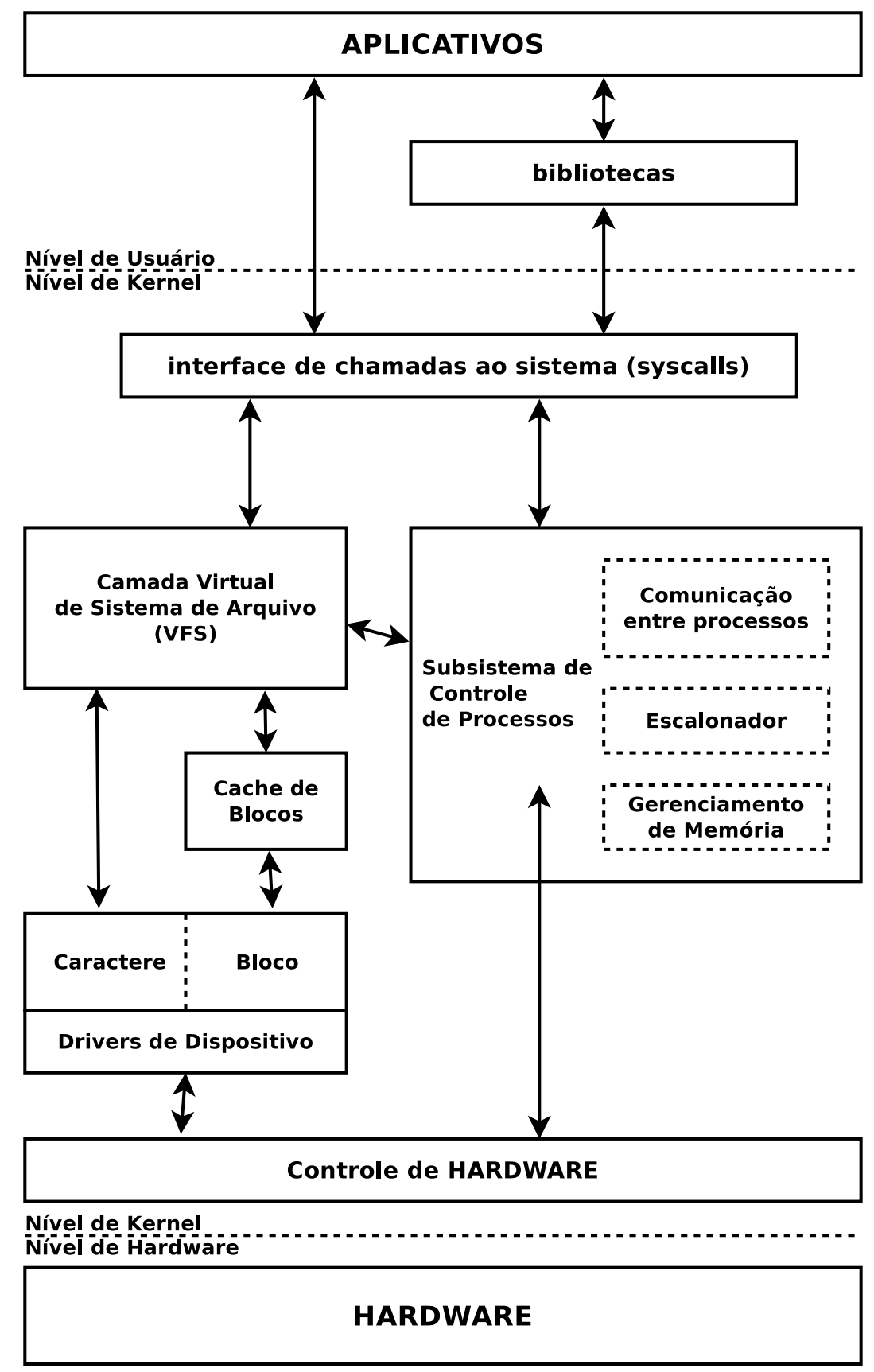

Figura 4.6: Arquitetura do kernel da plataforma TempOS. Figura adaptada de (Bach, 1986). 
A Arquitetura TempOS define as funções de cada módulo, porém, a forma de implementação é livre. Na descrição de cada módulo, detalhes da implementação do TempOS (SO) são fornecidos para atuarem como guia no aprendizado e desenvolvimento de outro Sistema Operacional. Muitos algoritmos e funções são diretamente derivados do Unix.

\section{Interface de chamadas ao sistema}

$\mathrm{Na}$ arquitetura monolítica todo o kernel é executado em um nível de privilégio máximo, onde possui total acesso ao hardware. Este nível é denominado Nível ou Espaço de Kernel. Já os aplicativos são executados em um nível de privilégio mínimo, denominado Nível ou Espaço de Usuário. Neste nível os processos não possuem acesso direto ao hardware assim como só são permitidos acessar determinado espaço da memória previamente mapeado. Os níveis de privilégio compõem um mecanismo de proteção que permite os processos serem executados isoladamente, impossibilitando que um determinado processo interfira na execução de outro, ou que comprometa a execução do sistema. Essa proteção deve ser provida pela arquitetura do processador, cabendo ao kernel efetuar as configurações e mapeamentos necessários para cada processo.

Se um processo tentar acessar uma área de memória proibida ou executar uma instrução não permitida, uma interrupção é gerada pelo processador e deve ser atendida pelo kernel, que será responsável por enviar um sinal ao processo ou até remover o mesmo de execução.

Algumas arquiteturas, como a Intel x86 (IA-32), implementam níveis intermediários de privilégio, que podem ser utilizados, por exemplo, em arquiteturas de microkernel. Neste caso, os serviços do microkernel executam em níveis intermediários, com menor privilégio que o microkernel mas com maior privilégio que os aplicativos de usuário. Entretanto, esta configuração não é uma obrigatoriedade para a arquitetura.

Dado que os aplicativos não possuem acesso direto ao hardware, todos os recursos da máquina são acessados (e abstraídos) pelo kernel através das chamadas ao sistema, que são executadas em espaço de kernel (máximo privilégio) pois terão total acesso ao hardware. O mecanismo utilizado para efetuar este salto entre privilégios e permitir que as chamadas ocorram foi o uso de interrupções de software, geradas pelo processo que deseja efetuar a chamada ao sistema.

No Linux para arquitetura x86, as chamadas ocorrem através da interrupção 0x80. Assim, quando um processo deseja efetuar uma chamada ao sistema, o número da chamada desejada é armazenado no registrador EAX e os parâmetros da mesma são armazenados nos registradores EBX, ECX e EDX. Em seguida, a interrupção 0x80 é gerada (através da instrução int 0x80) fazendo com que o kernel atenda a interrupção, proceda ajustes devido a troca de privilégios e execute a chamada desejada. A passagem dos parâmetros via registradores é uma maneira mais otimizada, poderia ser efetuada através da pilha do processo. A figura 4.7 contém o código em assembly (sintaxe AT\&T) que efetua duas chamadas ao sistema no Linux. A primeira, write() (que possui o número 0x04), escreve a mensagem "Olá Mundo!" na saída padrão (descritor 0x01). O tamanho da string é passado no registrador EDX. A string contém 11 (0x0B) caracteres, 10 da mensagem e 1 caractere de 
pulo de linha ( $\backslash \mathrm{n})$. Após executar a chamada write(), o programa executa a chamada exit() para finalizar o processo. O código de retorno (parâmetro de exit()) é passado pelo registrador EBX.

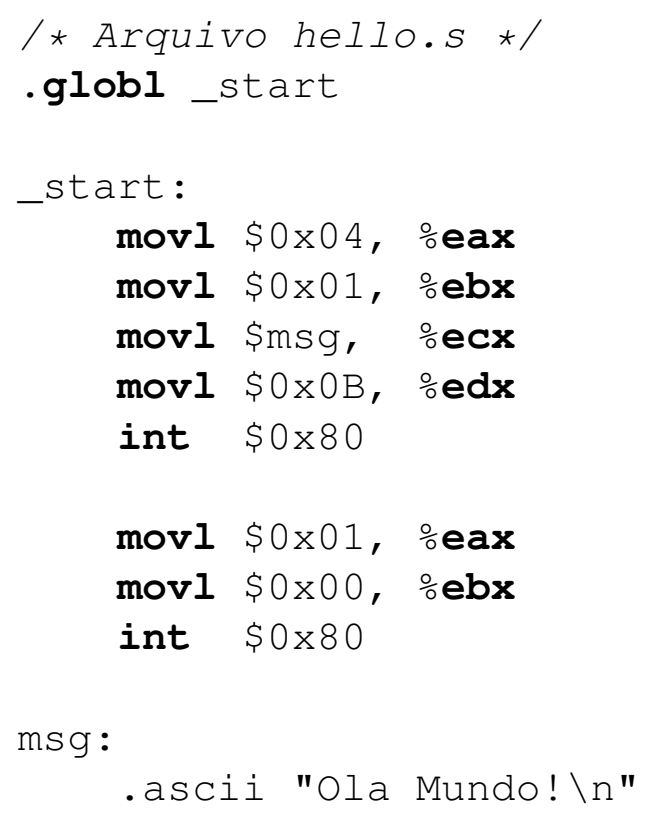

Figura 4.7: Código assembly (IA-32) para execução de chamadas ao sistema no Linux.

O programa pode ser facilmente compilado e executado no Linux através dos comandos:

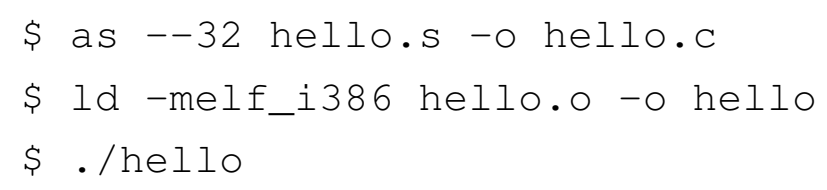

Para suportar chamadas ao sistema o kernel deve conter um vetor com o endereço de cada uma das funções. O número da chamada ao sistema corresponderá ao seu respectivo índice no vetor de funções. Logo, no Linux, o endereço da função write() encontra-se na posição 4 do vetor de chamadas ao sistema. Ao atender a interrupção de chamadas ao sistema, o kernel deve efetuar tarefas dependentes de arquitetura (do processador), depois deve verificar se o número da chamada que o processo deseja executar corresponde a uma entrada válida no vetor de funções, retornando um código de erro caso o número seja inválido. Caso contrário, o kernel irá executar a chamada e o código de retorno da função será repassado ao processo.

As chamadas ao sistema no TempOS ocorrem exatamente da mesma forma que no Linux, exceto pela interrupção, que é a de número 0x85. Este número não deve ser alterado em outras implementações da arquitetura para evitar a quebra de compatibilidade entre os programas portados para o TempOS.

No código fonte do TempOS o vetor das funções encontra-se no arquivo kernel/syscall.c. O nome da variável é syscall_table. O manipulador da interrupção 0x85 encontra-se no arquivo $\operatorname{arch/x86/kernel/sys\_ enter.S.~}$ 
Algumas arquiteturas, como a x86, possuem instruções especiais para chamadas ao sistema, tornando desnecessário o uso de interrupções e otimizando a troca entre os níveis de privilégio. Entretanto, o kernel ainda deve checar o número da chamada, efetuar a mesma e repassar o código de retorno ao processo.

É importante notar que apesar do kernel abstrair o hardware através das chamadas ao sistema, o mecanismo utilizado para efetuar as chamadas (interrupção ou instrução) ainda é dependente de arquitetura. As bibliotecas de sistema (como a biblioteca $\mathrm{C}$ ) elevam o nível de abstração provendo uma interface aos aplicativos para as chamadas ao sistema. Por exemplo, o código $\mathrm{C}$ da figura 4.8 efetua duas chamadas ao sistema: open() e close(). A primeira tenta abrir o arquivo /tmp/teste.txt, se o usuário possui as permissões de leitura e o arquivo existe, é retornado o descritor (maior que zero) correspondente ao arquivo, caso contrário um código de erro (menor que zero) é retornado. Se o arquivo foi aberto com sucesso, a mensagem de abertura é exibida e o arquivo é fechado através da chamada ao sistema close().

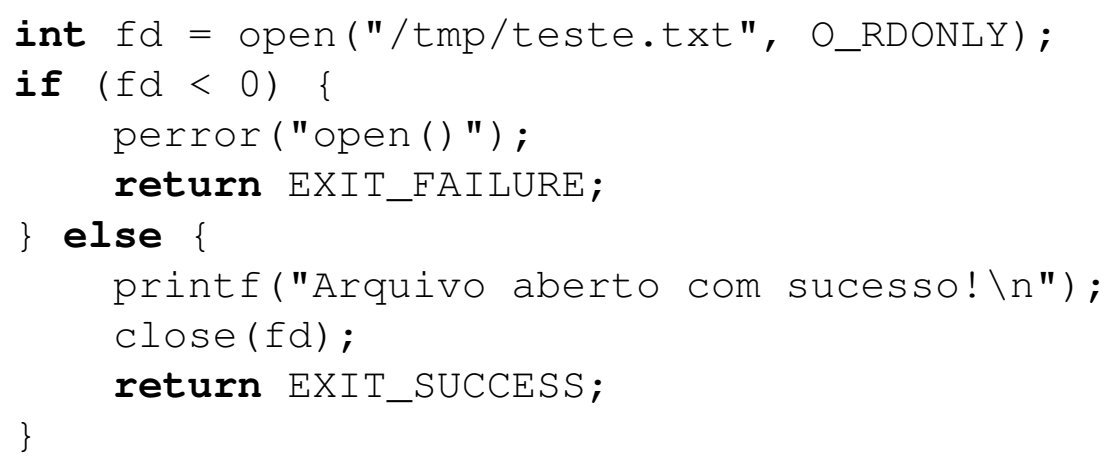

Figura 4.8: Código $\mathrm{C}$ usando as chamadas ao sistema open() e close().

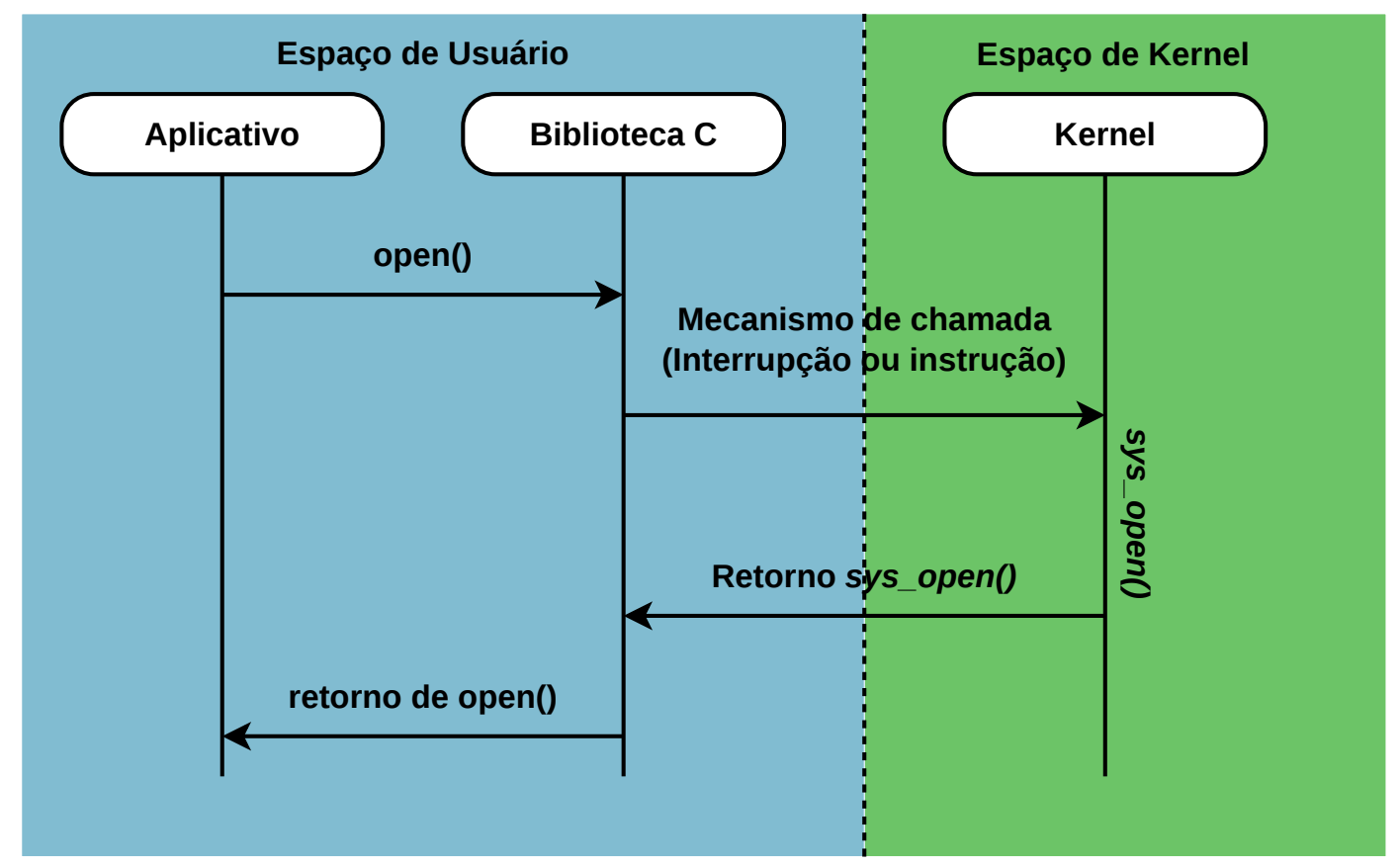

Figura 4.9: Aplicativo efetuando chamada ao sistema open(). 
Note que as funções open() e close() na verdade estão implementadas na biblioteca C, elas executam o mecanismo adequado para efetuar, de fato, as respectivas chamadas ao sistema. Este link é fundamental para a portabilidade dos aplicativos, pois neste caso, todos os aplicativos que utilizam a biblioteca $\mathrm{C}$ poderão ser compilados em outros sistemas que também possuam a biblioteca sem qualquer alteração no código. Padrões como o POSIX são indispensáveis, pois desde que diferentes SOs forneçam o mesmo conjunto de chamadas ao sistema, a portabilidade das bibliotecas se dá apenas com o ajuste do mecanismo de chamada respectivo a cada SO.

A figura 4.9 ilustra o processo efetuando a chamada ao sistema open() a partir da biblioteca C. O processo chama a função da biblioteca, ambos executam em espaço de usuário (arquitetura monolítica), a biblioteca pode ser compartilhada entre processos ou o processo pode ter sido linkado estaticamente. A função open() da biblioteca irá efetuar o mecanismo necessário, como colocar os parâmetros nos registradores e executar a devida interrupção de software, que levará a uma troca de privilégios, passando do Espaço de Usuário para o Espaço de Kernel, onde finalmente a chamada será executada, neste caso, a função do kernel sys_open() será executada. O retorno de sys_open() será passado para a função da biblioteca $\mathrm{C}$, que finalmente irá retornar para o processo.

Nem todas as chamadas ao sistema POSIX precisam ser implementadas pelo kernel para a execução dos aplicativos. As seguintes chamadas permitem executar uma considerável gama de aplicativos:

- Gerenciamento de processos: fork(), waitpid(), wait(), execve(), exit(), brk(), getpid().

- Sinais: sigaction(), sigreturn(), kill(), pause(), alarm(), sigpending().

- Sistema de Arquivos: $\operatorname{creat}(), \operatorname{mknod}(), \operatorname{open}(), \operatorname{read}()$, write(), close(), lseek(), stat(), fstat(), $\operatorname{dup}(), \operatorname{pipe}(), \operatorname{ioctl}(), \operatorname{rename}(), f \operatorname{cntl}(), \operatorname{mkdir}(), \operatorname{rmdir}(), \operatorname{link}(), \operatorname{unlink}(), \operatorname{mount}()$, umount(), sync(), chdir(), chroot(), chmod(), chown(), getuid(), getgid(), setuid(), setgid().

- Gerenciamento de tempo: time(), stime(), utime(), times().

Grande parte das chamadas ao sistema estão relacionadas ao sistema de arquivos, o que é realmente esperado devido a abstração do Unix (onde tudo é tratado com um arquivo).

\section{Cache de blocos}

Dispositivos de armazenamentos são organizados em blocos (setores) que podem ser acessados aleatoriamente. Os discos rígidos ainda são os dispositivos mais importantes da memória externa (Stallings et al., 2009). Apesar de sua grande capacidade, o tempo necessário para efetuar uma leitura ou escrita no disco é substancialmente alto quando comparado aos tempos de acessos a outros dispositivos, como a memória RAM. Assim, utilizar técnicas de cache para os blocos de dispositivos de armazenamento é fundamental nos Sistemas Operacionais. 
O subsistema de Cache de Blocos é talvez o módulo mais independente na arquitetura. Seu único dever é efetuar a leitura de um bloco de um dispositivo de armazenamento qualquer e armazená-lo na memória. Se este bloco for alterado ou requisitado novamente não será necessário a re-leitura no dispositivo, bastando apenas acessar o conteúdo do bloco na memória. Como qualquer sistema de cache, é necessário a sincronia dos dados do cache com os dados do dispositivo. Em sistemas Unix geralmente um daemon ${ }^{6}$ chamado update efetua a chamada para sincronizar o cache a cada 30 segundos (Wirzenius et al., 2000). No Linux existem threads do kernel responsáveis pelo sincronismo. Este sincronismo periódico é importante pois se o cache for sincronizado somente em determinadas operações ou na finalização do sistema, um desligamento abrupto acarretaria em perda dos dados do cache e tornaria facilmente o sistema de arquivos inconsistente.

O módulo de Cache de Blocos provê quatro funções para a camada VFS: bread(), que efetua a leitura de um bloco; breada(), que efetua a leitura de um bloco e do seu sucessor; bwrite(), que efetua a escrita de um bloco e brelse(), que libera um bloco do cache, sincronizando-o com o dispositivo. Todas possuem como parâmetro em comum os números major e minor do dispositivo de armazenamento que contém o bloco desejado. Isto permite que o sistema de Cache chame a função adequada do driver que manipula o dispositivo, permitindo que qualquer dispositivo de armazenamento possa ser acessado sem a necessidade do sistema de Cache atuar diretamente no hardware (desde que, é claro, exista o driver para manipular tal hardware). Logo, o sistema de Cache de Blocos é exatamente o mesmo para dispositivos IDE, SCSI ou USB, por exemplo.

Cada bloco no cache é composto de uma estrutura de dados que deve armazenar não só os dados do bloco, mas também informações sobre a qual dispositivo o mesmo pertence e seu status no cache. O status pode indicar as seguintes condições: o bloco contém dados válidos; o kernel deve escrever os dados no bloco no dispositivo antes de liberá-lo do cache; o bloco está ocupado (utilizado quando o kernel está manipulando o bloco e outros processos não podem acessá-lo); o kernel está lendo ou escrevendo dados no bloco; e um processo está aguardando o bloco ficar livre.

Existem diversas formas de implementar o módulo de Cache de Blocos. Uma maneira mais simples é utilizar uma tabela hash para cada dispositivo. Geralmente o kernel, em sua inicialização, reserva uma quantidade de memória (pré-definida na compilação ou configurada pelo administrador) para utilizar no Cache de Blocos. Todos os blocos de cache ficam inicialmente em uma lista de blocos livres. Quando uma operação de E/S (Entrada/Saída) é requisitada, o kernel busca o bloco em cache em uma tabela hash, se o bloco não está presente, então um bloco é retirado da lista de blocos livres e colocado na tabela hash de acordo com seu endereço. As informações são lidas do dispositivo e o bloco passa a constar no cache. Na próxima vez que for acessado, o kernel encontrará o bloco na tabela hash e retornará as informações sem a necessidade de acesso ao dispositivo. A escrita também será feita no bloco em cache, por isso há a necessidade de sincronismo com o dispositivo. Quando todos os blocos disponíveis para cache estão alocados (ou seja, a lista

\footnotetext{
${ }^{6}$ Disk And Execution MONitor. Programa executado em segundo plano. Geralmente executa uma tarefa específica, como prover um determinado serviço.
} 
de blocos livres está vazia) e um bloco que não está no cache é requisitado, o kernel deve bloquear o processo até que um bloco para cache esteja disponível para uso.

No TempOS, o cache é implementado através de um vetor de hash, que contém os blocos em cache, e uma lista circular duplamente encadeada que aponta para os blocos livres (que podem ser alocados para cache). O tamanho do vetor é pré-definido e o algoritmo de dispersão é dado por $p=(A D D R \bmod N)$, onde $p$ é a posição do bloco no vetor de hash, ADDR é o endereço do bloco e $N$ é o tamanho do vetor. Como o algoritmo é passível de colisões, cada entrada contém uma lista duplamente encadeada que aponta para os blocos correspondentes. A figura 4.10 esquematiza o sistema de cache no TempOS.

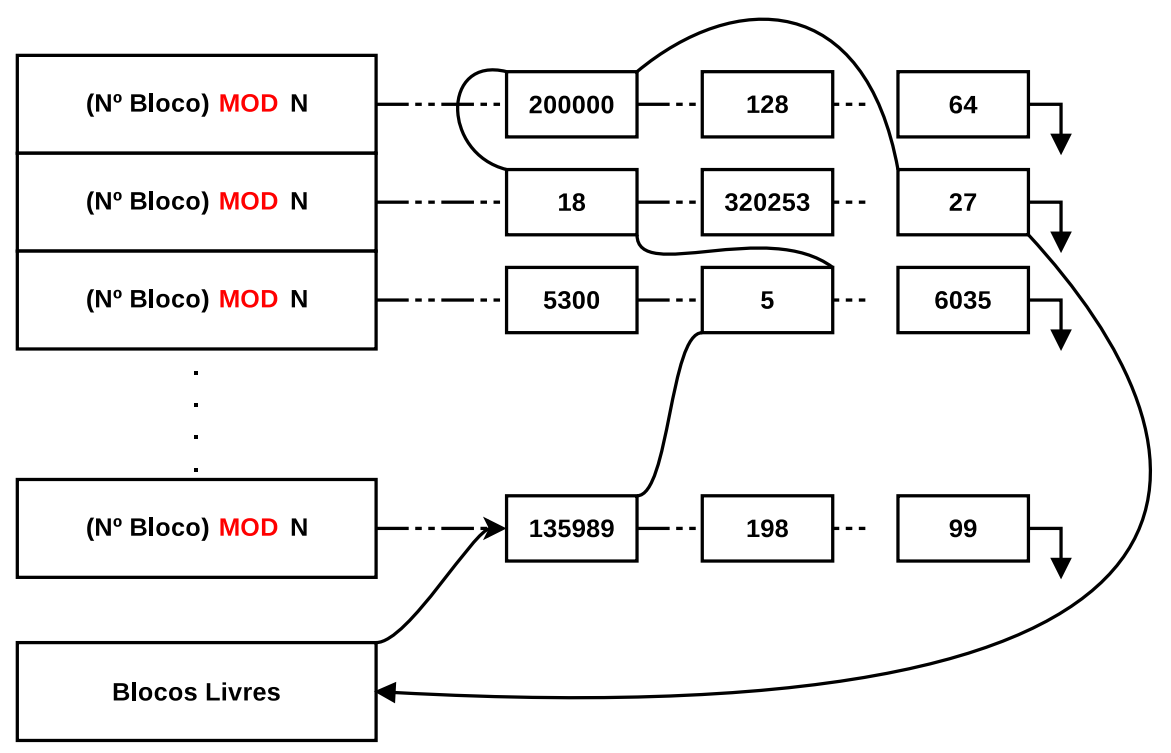

Figura 4.10: Tabela HASH para os blocos em cache no TempOS.

O tamanho do vetor de hash e a quantidade de blocos total em cache são definidos no código, podendo ser facilmente alterados nos arquivos de cabeçalho. Toda leitura de bloco de um dispositivo deve ser feita através da função $\operatorname{bread}($ ). Os parâmetros passados são o endereço do bloco e o major e minor number para identificação do dispositivo, permitindo assim que as funções do driver específico sejam executadas. A função $\operatorname{bread}()$ faz uma busca no respectivo vetor de hash para verificar se o bloco já está presente no cache. Se encontrado, o status do bloco é checado, pois o bloco pode estar ocupado sendo utilizado por outro processo, neste caso, a função deve bloquear (através da função sleep()) até que o bloco esteja disponível. O status do bloco também pode indicar que os dados devem ser gravados no dispositivo (processo chamado de escrita atrasada, do inglês, delayed write) antes do bloco ser utilizado. Se o bloco contém dados válidos, então pode ser utilizado sem a necessidade de leitura do dispositivo. Existe a possibilidade do bloco ter sido descartado e consequentemente colocado na lista de blocos livres, entretanto, os dados permanecem intactos até que o bloco seja utilizado para fazer o cache de outro bloco do dispositivo. Neste caso, também não é necessária a re-leitura, bastando apenas que o bloco seja retirado da lista de 
blocos livres. Se não houver blocos livres disponíveis o processo será bloqueado até que algum bloco seja liberado através da função brelse().

Caso o bloco não seja encontrado no vetor de hash (e nem na lista de blocos livres), então a função do driver do dispositivo é executada para efetuar a leitura. Esta tarefa é executada de maneira transparente pois todos os drivers estão registrados em uma tabela de drivers, permitindo que as funções corretas sejam chamadas a partir do major e minor number.

O bloco pode ser descartado do cache através da função brelse(). Esta função coloca o bloco na lista de blocos livres, se os dados do mesmo foram alterados, então o status é alterado para escrita atrasada, ou seja, quando este bloco for utilizado pela próxima vez, os dados serão gravados no dispositivo antes de serem, de fato, substituídos.

Os blocos em cache podem ser escritos no dispositivo (sincronizados) através da função bwrite(). A chamada da função sync() irá gravar todos os blocos em cache nos respectivos dispositivos, eliminando qualquer escrita atrasada pendente.

Todo o sistema de cache do TempOS está implementado no arquivo fs/bhash.c. Os protótipos das funções e as contantes que definem a quantidade de blocos e o tamanho do vetor de hash estão contidos no arquivo de cabeçalho include/fs/bash.h.

\section{Camada Virtual de Sistema de Arquivo}

Um sistema de arquivo é uma organização lógica dos dados em uma mídia de armazenamento que permite ao SO gravar e recuperar os arquivos e diretórios da mesma. Por exemplo, fisicamente o(s) prato(s) de um disco rígido é(são) dividido(s) em trilhas que por sua vez são divididas em setores. A forma (lógica) com que o dados são estruturados nestes setores é o que representa o sistema de arquivo.

Entender a Camada Virtual de Sistema de Arquivos implica em entender os princípios e a estrutura do sistema de arquivo original do Unix, que foi usado como referência para o desenvolvimento do sistema de arquivo do Minix, que por sua vez foi implementado no Linux, dando origem posteriormente a família de sistema de arquivos EXT (extended filesystem), amplamente utilizado em diversos sistemas Unix. O EXT2 (Second Extended Filesystem), faz parte da família EXT. Apesar de já existir o EXT3 e EXT4, que são versões mais recentes e com mais recursos, o EXT2 ainda é amplamente utilizado, tanto por seu legado, quanto por sua estabilidade, herdando as estruturas básicas do sistema de arquivo do Unix, trazendo melhorias e maior capacidade de armazenamento.

Cada arquivo ou diretório é representado unicamente por uma estrutura denominada nó-i (ou, do inglês, $i$-node). O $i$-node contém informações como permissões de leitura/escrita/execução, datas de ultima alteração, etc, e os endereços de blocos de dados do arquivo, ou outros blocos que podem apontar para blocos de dados ou de endereços, formando um encadeamento para que seja possível endereçar todos os blocos de dados de arquivos muito grandes. A figura 4.11 ilustra o sistema de $i$-node. 


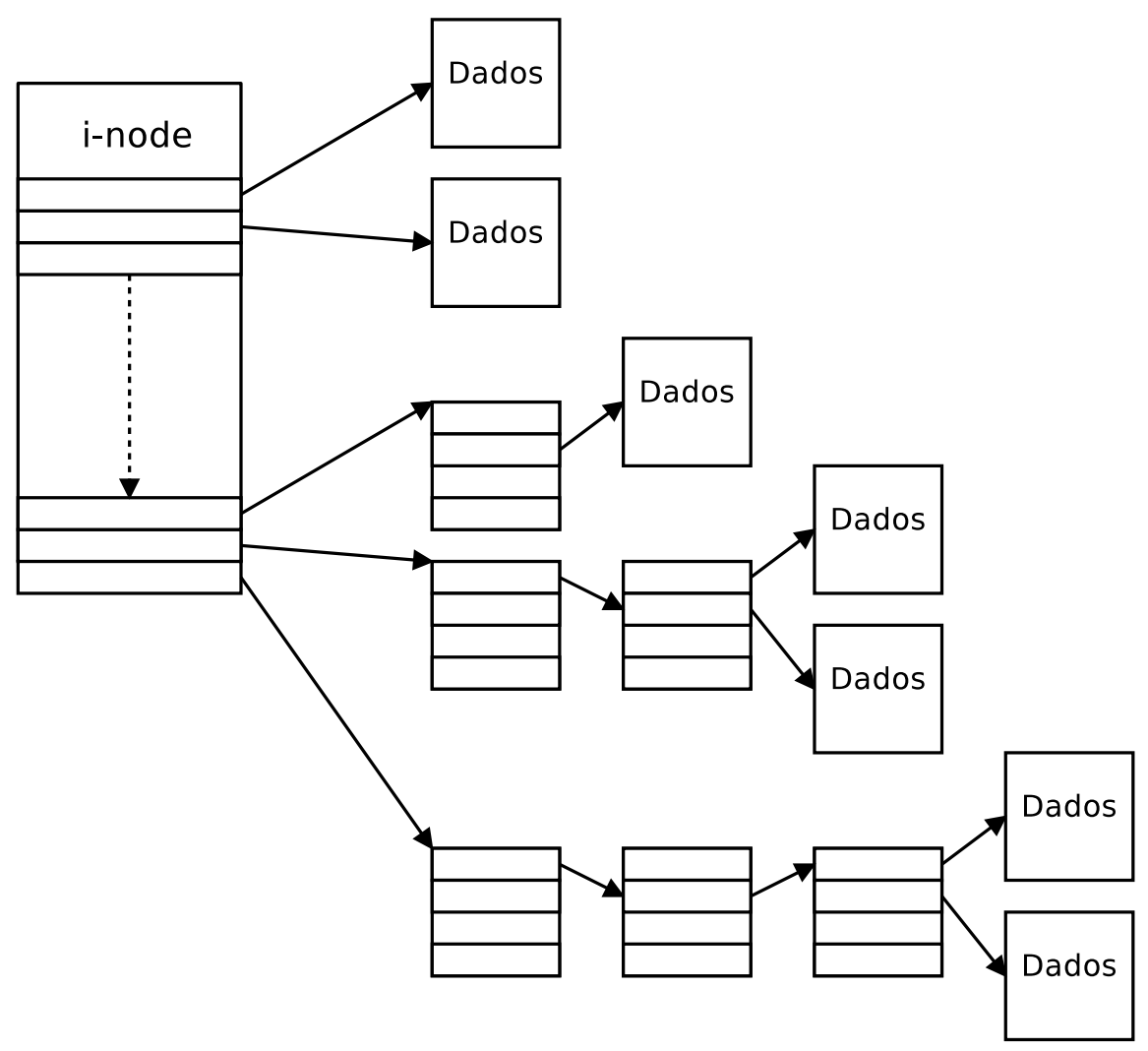

Figura 4.11: Ilustração de um $i$-node apontando para blocos de dados e de endereços (que apontam para blocos de dados) e seus respectivos encadeamentos.

Um bloco de dados é a menor unidade de alocação do sistema de arquivos, podendo ser representados por um ou mais setores. No EXT2 os blocos podem ser tipicamente de 1024, 2048 ou 4096 bytes (ou 2, 4 ou 8 setores de 512 bytes). O tamanho dos blocos é definido na criação do sistema de arquivo, e acaba definindo o tamanho máximo de arquivo suportado pelo sistema.

No EXT2, cada $i$-node contém 12 entradas que apontam para blocos de dados, 1 entrada que aponta pra um bloco de endereçamento simples, 1 entrada para endereçamento duplo e 1 entrada para endereçamento triplo. Os endereços de cada bloco são representados por um inteiro de 32 bits (4 bytes). A quantidade de blocos que podem ser endereçados é dada pela equação 4.1, onde $B$ é o tamanho do bloco de dados em bytes, $\frac{B}{4}$ é a quantidade de entradas disponíveis em um bloco de endereços, ou seja, o bloco de dados que contém endereços de outros blocos, utilizados nos endereçamentos indiretos.

$$
N_{\text {blocos }}=12+\left(\frac{B}{4}\right)+\left(\frac{B}{4}\right)^{2}+\left(\frac{B}{4}\right)^{3}
$$

O tamanho máximo teórico de um arquivo será dado por $\min \left(N_{\text {blocos }} \times B, 2^{32} \times B\right)$, pois a quantidade de blocos endereçáveis e o tamanho de cada endereço são os dois fatores limitantes. Fazendo $B=1024$ (tamanho de bloco normalmente utilizado), temos $N_{\text {blocos }}=16843020 \mathrm{e}$ $\left(N_{\text {blocos }} \times B\right)=17247252480=16 G B$. Logo, teoricamente o tamanho máximo de um arquivo 
para um bloco de 1KB (B=1024) é 16GB. Na prática, o tamanho dependerá também de outros fatores, como implementação no kernel e capacidades da arquitetura.

Os $i$-nodes que representam diretórios funcionam exatamente como os $i$-nodes de arquivos, a diferença está nos blocos de dados, que não contém dados de arquivo, mas sim entradas do diretório. Como exemplo, considere o diretório home com a hierarquia mostrada na figura 4.12(a). Neste caso, 1 bloco de dados será o suficiente para conter as três entradas do diretório home. O $i$-node aponta para o bloco de dados, que é estruturado conforme a figura 4.12(b).

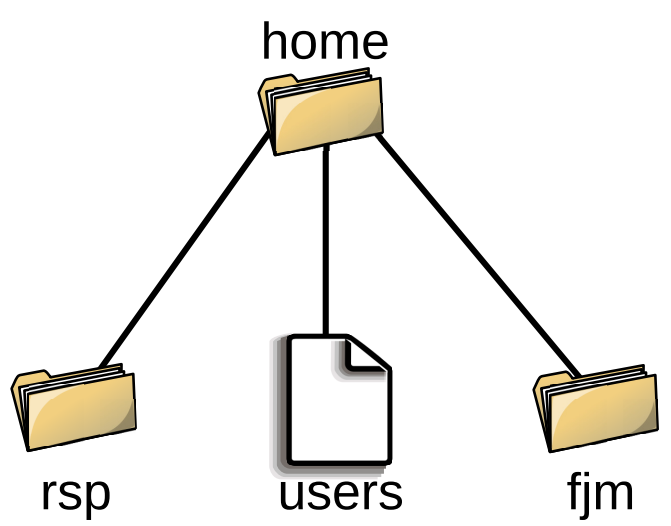

(a) Diretório home, contendo os diretórios rsp e fjm, e o arquivo users.

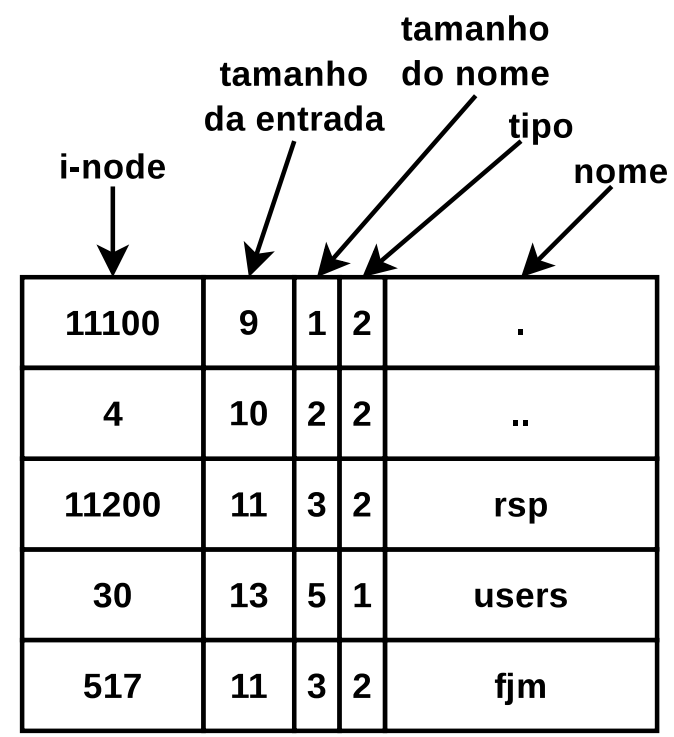

(b) Bloco de dados com as entradas do diretório /home.

O primeiro campo de cada entrada contém o endereço do $i$-node da entrada (arquivo ou diretório). Este endereço é o índice do i-node em uma tabela que contém o mesmo, denominada Tabela de i-nodes. O segundo campo contém o tamanho total (em bytes) da entrada. O terceiro campo contém tamanho do nome (quantidade de caracteres). O quarto campo contém o tipo da entrada, a tabela 4.4 contém os tipos de entrada no EXT2. O quinto e último campo contém o nome da entrada, uma string finalizada com o caracter " $\backslash 0$ ”.

Tabela 4.4: Tipos de entrada de diretório no EXT2. Fonte: (Bovet e Cesati, 2006).

\begin{tabular}{|c|l|}
\hline Tipo de Arquivo & Descrição \\
\hline 0 & Desconhecido \\
\hline 1 & Arquivo regular \\
\hline 2 & Diretório \\
\hline 3 & Dispositivo de caractere \\
\hline 4 & Dispositivo de bloco \\
\hline 5 & Named pipe \\
\hline 6 & Socket \\
\hline 7 & Link simbólico \\
\hline
\end{tabular}


Todo diretório contém pelo menos duas entradas: “.” e “..”. A primeira aponta para o próprio diretório, a segunda aponta para o diretório pai, no caso do diretório /home, /home/.. aponta para o diretório raiz (/) e /home/. aponta para/home.

$\mathrm{O}$ número total de $i$-nodes é definido na criação do sistema de arquivo. Logo, se todos os i-nodes estiverem em uso, mesmo que haja blocos de dados disponíveis na partição do sistema de arquivo não será possível criar novos arquivos ou diretórios, pois não haverá nenhum i-node disponível.

A estrutura que define as informações gerais do sistema de arquivo é o Superbloco. Geralmente armazenado no inicio da partição, o Superbloco contém os bitmaps de alocação dos blocos de dados e da tabela de $i$-nodes, assim como contém ou aponta para a tabela de i-nodes. Outras informações cruciais como tamanho do bloco de dados, quantidade e data da ultima montagem e quantidade de $i$-nodes também ficam armazenadas no Superbloco, que acaba sendo extremamente vital para a organização dos dados. Logo, cópias de segurança do Superbloco podem ser dispostas em toda partição do sistema de arquivo.

O sistema de arquivo genérico do VFS definido pelo TempOS é extremamente semelhante ao EXT2, tal fato se deve a facilidade de implementar o suporte a EXT2 no VFS dado que ambas as estruturas serão praticamente as mesmas. A figura 4.12 apresenta o Superbloco do sistema de arquivo do VFS (TempOS VFS).

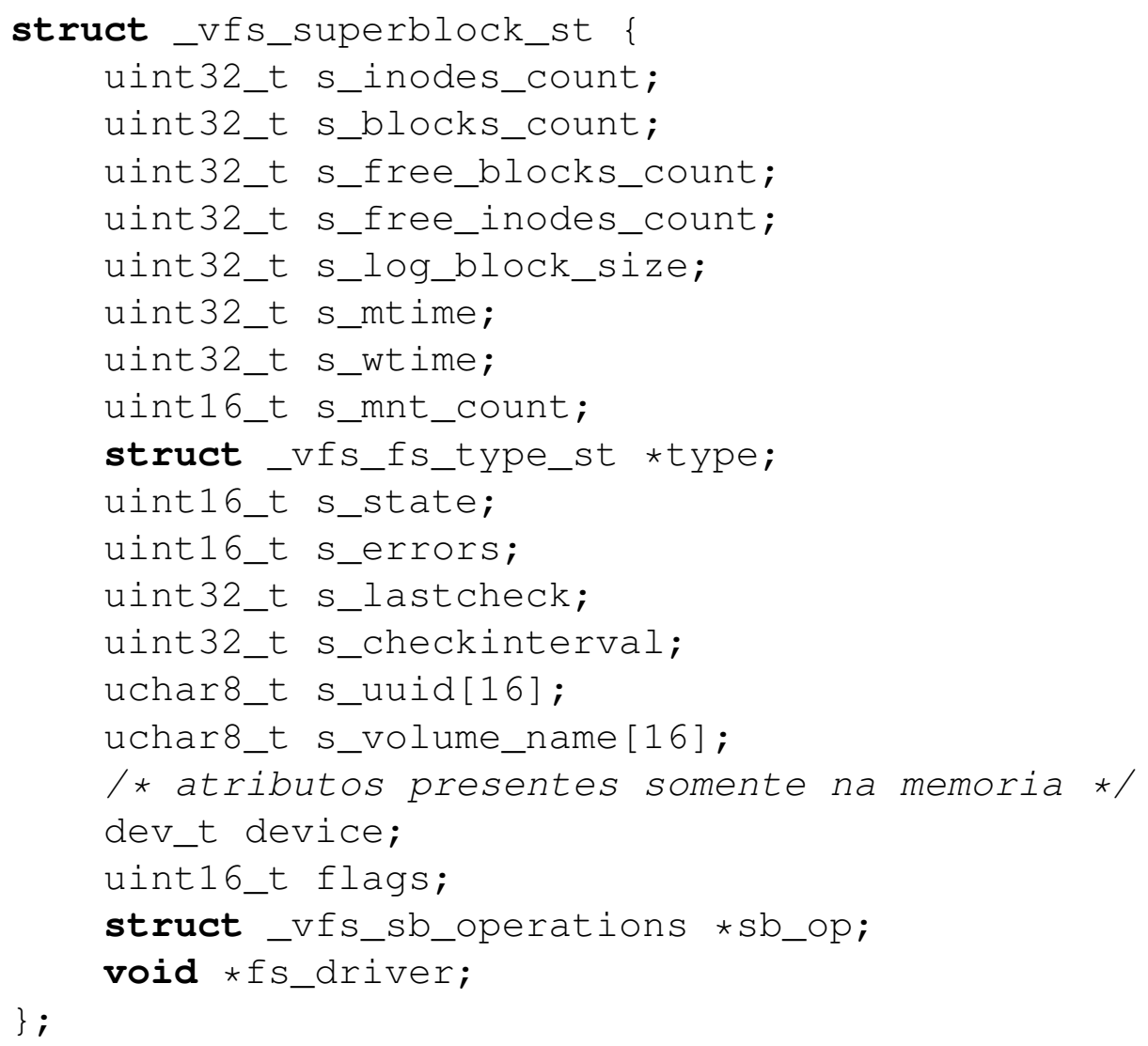

Figura 4.12: TempOS VFS: Estrutura do Superbloco. 
No TempOS VFS o Superbloco contém a quantidade de $i$-nodes e blocos de dados total e livres, datas da ultima montagem e da ultima escrita, quantidade de vezes que o sistema de arquivo foi montado, estado do mesmo, erros ocorridos, data da ultima checagem de consistência e intervalo para a próxima checagem, identificação da partição (UUID) e nome de volume. Outros atributos ficam presentes somente na memória durante a execução do SO.

A tabela de $i$-nodes é criada na memória através de uma lista encadeada. A figura 4.13 mostra a estrutura do $i$-node no TempOS VFS.

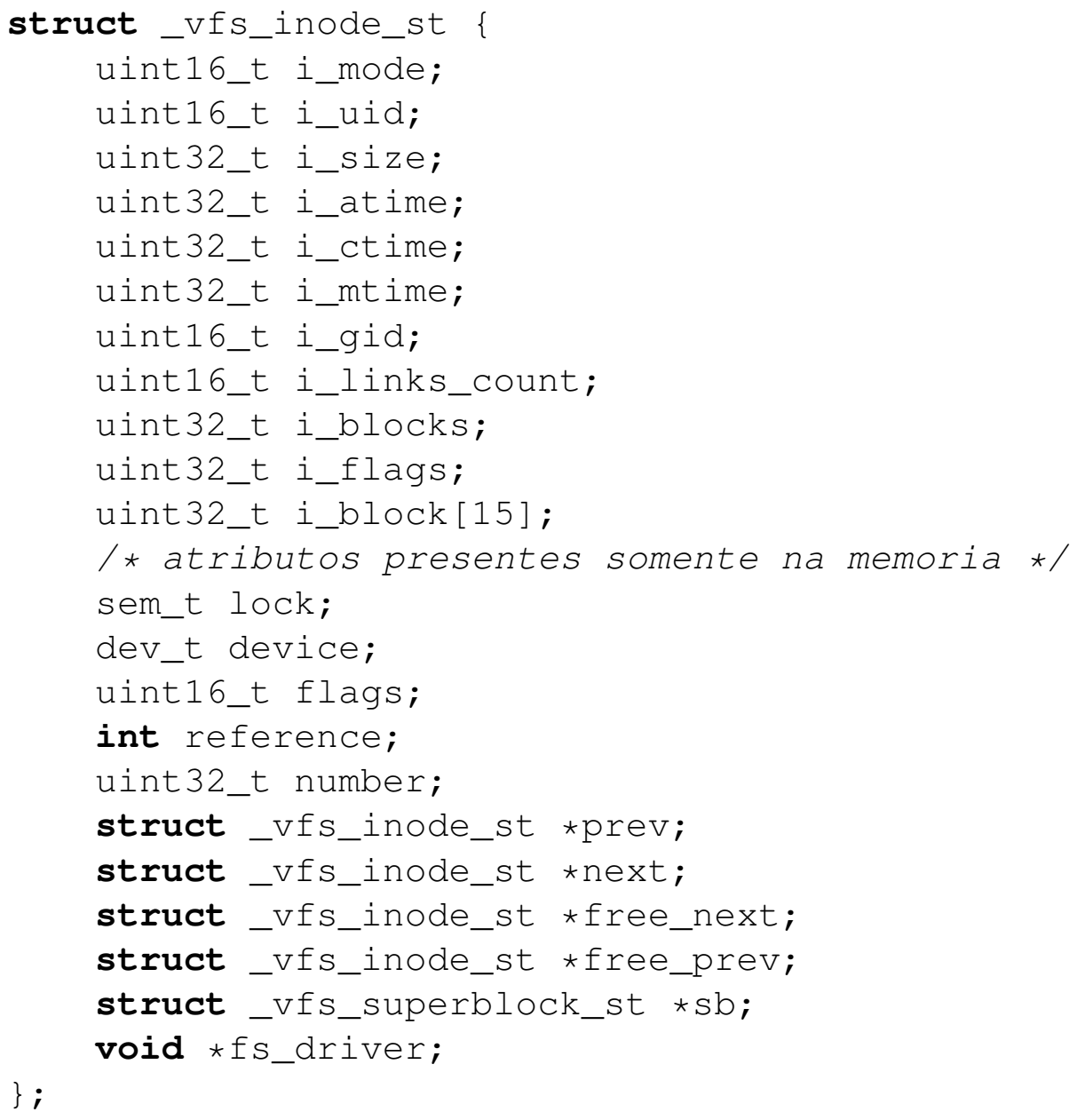

Figura 4.13: TempOS VFS: Estrutura do i-node.

O tamanho da tabela é predefinido no código e determina a quantidade máxima de arquivos abertos ao mesmo tempo, pois quando um arquivo é aberto o VFS chama o driver específico para ler o $i$-node do dispositivo para um $i$-node da tabela. Consequentemente, alterações feitas neste $i$-node deverão ser sincronizadas com o $i$-node presente no sistema de arquivo.

A tabela de $i$-nodes possui funcionamento semelhante aos blocos em cache no sistema. Entretanto, sua implementação é mais fácil dado que não há necessidade de um vetor de hash, pois o apontamento ao $i$-node é direto (a partir da entrada de diretório). Entretanto, o processo de abertura de um arquivo envolve buscar pelo $i$-node do mesmo e verificar se há alguma entrada disponível 
na tabela de $i$-nodes do sistema para que o mesmo seja carregado para memória. Quando o arquivo é fechado, o i-node é gravado de volta no dispositivo (caso tenha sido modificado) e a entrada é liberada.

O VFS também é responsável pela montagem/desmontagem dos dispositivos. Todos os dispositivos montados ficam armazenados em uma tabela de montagem que contém o Superbloco, o $i$-node da raiz e o nome do sistema de arquivo montado, assim como o $i$-node e o nome do ponto de montagem. A figura 4.14 mostra a estrutura de cada entrada na tabela de montagem.

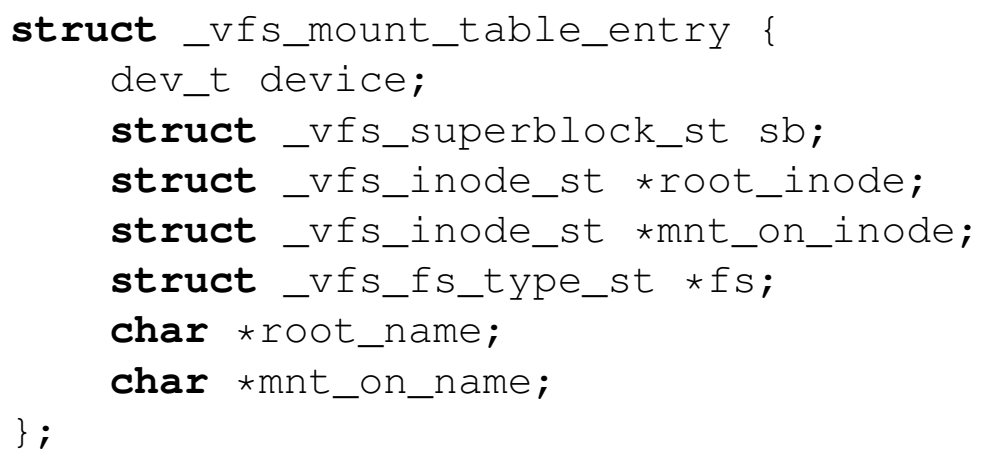

Figura 4.14: TempOS VFS: Estrutura da tabela de montagem.

Quando o sistema é iniciado, o kernel verifica o parâmetro de boot root, que deve conter qual dispositivo contém a raiz do sistema. Por exemplo, o valor root=8:1 indica que a raiz está presente no dispositivo com major number 8 e minor number 1, neste caso, a primeira partição do disco IDE instalado no canal primário, atuando como mestre. O kernel verifica então se há um sistema de arquivo suportado no dispositivo e se encontrado, efetua a leitura do Superbloco e do $i$-node da raiz (/). A montagem é procedida e a entrada criada na tabela de montagem. Com isso, o sistema já está apto a ler qualquer arquivo da raiz e efetuar montagens posteriores através da chamada ao sistema mount().

No TempOS, todas as estruturas do VFS estão definidas no arquivo include/fs/vfs.h. Definido o sistema de arquivo genérico (TempOS VFS), o suporte a sistemas de arquivos diversos (como o EXT2) se dá através de "drivers de sistema de arquivo". A função do driver é atuar como uma ponte entre o sistema de arquivo do dispositivo e o TempOS VFS. Portanto, se o sistema de arquivo no dispositivo não está baseado em i-nodes, Superbloco, etc, é dever do driver "traduzir" o formato lógico para o formato do TempOS VFS. A tabela 4.5 contém as funções que devem ser implementadas pelo driver.

Quando uma solicitação de montagem é feita ao kernel, o primeiro passo é fazer a leitura do arquivo de dispositivo para obtenção do major e minor number. Depois, o primeiro bloco do dispositivo é lido e a função $c h e c k \_f \_$type() de cada driver de sistema de arquivo é chamada para descobrir qual é o tipo de sistema de arquivo no dispositivo. Quando encontrado, o kernel chama a função get_sb() do respectivo driver para obter o Superbloco do sistema de arquivo do dispositivo. $\mathrm{O} i$-node da raiz é lido, assim como o $i$-node do ponto de montagem, se nenhum erro ocorrer, 
uma nova entrada na tabela de montagem é criada e a montagem finalizada. $\mathrm{O} i$-node do ponto de montagem é marcado como "montado", assim, qualquer endereço que aponte para este $i$-node, será automaticamente substituído pelo i-node do dispositivo montado. A figura 4.15 ilustra este mecanismo.

Tabela 4.5: Funções implementadas por um driver de sistema de arquivo.

\begin{tabular}{|l|l|}
\hline Função & Descrição \\
\hline get_inode & Lê um $i$-node do sistema de arquivo. \\
\hline write_inode & Atualiza o $i$-node no sistema de arquivo. \\
\hline put_inode & Escreve o $i$-node no sistema de arquivo e libera o $i$-node da memória. \\
\hline alloc_inode & Aloca um novo $i$-node. \\
\hline free_inode & $\begin{array}{l}\text { Libera um } i \text {-node e todos os blocos apontados pelo mesmo (utilizado na remo- } \\
\text { ção de um arquivo ou diretório). }\end{array}$ \\
\hline write_super & Atualiza o Superbloco no sistema de arquivo. \\
\hline get_fs_block & Lê um bloco de dados do sistema de arquivo. \\
\hline check_fs_type & $\begin{array}{l}\text { Responde se o sistema de arquivo fornecido é do tipo implementado pelo dri- } \\
\text { ver. }\end{array}$ \\
\hline get_sb & Lê o Superbloco do sistema de arquivo. \\
\hline
\end{tabular}

Dispositivo /dev/sda2 montado em /mnt mount("/dev/sda2","/mnt");

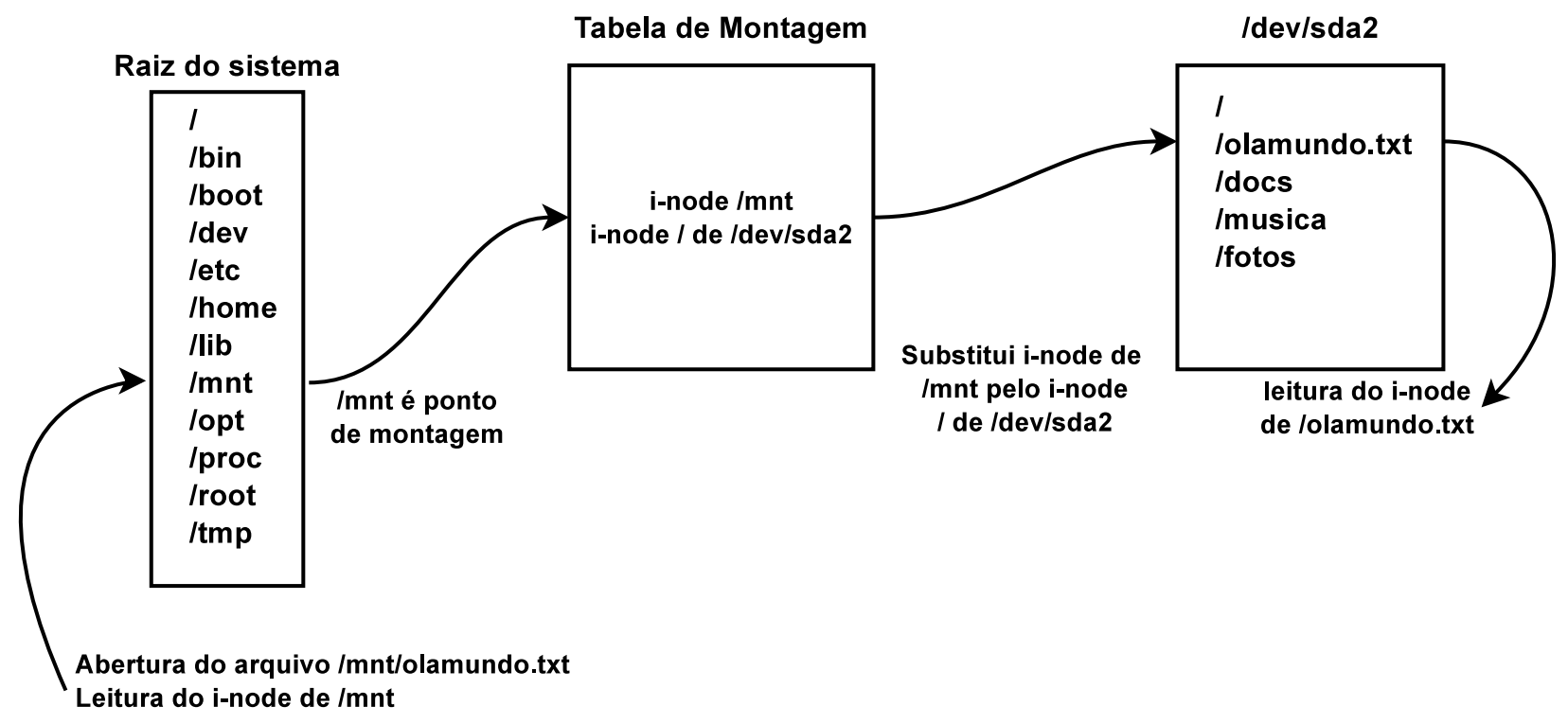

Figura 4.15: Mecanismo de montagem feito pelo VFS.

O acessos aos dispositivos é feito através dos respectivos drivers de maneira transparente. Este mecanismo é possível porque o VFS gerencia uma tabela de drivers de dispositivo, que contém funções como read() e write() de cada driver, permitindo que a função adequada seja executada a partir do major e minor number do dispositivo. 
A partir das funções implementadas pelos drivers de sistema de arquivo, o VFS implementa funções para o TempOS VFS que consequentemente funcionarão para qualquer sistema de arquivo que tenha o driver correspondente implementado. A tabela 4.6 contém as principais funções, que são fundamentais para a implementação das chamadas ao sistema open(), read(), write() e close(), que manipulam os arquivos.

Tabela 4.6: Funções implementadas pela camada VFS.

\begin{tabular}{|l|l|}
\hline Função & Descrição \\
\hline vfs_mount_root & $\begin{array}{l}\text { Monta a raiz do sistema a partir do dispositivo fornecido (major e minor num- } \\
\text { ber). }\end{array}$ \\
\hline vfs_mount & Monta um dispositivo em um ponto de montagem (diretório). \\
\hline vfs_iget & Lê um $i$-node do sistema de arquivo e o insere na tabela de $i$-nodes. \\
\hline vfs_bmap & $\begin{array}{l}\text { Converte a posição do conteúdo de um arquivo no bloco de dados em que a } \\
\text { mesma se encontra. }\end{array}$ \\
\hline vfs_namei & $\begin{array}{l}\text { Retorna o } i \text {-node } \text { correspondente a partir de um caminho, por exemplo, “/ho- } \\
\text { me/rsp/olamundo.txt” retorna o } i \text {-node do arquivo olamundo.txt. }\end{array}$ \\
\hline
\end{tabular}

O VFS ainda mantém uma tabela de arquivos abertos, que contém informações sobre cada arquivo aberto pelos processos. Cada entrada na tabela de arquivos abertos contém informações como o modo de abertura do arquivo, quantos processos estão referenciando a entrada e a localização do $i$-node do arquivo na tabela de $i$-nodes. A tabela de arquivos, assim como a tabela de $i$-nodes, é global pois vários processos podem abrir o mesmo arquivo com mesmo modo de acesso (somente leitura, leitura e escrita ou somente escrita). A abertura do arquivo é feito através da chamada ao sistema open().

Na chamada open() o kernel primeiro obtém o $i$-node do arquivo através da função $v f s \_n a m e i()$ e verifica as permissões do mesmo. Se o processo possui as permissões adequadas, o processo de abertura é continuado alocando uma nova entrada na tabela de arquivos. Uma nova entrada na tabela de descritores do processo será alocada e irá referenciar a entrada correspondente na tabela de arquivos. Cada processo possui sua própria tabela de descritores, que indicam todos os arquivos abertos pelo processo. Esta tabela é necessária pois irá indicar informações particulares a cada processo, como a posição atual no arquivo para as operações de leitura e escrita. Os três primeiros descritores da tabela $(0,1$ e 2$)$ são destinados a entrada padrão, saída padrão e saída de erros padrão do processo. Neste ponto faz-se fundamental a abstração do Unix de que tudo no sistema é tratado como um arquivo. Os terminais (saída no console de vídeo ou serial, por exemplo), assim como o teclado ou qualquer outro dispositivo são vistos como arquivos, e portanto, podem ser abertos e manipulados pelos processos como tal. A entrada 0 contém o descritor associado ao arquivo da entrada padrão do processo, por exemplo, o teclado. Já a entrada 1 contém o descritor associado ao arquivo da saída padrão, e a entrada 2 associa o arquivo da saída de erros padrão, onde geralmente é igual ao descritor 1. Estas saídas podem ser, por exemplo, o console de vídeo. 
A figura 4.16 ilustra a relação entre as tabelas do VFS e a figura 4.17 ilustra a abstração do acesso aos dispositivos de entrada e saídas padrão do processo.

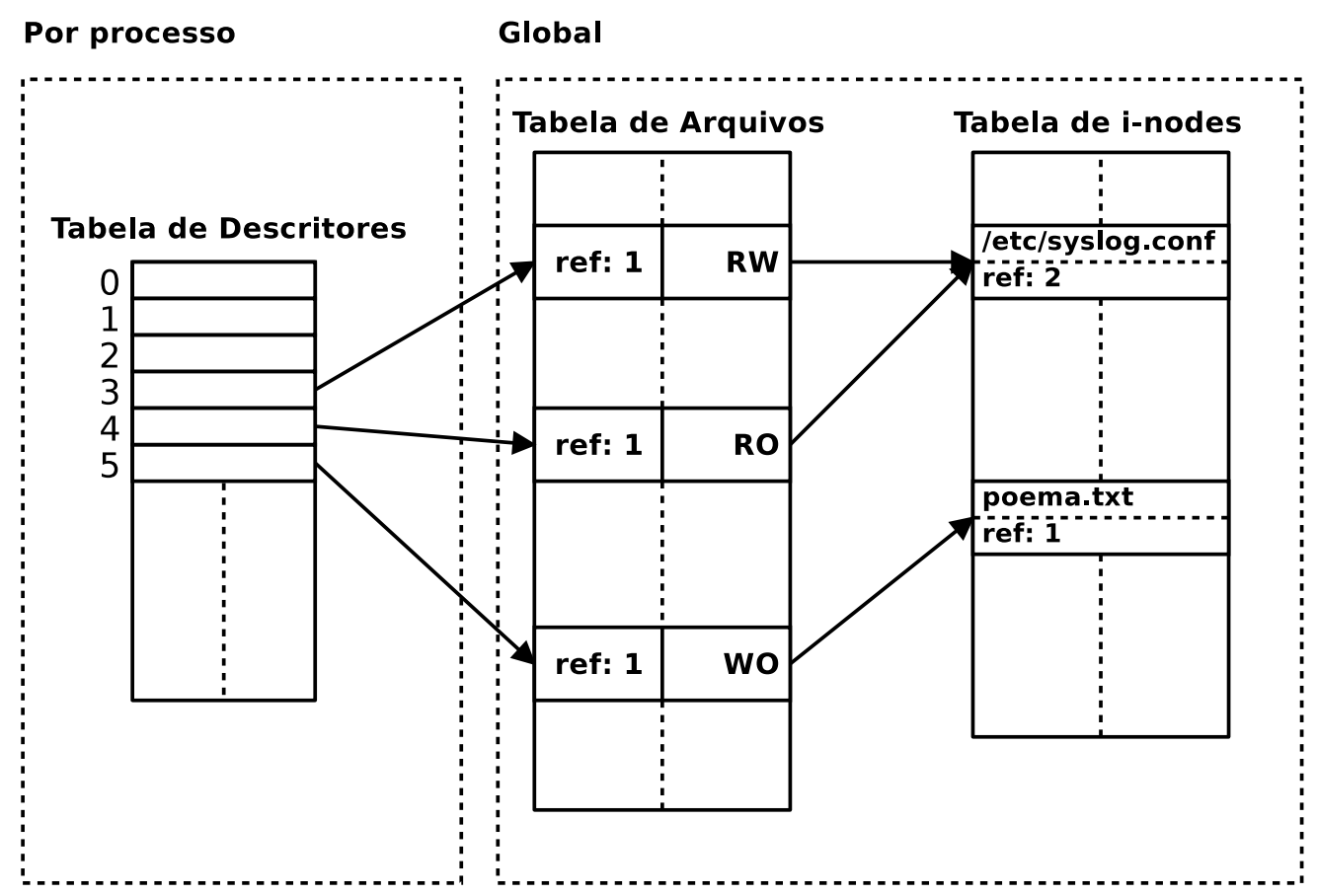

Figura 4.16: Tabelas utilizadas pelo SO para gerenciamento de arquivos e $i$-nodes.

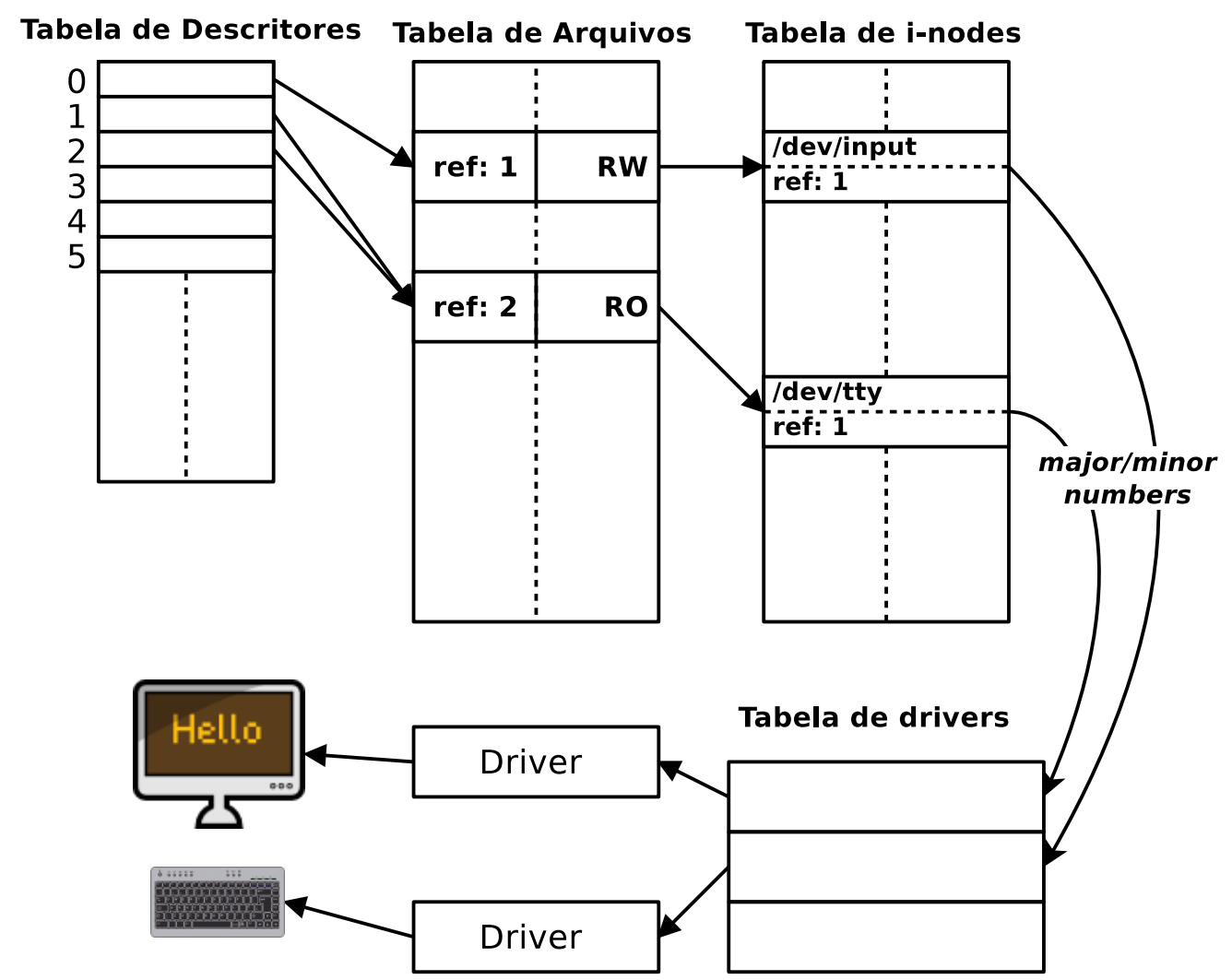

Figura 4.17: Abstração do acesso aos dispositivos de entrada e saídas padrão do processo. 


\section{Drivers de dispositivo (caractere / bloco)}

Este módulo contém os drivers para dispositivos de caractere e bloco. Durante a inicialização do kernel, cada driver é iniciado e deve se registrar na tabela de drivers através das funções providas pelo VFS, register_block_driver() e register_char_driver(). As informações do driver e endereços de suas funções, como a função $\operatorname{read}($ ) (para efetuar leitura de blocos de dispositivo) serão armazenadas na entrada da tabela cujo índice é o major number do driver, facilitando o acesso as informações do mesmo.

No TempOS os drivers de dispositivos de bloco e caractere encontram-se nos diretórios drivers/block e drivers/char, respectivamente. Todas estruturas utilizadas na tabela de drivers encontramse no arquivo de cabeçalho include/fs/device.h.

\section{Controle de Hardware}

Este módulo contém todo o código que trabalha diretamente no hardware, dependente de arquitetura, como drivers para controladores de interrupção (PIC no caso da arquitetura PC), configuração do processador e hardwares específicos. Separar ao máximo o código dependente de arquitetura é fundamental no desenvolvimento do SO pois além de permitir melhor modularização, facilita a portabilidade para outras arquiteturas. No TempOS, todo o código dependente da arquitetura x86 encontra-se no diretório $\mathbf{~ a r c h / \mathbf { x } 8 6 .}$

\section{Subsistema de controle de processos}

Este módulo contém o gerenciador de memória, responsável por alocar memória para os processos de usuário e de kernel, o escalonador, que implementa o chaveamento de processos baseado em uma política de escalonamento e funções para comunicação entre processos, como semáforos, filas de mensagens e pipes, assim como funções sleep() e wakeup() para bloqueio e execução de processos.

Uma das tarefas mais críticas de um SO é o gerenciamento da memória, o que implica em gerenciar a memória física e a memória ocupada por cada processo, inclusive pelo kernel. O sistema de paginamento é o método mais utilizado pelos Sistemas Operacionais modernos. Neste sistema, a memória é dividia em páginas (por exemplo, na arquitetura x86 geralmente são utilizadas páginas de $4 \mathrm{~KB}$ ), e cada página contém atributos que indicam as permissões de leitura/escrita, cache, privilégio, etc. O ponto mais interessante é que cada página define uma área apenas da memória física, podendo assim ser mapeada para qualquer endereço do espaço linear (lógico), isto é feito através do uso de tabelas de páginas. A técnica de swap também é implementada através de paginamento, pois sempre que uma página acessada pelo software não encontra-se na memória física o processador gera uma exceção automaticamente que deve ser tratada pelo SO, responsável por ler a página faltante do dispositivo de swap (geralmente o disco rígido) e coloca-lá na memória física. Neste contexto surgem os algoritmos de substituição de página, tais como $N R U$ 
(Não Recentemente Utilzada), Primeira Página a Entrar, Primeira a Sair (FIFO), Substituição de Página de Segunda Chance, dentre outros (Stallings e Paul, 1998). É importante lembrar que os mecanismos de proteção de memória devem ser providos pela MMU (Unidade de Gerenciamento de Memória, do inglês, Memory Management Unit) do processador, cabendo ao SO configurar e trabalhar com os mecanismos providos pela arquitetura.

Um dos métodos utilizados para gerenciar as páginas físicas de memória é o gerenciamento por pilha. Neste modelo, cada página que aponta para um espaço físico de memória livre é empilhada, assim, quando o SO precisar alocar uma página basta desempilhar uma da pilha. Analogamente, para liberar uma página alocada basta empilha-lá novamente. A implementação é fácil e o algoritmo não é pesado, pois não há cálculos para detectar a posição de uma página livre.

Outro método é o gerenciamento por mapa de bits, que é mais adequado para o gerenciamento do espaço linear. Cada bit representa uma página, 0 indicando que a página está livre e 1 indicando que a página está ocupada. Este algoritmo é mais lento para encontrar apenas uma página livre, porém possui melhor desempenho para se encontrar espaços contínuos livres (de várias páginas). Assim, os dois métodos utilizados podem ser utilizados em conjunto, o sistema de pilha é utilizado para alocar páginas físicas, estas páginas são mapeadas no espaço linear, que é gerenciado através de um mapa de bits. A figura 4.18 ilustra os dois métodos.

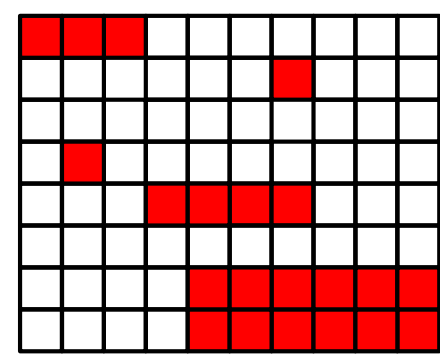

Mapa de Bits

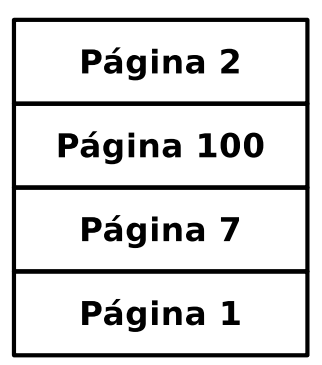

Pilha

Figura 4.18: Modelos de gerenciamento de memória: Mapa de bits e pilha.

Outras abordagens também podem ser utilizadas, como por exemplo o gerenciamento por lista encadeada, onde os espaços livres de memória são inseridos em uma lista encadeada, assim, na alocação é feita uma busca na lista por um espaço livre que satisfaça a quantidade de memória a ser alocada, enfim, o gerenciamento é feito através da manipulação da lista.

O TempOS gerencia as páginas físicas por pilha e o espaço lógico por mapa de bits. Por envolver a MMU do processador, o gerenciador de memória possui uma considerável parte dependente de arquitetura. O código do gerenciador de memória encontra-se nos diretórios kernel/mm (parte independente de arquitetura) e $\mathbf{a r c h} / \mathbf{x 8 6 / \mathbf { m m }}$ (parte dependente de arquitetura). A função alloc_page() efetua a alocação de uma página física, e a função _vmalloc_() faz a alocação no espaço linear a partir de um mapa de bits, que pode pertencer ao kernel ou a um processo. A função kmalloc() utiliza_vmalloc_() para alocar memória para o kernel, atuando como uma função malloc() da biblioteca C. Esta presente em grande parte do código do kernel. Para desalocar as 
páginas físicas alocadas com alloc_page() a funçãofree_page() é utilizada. Já a memória alocada com_vmalloc_() ou kmalloc() pode ser desalocada com a função $\mathrm{kfree}($ ) (funcionando de maneira análoga a função free() da biblioteca $\mathrm{C}$ ).

O módulo de controle de processo contém também o escalonador, responsável por alternar a execução dos processos e threads do kernel provendo assim um ambiente preemptivo, multiprogramado. A arquitetura TempOS não especifica capacidades SMP (multiprocessamento simétrico, do inglês, symmetric multiprocessing), arquitetura moderna onde vários núcleos iguais atuam no mesmo processador compartilhando memória principal. Entretanto, mesmo não implementando SMP o SO pode executar normalmente em processadores multi-núcleo, funcionando em apenas um dos núcleos. Considerar os sistemas SMP implicaria em uma série de detalhes que tornaria a implementação ainda mais complexa, fugindo do escopo da plataforma, que é o ensino. Neste caso, a abordagem pode ser feita em disciplinas de computação paralela ou mais avançadas, para pós-graduação.

Assim como o gerenciador de memória, o escalonador possui grande parte dependente de arquitetura, pois trata da configuração do processador para execução de um processo. Não menos importante, sua função também inclui escolher qual e como os processos serão executados alternadamente. Neste contexto estão presentes diversos algoritmos de escalonamento, como FIFO (First in, first out), SJF (Shortest Job First) e o clássico algoritmo Round-Robin(Tanenbaum, 1992). Qualquer algoritmo pode ser implementado. Portanto o código independente de arquitetura escolhe o processo a ser executado, e o código dependente coloca o processo em execução.

No TempOS o escalonador está implementado nos arquivos kernel/sched.c (parte indepen-

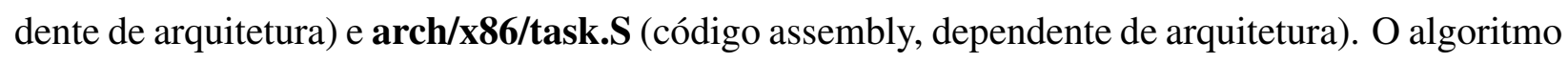
de escalonamento implementado é o Round-Robin com quantum definido pela variável scheduler_quantum, que pode ser alterada em tempo de execução. As estruturas de dados com as informações de cada processo são armazenadas em uma lista circular duplamente encadeada. A função schedule() é chamada quando o quantum determinado é atingido (através da interrupção do relógio), fazendo a decisão de qual processo será executado. O processo escolhido é colocado em execução através da função switch_to(), que chama o código dependente de arquitetura.

Tão importante quanto serem escalonados, deve existir a possibilidade dos processos serem bloqueados, seja em uma operação de I/O ou na espera de um recurso ocupado, por exemplo. Quando o escalonador já está implementado, as rotinas para bloqueio e desbloqueio de processos, sleep() e wakeup(), respectivamente, podem ser implementadas sem grande complexidade. Uma alternativa simples, da forma com a qual é implementada no TempOS, é utilizar um vetor onde cada posição representa uma fila de processos bloqueados. Por exemplo, a posição 2 do vetor contém todos os processos bloqueados que estão aguardando por um bloco no cache. Estes processos foram bloqueados através da chamada da função sleep(2). Quando um bloco é liberado, a chamada wakeup(2) é executada alterando o estado de todos os processos nesta fila para "PRONTO PARA EXECUTAR”. Não há prioridades, qualquer um dos processos da fila pode ser escalonado pelo escalonador, assim, todos os outros processos serão bloqueados novamente e o ciclo descrito se 
repete até quando não haja mais processos na fila. A figura 4.19 ilustra o vetor de filas e os processos bloqueados.

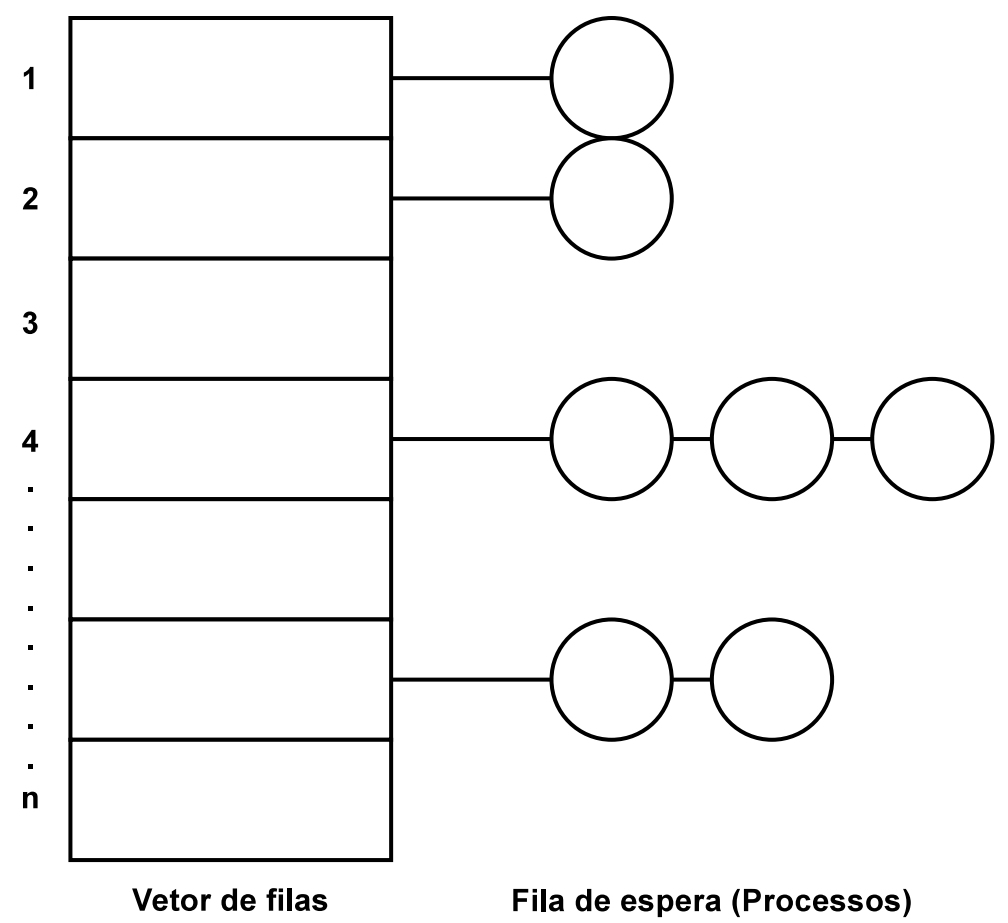

Figura 4.19: Filas de processos bloqueados.

A figura 4.20 mostra o algoritmo básico que deve ser utilizados nos processos e threads para o bloqueio e desbloqueio dos mesmos.

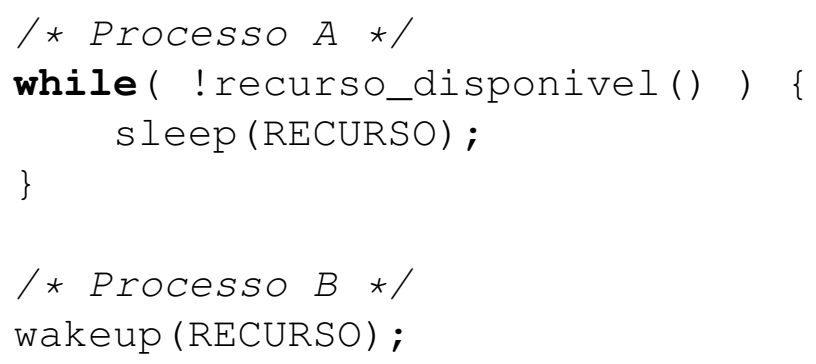

Figura 4.20: Uso das rotinas sleep() e wakeup().

É importante notar a necessidade do laço repetitivo no uso de sleep(). Considere o processo A que verifica a disponibilidade de um determinado recurso. Se o recurso está ocupado a função sleep() é executada e o processo é bloqueado, ou seja, vai para a fila de espera e o escalonador é chamado para executar outro processo. O processo B termina de utilizar o recurso aguardado por A e o libera chamando a função wakeup(). O processo A e qualquer processo que também esteja na fila serão marcados como "PRONTO PARA EXECUTAR", porém, suponha que um processo $\mathrm{C}$ que estava na fila foi escolhido pelo escalonador sendo colocado em execução e bloqueando o recurso para uso. Quando o escalonador colocar o processo A em execução o laço será executado 
novamente e chamará sleep() de novo, pois o recurso ainda não está disponível. Este processo se repetirá até que o recurso esteja disponível para A. O funcionamento das outras filas é exatamente análogo.

No TempOS, as funções sleep() (chamada de sleep_on()) e wakeup() estão implementadas no arquivo kernel/wait.c.

Por fim, o subsistema de controle de processos contém funções que implementam mecanismos de IPC (Comunicação entre processos, do inglês, Inter-process communication) e sincronismo (semáforos). Passagem de mensagens e pipes ainda não foram implementados no TempOS, mas podem seguir qualquer algoritmo desde que sejam fornecidas as chamadas ao sistema do padrão POSIX para IPC. Já os semáforos estão implementados no arquivo lib/semaphore.c. A implementação de semáforos, apesar de simples, necessita de código dependente de arquitetura pois há a necessidade da execução atômica de determinada parte do código, como o incremento/decremento do semáforo. Portanto, a única especificação rígida é que as operações $u p()$ e down() sejam executadas de maneira atômica não causando comportamentos espúrios dos processos.

\section{Notas finais sobre a especificação da Arquitetura TempOS}

A seção 4.2 apresentou toda a especificação e arquitetura da Plataforma TempOS, detalhando principalmente a arquitetura do kernel e cada um dos seus módulos, referenciando detalhes de implementação ao TempOS (SO modelo da plataforma) e buscando (até onde possível) uma visão independente de arquitetura. As principais funções de cada módulo foram especificadas acompanhadas da descrição de seus respectivos algoritmos.

Dado que a plataforma está inicialmente baseada nas arquiteturas PC e IA-32 (Intel x86 32 bits), o material não estaria completo sem uma descrição sobre detalhes de cada uma destas arquiteturas, o que é fundamental para a implementação do SO nas mesmas. A seção 4.3 apresenta a arquitetura PC e dispositivos específicos que deverão ser manipulados pelo SO. A seção 4.4 traz uma visão geral da arquitetura x86 e detalha mecanismos de proteção de memória e controle de interrupção, essenciais na implementação do kernel. A seção 4.5 contém o roteiro passo a passo para guiar o aluno no desenvolvimento do seu próprio SO seguindo a especificação da plataforma, com referências para materiais didáticos específicos.

\subsection{Arquitetura PC}

O Personal Computer (PC) foi lançado em 1981 pela IBM e revolucionou o mundo da computação, que era dominado pelas máquinas de grande porte, como os Mainframes. A decisão da IBM de manter a arquitetura do PC aberta permitiu que diferentes fabricantes desenvolvessem vários tipos de hardware, impulsionando o mercado e possibilitando um preço relativamente acessível para a época. Muitas empresas se envolveram no projeto do PC, desenvolvendo BIOS (Basic Input/Output System), barramentos (como o ISA) e novas tecnologias, que permitiram um 
rápido avanço tecnológico, transformando o computador em um utensílio doméstico praticamente indispensável nos dias atuais.

A figura 4.21 ilustra a arquitetura básica do PC contendo barramentos modernos, como o PCI Express $^{7}$ e mais antigos, como o PCI e o $\mathrm{AGP}^{8}$.

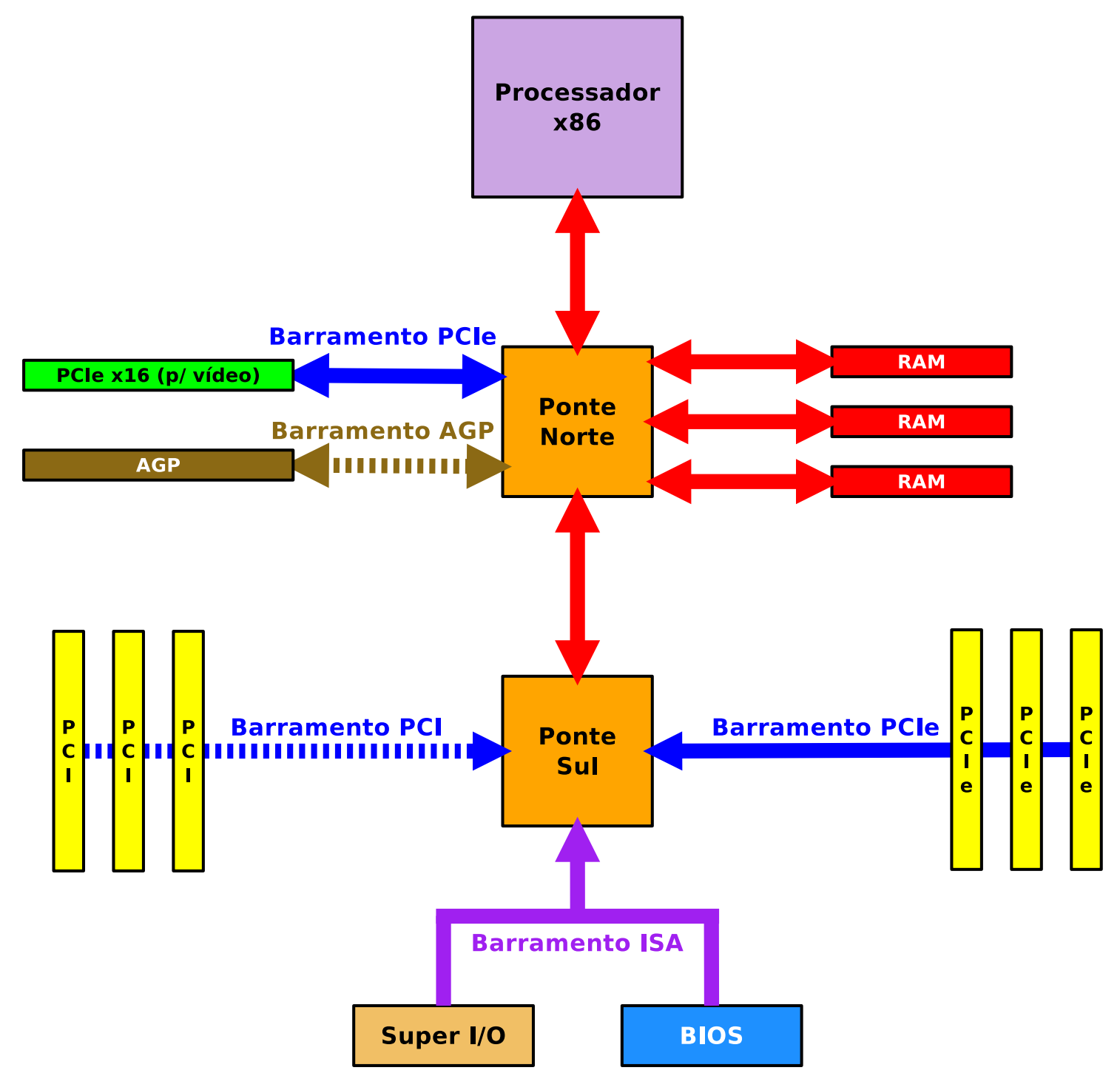

Figura 4.21: Arquitetura PC

A Ponte Norte e a Ponte Sul são circuitos integrados da placa-mãe que agregam inúmeros circuitos responsáveis por diversas funções.

A Ponte Norte faz o controle da memória principal e de barramentos AGP / PCIe para vídeo. Quando o processador acessa a memória ele simplesmente informa o endereço físico do byte que deseja acessar. É dever da controladora de memória (parte da Ponte Norte) verificar qual banco deve ser acessado e fazer toda comunicação com o circuito.

\footnotetext{
${ }^{7}$ Peripheral Component Interconnect Express, desenvolvido para substituir os barramentos PCI, PCI-X e AGP, possuindo altas taxas de transferência.

${ }^{8}$ Accelerated Graphics Port, barramento ponto-a-ponto de alta velocidade, padrão para conectar placa aceleradora gráfica. Foi descontinuado em 2005, em prol do PCIe x16.
} 
A Ponte Sul engloba uma série de circuitos importantes como:

- Controlador de teclado (i8042): Os primeiros PCs utilizavam o controlador de teclado da Intel 8042. Até hoje a interface do 8042 é utilizada para o controle de teclado.

- PIT - Programmable Interval Timer: É um oscilador e divisor de frequência. Pode ser utilizado para várias funções como geração de ondas, oscilador para o relógio de tempo real (RTC) e para o alto falante (speaker) do sistema, etc.

- PIC - Programmable Interrupt Controller (i8259A): Assim como o 8042, o controle de interrupções era feito com o chip da Intel 8259A. O PIC possui oito entradas para interrupções com controle de prioridade. A Arquitetura PC utiliza dois PICs ligados em cascata, o PIC ligado a entrada de interrupção do processador é chamado de mestre e o PIC ligado em cascata é chamado de escravo. Como uma das entradas do PIC mestre é ligada ao escravo, restam para o sistema quinze entradas de interrupção. Um ou mais periféricos são ligados em cada entrada, que recebe o nome de IRQ (Interrupt Request). A figura 4.22 ilustra a organização descrita.

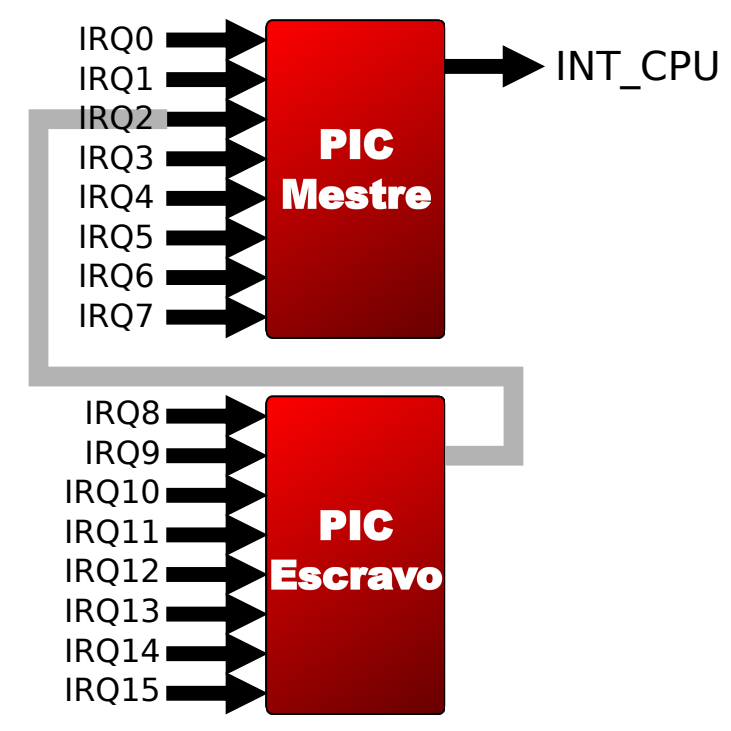

Figura 4.22: Esquema de ligação dos PICs Mestre e Escravo à entrada de interrupção da CPU

Alguns periféricos são ligados em IRQs específicas, tais como:

- IRQ 0: Reservada para o PIT (temporizador)

- IRQ 1: Teclado

- IRQ 2: Para ligação em cascata com o escravo

- IRQ 3: Porta serial COM2 (Padrão) ou COM4

- IRQ 4: Porta serial COM1 (Padrão) ou COM3

- IRQ 5: Porta paralela LPT2 ou placa de som 
- IRQ 6: Controlador de disquete

- IRQ 7: Porta paralela LPT1 ou placa de som

- IRQ 8: RTC (Real Time Clock)

- IRQ 9: Disponível (mapeada para IRQ2)

- IRQ 10: Disponível

- IRQ 11: Disponível

- IRQ 12: PS/2 mouse

- IRQ 13: ISA / Co-processador matemático

- IRQ 14: Canal IDE primário

- IRQ 15: Canal IDE secundário

O padrão para as IRQs ( 0 a 15) é mantido até hoje, entretanto as plataformas atuais suportam muito mais canais de interrupção, onde estão conectados dispositivos PCI, AGP, etc.

Muitos periféricos já são totalmente implementados (on-board) na Ponte Sul, como placas de rede, vídeo e som.

O chip Super I/O é responsável por serviços menos requisitados, como controle da unidade de disquete e portas seriais. Também pode estar implementado na Ponte Sul.

O BIOS (Basic Input Output System) é o software básico que é executado quando o PC é ligado. Sua função inclui verificar e configurar os dispositivos da máquina, checar a memória e dar continuidade ao boot da máquina. O BIOS também provê uma série de serviços que podem ser acessados através de interrupções pré definidas. Estes serviços estão disponíveis somente no modo

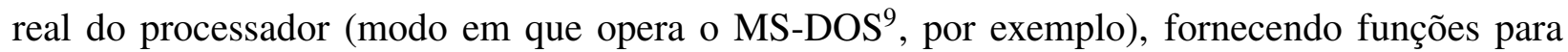
controle de vídeo, como plotagem de pixels, escrita de caracteres, seleção da resolução, funções de disco, como leitura e escrita de setores, além de funções para obter informações da máquina, como quantidade de memória instalada. A lista completa de interrupções providas pelo BIOS pode ser encontrada no sítio http://www.cs.cmu.edu/ ralf/files.html.

O Intel 8088, processador utilizado inicialmente no IBM PC possuía 20 bits de endereçamento, o que permitia endereçar até $1 \mathrm{MB}$ de memória. Um mapeamento pré definido deste $1 \mathrm{MB}$ foi criado na arquitetura PC para definir as áreas utilizadas pelo MS-DOS, pelo BIOS e para acesso direto aos dispositivos de vídeo. A Figura 4.23 mostra este mapeamento. Na arquitetura atual, outras regiões de memória (acima ou abaixo de $1 \mathrm{MB}$ ) também podem ser reservadas, por exemplo para uso do sistema $\mathrm{ACPI}^{10}$, entretanto, o mapeamento original ainda permanece. O BIOS implementa uma chamada (interrupção) que fornece todas as regiões da memória que são reservadas. O kernel

\footnotetext{
${ }^{9}$ MicroSoft Disk Operating System, sistema operacional comprado pela Microsoft ${ }^{\circledR}$ e utilizado nos computadores IBM PC na década de 1980. Foi parte integrante de Windows ${ }^{\circledR}$ 9x $(95,98$ e Me).

${ }^{10}$ Advanced Configuration and Power Interface, padrão para configuração e gerenciamento de energia.
} 
(durante sua inicialização) ou o gerenciador de boot devem executar esta chamada para obter os espaços disponíveis para o SO.

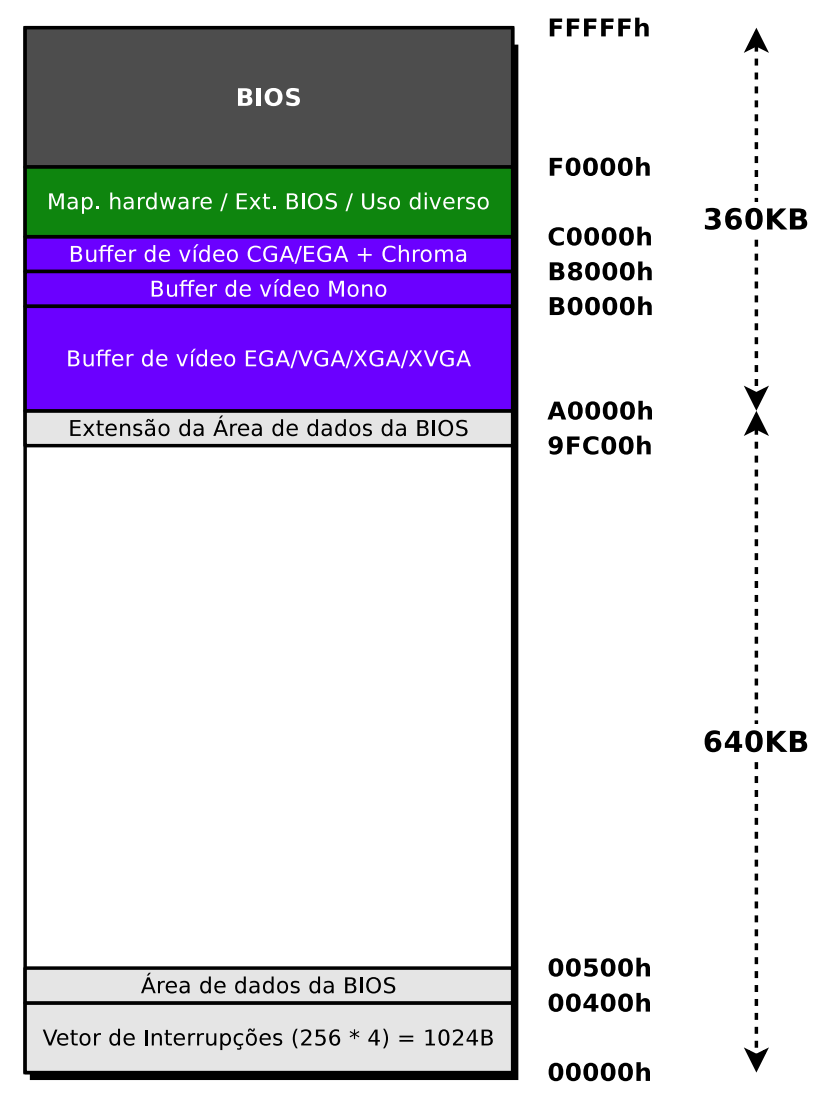

Figura 4.23: Mapeamento do primeiro $1 \mathrm{MB}$ de memória na Arquitetura PC. Adaptado de (Intel, 2009).

A partir deste mapeamento observa-se que nos computadores com apenas $1 \mathrm{MB}$ de memória restavam, no máximo, apenas $640 \mathrm{~K}$ que poderiam ser utilizados pelo MS-DOS. Este fato levou a famosa frase "640KB deveriam ser suficientes para qualquer um", por anos atribuída ao fundador da Microsoft $^{\circledR}$, Bill Gates, mas que teve autoria negada pelo mesmo. Naquela época, onde o MSDOS precisava de apenas $64 \mathrm{~KB}$ para executar, $640 \mathrm{~KB}$ representava dez vezes mais memória do que o necessário. Hoje, um simples documento de texto pode ultrapassar facilmente esta marca.

Quando o computador é ligado, o processador ao ser iniciado irá executar sua primeira instrução a partir do endereço F0000h, onde está mapeado o BIOS, logo, o BIOS é o primeiro software a ser executado. Após executar as rotinas de configuração e inicialização dos dispositivos da máquina, o BIOS lê o primeiro setor do $1^{\circ}$ dispositivo de boot configurado pelo usuário. Os últimos 2 bytes do setor devem conter a assinatura de boot, representada pelos números $55 \mathrm{~h}$ e AAh. Caso a assinatura não seja encontrada, o próximo dispositivo de boot configurado será lido. Caso a assinatura seja válida, o setor é carregado para o endereço de memória 7C00h e executado.

O código contido no setor de boot (chamado de bootloader) será responsável por identificar o disco onde o SO está instalado e carregar o kernel do mesmo para memória. Bootloaders modernos suportam diversos sistemas de arquivos, dispositivos e opções boot, o que acaba aumentando a 
complexidade e tamanho do programa, impossibilitando que todo o bootloader esteja contido no setor de boot. A solução encontrada foi dividir o bootloader em estágios, o primeiro estágio (contido no setor de boot) carrega o próximo estágio, que implementa as outras funcionalidades. Gerenciadores com esta abordagem são chamados de Bootloader multiestágio.

Existe ainda uma série de barramentos, protocolos e dispositivos que englobam a Arquitetura PC, mas que não serão abordados visto que os dispositivos mais primitivos apresentados (PIC, PIT, etc) já são suficientes para a implementação de um SO básico.

\subsection{Arquitetura Intel x86 (IA-32)}

A especificação completa da Arquitetura Intel x86 está disponível em três volumes do manual “Intel Architecture Software Developer's Manual”, da Intel. O volume 3, em específico, é destinado aos projetistas de Sistemas Operacionais, pois descreve os mecanismos básicos da arquitetura: Proteção de Memória (paginamento, segmentação), Controle de Interrupções, Multitarefa e muitas outras funcionalidades. Todos os volumes do manual são disponibilizados pela Intel, no sítio http: / /www. intel.com/products/processor/manuals/index.htm.

A Arquitetura Intel x86 de 64 bits (chamada também de AMD64, nome da implementação nos processadores da fabricante AMD) foi introduzida pelo processador Intel Pentium 4 Processor Extreme Edition e está fora do escopo deste trabalho, que desenvolve um SO para a Arquitetura Intel x86 de 32 bits (IA-32). Portanto, a partir de agora a IA-32 será referida apenas como "Arquitetura x86".

\subsubsection{Visão geral}

O primeiro microprocessador completo (em um só chip) foi o 4004, projetado pela Intel em 1969 e lançado ao mercado em 1971. Entretanto, o primeiro microprocessador a suportar a Arquitetura Intel x86 (IA) foi o 8086 (lançado em 1978), que possuía registradores e barramento de dados externo de 16 bits, e barramento de memória de 20 bits, o que permitia um endereçamento de até $1 \mathrm{MB}$. O 8086 representou um grande avanço para sua época, porém naquele tempo o hardware que suportava 16 bits de barramento de dados era escasso, fazendo com que a Intel lançasse em 1979 uma versão mais barata do 8086, o 8088, que diferia apenas no barramento externo, de 8 bits. Internamente ambos os modelos eram idênticos. O 8088 passou a integrar o IBM PC, lançado em 1981. Sucesso de vendas, o IBM PC colaborou para a disseminação da Arquitetura x86, que é amplamente utilizada até os dias atuais, aonde passou a integrar também dispositivos móveis (como os MIDs - Mobile Internet Devices) e até mesmo sistemas embarcados.

O 8086/8088 introduziu o conceito de segmentação da Arquitetura Intel, que consiste em dividir a memória em segmentos (partes) de mesmo tamanho, organizando o acesso não mais pelo endereço absoluto (número do byte a acessar), mas sim através do segmento e do deslocamento (dentro do segmento) em que o byte desejado se encontra. A figura 4.24 ilustra esta divisão. 
Com segmentação

Byte

0

64KB

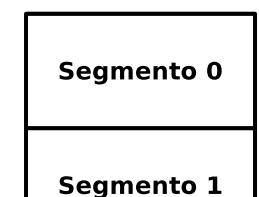

$128 \mathrm{~KB}$

Segmento 1

Byte 2
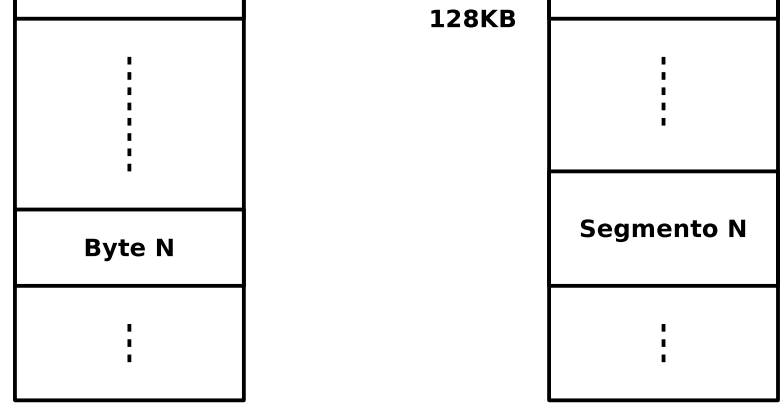

Figura 4.24: Segmentação de Memória.

No 8086/8088 (que possuem registradores de 16 bits) a memória é dividia em segmentos de 64KB. O endereço físico é acessado a partir do segmento e offset de acordo com a equação 4.2.

$$
E_{\text {fisico }}=\text { Segmento } \times 16+\text { Offset }
$$

A Intel utiliza a notação segmento:offset para representar o endereço de memória. Por exemplo, o endereço $52224(51 \mathrm{~KB})$ é acessado através do segmento 0:52224. De fato, de acordo com a equação $4.2, E_{\text {fisico }}=0 \times 16+52224=52224$.

A segmentação de memória é um dos meios pelo qual a memória pode ser protegida, pois podemos carregar e executar um processo em um só segmento, impedindo que outros segmentos sejam acessados. Apesar do 8086/8088 possuir segmentação de $64 \mathrm{~KB}$, a proteção de memória só foi efetivamente implementada a partir da segunda geração de processadores x86 da Intel: $\mathrm{O}$ Intel $^{\circledR} 286$, de 1982, foi o primeiro a incluir um esquema de proteção, onde os registradores de segmentos passaram a apontar para entradas em uma tabela denominada GDT (Tabela Global de Descritores, do inglês, Global Descriptor Table) que contém informações sobre o segmento desejado, permitindo que a memória seja segmentada de maneira dinâmica, ou seja, o SO poderia criar vários segmentos (de tamanhos diferentes) e setar permissões aos mesmos, como de leitura/escrita, e até 4 níveis de privilégios, permitindo por exemplo, que o código do usuário executasse em um privilégio menor que o do kernel, impedindo que a memória do kernel fosse acessada (invadida) por programas do usuário. Os níveis de privilégios foram organizados em anéis, como mostra a figura 4.25. O Anel 0 representa maior nível de privilégio. Logo, o kernel que é executado neste modo tem privilégio total de acesso a memória (I/O, DMA), configuração do processador, etc. Já o Anel 3 representa o menor nível de privilégio. Neste nível são executadas aplicações de usuário, que poderão acessar somente o que foi permitido (configurado) pelo kernel. 


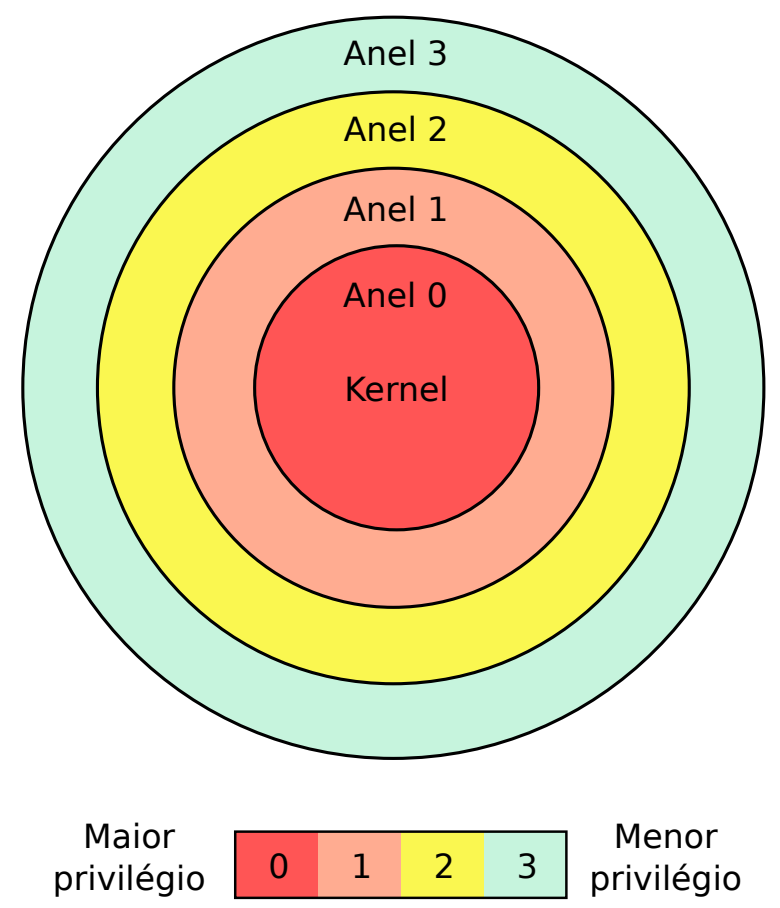

Figura 4.25: Anéis de privilégio na Arquitetura x86. Adaptado de (Intel, 1999a).

O Intel ${ }^{\circledR} 286$ também passou a utilizar um barramento de endereço de 24 bits, o que lhe permitia endereçar até $16 \mathrm{MB}$ de memória.

$\mathrm{Na}$ época de lançamento do Intel ${ }^{\circledast} 286$, a Arquitetura x86 já estava estabelecida e milhares de programas já tinham sido desenvolvidos, o que forçou a Intel a manter a compatibilidade entre os processadores antigos (8086/8088) e os novos processadores. A solução encontrada foi criar dois modos de execução do processador: o Modo Real e o Modo Protegido. No Modo Real, o processador comporta-se exatamente como um 8086/8088, sem proteção de memória e com segmentação de $64 \mathrm{~KB}$, endereçando somente $1 \mathrm{MB}$ de memória. Já no Modo Protegido o processador se vale de todos os recursos disponíveis: Proteção de memória, segmentação dinâmica e multitarefa, etc.

A terceira geração dos processadores x 86 da Intel iniciou-se com o lançamento do Intel $386^{\mathrm{TM}}$, que introduziu os registradores e barramentos de 32 bits na arquitetura, permitindo endereçamento de até 4GB de memória. Novamente a Intel manteve a compatibilidade com os processadores anteriores, os primeiros 16 bits de cada registrador de 32 bits representam um registrador inteiro dos modelos de 16 bits. Além dos modos Real e Protegido, um novo modo de operação foi introduzido, o Modo Virtual-8086. Este modo permite a execução de programas desenvolvidos para o 8086/8088 de maneira mais eficiente a partir do Modo Protegido. Outra grande evolução foi a introdução do Sistema de Paginamento, que permite dividir a memória em páginas permitindo um esquema de proteção e também memória virtual (swap).

A quarta geração foi marcada pelo Intel $486^{\mathrm{TM}}$, que adicionou maior paralelismo e capacidade de execução expandindo a unidade de Fetch e Decode de instruções em um pipeline de cinco estágios, permitindo que a decodificação de instrução fosse feita em apenas um ciclo de clock. Uma memória de cache L1 (8KB) também foi adicionada ao chip. O Intel486 ${ }^{\mathrm{TM}}$ também foi o 
primeiro a integrar o co-processador matemático on-chip para trabalho de ponto flutuante, pois até então este chip era ligado externamente ao processador.

A quinta geração começou em 1993, com o Intel ${ }^{\circledR}$ Pentium $^{\circledast}$, que adicionou um segundo pipeline de execução para alcançar uma performace superescalar, estes dois pipelines juntos podem executar duas instruções por pulso de clock. O cache L1 dobrou para $16 \mathrm{~KB}, 8 \mathrm{~KB}$ exclusivos para código e $8 \mathrm{~KB}$ exclusivos para dados. O Intel ${ }^{\circledR}$ Pentium $^{\circledR}$ também incorporou outras mudanças como extensões para tornar o Modo Virtual-8086 mais eficiente. Nesta geração (em 1997) também foi introduzida a tecnologia Intel MMX, que utiliza o modelo SIMD - Single-Instruction, MultipleData para executar computações paralelas em inteiros contidos em registradores de 64bits. Os processadores com esta tecnologia foram chamados de Intel ${ }^{\circledast}$ Pentium $^{\circledast}$ with MMX technology e incorporaram oito novos registradores (MM0-MM7).

A família P6 marcou a sexta geração dos processadores x86. Compreendida de 1995 a 1999 foi composta pelos processaodres: Intel Pentium Pro Processor, Intel Pentium II processor, Pentium II Xeon processor, Intel Celeron processor, Intel Pentium III processor e Pentium III Xeon processor. Esta família baseou-se em uma microarquitetura superescalar cujo um dos objetivos era melhorar a performace do processador significativamente utilizando o mesmo processo de fabricação $(0.6 \mu m$, BICMOS).

As gerações seguintes foram marcadas por outras famílias e processadores:

- 2000-2006: Intel ${ }^{\circledR}$ Pentium $^{\circledR} 4$ Family

- 2001-2007: Intel ${ }^{\circledR}$ Xeon $^{\circledR}$ Processor

- 2003-atual: Intel ${ }^{\circledR}$ Pentium $^{\circledR}$ M Processor

- 2005-2007: Intel ${ }^{\circledR}$ Pentium $^{\circledR}$ Processor Extreme Edition

- 2006-2007: Intel ${ }^{\circledR}$ Core $^{\mathrm{TM}}$ Duo e Intel ${ }^{\circledR}$ Core $^{\mathrm{TM}}$ Solo Processors

- 2006-atual: Intel ${ }^{\circledR}$ Xeon ${ }^{\circledR}$ Processor 5100,5300 Series e Intel ${ }^{\circledR}$ Core $^{\mathrm{TM}} 2$ Processor Family

- 2007-atual: Intel ${ }^{\circledR}$ Xeon $^{\circledR}$ Processor 5200,5400,7400 Series e Intel ${ }^{\circledast}$ Core $^{\mathrm{TM}} 2$ Processor Family

- 2008-atual: Intel ${ }^{\circledR}$ Atom ${ }^{\circledR}$ Processor Family e Intel ${ }^{\circledast}$ Core $^{\mathrm{TM}}$ i7 Processor Family

Todas estas famílias e processadores incorporaram novas funcionalidades como gerenciamento de energia, controle de temperatura, melhoria na tecnologia SIMD, sistemas de cache, HyperThreading, múltiplos núcleos e várias outras mudanças, uma delas inclui a extensão do endereço físico (PAE - Physical Address Extension), que permite o endereçamento de até 64GB de memória física, mantendo-se os mesmos 4GB no espaço virtual. Mesmo com todas estas mudanças, a estrutura da Arquitetura x86 definida ainda no Intel386 ${ }^{\mathrm{TM}}$ foi mantida, como o sistema de segmentação, 
controle de interrupções, paginamento, etc, o que permitiu uma compatibilidade muito grande entre os processadores e os Sistemas Operacionais, ou seja, um SO desenvolvido para Intel386 ${ }^{\mathrm{TM}}$ irá funcionar sem problemas em um Intel ${ }^{\circledR}$ Pentium $^{\circledR} 4$, por exemplo. Atualmente, Sistemas Operacionais livres, como o Linux, incluem partes de código específicas para cada tipo de processador (da Intel ou não), permitindo que o usuário configure e compile o kernel de acordo com o processador em que o SO irá atuar, obtendo muitas vezes um ganho satisfatório de performace, uma vez que o SO irá se valer de todos (ou quase) os recursos do processador.

\section{Ordem de Bits e Bytes e compatibilidade de software}

A Arquitetura x86 é little endian ${ }^{11}$, o que significa que os bits em cada byte (e os bytes em cada palavra) são armazenados do menos significante para o mais significante. A figura 4.26 ilustra a organização dos dados:

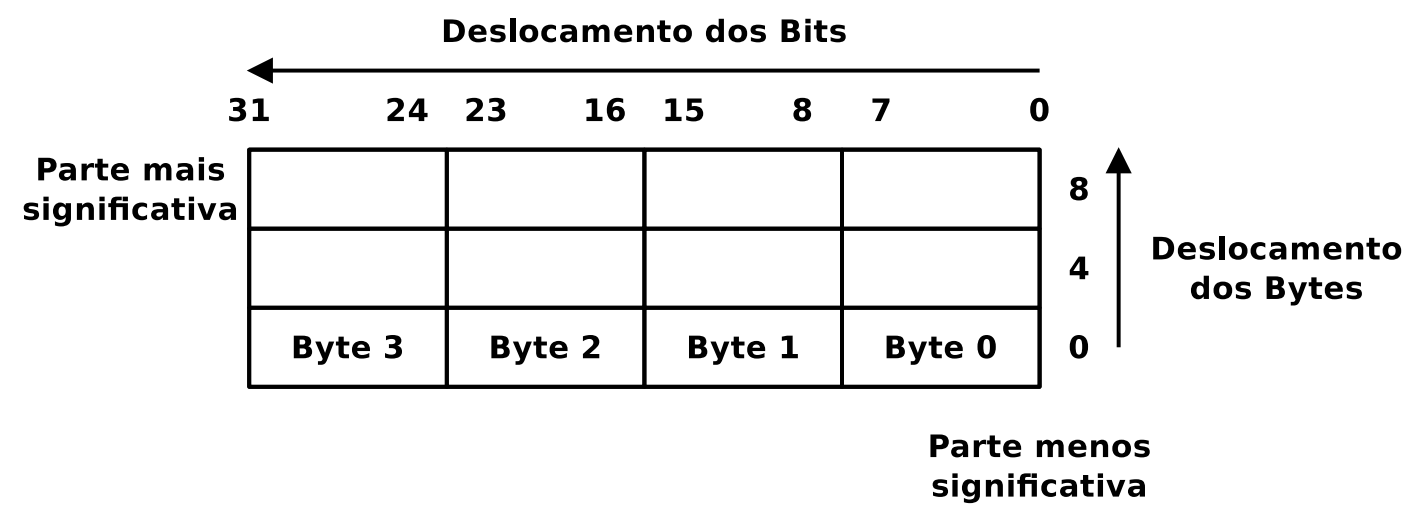

Figura 4.26: Ordem dos bits e bytes na memória

Uma série de bits em determinadas estruturas de dados definidas pela arquitetura são marcados como reservados. Segundo os manuais da Intel, os softwares devem seguir algumas recomenções para manusear tais bits:

- Não depender do estado de qualquer bit reservado quando ler de um registrador

- Não depender do estado de qualquer bit reservado quando gravar ou ler da memória ou registrador

- Não depender da habilidade de reter informação escrita em bits reservados

- Quando carregar um registrador, sempre utilizar os valores indicados no manual para os bits reservados.

\footnotetext{
${ }^{11}$ Para saber mais sobre esta denominação consulte o sítio http://www. cs. umd. edu/class/sum2003/ cmsc311/Notes/Data/endian.html
} 


\section{Exceções}

Uma exceção é um evento que ocorre geralmente quando ocorreu um erro na execução de uma instrução, porém, algumas exceções podem ocorrer sobre outras circunstâncias, como por exemplo em break points. A Intel utiliza a seguinte notação para exceções:

\#SIGLA(código de erro)

Por exemplo, uma divisão por zero irá gerar a exceção:

\#DE(0)

Quando um código de erro adequado não puder ser informado, o valor zero é utilizado.

\subsubsection{Ambiente Básico}

A Arquitetura x86 define alguns recursos básicos que o processador deve oferecer para que um aplicativo seja executado:

- 8 registradores (32 bits) de propósito geral.

- 6 registradores (16 bits) de segmento.

- Registrador (32 bits) EFLAGS.

- Registrador EIP (Instruction Pointer Register).

- Espaço físico de memória de até $2^{36}-1$ (64GB) bytes.

- Espaço linear de memória de até $2^{32}-1$ (4GB) bytes.

Estes recursos compõem o ambiente básico de execução da Arquitetura x86. Existem ainda registradores de controle, que são utilizados para trabalho com o sistema de paginamento, interrupção, etc, além de registradores utilizados em recursos especiais, como o MMX.

\subsubsection{Organização da Memória}

A Arquitetura x86 oferece várias facilidades para o controle, endereçamento e proteção da memória por parte do software. A memória física (acessada pelo processador através de seu barramento) é organizada em sequências de 8bits (1 byte). Com a extensão do endereço físico (PAE) habilitada é possível endereçar até $2^{36}-1$ bytes $(64 \mathrm{~GB})$ de memória, sem essa extensão, o máximo endereçamento permitido é de $2^{32}-1$ bytes (4GB). Existem três modelos de organização dos quais os softwares podem seguir: 
- Modelo Plano (Flat Model): A memória é vista pelos programas como um espaço de endereço contínuo, denominado espaço de endereço linear. Neste modelo, a Arquitetura x86 pode endereçar até $2^{32}-1$ bytes (4GB).

- Modelo Segmentado (Segmented Model): A memória é dividas em partes denominadas segmentos. Cada segmento representa um espaço do endereço linear, podendo haver sobreposição entre segmentos. A Arquitetura x 86 suporta até 16383 segmentos de vários tamanhos e tipos, onde cada um pode endereçar até $2^{36}$ bytes. O endereço de memória neste modelo deve informar qual segmento acessar e a posição dentro deste segmento.

- Modelo Modo de Endereço-Real (Real-Address Mode Model): Este é o modo utilizado pelo Modo Real da Arquitetura x86, definido no 8086. A memória é divida em segmentos iguais (de 64KB). No Modo Real este esquema é fixo, ou seja, não pode ser alterado por software. Qualquer software que queira se valer das funcionalidades de controle/proteção de memória, deverá atuar em Modo Protegido.

O Modelo Segmentado é extremamente útil para se fazer proteção de memória. Os softwares podem ser divididos e cada parte executar em um segmento separado. Por exemplo, a sessão de texto de um software pode executar em um segmento que seja de somente leitura, evitando assim que área de código seja re-escrita, já a parte de dados (que contém as variáveis) pode executar em outro segmento para leitura e escrita. Da mesma maneira, softwares do usuário podem executar em segmentos separados do kernel do SO e de menor privilégio, impedindo que a área do kernel seja invadida.

Apesar de ser extremamente útil para proteção de memória, o Modelo Segmentado torna-se um verdadeiro pesadelo dos compiladores de alto nível (como os compiladores de C). Além de dificultar a otimização de código, não seria possível prever a disponibilidade do segmento que o programa utilizaria, nem mesmo qual a segmentação utilizada pelo SO Assim, o que os compiladores modernos fazem é simplesmente considerar o Modelo Plano, atuando em um espaço de endereço linear.

Na realidade em todos os modelos há a segmentação de memória, a diferença é que no Modelo Plano os segmentos criados cobrem um espaço de 0 a $4 \mathrm{~GB}$, sendo assim enxergados como um espaço linear de 4GB. Os Sistemas Operacionais modernos (como o Linux e Windows) utilizam o Modelo Plano definindo pelo menos quatro segmentos:

- Segmento de Código para o kernel (espaço de kernel)

- Segmento de Dados para o kernel (espaço de kernel)

- Segmento de Código para programas do usuário (espaço de usuário)

- Segmento de Dados para programas do usuário (espaço de usuário) 
Todos estes segmentos cobrem o espaço de 0 a 4GB, caracterizando um Modelo Plano. A diferença é que o segmentos do kernel possuem o máximo nível de privilégio (Ring 0) e os segmentos do usuário possuem o menor nível de privilégio (Ring 3). Os segmentos de código conterão o código executável do software, por isso são marcados como somente leitura, já os segmentos de dados conterão a área de dados do software, sendo marcados como leitura/escrita.

A figura 4.27 ilustra os três modelos de organização da memória.

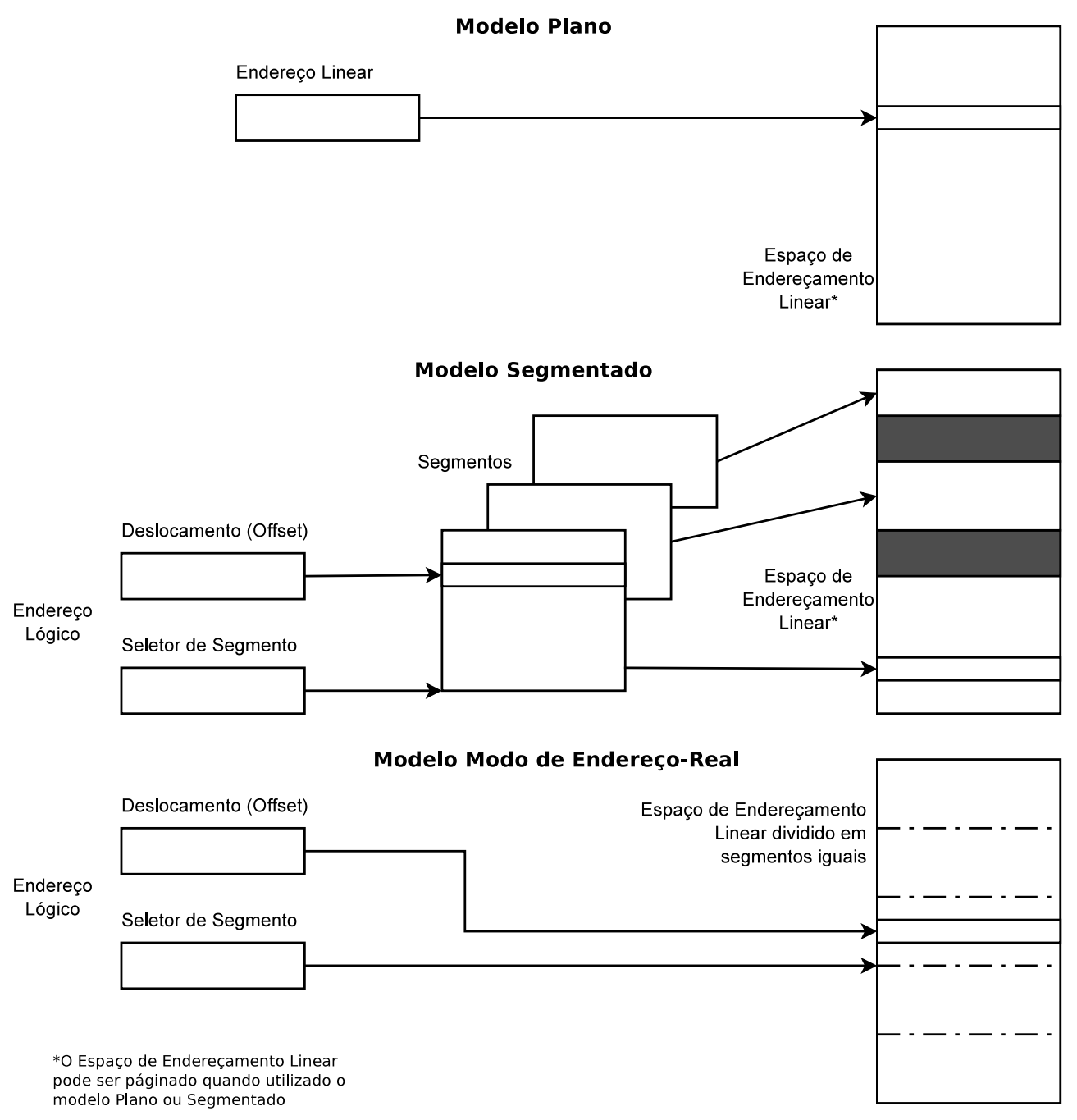

Figura 4.27: Os três modelos de organização da memória na Arquitetura x86. Fonte: (Intel, 1999a)

\subsubsection{Registradores}

A Arquitetura x86 oferece um conjunto básico de registradores para serem utilizados pelos aplicativos. Existem ainda outros registradores relacionados a controle (para sistema de paginamento, seleção de modo protegido) e funcionalidades específicas, como MMX. A figura 4.28 mostra o conjunto básico de registradores. 

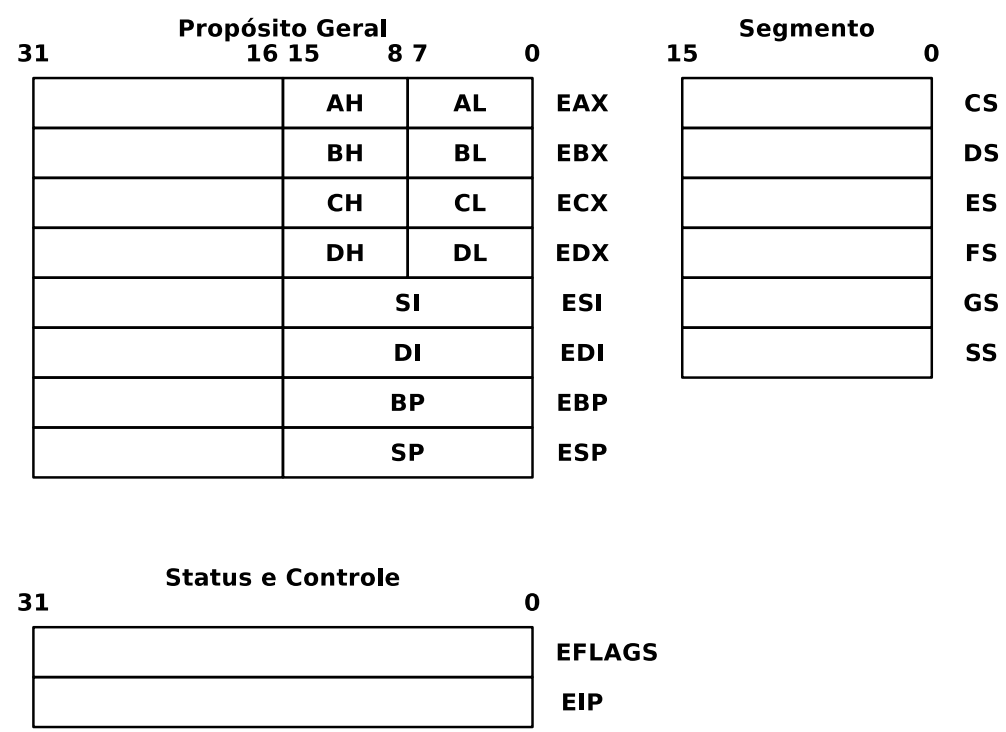

Figura 4.28: Registradores da Arquitetura x86

Para manter a compatibilidade com o 8086/8088 existem ainda os registradores de 16bits AX (formado por AH/AL), BX (formado por BH/BL), CX (formado por CH/CL), DX (formado por DH/DL), BP, SI, DI e SP. Estes registradores são utilizados no modo real. Estes registradores são simplesmente os primeiros 16 bits de seus registradores equivalentes de 32 bits. Por exemplo, o registrador $\mathrm{AX}$ na verdade corresponde aos primeiros 16 bits do registrador EAX, e assim por diante.

Os registradores de segmento (CS, DS, ES, FS, GS, SS) devem apontar para segmentos ou para alguma entrada na tabela GDT (ou LDT) que descreva um segmento, alguns deles são específicos:

- CS (Code Segment): Aponta para o segmento de código

- DS (Data Segment): Aponta para o segmento de dado

- SS (Stack Segment): Aponta para o segmento de pilha

Os registradores de propósito geral, apesar de estarem disponíveis para qualquer uso foram nomeados de acordo com o uso previsto para cada um deles:

- EAX: Acumulador

- EBX: Base

- ECX: Contador

- EDX: Dado

- ESI: Índice (Source Index)

- EDI: Índice (Destination Index) 
- EBP: Posição na Pilha (Stack Base Pointer)

O registrador ESP (Stack Pointer) aponta para a pilha e EIP (Instruction Pointer) para a instrução atual.

\subsubsection{Tabelas GDT, LDT e IDT}

O modo protegido da Arquitetura x86 permite que a memória seja segmentada de maneira dinâmica, ou seja, é possível dividir a memória em vários segmentos de tamanhos variáveis. A tabela GDT (Global Descriptor Table) define todos os segmentos da memória. Cada processo também pode possuir sua própria segmentação de memória, neste caso os segmentos são descritos em uma tabela denominada LDT (Local Descriptor Table), cada processo pode portanto ter uma tabela LDT. Com o sistema de paginamento o uso de segmentação tornou-se obsoleto e raramente tabelas LDT são utilizadas em Sistemas Operacionais modernos.

A tabela IDT é utilizada para a configuração de interrupções, podendo conter até 256 entradas (0 à 255). Cada entrada da tabela possui um descritor que configura uma interrupção. Os descritores contém várias informações e principalmente o endereço da função que o processador deverá executar quando determinada interrupção acontecer. As exceções geradas pelo processador geram as interrupções listadas na tabela 4.7.

Tabela 4.7: Exceções geradas pelo processador

\begin{tabular}{|c|l|}
\hline Interrupção & Descrição da exceção \\
\hline 0 & Divisão por zero \\
\hline 1 & Debug \\
\hline 2 & Interrupção NMI \\
\hline 3 & Breakpoint \\
\hline 4 & Overflow \\
\hline 5 & Limite de intervalo excedido \\
\hline 6 & Opcode inválido \\
\hline 7 & Dispositivo não disponível (sem co-processador matemático) \\
\hline 8 & Falha dupla \\
\hline 9 & Reservado \\
\hline 10 & TSS inválido \\
\hline 11 & Segmento não presente \\
\hline 12 & Falha de segmento de pilha \\
\hline 13 & Falha de Proteção Geral \\
\hline 14 & Falha de página \\
\hline 15 & Reservado para Intel (não utilizar) \\
\hline 16 & Erro de ponto flutuante \\
\hline 17 & Falha na checagem de alinhamento \\
\hline 18 & Falha na checagem de máquina \\
\hline 19 & Falha no fluxo das extensões SIMD \\
\hline
\end{tabular}


As interrupções de 20 à 31 são reservadas e não devem ser utilizadas, restando 223 interrupções disponíveis para uso geral (32 à 255).

Ao alternar a execução entre processos o SO deve salvar o estado do processo atual (registradores, pilha, etc) e carregar o novo processo. A Arquitetura x86 implementa mecanismos para a troca de execução de processos facilitando a implementação por parte do SO. Para usar este mecanismo, cada processo deve ser descrito através de um descritor denominado TSS (Task State Segment), contido na tabela GDT. Assim, ao alternar a execução para um outro processo, o processador automaticamente salvará o estado do processo atual em sua respectiva entrada na GDT. A desvantagem deste mecanismo é que o número máximo de processos fica restrito ao tamanho máximo da GDT (8192 entradas). Uma alternativa é o SO gerenciar todos TSSs na memória e compartilhar entradas da GDT entre os mesmos. Sistemas Operacionais modernos, como o Linux, não utilizam mais este mecanismo, implementando a troca de processos totalmente via software.

Cada entrada na tabela GDT contém 8 bytes que representam o descritor de segmento (ou um TSS). A figura 4.29 contém a estrutura do descritor de segmento.

\begin{tabular}{|c|c|c|c|c|c|c|c|c|c|c|}
\hline & 23 & 22 & 21 & 20 & & 15 & 413 & 12 & & \\
\hline Base 31:24 & $\mathbf{G}$ & $\begin{array}{l}\mathrm{D} \\
I \\
\mathrm{~B}\end{array}$ & L & $\begin{array}{l}A \\
V \\
L\end{array}$ & $\begin{array}{c}\text { Lim. } \\
\text { Seg. } \\
19: 16\end{array}$ & $\mathbf{P}$ & $\begin{array}{l}\text { D } \\
\text { P } \\
L\end{array}$ & $\mathbf{s}$ & Tipo & Base 23:16 \\
\hline
\end{tabular}

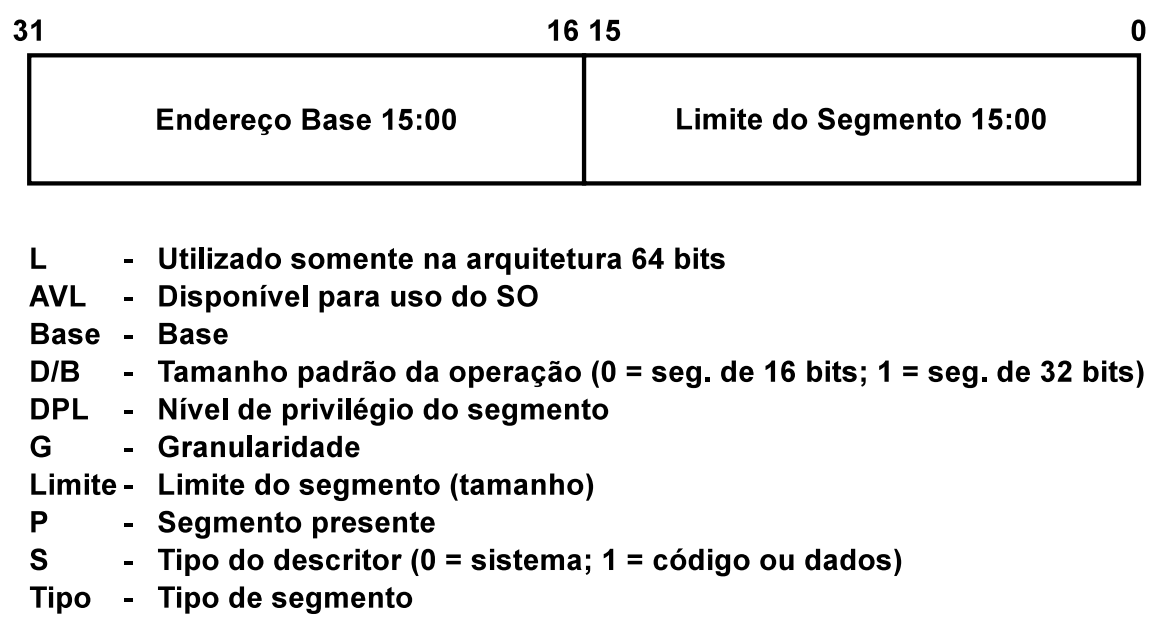

Figura 4.29: Estrutura do Descritor de Segmento. Fonte: (Intel, 1999b).

A primeira entrada da GDT deve obrigatoriamente conter um descritor NULO (composto por zeros). Como exemplo, considere que a memória será dividia em dois segmentos A e B. O segmento $\mathrm{A}$, de 0 à $2 \mathrm{~GB}$, e $\mathrm{B}$ de 2 à $4 \mathrm{~GB}$. Então serão necessários ao menos 2 descritores, o descritor do segmento A teria endereço base 0 e limite $2 \mathrm{~GB}$. O descritor de $\mathrm{B}$ teria endereço base $2 \mathrm{~GB}$ e limite 4GB.

Como o uso de segmentação tornou-se obsoleto em prol do mecanismo de paginamento, SOs modernos configuram geralmente 4 segmentos de 0 à $4 \mathrm{~GB}$ (sobrepostos) caracterizando o modelo plano de memória. Dois segmentos possuem privilégio máximo (nível 0) para execução em espaço 
de kernel e os outros dois segmentos possuem privilégio mínimo (nível 3) para execução em espaço de usuário. O que determina o ambiente de execução são os registradores de segmento, que poderão apontar para entrada dos segmentos de espaço de kernel na GDT, ou para segmentos de espaço de usuário. A proteção de memória é obtida através de paginamento.

As rotinas atendimento de interrupção são configuradas através de descritores contidos na tabela IDT onde cada entrada corresponde a interrupção atendida. Por exemplo, a interrupção 4 será atendida pela rotina configurada na entrada 4 da tabela.

A IDT aceita diferentes descritores, pois por exemplo, a Arquitetura x 86 permite que a rotina de atendimento seja disparada como uma tarefa (processo) quando o mecanismo de chaveamento pela GDT é utilizado, neste caso um descritor especial deverá descrever a tarefa na interrupção. Geralmente o mecanismo mais simples é utilizado, quando ocorre uma interrupção a execução é desviada imediatamente para a rotina de atendimento, que deve chamar a instrução iret ao seu término para voltar a execução normal do processador. A rotina de atendimento é descrita por um Descritor de Interrupção, cuja estrutura é exibida na figura 4.30.
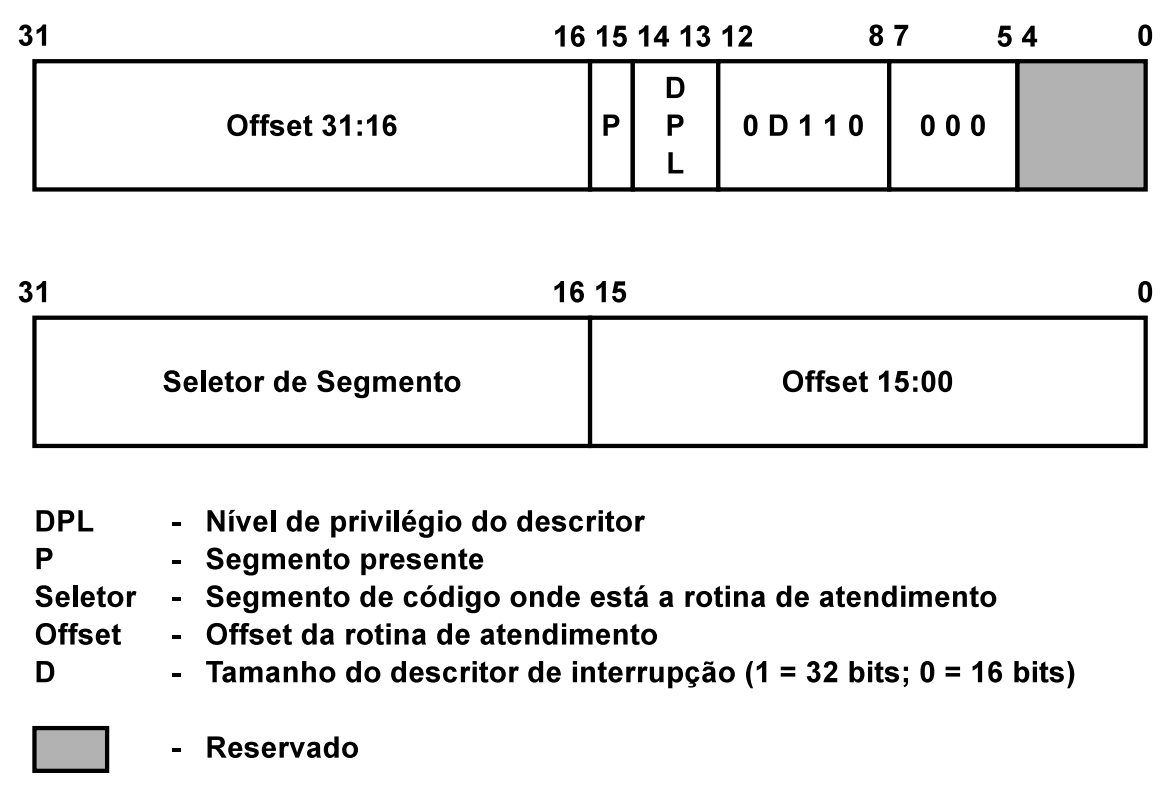

Figura 4.30: Estrutura do Descritor de Interrupção. Fonte: (Intel, 1999b).

No caso em que todos os segmentos configurados possuem endereço base 0, o Offset representará o próprio endereço da rotina de atendimento. O campo DPL define o nível de acesso a interrupção. As interrupções de 0 a 19 são destinadas as exceções do processador, listadas na tabela 4.7 .

As tabelas GDT e IDT são setadas no processador através das instruções $l g d t$ e $l i d t$, respectivamente. Ambas as funções funcionam de maneira análoga, recebem como parâmetro um endereço de memória que contém o endereço e o tamanho da tabela.

No TempOS os arquivos que configuram as tabelas GDT e IDT são arch/x86/gdt.c e arch/x86/idt.c, respectivamente. 


\subsubsection{Sistema de Paginamento de Memória}

O Sistema de Paginamento além de ser outra forma de proteção de memória ainda possibilita o recurso de memória virtual, onde a memória do sistema é estendida através do auxílio de dispositivos de armazenamento em massa (como o disco rígido).

No Sistema de Paginamento o espaço de endereçamento linear é dividido em páginas de tamanho fixo (geralmente $4 \mathrm{~KB}$ ) que podem ser mapeadas tanto para a memória física quanto para outro dispositivo de armazenamento, como o disco rígido. Quando um endereço linear é referenciado o processador faz a tradução para localizar na memória física a página que contém o local a ser acessado, caso esta página não esteja na memória uma exceção de falha de página é gerada. O SO pode capturar esta falha, localizar a página faltante em disco e carrega-lá para memória, permitindo que o acesso seja feito corretamente. Este importante recurso da Arquitetura x86 permite a implementação de memória virtual (swap) pelo Sistema Operacional.

Para traduzir o endereço linear na página correspondente o processador utiliza quatro estruturas de dados:

- Página: É um espaço de memória de tamanho fixo (pode ser de 4KB, 2MB ou 4MB). Geralmente é utilizado páginas de $4 \mathrm{~KB}$.

- Tabela de páginas: É uma página de 4KB que contém 1024 entradas onde cada uma representa uma página física da memória. Cada entrada contém o endereço físico da página correspondente e campos que indicam informações da mesma, como nível de privilégio, presença na memória ou não (indica se a página foi removida no swap) e permissões de leitura/escrita ou somente leitura. Esta estrutura somente é utilizada quando o Sistema de Paginamento está configurado para páginas de $4 \mathrm{~KB}$. Para páginas de $2 \mathrm{MB}$ e $4 \mathrm{MB}$ somente Diretórios de Páginas são utilizados.

- Diretório de páginas: É uma página de 4KB que contém 1024 entradas onde cada uma representa uma tabela de páginas. Seu funcionamento é semelhante a tabela de páginas, cada entrada contém o endereço físico da tabela correspondente e campos com informações da mesma. Quando páginas de 2MB ou 4MB são utilizadas então o diretório aponta diretamente para as páginas, sem a necessidade de uso das tabelas.

- Tabela de ponteiros para Diretórios de página: Esta estrutura somente é utilizada quando a extensão de endereço físico (PAE) está habilitada.

Considerando páginas de $4 \mathrm{~KB}$ (padrão na maioria do sistemas), cada tabela de página pode endereçar até $4 \mathrm{MB}$ (1024 entradas $\times 4 \mathrm{~KB}$ por página). Por sua vez, o diretório de páginas pode conter até 1024 tabelas, endereçando $1024 \times 4 M B=4 G B$, que corresponde a todo espaço de endereço linear. Assim, a entrada 0 do diretório corresponde aos endereços de 0 a $4 \mathrm{MB}$, a entrada 1 de $4 \mathrm{MB}$ a $8 \mathrm{MB}$, e assim por diante. Logo, a partir do endereço linear é possível determinar os 
índices no diretório e na tabela de páginas, obtendo assim a página e o endereço físico. A figura 4.31 ilustra a tradução do endereço linear.

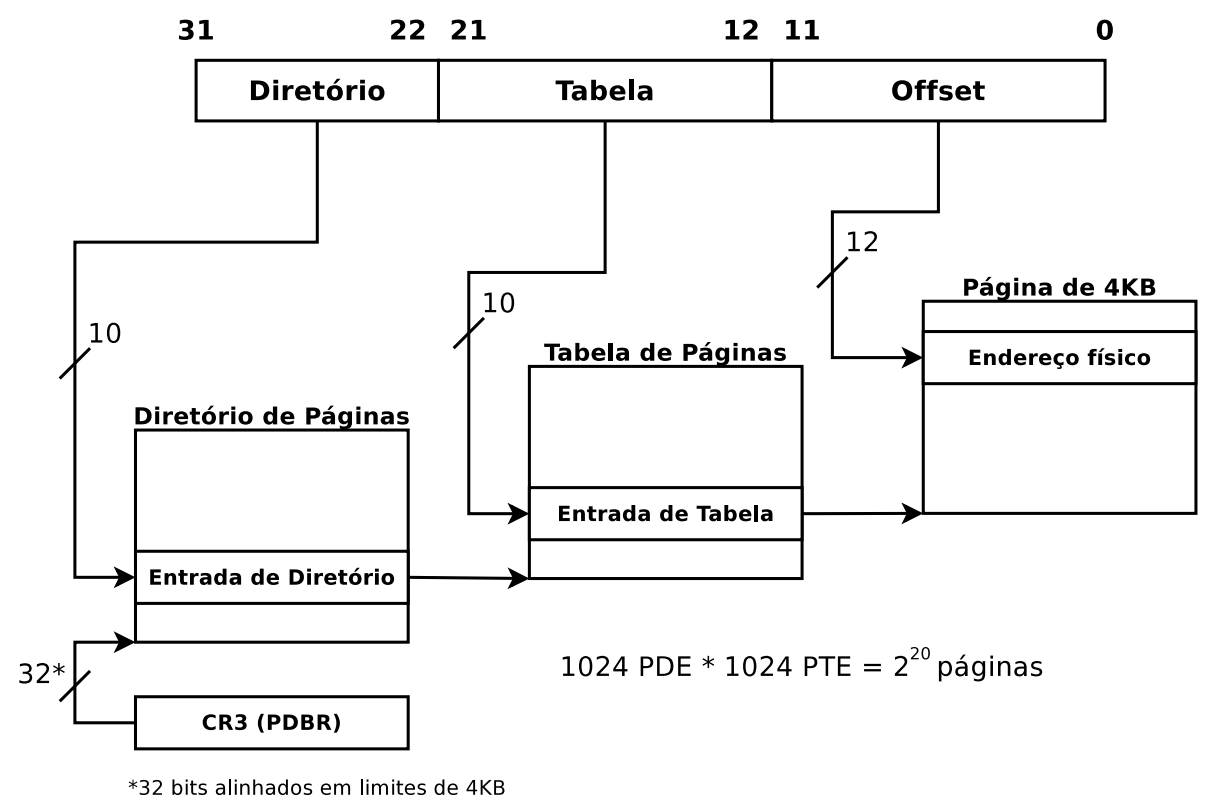

Figura 4.31: Tradução de endereço no Sistema de Paginamento. Fonte: (Intel, 1999b)

Como exemplo, considere o seguinte endereço linear 3227518452, que em binário é igual a 11000000011000000000010111110100 . A entrada no diretório de páginas é dada pelos bits 22 a 31 , neste caso $1100000001_{2}=769_{10}$. O índice na tabela de páginas é obtido pelos bits 12 a 21 , neste caso $100000000_{2}=512_{10}$. Os bits restantes definem o deslocamento (offset), neste caso $0111110100_{2}=500_{10}$. A entrada 512 da tabela de páginas contida na entrada 769 do diretório de páginas contém o endereço da página física correspondente ao endereço linear. O endereço final será a soma do endereço físico da página com o deslocamento. Suponha que o endereço físico da página seja 8388608 , então o endereço físico final será $8388608+500=8389108$.

Cada processo, assim como o kernel, possui seu próprio diretório de páginas, que é passado ao processador através do registrador $C R 3$, que contém o endereço físico do diretório. Com este mecanismo é possível obter a proteção de memória mapeando nas tabelas de páginas somente o espaço de memória desejado para cada processo. É válido ressaltar que a memória física pode ser mapeada em qualquer endereço do espaço linear, portanto um processo pode acessar um endereço em 3GB, por exemplo, que na verdade encontra-se em 20MB da memória física.

Antes de habilitar o Sistema de Paginamento, o SO deve criar corretamente as estruturas de dados necessárias (diretórios e tabelas) e passar o endereço físico das mesmas através de registradores de controle. Só depois de configurado é que o Sistema de Paginamento pode ser habilitado, fazendo com que toda tradução de endereço passe a ocorrer automaticamente pela MMU do processador. Todas essas estruturas possuem formatos específicos e estão completamente descritas nos manuais da Intel. 


\subsection{Roteiro passo a passo}

Esta seção sintetiza em um roteiro passo a passo com os conceitos e especificações já abordados para o desenvolvimento de um Sistema Operacional, a partir do zero, que segue a Arquitetura TempOS. Detalhes de implementação do SO TempOS serão fornecidos como guia e referência. Cada etapa pode ser divida em uma ou mais práticas de laboratório para utilização em um curso universitário (de graduação ou pós-graduação) em desenvolvimento de Sistemas Operacionais. A organização e estruturação das práticas fica a critério de cada professor, que deve adequar os tópicos e os materiais de acordo com o propósito do curso.

Será considerado o desenvolvimento para Arquitetura PC com processador x86 (32 bits). O roteiro considera que o leitor possui conhecimentos prévios em organização e arquitetura de computadores digitais, algoritmos e estruturas de dados, programação em Linguagem C e Assembly para x86 (sintaxe AT\&T), Sistemas Operacionais (teoria), e conhecimento básico do ambiente Unix (ou seus derivados, como o Linux) e seus comandos. Tabelas com referências para materiais, especificações e para softwares utilizados são fornecidas em cada etapa.

\subsubsection{Preparação das ferramentas}

O primeiro passo na jornada de desenvolvimento de um Sistema Operacional é possuir um ambiente preparado para o desenvolvimento. Um sistema Linux (ou derivados) é o suficiente, desde que suporte as ferramentas:

- Compilador C: O gcc (GNU Compiler Collection) é o conjunto de compiladores padrão de diversas distribuições Linux e derivados, robusto e amplamente utilizado.

- Montador Assembly x86 e Linkador: O gas (GNU assembler) e o ld (GNU linker) fazem parte do pacote binutils presente por padrão em distribuições Linux e derivados. O gas é um montador que suporta diversas arquiteturas e por padrão utiliza a sintaxe AT\&T, que difere consideravelmente da clássica sintaxe Intel. O ld é o linkador da GNU que suporta geração de diversos formatos de arquivo executável ou binário puro.

- Utilitário de compilação: O make é um utilitário de compilação que automatiza a geração de dependência e a compilação de softwares, sendo fundamental no compilação de códigos extensos, como de um kernel.

- Emulador: É imprescindível o uso de um emulador durante o desenvolvimento para facilitar a depuração, testes e execução do kernel em desenvolvimento, pois o teste na máquina real envolve preparar uma imagem de boot e reiniciar a máquina, demandando um tempo muito maior comparado ao uso do emulador. Eventuais testes em uma máquina também são importantes para validar o software desenvolvido em um hardware real. O TempOS utiliza o emulador $Q E M U$ para o desenvolvimento. 
- Editor de textos ou IDE: Um simples editor de texto é o suficiente para a edição do código fonte, porém editores robustos, como VIM ${ }^{12}$ ou IDEs como o Eclipse fornecem interfaces mais agradáveis e recursos para agilizar o desenvolvimento.

- Ferramentas de documentação: O TempOS utiliza a ferramenta doxygen para gerar automaticamente toda a documentação do kernel (parâmetros de todas as funções, especificação de estruturas de dados e variáveis, etc). O uso deste tipo de ferramenta é opcional, mas extremamente aconselhável.

Tabela 4.8: Preparação das ferramentas: Tabela de referências.

\begin{tabular}{|l|l|}
\hline \multicolumn{2}{|c|}{ Referências } \\
\hline $\begin{array}{l}\text { Ubuntu (distribui- } \\
\text { ça Linux) }\end{array}$ & http://www.ubuntu.com/ \\
\hline gcc & http://gcc.gnu.org/ \\
\hline binutils & http://www.gnu.org/software/binutils/ \\
\hline Sintaxe AT\&T & $\begin{array}{l}\text { http://www.ibiblio.org/gferg/ldp/ } \\
\text { GCC-Inline-Assembly-HowTo.html }\end{array}$ \\
\hline make & $\begin{array}{l}\text { http://www.gnu.org/software/make/manual/make. } \\
\text { html }\end{array}$ \\
\hline QEMU & http://www.qemu.org \\
\hline VIM & http://www.vim.org \\
\hline Eclipse & http://www.eclipse.org \\
\hline Doxygen & http://www.stack.nl/ dimitri/doxygen/ \\
\hline
\end{tabular}

\subsubsection{Sistema de boot}

Com o ambiente de desenvolvimento pronto, o primeiro passo na implementação do SO é fazer o sistema de boot. Duas práticas distintas podem ser abordadas: a primeira constitui em fazer um boot simples, em assembly, que seja inicializável pelo BIOS da máquina e escreva um caractere na tela (modo texto). A segunda implementa um boot utilizando o GRUB ${ }^{13}$ como bootloader, opção que será utilizada no SO pois o GRUB irá fornecer diversas informações para o kernel (quantidade de memória, mapa de espaços reservados, etc), além de entrar no modo protegido e carregar o kernel do disco para a memória. Escrever um bootloader completo para o SO demandaria ainda mais tempo e fugiria do escopo da plataforma de ensino.

O código de boot simples consiste apenas em fazer um pequeno programa em assembly que esteja linkado no endereço 7C00h (que é o endereço de memória onde o BIOS carrega o setor de

\footnotetext{
${ }^{12}$ VI Improved, é uma versão melhorada do famoso, robusto e popular editor de textos VI. Disponível em http://www.vim.org.

${ }^{13}$ GRand Unified Bootloader, amplamente utilizados por diversas distribuições Linux e derivados. Faz parte do projeto GNU.
} 
boot) e escreva na memória de vídeo CGA mapeada no endereço B8000h (conforme a figura 4.23) um caractere. O binário final deve possuir exatamente 512 bytes (tamanho do setor) e conter a assinatura de boot 55h, AAh nos bytes 511 e 512, respectivamente. A figura 4.32 mostra uma implementação do boot.

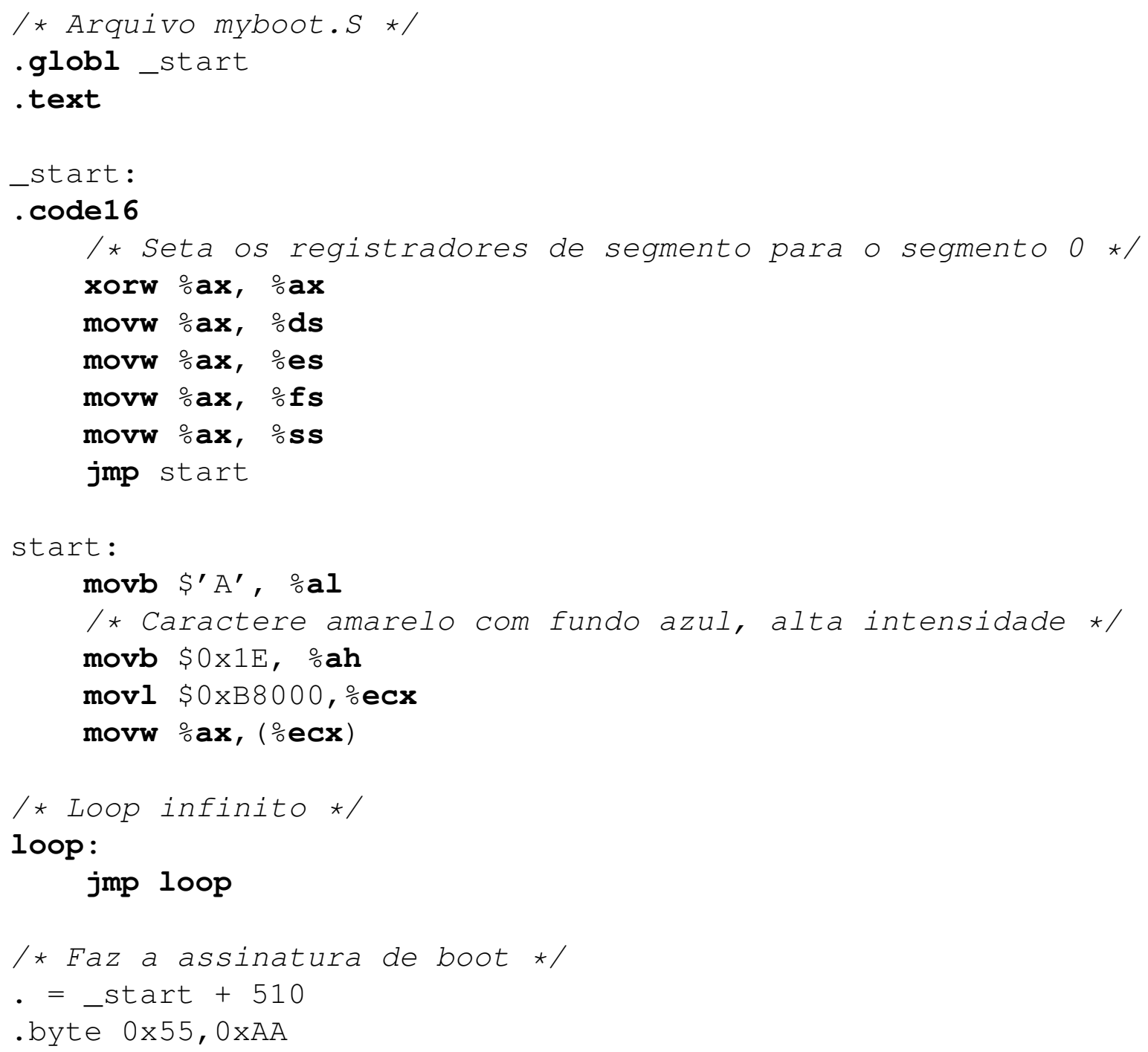

Figura 4.32: Código de boot.

O modo texto de vídeo padrão é composto por 80 colunas x 25 linhas de caracteres. No padrão CGA (Color Graphics Adapter) cada caractere é representado na memória por dois bytes, o primeiro indica o código ASCII ${ }^{14}$ do caractere e o segundo o atributo, que define a cor do caractere, cor de fundo e a intensidade da cor. Portanto, no modo 80x25, o total de caracteres na tela é $80 \times 25=2000$, considerando dois bytes para representar cada caractere, $2000 * 2=4000$ bytes de memória. O endereço B8000h representa o primeiro caractere da tela, B8002h o segundo, B8004h o terceiro e assim por diante. Considerando um caractere na posição $(a, b)$ da tela $(a=$

\footnotetext{
${ }^{14}$ American Standard Code for Information Interchange, define o código numérico de cada caractere.
} 
linha, $b=$ coluna) a posição na memória de vídeo do caractere será dada por $((a \times 80)+b) \times 2$. A figura 4.33 ilustra o mapeamento da memória de vídeo CGA.

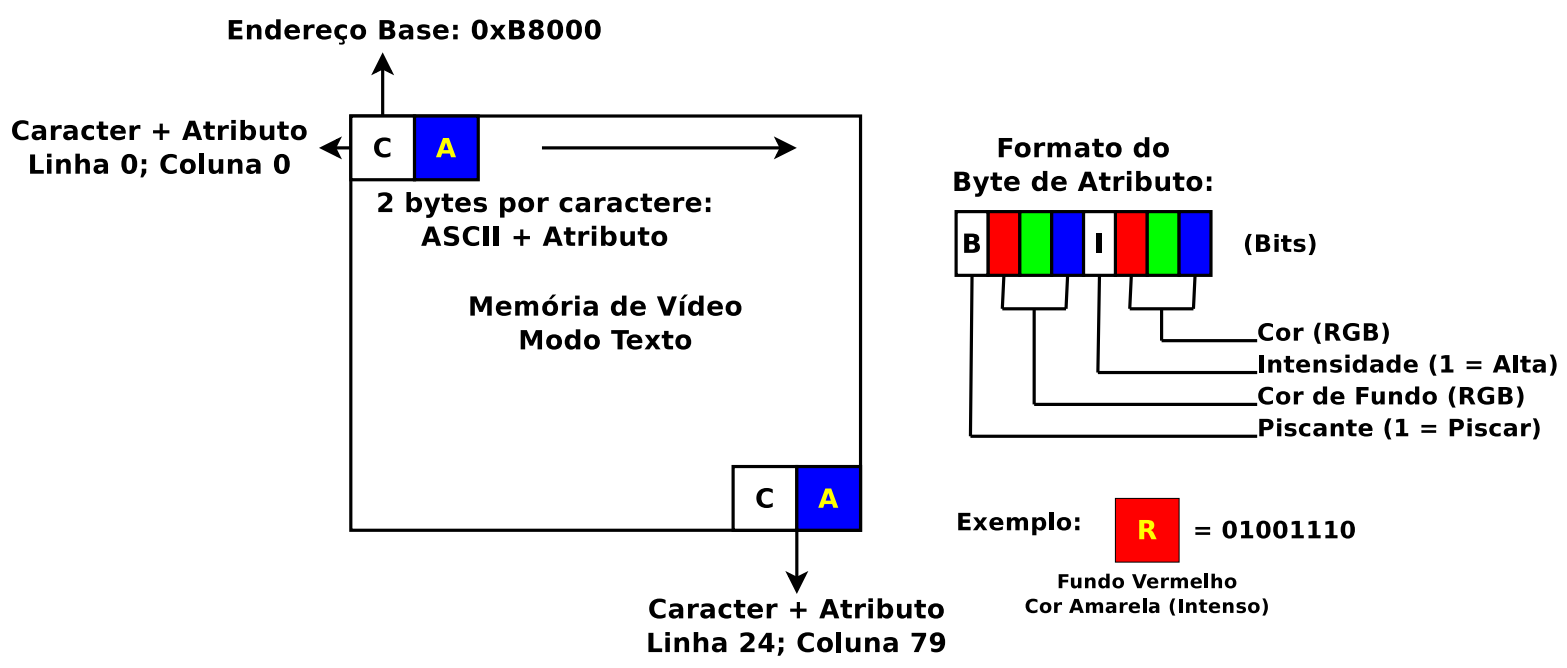

Figura 4.33: Esquema de mapeamento da memória de vídeo CGA.

O código de boot deve ser compilado através dos comandos:

\$ as --32 myboot.s -o myboot.o

\$ ld -m elf_i386 -nostdlib -N -Ttext 7C00 myboot.o -o myboot.elf

\$ objcopy -o binary myboot.elf myboot.bin

O primeiro comando chama o montador para gerar o código objeto. O segundo comando executa o linkador para gerar o binário executável em formato ELF, entretanto para ser inicializável pelo BIOS o código necessita ser um binário puro, por isso o comando objcopy (que também faz parte do pacote binutils) é utilizado para transformar o arquivo em formato ELF para binário puro. O programa final pode ser facilmente testado com o QEMU:

\$ qemu -fda myboot.bin -boot a

O caractere "A" em amarelo com fundo azul deve aparecer na primeira posição da tela.

O segundo método de boot, utilizado pelo TempOS, é através do uso do bootloader GRUB. O GRUB é um bootloader robusto, e talvez o mais utilizado atualmente para iniciar o boot de máquinas com Linux. Segue a especificação de Multiboot, permitindo que vários Sistemas Operacionais sejam carregados por ele. Esta especificação é definida pela GNU, que faz uma série de definições para que diversos Sistemas Operacionais possam ser carregados por um só bootloader, por exemplo o GRUB. A idéia geral da especificação é que o bootloader isente o kernel de uma série de tarefas permitindo um boot mais simplificado em termos de implementação do mesmo. Por exemplo, o bootloader permite que o kernel esteja em formato ELF, entra no Modo Protegido, recebe do BIOS todas as informações da máquina, como quantidade de memória instalada e o mapeamento 
das áreas reservadas, pode fornecer até informações sobre os modos da placa de vídeo. Todas estas informações são carregadas para memória e o ponteiro da estrutura que contém os dados é passado através dos registrador EBX. Um kernel é reconhecido como inicializável pelo padrão de multiboot se o número mágico 0x2BADB002 estiver nos primeiros 8192 bytes do arquivo executável. Isto é facilmente conseguido pois o código de boot encontra-se no início do kernel.

O kernel é sempre carregado no endereço $1 \mathrm{MB}$ na memória física, portanto na compilação do kernel no formato ELF os valores corretos das seções de texto (que contém o código executável), de dados (que contém variáveis globais inicializadas) e bss (que contém variáveis globais não inicializadas) precisam ser informados. É possível linkar o kernel em um endereço específico (por exemplo, 3GB), mas neste caso a GDT deverá ser configurada para fazer a tradução correta do endereço linear para o físico até que o sistema de paginamento seja habilitado, e o kernel possa fazer o mapeamento correto.

A especificação do endereço de cada seção do arquivo ELF pode ser feita através de um script do linkador que é passado como parâmetro para o mesmo. A figura 4.34 mostra o script para compilar um kernel básico carregado pelo GRUB.

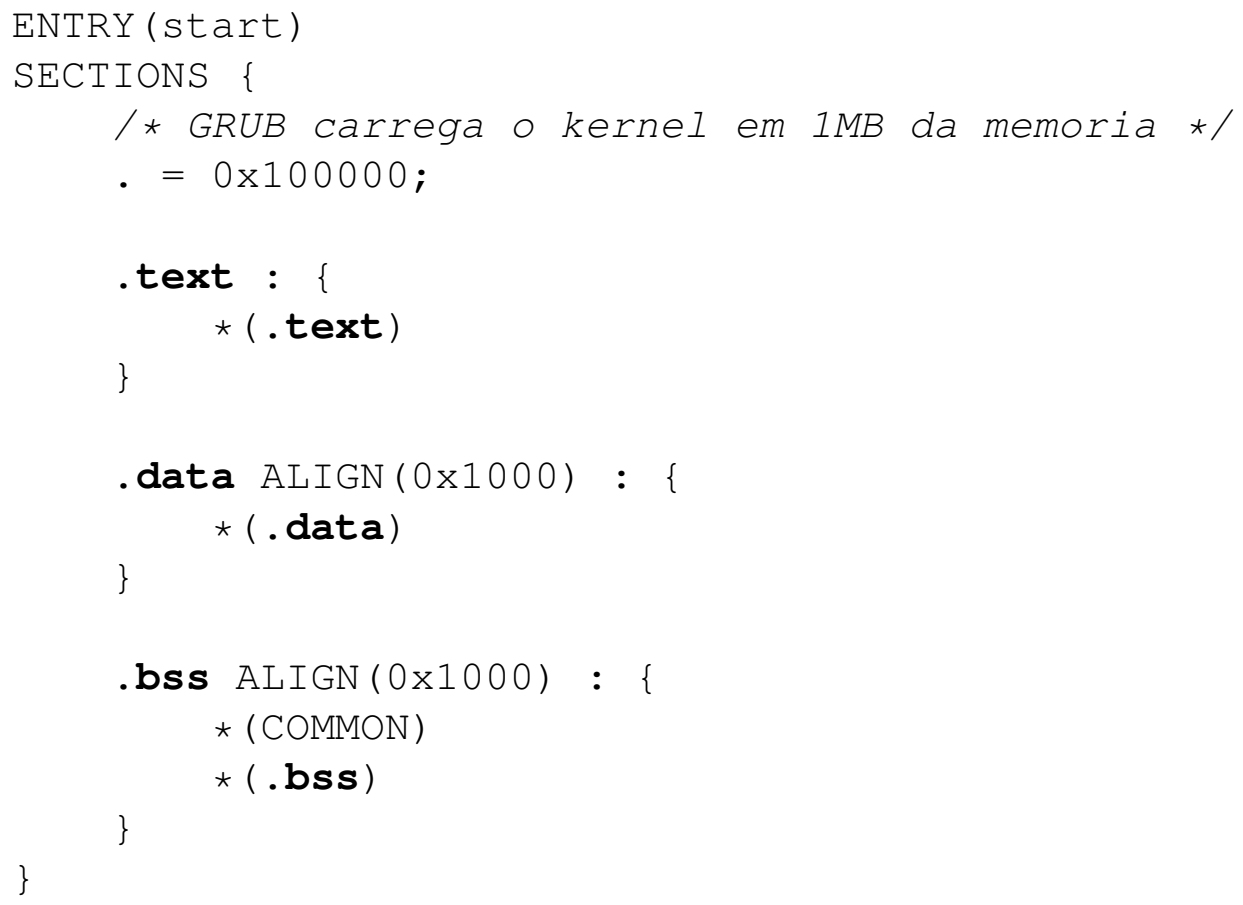

Figura 4.34: Script do ld que defina os endereços das seções do arquivo ELF.

O módulo de boot do TempOS está implementado em assembly no arquivo $\mathbf{a r c h} / \mathbf{x 8 6 / b o o t / b o o t . S ~}$ e o script passado para o linkador é o arquivo $\mathbf{~ a r c h / x 8 6 / b o o t / s e t u p . l d . ~ A ~ f u n c ̧ a ̃ o ~ d o ~ c o ́ d i g o ~ d e ~ b o o t ~}$ é basicamente fornecer ao GRUB as flags necessárias, assim como o número mágico (Magic Number) do multiboot, além de ler e passar a estrutura retornada pelo GRUB a parte independente de arquitetura do TempOS. Esta estrutura contém informações fundamentais como quantidade dis- 
ponível e regiões reservadas da memória, e parâmetros de linha de comando passados através do GRUB. O sistema de carregamento do TempOS é dividido em três estágios:

- Estágio de Boot: Executado pelo arquivo arch/x86/boot/boot.S. As informações de multiboot são fornecidas, a pilha do kernel (de 16KB) é iniciada e o próximo estágio, implemen-

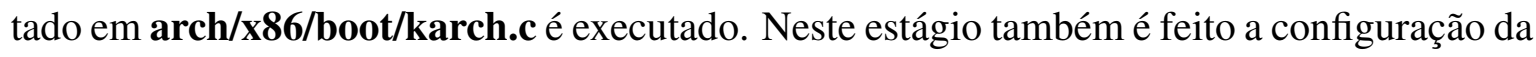
GDT com a base adequada para se ter tradução de endereço em 3GB, espaço em que o kernel é linkado. Esta técnica é necessária enquanto o sistema de paginamento não é habilitado.

- Primeiro estágio: Este estágio está implementado em $\mathbf{a r c h} / \mathbf{x 8 6} / \mathbf{b o o t} / \mathbf{k a r c h . c}$. Contém o primeiro código $\mathrm{C}$ executado pelo TempOS após o boot. Sua função é validar a estrutura passada pelo GRUB, mapear a memória e iniciar toda a configuração do processador: Sistema de paginamento, gerenciador de memória, interrupções, PIC, sistemas de IRQ e por fim passar para o próximo e último estágio de carregamento do TempOS.

- Segundo estágio: Neste estágio o código dependente de arquitetura já foi executado e o kernel principal do TempOS é chamado. A inicialização do subsistemas do kernel, como VFS, escalonador, etc é prosseguida até que o programa inicial do usuário (/sbin/init) seja executado.

A leitura da especificação de multiboot é fundamental pois contém todos os detalhes das estruturas de dados utilizados, assim como diversos códigos de exemplo. O código do TempOS também pode ser usado como referência para implementação.

Tabela 4.9: Sistema de boot: Tabela de referências.

\begin{tabular}{|l|l|}
\hline \multicolumn{2}{|c|}{ Referências } \\
\hline GRUB & http://www.gnu.org/software/grub/ \\
\hline $\begin{array}{l}\text { Especificação Mul- } \\
\text { tiboot }\end{array}$ & $\begin{array}{l}\text { http://www.gnu.org/software/grub/manual/ } \\
\text { multiboot/multiboot.html }\end{array}$ \\
\hline linkador & $\begin{array}{l}\text { http://ftp.gnu.org/old-gnu/Manuals/ld-2.9.1/ } \\
\text { html_mono/ld.html }\end{array}$ \\
\hline
\end{tabular}

\subsubsection{Funções internas do kernel}

Diferentemente dos aplicativos de usuário, o kernel é um software básico executando diretamente no hardware sem o auxílio de bibliotecas ou outros softwares. Algumas funções básicas da biblioteca $C$ são fundamentais para as funções internas do kernel, e portanto, necessitam ser implementadas. O diretório lib do código do TempOS contém diversas funções gerais, como:

- $\operatorname{char} * \operatorname{strcat}(\mathrm{char} *$ dest, const char *src); 
- int strcmp(const char *s1, const char *s2);

- $\operatorname{char} *^{*} \operatorname{strcpy}(\mathrm{char} *$ dest, const char *src);

- size_t strlen(const char *s);

- $\operatorname{char} *^{*}$ strncat(char *dest, const char *src, size_t n);

- int strncmp(const char *s1, const char *s2, size_t n);

- char *strncpy $($ char *dest, const char *src, size_t n);

- $\operatorname{char} * \operatorname{strstr}($ const char *haystack, const char *needle);

- void *memcpy $($ void *dest, const void *src, size_t n);

- int $\operatorname{sprintf}($ char $*$ str, const char *format, ...);

A função de maior complexidade implementada é a sprintf, que suporta parâmetros infinitos e vários tipos de impressão: Inteiro, Longo, Hexadecimal, Caractere e String. A função kprintf utiliza sprintf e é usada em todo o código do kernel, pois suporta macros para indicar o tipo de mensagem passada. Isto é fundamental se sistemas de console ou log forem implementados.

Uma API para listas encadeadas (singularmente, duplamente e circular) também foi desenvolvida e testada, sendo utilizada em diversos módulos, como no sistema de tratamento de IRQs.

Padronizar os tipos de dados utilizados é fundamental, principalmente para facilitar a portabilidade para outras arquiteturas. A tabela 4.10 contém os tipos de dados definidos pelo TempOS para cada tipo de variável.

Tabela 4.10: Tipos de dados utilizados pelo TempOS.

\begin{tabular}{|c|c|}
\hline Nome & Tipo de dado \\
\hline char8_t & Caractere (com sinal) de 8 bits \\
\hline uchar8_t & Caractere (sem sinal) de 8 bits \\
\hline int16_t & Inteiro (com sinal) de 16 bits \\
\hline uint16_t & Inteiro (sem sinal) de 16 bits \\
\hline int32_t & Inteiro (com sinal) de 32 bits \\
\hline uint32_t & Inteiro (sem sinal) de 32 bits \\
\hline long32_t, ssize_t & Longo (com sinal) de 32 bits \\
\hline ulong32_t, size_t & Longo (sem sinal) de 32 bits \\
\hline
\end{tabular}

Estes tipos são representações para os tipos definidos na linguagem $\mathrm{C}$ que correspondem ao tamanho e sinalização na Arquitetura x86 especificamente. Caso o TempOS seja portado para uma nova arquitetura basta que estes tipos sejam redefinidos adequadamente, dispensando qualquer 
outra alteração do gênero em todo kernel, colaborando para a portabilidade. O arquivo include/unistd.h contém todas as definições utilizadas.

Estas funções podem ser implementadas e testadas primeiramente em um aplicativo de usuário em um SO já pronto, como o Linux. Depois podem ser incluídas no kernel em desenvolvimento.

Para exibir as mensagens no kernel no vídeo (modo texto), um driver básico também deve ser desenvolvido. A memória de vídeo CGA mapeada no endereço B8000h pode ser facilmente manipulada em um código $C$ através de um ponteiro atribuído a este endereço, por exemplo através do código:

static unsigned char $\star$ videomem $=$ (unsigned char $\star$ ) $0 \times B 8000$;

A memória de vídeo poderá ser acessada diretamente através da variável videomem, devendo ser manipulada de acordo com a especificação apresentada na seção 4.5.2. A figura 4.35 mostra uma possível implementação para a escrita de um caractere em qualquer posição da tela. O parâmetro ch contém o caractere a ser escrito, attr contém o atributo do mesmo, row e col são as posições de linha e coluna onde o caractere será escrito na tela, respectivamente.

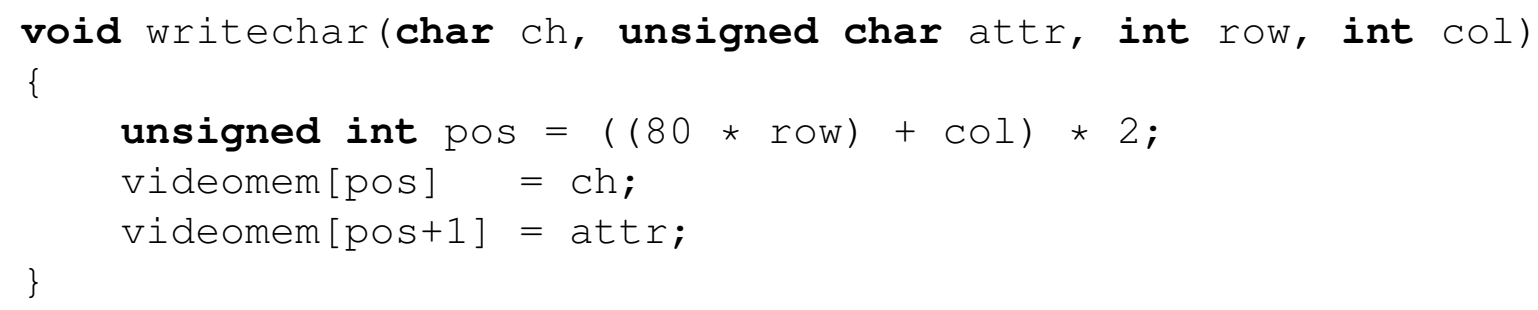

Figura 4.35: Função para escrever um caractere no vídeo.

No TempOS, o arquivo $\mathbf{a r c h} / \mathbf{x 8 6 / b o o t / v i d e o . c ~ i m p l e m e n t a ~ o ~ d r i v e r ~ p a r a ~ m o d o ~ t e x t o ~ d e ~ v i ́ d e o . ~}$

Tabela 4.11: Funções internas do kernel: Tabela de referências.

\begin{tabular}{|l|l|}
\hline \multicolumn{2}{|c|}{ Referências } \\
\hline $\begin{array}{l}\text { Modo texto de ví- } \\
\text { deo }\end{array}$ & http://wiki.osdev.org/Text_mode \\
\hline Biblioteca C & http://www.gnu.org/software/libc/ \\
\hline
\end{tabular}

\subsubsection{Controle e configuração de interrupções}

Após o kernel ter sido carregado pelo GRUB e ajustado a tabela GDT para execução correta do restante do código, o próximo passo envolve a configuração da tabela IDT para o atendimento das interrupções. A tabela IDT contém descritores de interrupção onde as funções de serviço são 
configuradas. As exceções do processador geram interrupções que devem ser tratadas, assim como todos os dispositivos de hardware conectados ao PIC, que gerem interrupções através das IRQs.

Quando ocorre uma interrupção é dever do kernel ajustar os registradores de segmento de dados para o segmento de dados do kernel, salvar todo o estado da máquina (registradores), executar a rotina de interrupção, restaurar o estado da máquina e por fim retornar da interrupção. No TempOS este processo está implementado no arquivo $\mathbf{a r c h} / \mathbf{x 8 6} / \mathbf{i s r} . \mathbf{S}$, que contém as rotinas de atendimento das exceções e das IRQs. Já a configuração da tabela IDT é feita no arquivo arch/x86/idt.c.

A configuração das IRQs envolve não só interrupções mas principalmente o PIC (Programmable Interrupt Controller), que deve ser iniciado e configurado corretamente. O PIC associa uma interrupção para cada IRQ, por exemplo, toda vez que uma interrupção é gerada na IRQ0 o PIC gera uma interrupção 0, na IRQ1, gera interrupção 1, e assim por diante. Porém, as interrupções de 0 à 19 são destinadas as exceções do processador e por isso um remapeamento é necessário. Com o remapeamento, uma interrupção na IRQ0 irá gerar uma interrupção 32, na IRQ1 uma interrupção 33, e assim por diante. O driver para o PIC no TempOS está implementado no arquivo arch/x86/kernel/i8259A.c, que contém as rotinas para a inicialização dos PICs mestre e escravo e para o remapeamento das IRQs.

Um ou mais periféricos podem estar ligados a cada IRQ portanto o kernel deve oferecer um meio para que várias rotinas de interrupção compartilhem a mesma IRQ. O TempOS define uma API para esta função, que está implementada em $\mathbf{a r c h} / \mathbf{x 8 6} / \mathbf{i r q . c}$. Qualquer driver de dispositivo do TempOS que queira registrar uma interrupção em alguma IRQ deverá fazê-lo através da função:

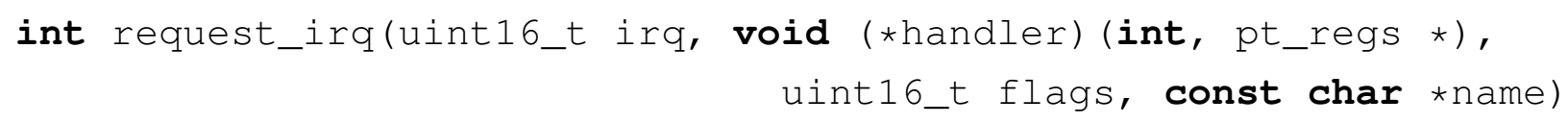

Os parâmetros passados são:

- irq: Número da IRQ utilizada.

- handler: É a rotina de interrupção.

- flags: Indica se a IRQ será compartilhada ou não. A flag SA_SHIRQ permite que outras rotinas sejam instaladas na IRQ indicada, se esta flag não é especificada nenhum outro driver poderá registrar outra rotina de interrupção nessa IRQ.

- name: A idéia deste parâmetro é que o driver passe um nome para a interrupção que está instalando, permitindo que um sistema de log ou monitoramento do kernel informe ao usuário as interrupções do sistema através de uma interface amigável.

Para tratar as interrupções de IRQ, o TempOS utiliza a mesma idéia da série 2.6 do kernel do Linux. Uma lista encadeada é criada para cada IRQ (0 à 15). Quando um driver de dispositivo instala uma rotina de interrupção, a função é inserida na lista correspondente à IRQ desejada. Portanto várias rotinas podem ser inseridas na lista de cada IRQ. Quando uma interrupção de 
IRQ ocorre, o TempOS percorre a lista encadeada correspondente executando todas as rotinas instaladas. Por isso, para que haja compartilhamento de IRQ é necessário que os drivers saibam se foi mesmo o hardware que os mesmos controlam que geraram a interrupção. Por exemplo, a placa de rede e a placa de som podem compartilhar a IRQ5. Quando uma interrupção acontecer na IRQ5 o TempOS irá executar tanto a rotina do driver da placa de rede quanto a rotina do driver da placa de som. Logo, cada driver precisa comunicar-se com seu hardware para saber se a interrupção foi mesmo gerada por ele. Dispositivos ISA não possuem esta funcionalidade, por isso não podem compartilhar IRQs. Já dispositivos mais modernos, como os ligados ao barramento PCI possuem esta funcionalidade, podendo compartilhar IRQs sem problemas.

A implementação do compartilhamento de IRQs é opcional, entretanto as interrupções devem ser tratadas, mesmo que seja por um rotina que não faça nada, simplesmente retorne da interrupção.

\section{Relógio do kernel}

Com as interrupções devidamente configuradas o relógio do kernel pode ser implementado. Uma forma normalmente adotada para a implementação do relógio é incrementar uma variável global a cada intervalo de tempo bem definido. Todas as operações do relógio serão baseadas nos valores desta variável.

O oscilador do PIT oscila a uma frequência próxima a 1,193182 $\mathrm{MHz}$. O PC original utilizava um oscilador muito comum (e barato) presente nos televisores da época, que oscilava a $14,31818 \mathrm{MHz}$. Esta frequência passava por um divisor de frequência de 3 resultando em um sinal de 4,772726667 MHz que era fornecido a CPU, e por um divisor de 4 resultando em um sinal de $3,579545 \mathrm{MHz}$ que era utilizado pelo controlador de vídeo CGA. Fazendo uma operação lógica AND com ambos os sinais o resultado é um sinal de 1,193181667 M Hz, que é a frequência base $(14,31818 \mathrm{M} \mathrm{Hz})$ dividia por 12, e que foi a frequência fornecida ao PIT. Esta solução permitia que apenas um oscilador (barato) fosse utilizado para fornecer todas as frequências necessárias ao hardware. Nos dias atuais os circuitos funcionam a frequências muito maiores, e o PIT está integrado na Ponte Sul apenas para manter o legado na Arquitetura PC.

O PIT possui três canais divisores de frequência, onde atualmente apenas dois são utilizados. O canal 0 está ligado a IRQ0 e o canal 2 está ligado ao speaker do sistema. O valor de divisão da frequência é passado através de um registrador de 16 bits. Este registrador é decrementado a cada ciclo de oscilação, quando o valor muda de 1 para 0 , um sinal é gerado no canal correspondente. No caso do canal 0 (conectado a IRQ0) uma interrupção será gerada no sistema.

Para implementar o relógio, o kernel deve configurar uma frequência de oscilação do PIT. Este valor deve ser conhecido e geralmente é definido no código do kernel. A frequência de oscilação é obtida dividindo-se a frequência base do PIT $(1,193182 \mathrm{MHz})$ pelo valor setado no registrador. Por exemplo, se o valor configurado no registrador pelo kernel for 30000, então as interrupções na IRQ0 serão geradas em uma frequência de $(1,193182 / 3000) M H z=0,000039773 \mathrm{MHz}=$ $3,9773 H z$, ou seja, a cada 0,251426847 segundos. 
Dado que o kernel conhece a quantidade de tempo decorrido entre cada interrupção na IRQ0, o valor do tempo transcorrido é facilmente obtido através da variável do relógio incrementada a cada interrupção. O TempOS adotou o nome da variável utilizada no Linux: jiffies, que está definida no arquivo kernel/timer.c. Este arquivo também contém a implementação de alarmes, que permite a execução de funções pré definidas em um determinado período de tempo.

No TempOS, o driver que faz a configuração e inicialização do PIT é implementado no arquivo arch/x86/kernel/i82C54.c. A frequência de oscilação padrão é $200 H z$ e pode ser alterada no arquivo de configuração da compilação do kernel (.config).

A tabela 4.12 contém a referência PIT, que explica detalhadamente como proceder a configuração do registrador do PIT.

Tabela 4.12: Controle e configuração de interrupções: Tabela de referências.

\begin{tabular}{|l|l|}
\hline \multicolumn{2}{|c|}{ Referências } \\
\hline IDT & Intel architecture software developer's manual, vol. 3. Capítulo 5. \\
\hline Interrupções & http://wiki.osdev.org/Interrupt \\
\hline PIC & http://wiki.osdev.org/PIC \\
\hline PIT & http://wiki.osdev.org/PIT \\
\hline
\end{tabular}

\subsubsection{Gerenciamento de memória}

O desenvolvimento inicial do kernel, como código de boot, configuração de interrupções e do relógio envolvem bastante código dependente de arquitetura. O gerenciador de memória faz parte do subsistema de controle de processos da arquitetura TempOS e apesar de envolver uma parte de código dependente de arquitetura, já implementa algoritmos em alto nível. Os desenvolvimento dos módulos seguintes, como Cache de Blocos e Camada VFS serão mais independentes da arquitetura do processador.

O gerenciador de memória deve prover o gerenciamento (alocação e desalocação) das páginas de memória física e do espaço de endereço linear, do kernel e dos processos, ou seja, gerenciar o diretório e as tabelas de páginas de ambos.

O primeiro passo na implementação é definir as funções que serão providas pelo gerenciador. No TempOS a alocação/desalocação de páginas físicas é feita através das funções alloc_page() e free_page(), respectivamente. A estrutura de dados utilizada na implementação é a pilha de páginas, conforme já detalhado na especificação da arquitetura do kernel (seção 4.2.2). Esta parte do gerenciador está implementada no arquivo $\mathbf{~} \mathbf{r c h} / \mathbf{x} 86 / \mathbf{m m} / \mathbf{m m}$.c, que contém também as rotinas para inicialização do diretório de páginas do kernel e do sistema de paginamento no processador.

Já a alocação/desalocação dos espaços de endereço linear em qualquer diretório de páginas (seja do kernel ou de um processo) é feita através das funções _vmalloc_() e kfree(), respectivamente. A função _vmalloc_() recebe como parâmetro uma estrutura que contém o diretório de 
páginas do espaço de endereço linear e o seu mapa de bits, e a quantidade de memória a ser alocada. Uma busca no mapa de bits é feita para encontrar o primeiro espaço contínuo que comporte a quantidade de memória solicitada (cada bit corresponde a uma página de $4 \mathrm{~KB}$, que é a menor unidade de alocação). Quando encontrado, o número de páginas físicas necessário é alocado (através de alloc_page()) e mapeado nas tabelas de páginas referentes ao espaço selecionado. A função $k f r e e()$ funciona de maneira inversa, liberando as páginas alocadas e setando os respectivos bits no mapa em 0. O arquivo kernel/mm/init_mm.c contém as funções para trabalhar com os mapas de bits e para iniciar a parte alto nível do gerenciador de memória do kernel.

Para facilitar a alocação de memória no espaço de endereço linear do kernel, a função kmalloc() foi criada para atuar como um atalho para _vmalloc_(). Qualquer driver ou subsistema do kernel pode simplesmente utilizar kmalloc() para alocação dinâmica de memória (de maneira análoga a função malloc() da biblioteca C). A desalocação funciona normalmente com $k$ free(). Todas estas funções estão implementadas no arquivo kernel/mm/kmalloc.c.

A função $k f r e e($ ) recebe como parâmetro somente o endereço linear da memória alocada. Entretanto para proceder a desalocação é preciso saber qual o diretório de páginas do endereço fornecido e qual foi a quantidade de memória alocada. Para resolver este problema, a função kamlloc() adiciona ao início de cada bloco alocado informações sobre a alocação efetuada, como ilustra a figura 4.36.

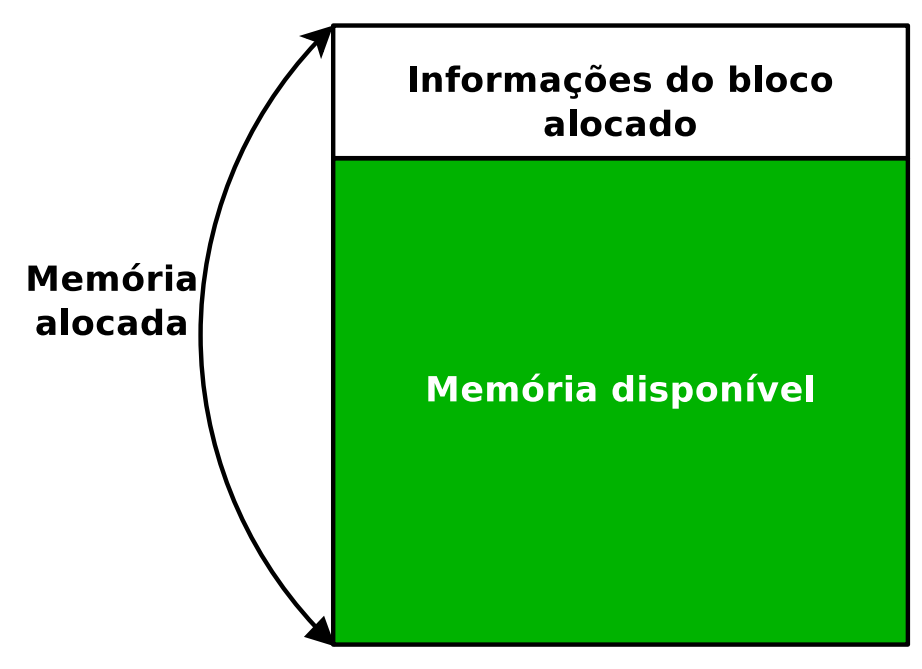

Figura 4.36: Bloco de memória alocado pela função kmalloc().

\section{Realocação dinâmica do kernel}

O kernel do TempOS é linkado no formato ELF com endereço base de 3GB, ou seja, todas as instruções, endereços de variáveis, etc, estão definidas considerando que o programa está carregado no endereço $3 \mathrm{~GB}$ da memória. Entretanto, o GRUB carrega o kernel no endereço $1 \mathrm{MB}$ da memória física. Com o sistema de paginamento habilitado basta colocarmos as tabelas de página do kernel na posição correta dentro do diretório de páginas (posição 768) que a tradução será feita automaticamente pela MMU do processador. Toda esta configuração é feita pelo TempOS no se- 
gundo estágio de carregamento. Porém, antes do sistema de paginamento ser habilitado não há esta tradução de endereços adequada, o que impede que qualquer variável seja acessada ou qualquer função seja chamada, uma vez que todo o endereçamento é feito na base 3GB. Para sanar este problema, no estágio de boot, o TempOS carrega a tabela GDT com dois segmentos, um de código e um de dados, ambos em privilégio 0 uma vez que somente código e dados do kernel serão executados até a reconfiguração da GDT. A principal diferença é que estes segmentos são configurados com base 0x40100000 (1GB+1MB), isto significa que o processador soma $1 \mathrm{~GB}+1 \mathrm{MB}$ em cada endereço para formar o endereço linear/físico. Assim, se uma função do kernel está linkada no endereço 3GB, fisicamente ela estará na posição $1 \mathrm{MB}$ (posição que o GRUB carrega o kernel), o endereço final será $3 \mathrm{~GB}+1 \mathrm{~GB}+1 \mathrm{MB}$ o que dá um total de $4 \mathrm{~GB}+1 \mathrm{MB}$, porém o tamanho máximo para o endereço linear é de $4 \mathrm{~GB}$, logo o endereço final será $1 \mathrm{MB}$, o próprio endereço físico da função. A figura 4.37 ilustra como o processador faz a tradução de endereço descrita.

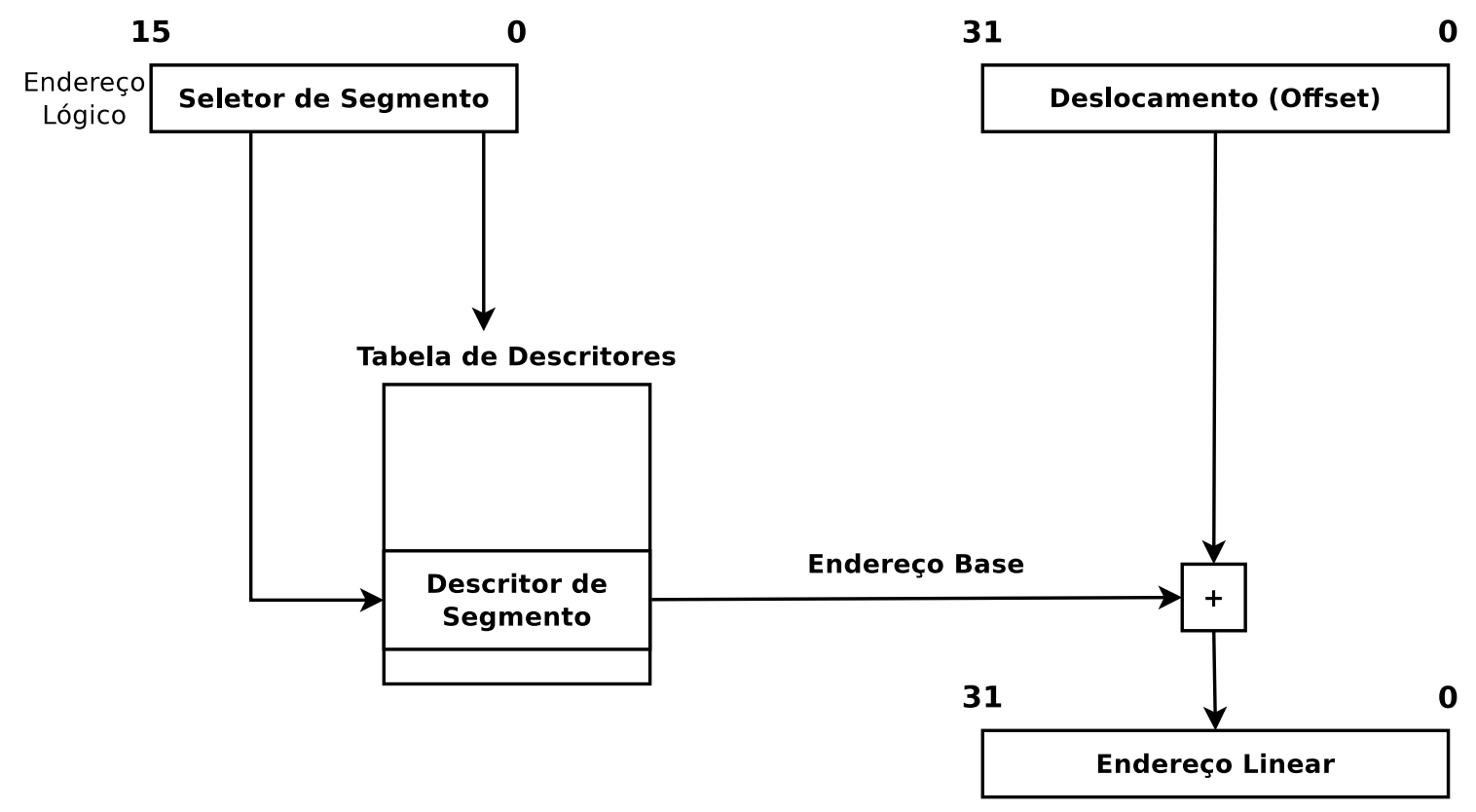

Figura 4.37: Tradução para o endereço linear, a base do segmento é somada. Fonte: (Intel, 1999a)

Esta solução é chamada de "artifício" da GDT, e é o que torna possível a execução de um código C linkado em 3GB antes mesmo do sistema de paginamento estar habilitado, o que é a função do segundo estágio de carregamento do TempOS, que configura as tabelas e diretório de páginas do kernel e habilita o sistema de paginamento. Após este passo a tabela GDT pode ser reconfigurada com os segmentos adequados para atuarem com o sistema de paginamento.

O TempOS utiliza o modelo plano para organização de memória, portanto a memória é vista apenas como um grande segmento de 0 a 4GB. São necessários quatro descritores na GDT pois dois serão destinados ao kernel, portanto com privilégio máximo (nível 0) sendo um para código (somente leitura) e outro para dado (leitura e escrita) e outros dois analogamente serão destinados para o usuário, com a diferença de que possuem o menor privilégio possível (nível 3). A primeira 
entrada da GDT é sempre um descritor nulo, necessidade imposta pela arquitetura x86. Por fim, a ultima entrada contém um descritor de tarefa, apesar do TempOS fazer o chaveamento de processos inteiramente via software, é necessário a configuração de pelo menos um descritor de tarefas, pois quando ocorre o chaveamento de contexto do espaço de usuário para o espaço de kernel, o endereço da pilha utilizada é lido desta estrutura e não do registrador ESP.

Tabela 4.13: Entradas da tabela GDT configurada pelo TempOS

\begin{tabular}{|c|}
\hline Segmento NULO \\
\hline Seg. Código do Kernel \\
\hline Seg. Dados do Kernel \\
\hline Seg. Código do Usuário \\
\hline Seg. Dados do Usuário \\
\hline Estrutura TSS \\
\hline
\end{tabular}

Outros algoritmos podem ser implementados para o gerenciamento de memória, tanto de páginas físicas quando do espaço de endereço linear. Os manuais da Intel da arquitetura x 86 fornecem toda especificação e os detalhes dos mecanismos de proteção e gerenciamento de memória na arquitetura.

Tabela 4.14: Gerenciamento de memória: Tabela de referências.

\begin{tabular}{|l|l|}
\hline \multicolumn{2}{|c|}{ Referências } \\
\hline $\begin{array}{l}\text { Gerenciamento de } \\
\text { Memória no Modo } \\
\text { Protegido }\end{array}$ & Intel architecture software developer's manual, vol. 3. Capítulo 3. \\
\hline $\begin{array}{l}\text { Proteção de Memó- } \\
\text { ria }\end{array}$ & Intel architecture software developer's manual, vol. 3. Capítulo 4. \\
\hline $\begin{array}{l}\text { Gerenciamento de } \\
\text { Memória (teoria) }\end{array}$ & $\begin{array}{l}\text { TANENBAUM , A. S. Sistemas operacionais: projeto e implementação. } \\
\text { Capítulo 4. }\end{array}$ \\
\hline $\begin{array}{l}\text { Gerenciamento de } \\
\text { Memória }\end{array}$ & http://wiki.osdev.org/Memory_management \\
\hline $\begin{array}{l}\text { Alocação de Me- } \\
\text { mória }\end{array}$ & http://wiki.osdev.org/Memory_Allocation \\
\hline $\begin{array}{l}\text { Gerenciamento de } \\
\text { Memória no Linux }\end{array}$ & BOVET, D.; CESATI, M. Understanding the linux kernel. Capítulo 6. \\
\hline $\begin{array}{l}\text { Configuração da } \\
\text { GDT }\end{array}$ & http://wiki.osdev.org/GDT_Tutorial \\
\hline
\end{tabular}




\subsubsection{Threads de kernel e o escalonador}

Nesta etapa do desenvolvimento o kernel já deve possuir uma robusta estrutura, sendo da capaz de inicializar, gerenciar interrupções, exceções, possuir temporizadores (relógio) e o principalmente, gerenciamento de memória, permitindo alocação e desalocação através das funções kmalloc() e $k f r e e()$, respectivamente. Funções gerais para manipulação de listas, strings e escrita de mensagem na tela (modo texto) também devem estar disponíveis.

O próximo passo envolve a implementação do suporte a threads de kernel e do escalonador, incluindo funções sleep() e wakeup() para bloqueio e desbloqueio dos processos, necessárias para o desenvolvimento dos outros subsistemas do kernel, como o cache de blocos os drivers de dispositivos.

Cada tarefa (thread ou processo) no sistema deve ser representado por uma estrutura de dados que irá armazenar informações como estado da tarefa, código de retorno, prioridade de escalonamento e também dados dependente de arquitetura, como valor de registradores, etc. A figura 4.38 mostra uma parte da estrutura de dados que representa uma tarefa no TempOS. Contém os campos básicos para a implementação do chaveamento entre threads. Campos da camada VFS, como o $i$ node da raiz do processo e do diretório atual foram omitidos, pois podem ser adicionados somente na implementação do VFS.

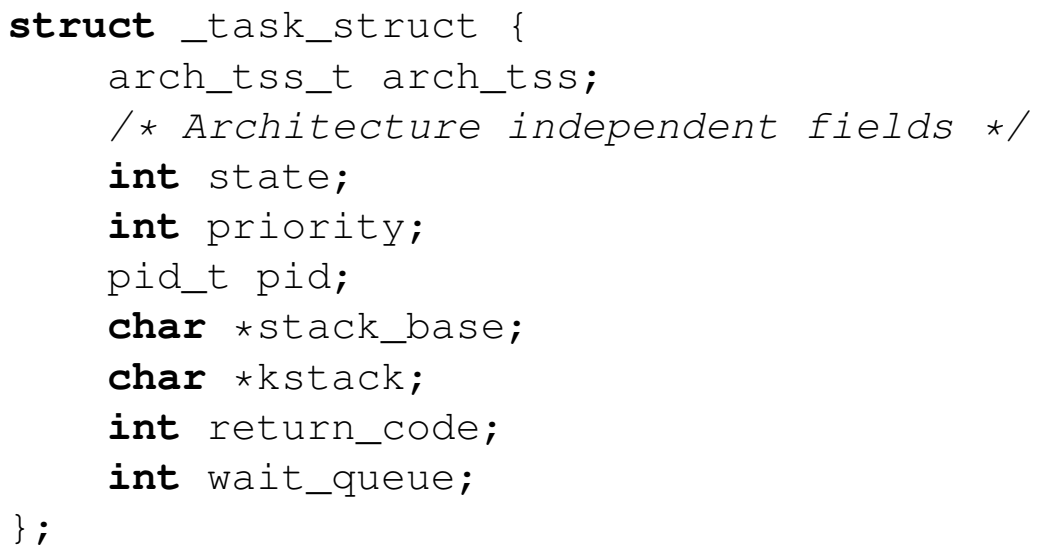

Figura 4.38: Estrutura com informações de uma tarefa no TempOS.

A estrutura $a r c h \_t s s \_t$ define campos relacionados a arquitetura $\mathrm{x} 86$, como valor de todos os registradores, etc. O campo state define o estado da tarefa, que pode ser EXECUTANDO, quando a tarefa está em execução, PRONTO_PARA_EXECUTAR, quando a tarefa não está executando, mas pode ser executada quando desejado, BLOQUEADO, quando a tarefa está bloqueada aguardando uma chamada wakeup() para mudar seu estado para PRONTO_PARA_EXECUTAR ou ZUMBI, quando a tarefa já foi finalizada, mas sua estrutura não pode ser totalmente desalocada pois o processo pai ainda não efetuou a chamada wait().

A estrutura de cada tarefa compõe uma lista circular duplamente encadeada que permite ao escalonador escolher qual tarefa será executada. O escalonador do TempOS implementa uma polí- 
tica Round-Robin com quantum definido em uma variável que pode ser alterada durante a execução do sistema. A cada interrupção do relógio a função do_schedule() é executada para verificar se o quantum já foi excedido. Quando o quantum é alcançado, a função schedule() é chamada para chavear um novo processo para execução. Essa função é independente de arquitetura, e simplesmente escolhe o próximo processo da lista de tarefas. Todas estas funções estão implementadas no arquivo kernel/sched.c.

Para colocar o processo de fato em execução a função switch_to() é executada. Esta função atualiza o estado das tarefas e chama a função task_switch_to(), implementada em assembly no arquivo $\mathbf{a r c h} / \mathbf{x 8 6 / t a s k . S . ~}$

Quando o escalonador vai colocar uma nova tarefa para execução, todo o estado da tarefa atual necessita ser salvo. Como o TempOS não utiliza o mecanismo de chaveamento da própria arquitetura x86, é dever do kernel salvar o contexto e promover o chaveamento dos processos. Quando uma interrupção é atendida, todos os valores dos registradores são salvos na pilha do processo para que possam ser restaurados no retorno da interrupção. A função task_switch_to() utiliza o mesmo recurso, salvando todos os valores dos registradores na pilha do processo. A pilha é então reorganizada para manter os valores dos registradores EFLAGS, CS, EIP, SS e ESP no formato correto para a chamada da instrução iret, que irá fazer o chaveamento entre os níveis de privilégio. É importante notar que neste caso iret não está sendo chamada em um contexto de interrupção, na verdade o kernel prepara a pilha do processo como se tivesse ocorrido uma interrupção e chama iret para retornar da mesma, promovendo assim o chaveamento entre diferentes níveis (ou não) de privilégio sem a necessidade do uso do mecanismo de chaveamento nativamente provido pela arquitetura x86 (através da tabela GDT). Esta função é talvez uma das mais difíceis de ser implementada durante o desenvolvimento do SO, assim, utilizar códigos prontos como referência (como o código do TempOS) pode economizar tempo e ajudar na resolução de bugs.

Outro ponto importante e que deve ser levado em consideração é o caso de chaveamento do espaço do usuário para o espaço de kernel. Quando este tipo de chaveamento ocorre o processador lê o valor do endereço da nova pilha a partir do descritor TSS configurado na GDT e não a partir da pilha do processo. Portanto, o kernel deve deixar um endereço válido de memória (previamente alocada) no descritor TSS na GDT e quando verificar este tipo de chaveamento, configurar a pilha adequada para o processo atual. Esta é a solução implementada pelo TempOS (presente no arquivo

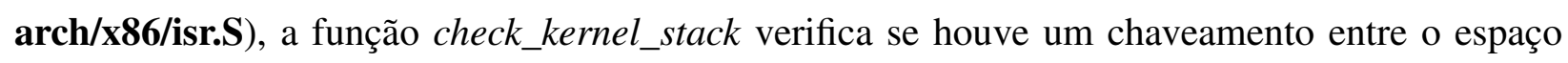
do usuário para o espaço do kernel. Neste caso, os valores empilhados na pilha apontada pela estrututra TSS são copiados para a pilha do processo e a troca de pilha é efetuada, fazendo o registrador ESP apontar para a pilha do processo e não para a pilha da estrutura TSS.

Com o mecanismo de chaveamento desenvolvido, o escalonador e as threads de kernel podem ser implementados concorrentemente. As threads são vistas como tarefas do sistema, a única diferença é que executam em espaço do kernel, ou seja, possuem o mesmo diretório de tabela de páginas que o kernel, porém cada thread possui uma pilha separada. Logo, a criação de uma thread de kernel é feita alocando memória para a pilha da thread e configurando os registradores 
adequados, como o EIP, que deve conter o endereço da função inicial da thread. Devidamente configurada, a estrutura da tarefa pode ser adicionada na lista de tarefas do sistema para ser posteriormente chaveada pelo escalonador.

No TempOS, a funções para trabalhar com threads de kernel estão implementadas no arquivo kernel/thread.c.

O modo de operação (e implementação) das funções sleep() e wakeup() são detalhados na arquitetura do kernel do TempOS. Quando as funções de chaveamento já estão disponíveis, para bloquear um processo basta que o função sleep() mude o estado da tarefa atual para BLOQUEADO e chame a o escalonador (função schedule()) para alternar para a próxima tarefa, adicionando o processo bloqueado a fila de espera correspondente. A função wakeup() é ainda mais simples, pois quando chamada simplesmente muda o estado de todas as tarefas da fila de espera correspondente para PRONTO_PARA_EXECUTAR, consequentemente estas tarefas serão chaveadas para execução em algum momento através do processo descrito na especificação do kernel.

Tabela 4.15: Threads de kernel e o escalonador: Tabela de referências.

\begin{tabular}{|l|l|}
\hline \multicolumn{2}{|c|}{ Referências } \\
\hline $\begin{array}{l}\text { Gerenciamento de } \\
\text { Tarefas }\end{array}$ & Intel architecture software developer's manual, vol. 3. Capítulo 6. \\
\hline Processos & BOVET, D.; CESATI, M. Understanding the linux kernel. Capítulo 3. \\
\hline $\begin{array}{l}\text { Chaveamento de } \\
\text { contexto }\end{array}$ & http://wiki.osdev.org/Context_Switching \\
\hline $\begin{array}{l}\text { Sistemas Multita- } \\
\text { refa }\end{array}$ & http://wiki.osdev.org/Multitasking_Systems \\
\hline $\begin{array}{l}\text { Algoritmos de es- } \\
\text { calonamento }\end{array}$ & http://wiki.osdev.org/Scheduling_Algorithms \\
\hline
\end{tabular}

\subsubsection{Drivers de dispositivos}

Esta etapa envolve o desenvolvimento de drivers de dispositivos que serão suportados pelo kernel. Qualquer driver pode ser desenvolvido, e para a implementação é necessário conhecer o modo de programação/funcionamento do hardware a ser suportado.

A implementação de um driver pode demandar muito tempo se o programador não conhecer o hardware e for necessário a leitura dos datasheets ${ }^{15}$ e especificações. Entretanto para o funci-

\footnotetext{
${ }^{15}$ Todo componente eletrônico (transistores, circuitos TTL/CMOS, chipsets, processadores) possuem um manual fornecido pelo fabricante com a especificação completa do produto: Tensões, correntes, temperatura de operação, dimensões, e principalmente, os protocolos e meios de programação do dispositivo. Alguns fabricantes mantém esses manuais em sigilo, divulgando-os apenas para outros fabricantes, o que dificulta o desenvolvimento de drivers em sistemas livres, como o Linux. Uma alternativa para este impace é fazer a engenharia reversa do dispositivo, que muitas vezes é proibida por lei, tornando a questão ainda mais delicada.
} 
onamento básico do SO apenas alguns drivers básicos precisam ser desenvolvidos, dentre eles, o driver para o controlador de teclado e de discos (PATA ou SATA, por exemplo).

O controlador de teclado, antigamente composto pelo chip i8042, da Intel, é responsável pela comunicação do teclado com o hardware do PC, implementando protocolos como o PS/2, por exemplo. Atualmente já vem integrado na Ponte Sul. O controlador está conectado a IRQ1 e mapeado na memória de E/S nas portas 0x60 e 0x64, sendo composto por dois registradores: o de status, que indica o estado do controlador, e o registrador de comandos, utilizado para o envio de comandos pelo driver. Para reduzir custos, o IBM PC original também utilizava o controlador de teclado para outras tarefas, como efetuar o reset e controlar o speaker do sistema.

Após habilitado, o controlador irá gerar uma interrupção (IRQ1) sempre que uma tecla for pressionada ou liberada (“despressionada”). Em cada interrupção, o driver pode ler da porta 0x60 (através da instrução in) o código da tecla. Esse código é chamado de scancode e vai depender do padrão do teclado. A tradução do scancode para o código ASCII da tecla pode ser feita através de arquivos de mapas de scancodes, disponíveis para diversos modelos de teclado. O kernel deve ser capaz de carregar um mapa na memória e utilizá-lo na tradução dos scancodes. Um mapa padrão deve estar contido no código do kernel para ser utilizado até que outro mapa seja carregado no sistema.

$\mathrm{O}$ arquivo drivers/char/i8042.c contém o driver do controlador de teclado implementado no TempOS. Um mapa padrão para teclados do modelo United States International é utilizado. O suporte para carregamento de novos mapas ainda não foi implementado.

Outro driver importante a ser implementado é o driver de disco, para que seja possível o kernel carregar o /sbin/init e outros programas de usuário para a memória. O TempOS implementa um driver para a controladora PATA (IDE) no arquivo drivers/block/ata_generic.c, porém outros drivers, por exemplo para controladora SATA, podem ser implementados ao invés do PATA.

Apesar de suportar DMA ${ }^{16}$ a comunicação com a controladora PATA é feita através do modo PIO (Entrada e Saída programada, do inglês, Programmed input/output) que não exige comunicação com o barramento PCI podendo ser efetuada simplesmente através das instruções in e out do processador, facilitando assim a implementação.

A função do driver é simplesmente ler ou escrever setores no disco, deve prover funções que serão chamadas pelo sistema de cache de blocos quando a leitura ou escrita de um setor for solicitada. As funções providas são: read_sync_sector() que faz a leitura de um setor de maneira sincrona, ou seja, a função do driver bloqueia até que os dados estejam prontos, read_async_sector(), que faz a leitura de um setor sem aguardar pelo término da mesma, e as funções write_sync_sector() e write_async_sector(), que funcionam de maneira análoga as funções read, porém, efetuam a escrita do setor.

A controladora está conectada as IRQs 14 (canal primário) e 15 (canal secundário), gerando uma interrupção quando a leitura ou escrita de um setor foi finalizada. Portanto o driver deve

\footnotetext{
${ }^{16}$ Direct Memory Access, a comunicação com o dispositivo é feita através de acesso direto a memória.
} 
mandar o comando a ser executado (leitura ou escrita) e gerenciar a chegada da interrupção correspondente. Vários processos podem requisitar a leitura de setores do disco, gerando um acúmulo de requisições. O driver do TempOS gerencia este acúmulo adicionando as requisições em uma lista encadeada respeitando a ordem de chegada (algoritmo FIFO) para as mesmas. Neste ponto, outros algoritmos podem ser implementados, como o clássico algoritmo do elevador (Tanenbaum, 2000).

O driver também deve ser capaz de prover o acesso aos setores respeitando a divisão definida pelas partições do disco, que devem ser lidas do registro MBR (Master Boot Record), presente no setor 0 (primeiro setor do disco). A tabela 4.16 contém referências para a especificação completa de como o registro MBR é organizado, assim como a estrutura EBR (Extended Boot Record), que define partições estendidas. O TempOS implementa no arquivo fs/partition.c o suporte completo as partições primárias e estendidas. Este arquivo provê a função translate_part_address() que traduz o endereço do setor de uma partição no setor correspondente do disco.

Os drivers também devem chamar as funções register_block_driver() ou register_char_driver() para se registrarem na tabela de drivers permitindo acesso transparente por outros subsistemas do kernel. Entretanto, estas chamadas só serão adicionadas quando a camada VFS estiver implementada.

Tabela 4.16: Drivers de dispositivos: Tabela de referências.

\begin{tabular}{|l|l|}
\hline \multicolumn{2}{|c|}{ Referências } \\
\hline Teclado PS/2 & http://wiki.osdev.org/PS2_Keyboard \\
\hline Controlador 8042 & http://wiki.osdev.org/"8042"_PS/2_Controller \\
\hline Protocolo PS/2 & http://www.computer-engineering.org/ps2protocol/ \\
\hline $\begin{array}{l}\text { Scancodes de te- } \\
\text { clado }\end{array}$ & $\begin{array}{l}\text { http://www.win.tue.nl/ aeb/linux/kbd/scancodes. } \\
\text { html }\end{array}$ \\
\hline ATA modo PIO & http://wiki.osdev.org/ATA_PIO_Mode \\
\hline $\begin{array}{l}\text { Especificação } \\
\text { ATA/ATAPI }\end{array}$ & http://www.ata-atapi.com/ \\
\hline MBR & http://en.wikipedia.org/wiki/Master_boot_record \\
\hline EBR & $\begin{array}{l}\text { http://en.wikipedia.org/wiki/Extended_boot_ } \\
\text { record }\end{array}$ \\
\hline
\end{tabular}

\subsubsection{Cache de blocos}

O Cache de blocos é talvez o subsistema mais fácil de ser implementado no kernel, pois pode utilizar qualquer algoritmo de hash para fazer a manipulação dos blocos em cache e será utilizado somente pela camada VFS. O funcionamento do Cache de blocos está detalhado na especificação do kernel incluindo as funções que devem estar disponíveis. 
O TempOS define uma quantidade fixa de blocos que serão utilizados para o cache. Esses blocos são alocados na memória na inicialização do kernel, sendo organizados em filas encadeadas e através de um vetor de hash, ilustrado pela figura 4.10 e implementado no arquivo fs/bhash.c.

Um detalhe importante é que nesta etapa as funções para acesso transparente ao driver que faz a leitura dos blocos do dispositivo não estarão disponíveis, pois a camada VFS ainda não estará implementada. Todavia, o cache de blocos pode ser testado chamando diretamente as funções de um driver em específico, como o driver PATA, por exemplo. Quando o VFS for implementado, facilmente as funções podem ser substituídas. Infelizmente não há como separar totalmente o desenvolvimento do cache de blocos e dos drivers de dispositivo do VFS pois estes subsistemas possuem uma dependência recursiva, ou seja, um subsistema utiliza funções do outro e vice versa. Talvez uma mudança na arquitetura pode sanar este problema, entretanto, o intuito da plataforma TempOS é seguir a especificação do Unix e não promover mudanças substanciais na mesma.

Tabela 4.17: Cache de blocos: Tabela de referências.

\begin{tabular}{|l|l|}
\hline \multicolumn{2}{|c|}{ Referências } \\
\hline O chache de buffer & BACH , M. J. The design of the unix operating system. Capítulo 3. \\
\hline Caches de disco & BOVET, D.; CESATI , M. Understanding the linux kernel. Capítulo 14. \\
\hline
\end{tabular}

\subsubsection{Camada VFS e driver para sistema de arquivo}

O funcionamento da camada VFS e dos drivers para sistema de arquivos está detalhado na especificação da arquitetura do kernel. A implementação pode ser iniciada através do desenvolvimento da tabela de drivers e das funções register_block_driver() e register_char_driver(), que faz o registro de drivers de bloco e caractere nas respectivas tabelas, assim como define a estrutura de dados para acesso transparente as funções.

No TempOS, estas funções estão implementadas no arquivo fs/devices.c. As estruturas de dados que representam os drivers são definidas no arquivo de cabeçalho include/fs/device.h.

Para a implementação do restante da camada VFS as estruturas e funções detalhadas na especificação do kernel deverão ser definidas. É fundamental desenvolver também um driver para um sistema de arquivo específico para que as funções do VFS possam ser testadas durante o desenvolvimento. Como o TempOS VFS é extremamente semelhante ao EXT2, implementar um driver para o EXT2 será mais simples, pois as estruturas serão praticamente as mesmas do TempOS VFS.

As funções da camada VFS estão implementadas nos arquivos do diretório fs/. O driver para o EXT2 está implementado nos arquivos do diretório fs/ext2. Este driver ainda não possui funcionalidade completa, como gravação no sistema de arquivo, mas já consegue consegue ler o $i$-nodes e os blocos de dados no EXT2. 
O EXT2 organiza os blocos de dados da partição em grupos de blocos. A quantidade de grupos depende do tamanho da partição a ser formatada com o sistema de arquivo. Esta organização também permite uma busca pelos dados de forma mais otimizada, pois se todos os $i$-nodes e bitmaps estivessem concentrados no início da partição, o braço do disco deveria se movimentar com maior frequência sempre para o início para fazer a leitura destas estruturas. Distribuindo os grupos ao longo do disco, consequentemente o braço não precisará voltar sempre ao início para ler $i$-nodes e bitmaps. A figura 4.39 contém o layout de uma partição formatada com EXT2, descrevendo o grupo de blocos.

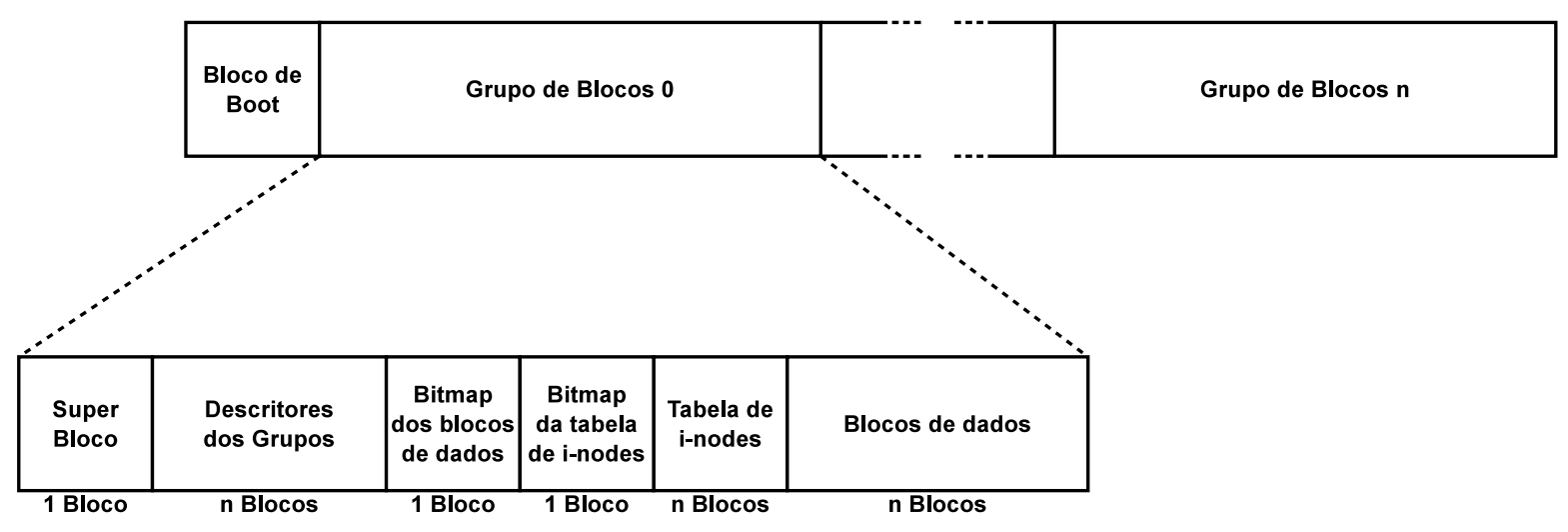

Figura 4.39: Layout da partição de um sistema de arquivo EXT2.

O Bloco de Boot é composto por um bloco não utilizado pelo sistema de arquivo. A função deste bloco é conter um código de boot da partição, por exemplo um bootloader (como o GRUB) pode ser instalado na partição ao invés de ser instalado no MBR do disco.

Cada grupo contém uma cópia do Super Bloco (que contém informações vitais do sistema de arquivo), assim, se o Super Bloco do grupo 0 for corrompido, é possível recuperar a consistência do sistema de arquivo lendo o backup em outro grupo de blocos. Os descritores dos grupos contém informações como quantidade de blocos de dados e $i$-nodes no grupo assim como o endereço dos bitmaps e da tabela de $i$-node. O bitmaps dos blocos de dados contém os blocos de dados alocados e livres no grupo de blocos. Analogamente, o bitmap da tabela de $i$-nodes contém a disponibilidade de cada $i$-node da tabela de $i$-nodes do grupo.

A partir da revisão 1 do EXT2, as cópias do Super Bloco passaram a ser inseridas apenas nos grupos de blocos 0,1 e cujos números são potências de 3, 5 e 7. O intuito foi economizar espaço, já que em partições com muitos blocos de grupos haveriam muitas cópias do Super Bloco.

As entradas de diretório possuem a mesma estrutura da entrada do TempOS VFS (mostrada na figura 4.12(b)), com exceção que o EXT2 também possui campos para informações de hash das entradas, o que permite uma busca otimizada no diretório. Entretanto, a implementação da leitura e escrita não depende destes campos, que funcionam apenas para otimização.

No TempOS, o arquivo de cabeçalho include/fs/ext $2 / \mathbf{e x t} 2 . \mathbf{h}$ contém todas as definições das estruturas de dados ( $i$-node, Super Bloco, etc) do EXT2. Convém observar a semelhança entre estas estruturas e as definidas pelo TempOS VFS, que estão presentes no arquivo include/fs/vfs.h. 
Tabela 4.18: Camada VFS e driver para sistema de arquivo: Tabela de referências.

\begin{tabular}{|l|l|}
\hline \multicolumn{2}{|c|}{ Referências } \\
\hline $\begin{array}{l}\text { Representação in- } \\
\text { terna dos arquivos }\end{array}$ & BACH , M. J. The design of the unix operating system. Capítulo 4. \\
\hline $\begin{array}{l}\text { Chamadas ao sis- } \\
\text { tema para sistema } \\
\text { de arquivo }\end{array}$ & BACH , M. J. The design of the unix operating system. Capítulo 5. \\
\hline $\begin{array}{l}\text { O sistema de ar- } \\
\text { quivo virtual }\end{array}$ & BOVET, D.; CESATI , M. Understanding the linux kernel. Capítulo 12. \\
\hline $\begin{array}{l}\text { O sistema de ar- } \\
\text { quivo EXT2 }\end{array}$ & BOVET, D.; CESATI , M. Understanding the linux kernel. Capítulo 17. \\
\hline $\begin{array}{l}\text { Especificação do } \\
\text { EXT2 }\end{array}$ & $\begin{array}{l}\text { http://uranus. chrysocome. net/explore2fs/es } 2 \text { fs. } \\
\text { htm }\end{array}$ \\
\hline VFS & http://wiki.osdev.org/VFS \\
\hline
\end{tabular}

\subsubsection{Chamadas ao sistema}

O funcionamento das chamadas ao sistema está detalhado na especificação da arquitetura do kernel. O TempOS faz chamadas ao sistema através da interrupção de número 0x85. Assim como no Linux, os seguintes registradores são utilizados:

- EAX: Contém o número da chamada ao sistema a ser executada. A tabela de chamadas do TempOS encontra-se no arquivo kernel/syscall.c. Após a execução da chamada o valor de retorno é colocado neste registrador.

- EBX, ECX, EDX: Contém os parâmetros a serem passados para chamada ao sistema, que portanto pode aceitar no máximo três argumentos.

O TempOS configura uma rotina para atender a interrupção $0 \times 85$, esta rotina salva o estado da máquina, verifica se o código da chamada de sistema é válido, empilha os argumentos (EBX, ECX e EDX), chama a função correspondente a partir da tabela de chamadas, coloca o valor de retorno no registrador EAX, e chaveia novamente para o contexto do usuário. Todo este processo

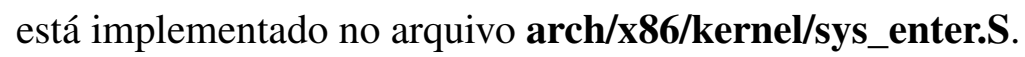

A figura 4.40 contém o código assembly do programa de usuário init, que é executado ao final da inicialização do kernel. O programa efetua a chamada ao sistema write() para escrever uma mensagem na tela e entra em um laço de repetição infinito. 


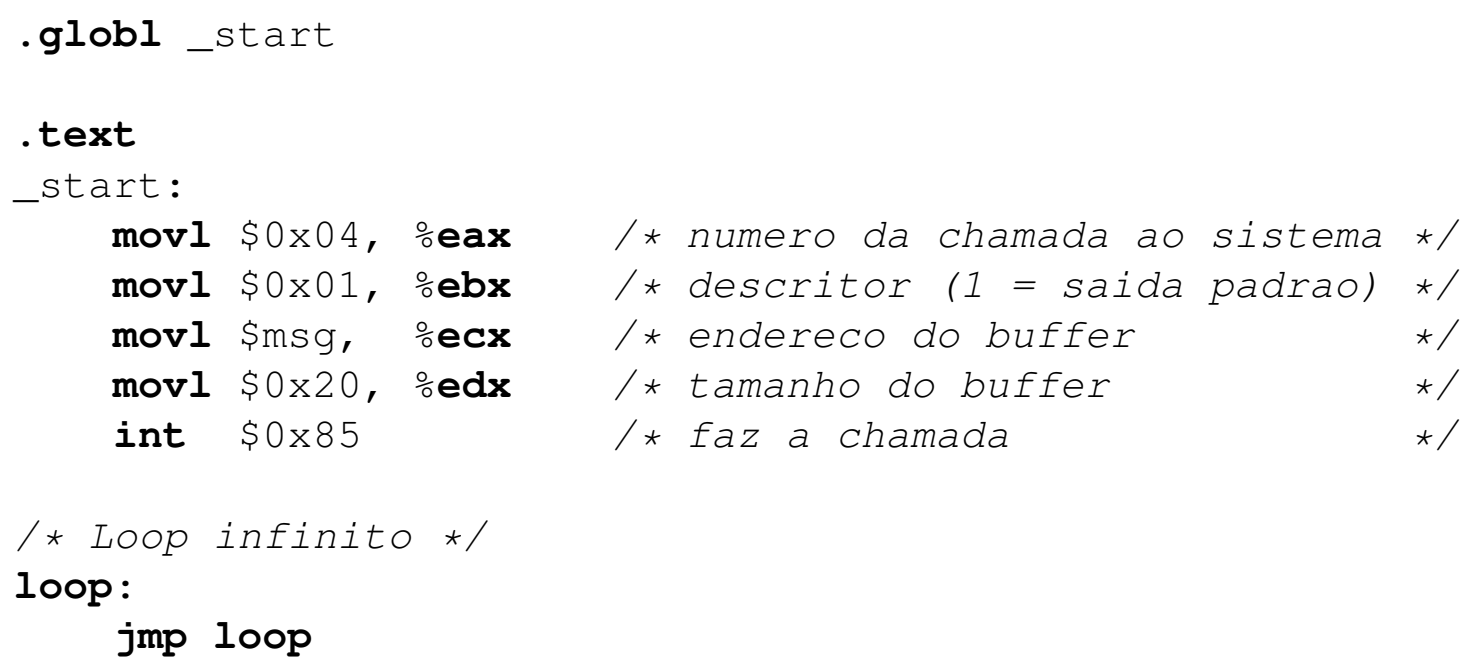

Figura 4.40: Programa de usuário que faz uma chamada ao sistema no TempOS.

Atualmente o TempOS declara cinco chamada ao sistemas: exit, fork, execve, read e write. Porém somente a chamada write() foi substancialmente implementada.

Tabela 4.19: Chamadas ao sistema: Tabela de referências.

\begin{tabular}{|l|l|}
\hline \multicolumn{2}{|c|}{ Referências } \\
\hline $\begin{array}{l}\text { Chamadas ao sis- } \\
\text { tema (1) }\end{array}$ & BOVET, D.; CESATI, M. Understanding the linux kernel. Capítulo 8. \\
\hline $\begin{array}{l}\text { Chamadas ao sis- } \\
\text { tema (2) }\end{array}$ & http://wiki.osdev.org/System_Calls \\
\hline $\begin{array}{l}\text { Chamadas ao sis- } \\
\text { tema (3) }\end{array}$ & $\begin{array}{l}\text { http://www.freebsd.org/doc/en_US.ISO8859-1/ } \\
\text { books/developers-handbook/x86-system-calls.html }\end{array}$ \\
\hline $\begin{array}{l}\text { Chamadas ao sis- } \\
\text { tema do Linux }\end{array}$ & $\begin{array}{l}\text { http://docs.cs.up.ac.za/programming/asm/derick_ } \\
\text { tut/syscalls.html }\end{array}$ \\
\hline
\end{tabular}

\subsubsection{Execução de aplicativos do usuário}

Os programas de usuário são compilados e linkados resultando em um formato de arquivo binário executável pelo SO. Nos sistemas Unix atuais (Linux, FreeBSD, etc), o formato padrão para a arquitetura x86 e diversas outras arquiteturas é o ELF (Executable and Linkable Format), que define a estrutura de arquivos executáveis, de objeto, de bibliotecas compartilhadas e de descargas de memória (do inglês, core dumps). Um arquivo executável no formato ELF define pelo menos três regiões, chamadas de segmentos: 
- Segmento de Texto: Contém todo o código executável, as instruções que o processo irá executar.

- Segmento de Dados: Contém as variáveis globais inicializadas utilizadas pelo processo. As variáveis locais (de cada função) são armazenadas na pilha do processo.

- Segmento BSS: Block Started by Symbol ${ }^{17}$. Esta região contém todas as variáveis globais não inicializadas do processo, por isso geralmente é zerada pelo SO quando um processo é carregado. Pode ser considerada parte do segmento de Dados.

Outros segmentos podem estar presentes, como os que incluem informações do compilador utilizado, comentários, bibliotecas compartilhadas, etc. O utilitário readelf (presente no pacote binutils) permite examinar todos os segmentos e informações de um arquivo ELF.

O TempOS ainda não possui suporte a arquivos ELF, portanto, os programas de usuário devem ser compilados e linkados em um binário puro, cujo endereço base é 0xC0000C. Este endereço foi escolhido a partir do endereço 0xC00000 (12MB) escolhido arbitrariamente. O kernel aloca a memória para carregar o programa e mapeia o bloco alocado no diretório de páginas do novo processo no endereço 0xC00000 (entrada de índice 3), porém, o bloco alocado (por kmalloc()) contém as informações de alocação (que ocupam 12 bytes na memória), portanto utilizando a base 0xC0000C para a primeira instrução do programa, automaticamente ela estará mapeada corretamente. Todo este processo é implementado no arquivo kernel/fork.c.

Considerando como exemplo o programa da figura 4.40, a compilação e linkagem do código para execução no TempOS pode ser feita através dos comandos:

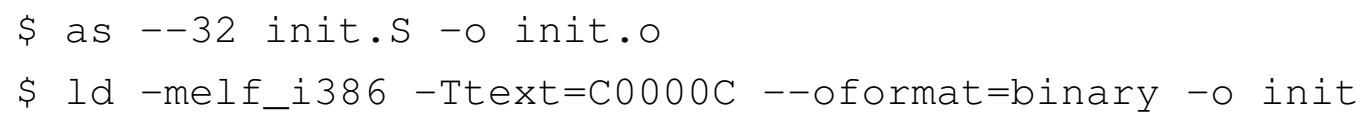

$\mathrm{O}$ arquivo final (init) será um binário puro linkado com endereço base 0xC0000C $(12 \mathrm{MB}+12$ bytes).

Tabela 4.20: Execução de aplicativos do usuário: Tabela de referências.

\begin{tabular}{|l|l|}
\hline \multicolumn{2}{|c|}{ Referências } \\
\hline $\begin{array}{l}\text { Execução de pro- } \\
\text { cessos }\end{array}$ & BOVET, D.; CESATI, M. Understanding the linux kernel. Capítulo 19. \\
\hline Formato ELF (1) & http://wiki.osdev.org/ELF \\
\hline Formato ELF(2) & $\begin{array}{l}\text { http://www.skyfree.org/linux/references/ELF_- } \\
\text { Format.pdf }\end{array}$ \\
\hline System V ABI & $\begin{array}{l}\text { http://www.sco.com/developers/gabi/latest/ } \\
\text { contents.html }\end{array}$ \\
\hline
\end{tabular}

\footnotetext{
${ }^{17}$ A sigla BSS vem de uma pseudo-operação do UA-SAP (United Aircraft Symbolic Assembly Program), um montador desenvolvido no meio da década de 1950 para o IBM 704. Foi mantida por razões históricas.
} 


\subsubsection{Notas finais}

Ao final da última etapa o aluno terá implementado um Sistema Operacional básico porém funcional, que é capaz de gerenciar os recursos e hardware básico da máquina, além de prover gerenciamento de memória e carregar um processo de usuário do sistema de arquivo para a memória, suportando threads de kernel e fazendo escalonamento dos processos. Mesmo que suporte apenas uma chamada ao sistema, o kernel pode ser estendido até transforma-se em um clone completo do Unix (implementado as chamadas POSIX). O desenvolvimento envolve cada subsistema da arquitetura TempOS (e presentes na arquitetura Unix), ou seja, mesmo que o aluno tenha implementado funções básicas e utilizado algoritmos simples, esta experiência levará a um sólido conhecimento no funcionamento e detalhes de implementação de cada parte do kernel, assim como dispositivos específicos presentes na arquitetura atuais. Ao abordar o código de um Sistema Operacional moderno e complexo, como o Linux, o aluno possuirá a base necessária para entender de maneira mais simples e aprofundar-se na implementação do código, requisitos fundamentais para profissionais que atuarão no desenvolvimento de Sistemas Operacionais, de propósito geral ou embarcados, de sistemas complexos, críticos e de tempo real. Conhecer com maior profundidade os mecanismos que de fato provêm suporte e abstração as camadas superiores também pode auxiliar no desenvolvimento alto nível através de soluções otimizadas, feitas pelos programadores que conhecem o funcionamento, como o código de alto nível resultará nas camadas de baixo nível do sistema. 
O Capítulo 4 apresentou a especificação da arquitetura da plataforma de ensino TempOS, desde a estrutura geral do Sistema Operacional até o detalhamento de toda a estrutura e módulos que compõem o kernel. A especificação de cada módulo foi acompanhada de referências e detalhes de implementação do SO TempOS, que implementa a arquitetura da plataforma. As arquiteturas PC e x86 também foram abordadas, dado que a plataforma está inicialmente instanciada nestas arquiteturas. O material didático da plataforma é composto por um roteiro que sintetiza cada etapa de desenvolvimento do kernel através de dez tópicos de estudo estruturados para serem aplicados em um curso de desenvolvimento de Sistemas Operacionais. A abordagem de cada tópico deverá ser adequada ao tipo do curso (graduação, pós-graduação, etc) e ficará a critério do professor definir o nível de detalhamento de cada um dos tópicos aplicados. Cada tópico está organizado no desenvolvimento de cada módulo apresentado na arquitetura de maneira sequencial, permitindo que o kernel seja construído e testado de forma incremental.

O TempOS, Sistema Operacional da plataforma de ensino, possui seu código estruturado com os módulos da especificação da arquitetura, contendo os seguintes diretórios:

- arch: Contém todas as partes dependentes de arquitetura. Todas as funções ligadas a arquitetura x86 (configuração do processador, interrupções) estão contidas neste diretório.

- drivers: Contém o código dos drivers de dispositivo.

- kernel: Contém a parte independente de arquitetura. Neste diretório estão presentes a maior parte do kernel: chamadas ao sistema, escalonador, funções para threads, temporizadores e o gerenciador de memória do espaço linear de endereço. 
- fs: Contém a camada VFS e o driver de sistema de arquivo para o EXT2.

- lib: Contém uma série de funções internas do kernel, como para manipulação de strings, listas encadeadas, printf, etc.

- include: Contém os arquivos de cabeçalho de toda parte independente de arquitetura. Os arquivos de cabeçalho específicos de arquitetura estão contidos na pasta arch/include/. No caso da arquitetura $\mathrm{x} 86, \mathbf{a r c h} / \mathbf{i n c l u d e / x 8 6 .}$

A figura 5.1 mostra a associação dos arquivos de código do kernel com cada módulo da arquitetura. Os octógonos representam diretórios, onde mais arquivos de código estão presentes.

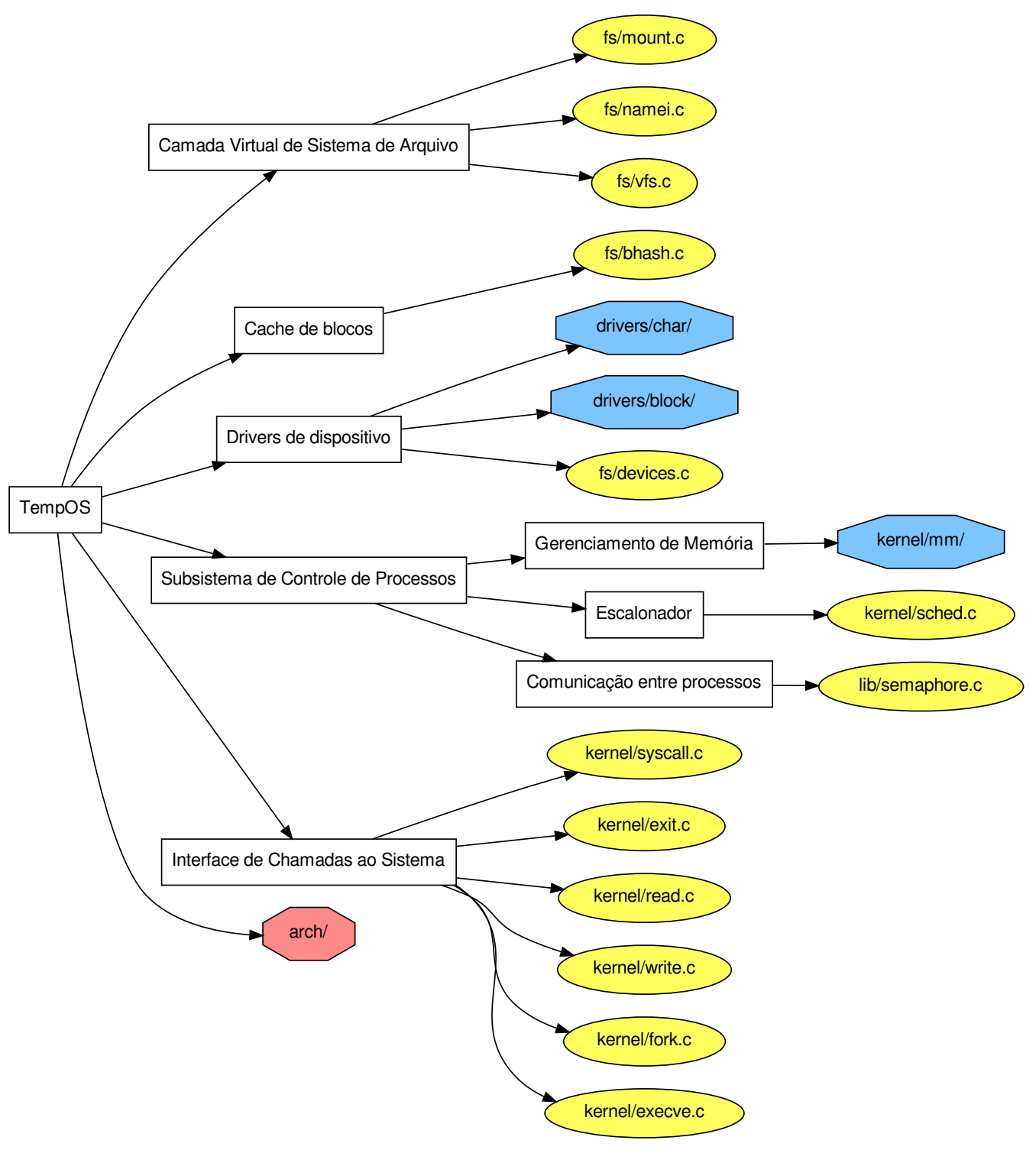

Figura 5.1: Associação do código do TempOS com os módulos da arquitetura do kernel. 
Faz parte também do material didático a documentação interna do kernel do TempOS gerada com a ferramenta doxygen, a partir dos comentários do código. Esta documentação pode ser gerada em formato HTML ou PDF, contendo os parâmetros e a descrição de cada função do código, assim como detalhes de implementação e até o grafo de chamadas de cada função. A figura 5.2 ilustra uma página HTML desta documentação. Esta documentação, assim como o roteiro de desenvolvimento estão integralmente disponíveis nos anexos.

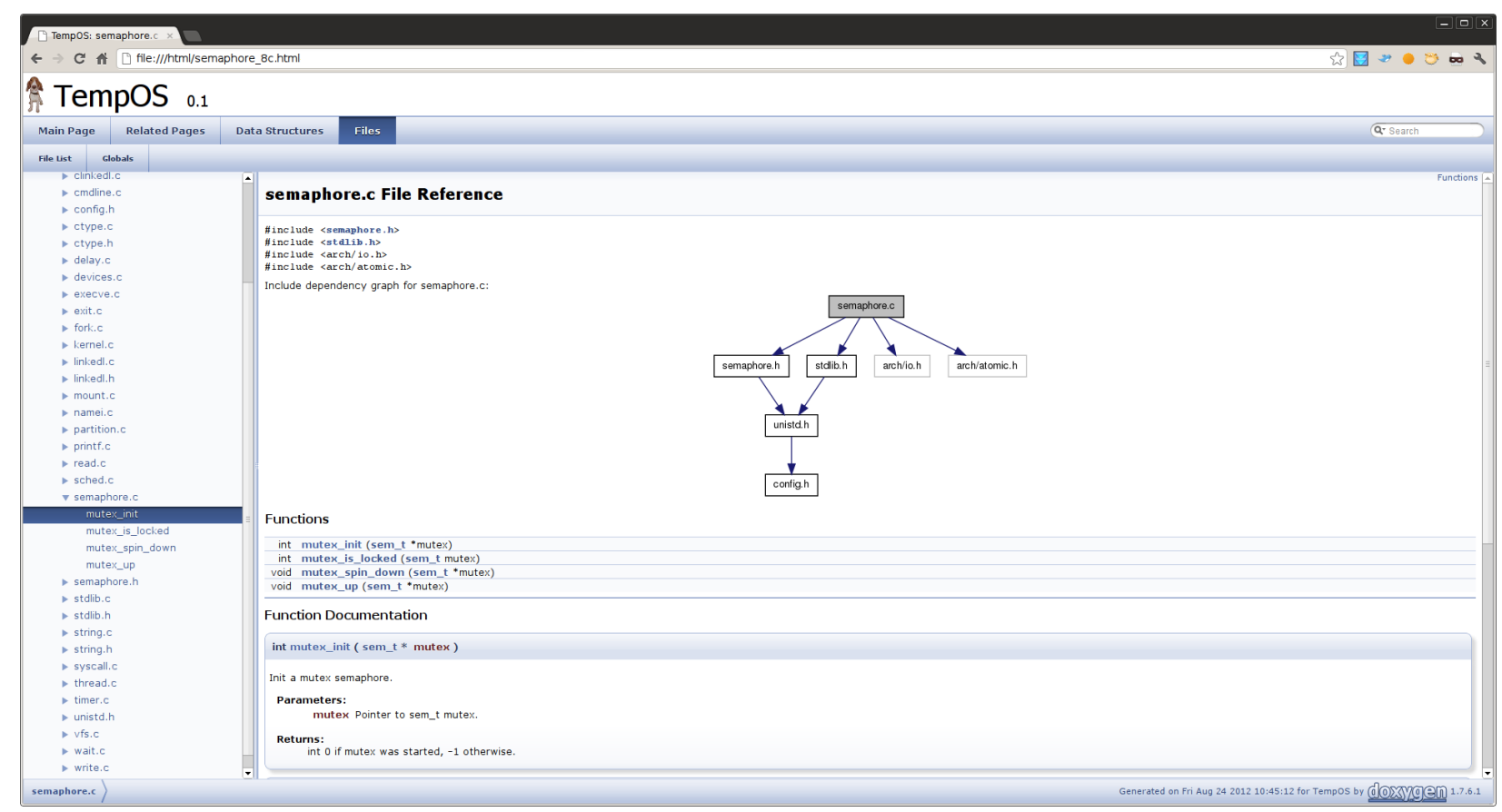

Figura 5.2: Exemplo da documentação do código do kernel do TempOS.

Por ter sido implementado tendo em mente o propósito da plataforma, a relação direta do código do TempOS com os conceitos teóricos e módulos da arquitetura facilitam o aprendizado e entendimento da teoria. Considere como exemplo, o estudo do escalonador do TempOS, composto pelas funções schedule() e init_scheduler():

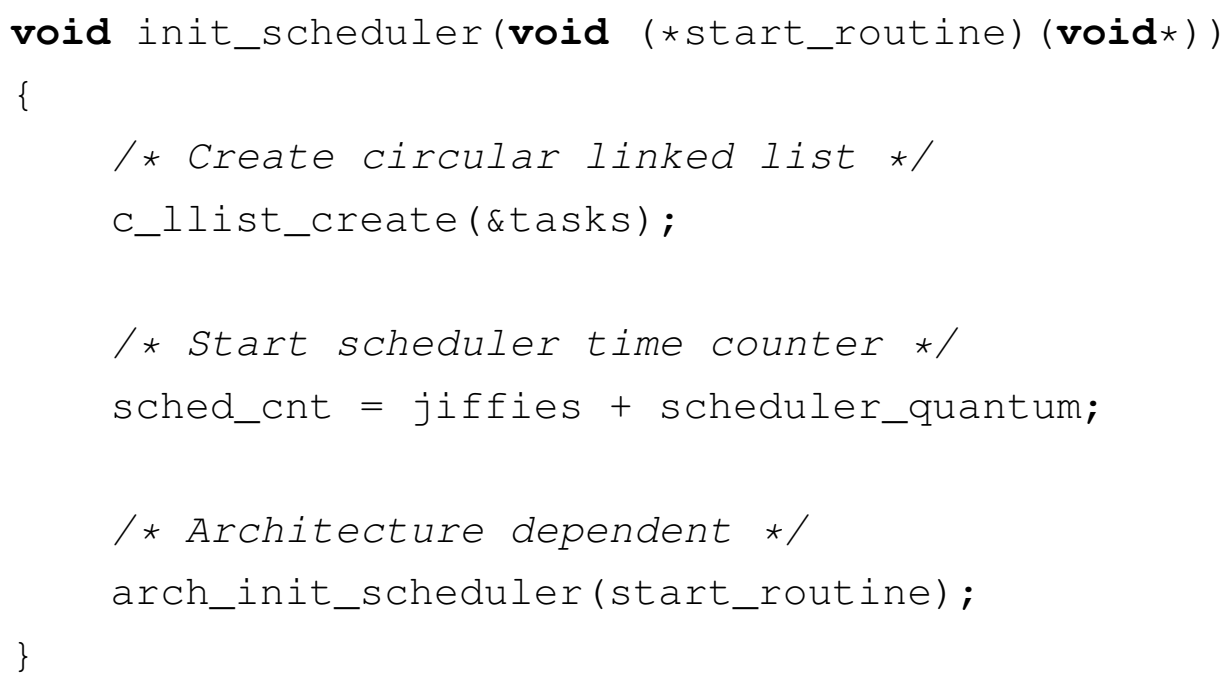


O primeiro passo de init_scheduler() é iniciar a lista circular que conterá a estrutura de cada processo. Em seguida, o contador de tempo, que indica o próximo horário em que uma tarefa será chaveada, é iniciado com o tempo atual (jiffies) somado ao quantum de escalonamento (scheduler_quantum). O ultimo passo é chamar a rotina que executa o código dependente de arquitetura que transforma a função passada (start_routine) na thread inicial do kernel.

A função schedule() é chamada sempre que o quantum de tempo for atingido. O primeiro passo é verificar se cur_task (que aponta para a tarefa em execução) já foi iniciada. Em caso negativo, a função simplesmente retorna, do contrário, uma nova tarefa será chaveada para execução. A escolha da próxima tarefa é feita através do algoritmo Round-Robin, ou seja, a próxima tarefa da lista que esteja no estado "PRONTO_PARA_EXECUTAR" será colocada em execução através da função switch_to(), conforme o código:

void schedule (void)

\{

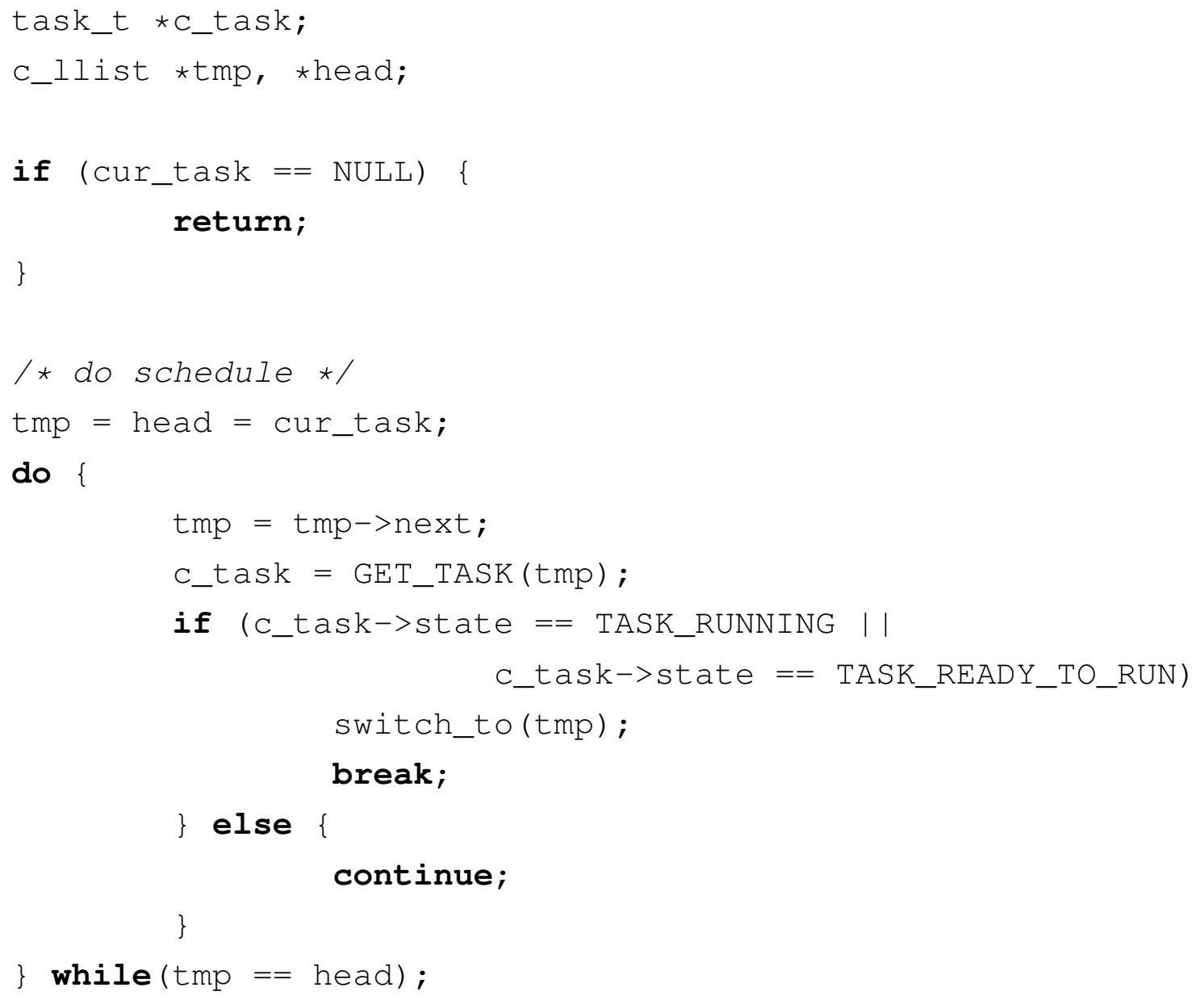

A função da macro GET_TASK é simplesmente retornar o ponteiro da estrutura da tarefa a partir do ponteiro da entrada na lista circular.

O escalonador do Linux (0.99.15) atua com a mesma política de escalonamento do TempOS (Round-Robin), sendo também baseado em duas funções, sched_init(), que inicia o escalonador 
e schedule(), que faz o escalonamento quando o quantum é atingido. A função sched_init() é implementada pelo seguinte código:

void sched_init(void)

\{

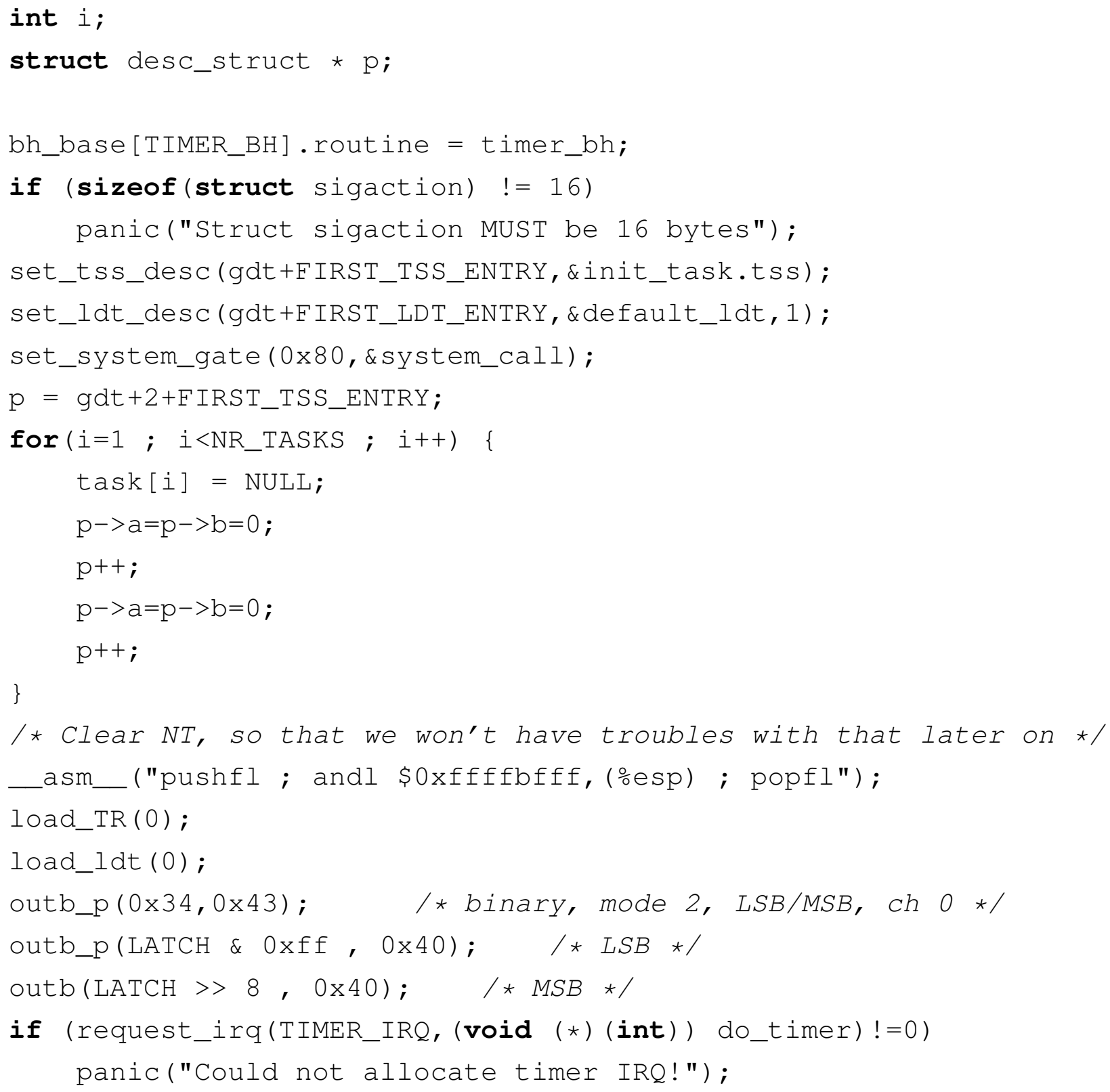

Como nessa versão o Linux utilizava o mecanismo de chaveamento de tarefas da arquitetura x86, a função sched_init() inicia uma estrutura TSS em cada entrada disponível da GDT. Em seguida a flag NT é limpa e os registradores TR (Task Register) e a tabela LDT são carregados. Por fim, os registradores do PIT são configurados e a rotina para atendimento da IRQ0 é registrada através da função register_irq(). 


\section{continue;}

if ( $\mathrm{p}->$ signal \& $\sim \mathrm{p}->$ blocked) \{

p->state $=$ TASK_RUNNING;

\section{continue;}

if (p->timeout $\& \& p$->timeout $<=$ jiffies $) \quad\{$

$\mathrm{p}->$ timeout $=0$;

p->state = TASK_RUNNING;

confuse_gcc1:

/* this is the scheduler proper: * /

\section{\#if 0}

I* give processes that go to sleep a bit higher priority.. */

I* This depends on the values for TASK_XXX */

/* This gives smoother scheduling for some things, but */

I* can be very unfair under some circumstances, so. * *

if (TASK_UNINTERRUPTIBLE $>=$ (unsigned) current->state \&\& current->counter < current->priority*2) \{ ++ current->counter;

\}

\section{\#endif}

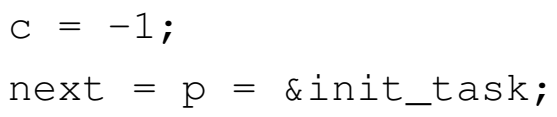

for $(; ;) \quad\{$

if $((\mathrm{p}=\mathrm{p}->$ next_task $)==$ \&init_task $)$

goto confuse_gcc2;

if $(p->$ state $==$ TASK_RUNNING $\& \& p->$ counter $>c)$ $c=p->$ counter, next $=p$;

\}

confuse_gcc2:

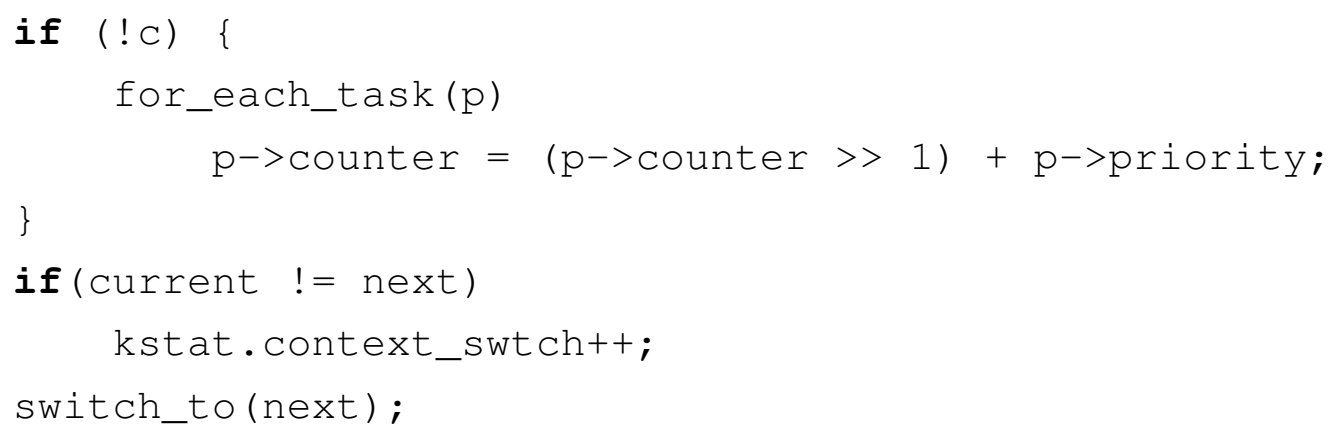




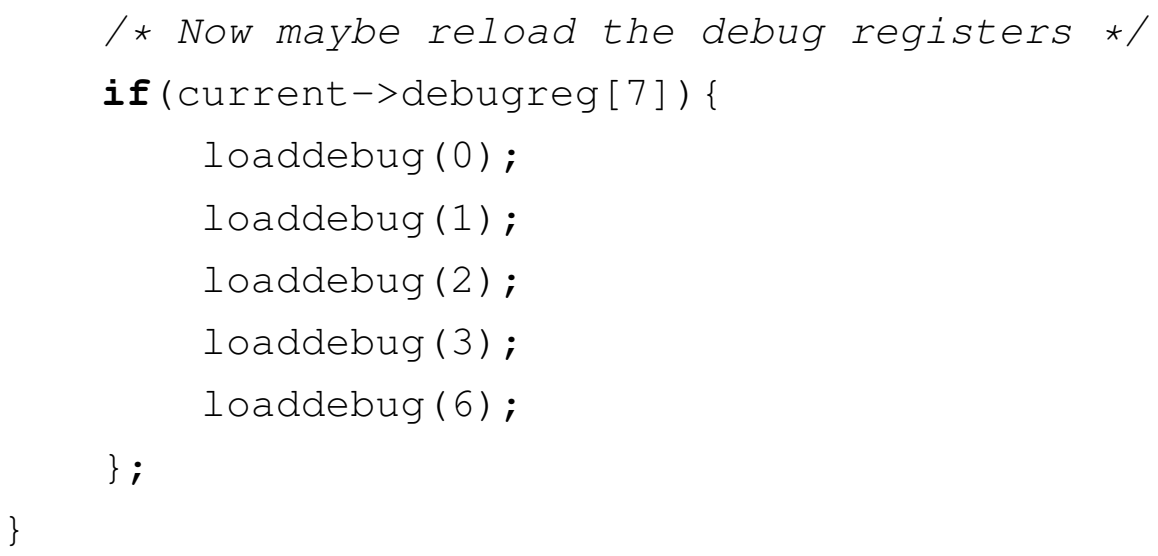

Ao contrário do código do TempOS, o código do escalonador do Linux apresentado não separa as rotinas dependentes de arquitetura. A função de escalonamento no Linux executa checagem de alarmes e sinais na mesma rotina, além de programar um hardware específico (PIT) na rotina de inicialização do escalonador, todas estas funções poderiam estar modularizadas e separadas em outro arquivo. Logo, utilizar o código do Linux em uma aula de escalonamento implicaria na necessidade dos alunos conhecerem detalhes da arquitetura x86 e do PIT. Já o código do TempOS não agrega outras funções ao código do escalonador e as partes dependentes de arquitetura estão separadas em uma função especificada. Assim, o código apresentado aos alunos estará inteiramente relacionado ao tópico de estudo (escalonamento), e se desejado, o código relacionado a arquitetura poderá ser abordado; caso contrário, o código do escalonamento não tem sua compreensão dificultada pela implementação de funcionalidade diferente daquela abordada no tópico de estudo.

A esse propósito, o tamanho do código fonte do TempOS foi comparado com o do Linux 0.99.15 e do Minix 2.0.0 (somente micronúcleo) com o auxílio da ferramenta CLOC $^{1}$, considerando apenas linhas de código e comentários (descartadas linhas em branco). A figura 5.3 apresenta essa comparação graficamente. O Linux apresentou 120874 linhas de código e 26846 de comentários, ou seja, 18,17\% do total (código + comentários). Já o Minix apresentou 17421 linhas de código e 4726 de comentários (21,12\%). O TempOS apresentou 6236 linhas de código, e 4307 linhas de comentários, correspondendo a 40,63\% do total. Essa medida não deve ser interpretada como avaliação de qualidade de implementação entre os três sistemas, uma vez que não se baseia num mesmo conjunto de funcionalidades e capacidades, e logo não é explicitado um parâmetro comum que permita comparação nesse sentido. O fator "dimensão do código", nesse caso, tem valor apenas como informativo do tamanho do sistema em relação às alternativas mencionadas. O aspecto positivo de um tamanho reduzido de código fonte é que, para o conjunto específico de funcionalidades estuadas, presentes nos três sistemas, o TempOS fornece uma implementação completa e funcional de todas elas em menos linhas de código. Assim, para estudar completamente a implementação de dada função, um código menor (e menos acoplado) facilita que seja estudado com menor esforço. A tentativa aplicar algum método de redução de código seja do Linux ou do

\footnotetext{
${ }^{1}$ Count Lines of Code, ferramenta livre que faz diversas aferições (número de linhas em branco, de código, etc) em arquivos de código fonte de diversas linguagens. Disponível em http: / / cloc. sourceforge. net/.
} 
Minix para remover partes alheias aos tópicos estudados revela-se desafiadora e em geral, propensa a resultar em um software que não compila ou não funciona como esperado.

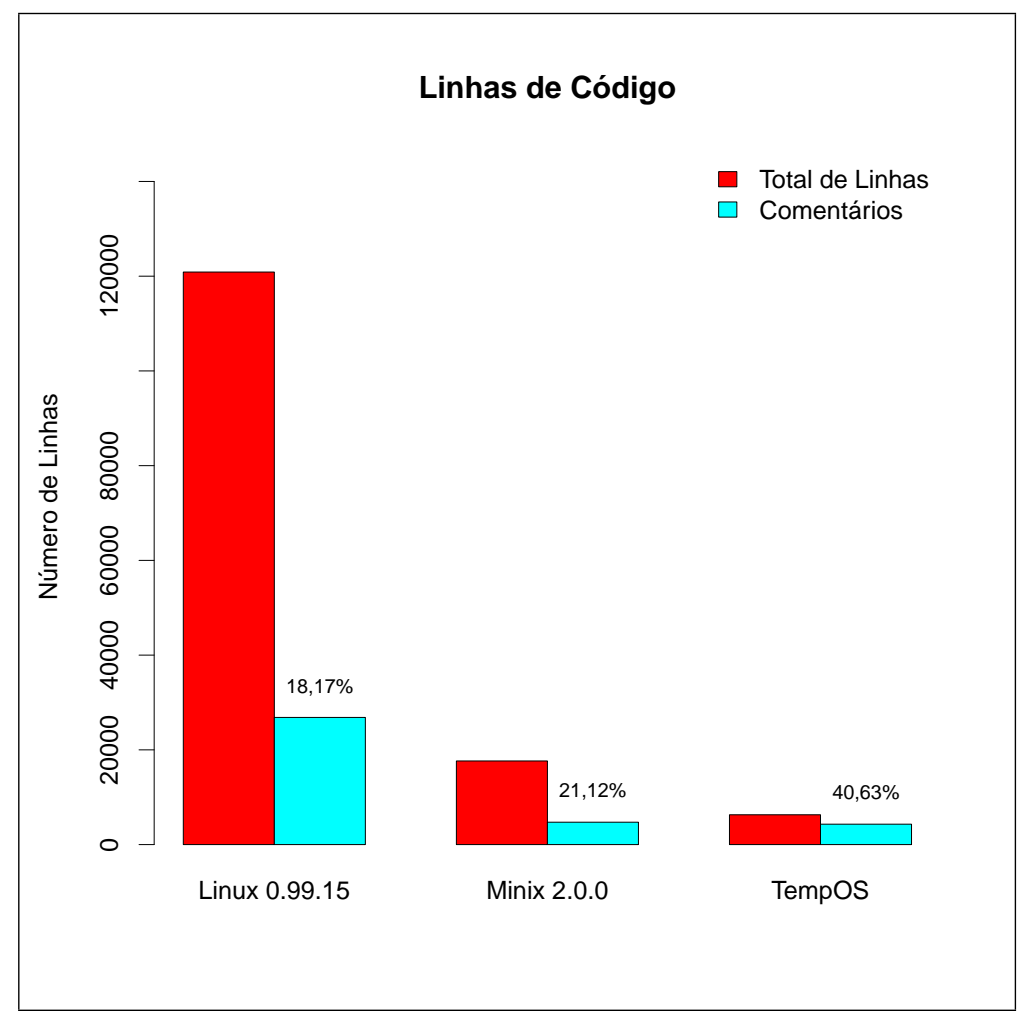

Figura 5.3: Total de linhas de código e de comentários.

A porcentagem de comentários no código do TempOS reforça a característica de ensino na implementação do código do mesmo, onde a extensiva documentação interna, incrementada de referências, modo de uso e detalhes dos mecanismos implementados fornecem ao estudante informações e referências necessárias para que o mesmo possa entender e implementar as mesmas funcionalidades utilizando seus próprios algoritmos ou aqueles utilizados pelo TempOS. 



\section{CAPítulo \\ 6}

Conclusões

A recente evolução das arquiteturas de computador embarcadas tem tornado possível a implantação de Sistemas Operacionais sofisticados onde apenas rudimentares sistemas de propósito específico eram lugar comum na indústria. Depois de décadas sob o status de fundamentação teórica para cientistas e engenheiros de computação, o conhecimento técnico em projeto e implementação de Sistemas Operacionais reemerge como uma capacitação crescentemente relevante em uma indústria em expansão. O ensino em Sistemas Operacionais sob essa nova perspectiva, e sob novos requisitos de sistemas embarcados críticos, pervasivos e móveis, constitui um desafio. A principal colaboração deste trabalho é a introdução de uma nova plataforma cujo diferencial é a metodologia de aprendizagem baseada em projeto e uma correspondente implementação de um sistema operacional educacional, que é estruturalmente mapeado em um programa de treinamento em desenvolvimento de Sistemas Operacionais.

Este trabalho introduz uma plataforma de ensino e treinamento em técnicas de projeto e desenvolvimento de sistemas operacionais baseada em um roteiro de instrução teórico-prático. A metodologia propõe o desafio de desenvolver um sistema operacional funcional e sintetiza um roteiro para estudo. A característica mais importante do sistema proposto é a associação entre tópicos conceituais de aprendizagem e uma arquitetura de implementação que busca uma correlação mais simples e direta entre o módulo teórico e o código fonte estudado. Um caso de uso é fornecido como ilustração dessa abordagem, e comparado como alternativas tradicionalmente empregadas em programas de ensino.

O material didático composto pela especificação completa da arquitetura com detalhes de cada módulo do kernel, bem como de suas funções e estruturas gerais, além do roteiro passo a passo que 
referencia a implementação do kernel em um programa sequenciado com a arquitetura TempOS, notas técnicas e didáticas.

Como desdobramento desse trabalho, é sugerida a continuidade do desenvolvimento da plataforma TempOS, incluindo-se a implementação completa das chamadas de sistema POSIX e porte da biblioteca C padrão e do compilador gec para o sistema. Com isso, o estudante poderá desenvolver programas para seu sistema operacional e ter a visão integrada do que acontece em ambos os lados: o uso das chamadas de sistema pelo processo, e suas respectivas implementações pelo SO. 
Nachos operating system. Http://www.cs.washington.edu/homes/tom/nachos/, 2010.

AIOROS https://www.ohloh.net/p/aioros. Último acesso em 12 de Março, 2012.

Anderson, C. L.; NGUYEN, M. A survey of contemporary instructional operating systems for use in undergraduate courses. J. Comput. Small Coll., v. 21, n. 1, p. 183-190, 2005.

BACH, M. J. The design of the unix operating system. Prentice-Hall, 1986.

BonAFIDE http://www.osdever.net/. Último acesso em 12 de Março, 2012.

Bovet, D.; Cesati, M. Understanding the linux kernel. O’Reilly Media, 2006.

CARISSIMO, J. XINU-an easy to use prototype for an operating system course. ACM SIGCSE Bulletin, v. 27, n. 4, p. 56, 1995.

Christopher, W.; Procter, S.; Anderson, T. The Nachos instructional operating system. In: Proceedings of the USENIX Winter 1993 Conference Proceedings on USENIX Winter 1993 Conference Proceedings, Usenix Association, 1993, p. 4.

Cox, A. Linux allocated devices (2.6+ version). Documentação Kernel Linux, versão 3.2.12, 2009.

DEXOS http://www.opensolaris.org. Último acesso em 12 de Março, 2012.

DiBona, C.; Ockman, S.; Stone, M. Open sources: Voices from the open source revolution. O’Reilly \& Associates, Inc. Sebastopol, CA, USA, 1999.

DREAMOS https://developer.berlios.de/projects/dreamos/. Último acesso em 12 de Março, 2012.

Fankhauser, G.; Conrad, C.; Zitzler, E.; Plattner, B. Topsy-a teachable operating system. Computer Engineering and Networks Laboratory, ETH Zurich, v. 2001, 1996. 
FIASCO http://os.inf.tu-dresden.de/fiasco/. Último acesso em 12 de Março, 2012.

FILESYSTEM HIERARCHY StANDARD GROUP Filesystem hierarchy standard. 2004.

FREEBSD http://www.freebsd.org. Último acesso em 12 de Março, 2012.

GNU/HURD http://www.gnu.org/software/hurd/. Último acesso em 12 de Março, 2012.

Holland, D.; Lim, A.; Seltzer, M. A new instructional operating system. In: Proceedings of the 33rd SIGCSE technical symposium on Computer science education, ACM, 2002, p. 111115.

IEEE, T. O. G. Ieee std 1003.1-2001. 2004.

INTEL Intel architecture software developer's manual. 1999a.

INTEL Intel architecture software developer's manual. $1999 \mathrm{~b}$.

INTEL Introduction to pc architecture. Disponível em http://software.intel.com/enus/articles/introduction-to-pc-architecture/. Último acesso em 17 de Maio de 2012, 2009.

KEYOS http://sourceforge.net/projects/keyos. Último acesso em 12 de Março, 2012.

KRAFT, G. D. Building applications with the linux standard base / written by core members of the linux standard base team. Pearson plc, 2005.

LINUX http://www.kernel.org. Último acesso em 12 de Março, 2012.

Locke, C. Posix and linux application compatibility design rules. system, v. 20, p. 21, 2005.

Machado, F.; MAiA, L. Arquitetura de sistemas operacionais. 4 ed.. Livros Tecnicos e Cientificos, 2007.

Mit OPEN COURSE: OPERATING SyStem ENGINEERING http://ocw.mit.edu/ocwweb/electrical-engineering-and-computer-science/6-828fall2006/coursehome/index.htm. Último acesso em 12 de Março, 2012.

O’Gorman, J. Operating systems with linux. Palgrave Macmillan, 2001.

OPEnSOlARIS http://www.opensolaris.org. Último acesso em 12 de Março, 2012.

OPLC http://laptop.org/en/. Último acesso em 12 de Março, 2012.

OSDEV http://wiki.osdev.org. Último acesso em 12 de Março, 2012.

Projet, G. http://www.gnu.org. Último acesso em 12 de Março, 2012.

PUC RiO GRANDE DO SUL http://www.inf.pucrs.br/ celso/sisop.html. Último acesso em 12 de Março, 2012. 
PUCPR http://www.ppgia.pucpr.br/maziero/doku.php/so:programa_ec_2008-2. Último acesso em 12 de Março, 2012.

Ritchie, D. The evolution of the unix time-sharing system. Language Design and Programming Methodology, p. 25-35, 1980.

Ritchie, D.; Thompson, K. The unix time-sharing system. Communications of the ACM, v. 17, n. 7 , p. $365-375,1974$.

SO NuMA BoA http://www.numaboa.com/informatica/oficina/215-so. Último acesso em 12 de Março, 2012.

Stallings, W.; Figueiredo, C.; Figueiredo, L. Arquitetura e organização de computadores: projeto para o desempenho. Prentice-Hall, 2009.

Stallings, W.; Paul, G. Operating systems: internals and design principles, v. 148. Prentice Hall, 1998.

TANENBAUM, A. A UNIX clone with source code for operating systems courses. ACM SIGOPS Operating Systems Review, v. 21, n. 1, p. 29, 1987.

Tanenbaum, A. Modern operating systems, v. 2. Prentice Hall New Jersey, 1992.

TAnenbaum, A. S. Sistemas operacionais: projeto e implementação. Bookman, 2000.

The OPERATING SYSTEM RESOURCE CENTER http://www.nondot.org/sabre/os/articles/. Último acesso em 12 de Março, 2012.

The SANTA CRUZ Operation 4.1 ed.System V Application Binary Interface. 1996.

UFES http://www.inf.ufes.br/ rgomes/so.htm. Último acesso em 12 de Março, 2012.

UFRGS http://www.inf.ufrgs.br/ asc/sisop/. Último acesso em 12 de Março, 2012.

UFSCAR http://www2.dc.ufscar.br/ helio/lab-so. Último acesso em 12 de Março, 2012.

UNIVERSIDADE ESTADUAL DO CEARÁ http://www.larces.uece.br/ jeandro/so.html. Último acesso em 12 de Março, 2012.

USP - IME http://www.ime.usp.br/ durham/cursos/mac422/. Último acesso em 12 de Março, 2012.

WirzeniUs, L.; OJA, J.; StAFFORD, S.; WeEKs, A. Linux system administrator's guide. iUniverse, 2000.

Yaghmour, K.; Masters, J.; Ben-Yossef, G.; Gerum, P. Building embedded Linux systems. O’Reilly Media, Inc., 2008. 
Anexos 

TempOS: Plataforma para ensino e treinamento no desenvolvimento de Sistemas Operacionais

Roteiro de desenvolvimento

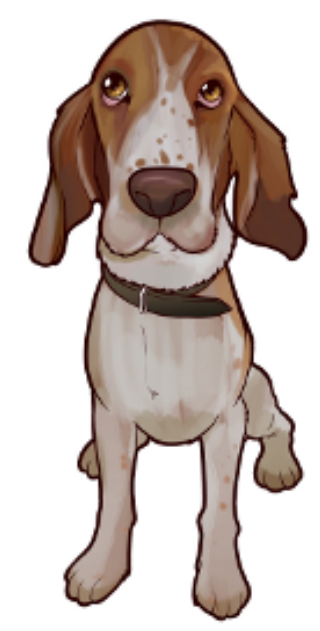

Versão: 0.1 (Ago/2012) 


\section{TempOS: Plataforma para ensino e treinamento no desenvolvimento de Sistemas Operacionais}

Documento: Roteiro de desenvolvimento

Autor Original: Renê de Souza Pinto <rene@ @renesp.com.br>

Licença: Este documento é licenciado pela Creative Commons Atribuição - Não Comercial - Compartilha Igual 3.0. O resumo assim como a cópia completa da licença podem ser obtidos no endereço http://creativecommons . org/licenses/by-nc-sa/3.0/deed.pt.

\section{Histórico:}

Versão inicial: 0.1 (Ago/2012). 


\section{Sumário}

LISTA DE TABELAS iii

LISTA DE FIGURAS iv

1 Introdução 1

2 Tópico de Estudo 1

3 Tópico de Estudo 2

4 Tópico de Estudo $3 \quad 11$

$5 \quad$ Tópico de Estudo 4

6 Tópico de Estudo 5

6.0.1 Temporizadores . . . . . . . . . . . . . . . . . . . . 14

6.0 .2 Threads de Kernel . . . . . . . . . . . . . . . . . . . . 15

7 Tópico de Estudo $6 \quad 17$

8 Tópico de Estudo $7 \quad 19$

9 Tópico de Estudo 8 21

10 Tópico de Estudo 9

11 Tópico de Estudo $10 \quad 28$

12 Notas finais $\quad 30$

REFERÊNCIAS 


\section{Lista de Tabelas}

6.1 Arquivos do código fonte do TempOS para o gerenciamento de threads e processos. . . . . . . . . . . . . . . . . . . . . . . 16

9.1 Funções implementadas por um driver de sistema de arquivo. . . . . . . . . . . 24

9.2 Funções implementadas pela camada VFS. . . . . . . . . . . . . . . . . . . . 25 


\section{Lista de Figuras}

2.1 Sistema Operacional: Arquitetura Monolítica. . . . . . . . . . . . . 7

2.2 Visão geral do SO, mostrando as camadas envolvidas desde o usuário até o kernel. 7

2.3 Arquitetura do kernel da plataforma TempOS. Figura adaptada de [1] . . . . . . 8

9.1 TempOS VFS: Estrutura do Superbloco. . . . . . . . . . . . . . . . . . 22

9.2 TempOS VFS: Estrutura do $i$-node . . . . . . . . . . . . . . . . . . 23

9.3 TempOS VFS: Estrutura da tabela de montagem. . . . . . . . . . . . . . 24

10.1 Código assembly do programa init para testar execução em espaço de usuário. . 27 


\section{Capítulo 1}

\section{Introdução}

Este documento apresenta um guia de desenvolvimento para a plataforma TempOS, principalmente destinado a professores que ministram ou ministrarão disciplinas de Sistemas Operacionais ou afins utilizando esta plataforma.

A Plataforma TempOS é uma plataforma para ensino e treinamento no desenvolvimento de Sistemas Operacionais criada a partir do projeto de mestrado de Renê de Souza Pinto sob orientação do Prof. Dr. Francisco José Monaco, no Instituto de Ciências Matemáticas e de Computação da Universidade de São Paulo - USP, São Carlos - SP. Fundada na abordagem de aprendizado baseado em projeto (project-based learning), a plataforma é constituída de uma especificação de arquitetura de Sistema Operacional (SO) correspondente a arquitetura do Unix, cuja estrutura de implementação pode ser mapeada em uma sequência coerente aliada a um material didático e a um SO exemplo (simples, porém funcional), formando os componentes necessários para o desenvolvimento de um projeto de kernel em um curso que aborde o desenvolvimento de Sistemas Operacionais. O SO exemplo da plataforma é denominado TempOS, e segue a especificação da arquitetura apresentada.

A plataforma TempOS foi desenvolvida tendo em mente um curso que aborde o desenvolvimento de um kernel para a Arquitetura Intel x86 básico, porém funcional, a partir do zero. A implementação deve seguir a estrutura e o roteiro presentes na plataforma, utilizando o código do TempOS como apoio, referência ou até mesmo integralmente, para implementações que não sejam abordadas durante o curso. Adicionalmente, a plataforma também poderá ser utilizada em cursos teóricos, como referência para algoritmos ou detalhes de implementação.

Toda a plataforma (códigos, documentação, etc) está disponível no sítio http://wWw . tempos-project . org. O código do TempOS está licenciado pela GNU GPL v2 (Versão 2)[4]. Já o material didático é licenciado através das licenças da Creative Commons[2]. Atualizações da plataforma devem ser obtidas sempre do endereço oficial do projeto.

Este roteiro está divido em Tópicos de Estudo. Cada tópico deve ser apresentado de maneira sequencial, guiando o desenvolvimento de um kernel básico, a partir do zero. O kernel do TempOS é utilizado como referência, podendo também ser utilizado para sugestões de implementação ou integralmente em determinadas partes, quando a implementação não for de 
interesse do curso, por exemplo para determinados drivers de dispositivo.

A distribuição dos tópicos de estudo entre as aulas do curso fica a encargo do professor, que deverá fazer a divisão de acordo com a carga horária e tipo do curso a ser desenvolvido. Alguns tópicos poderão ser apresentados em apenas uma aula, outros exigirão maior atenção por abordarem subsistemas mais complexos do kernel, como o gerenciador de memória e a camada virtual de sistema de arquivos (VFS).

O professor também deve decidir qual o nível de detalhamento no desenvolvimento de cada tópico, o que estará relacionado com o nível de conhecimento dos alunos e com os objetivos do curso. Determinados tópicos, como especificações de sistemas, também podem ser abordados através de tarefas extra-aula, em casos onde o tempo da aula seja escasso dado todo o conteúdo a ser apresentado.

Este roteiro apresenta uma espécie de cronograma para um curso baseado na plataforma TempOS, não especificando detalhes de implementação uma vez que o professor é livre para decidir sobre como e com quais funcionalidades o kernel será desenvolvido, desde que esteja de acordo com a arquitetura definida na plataforma. Os tópicos de estudo abordados são:

\section{- Tópico 1:}

- Revisão sobre Sistemas Operacionais

- Apresentando a plataforma

* Arquitetura do kernel

* TempOS

- Ferramentas utilizadas

* gcc, gas, make, qemu, eclipse

* Como utilizar o TempOS

- Introdução a Arquitetura PC

- Introdução a Arquitetura Intel x86

- Prática 1: Sistema de BOOT

* Código de boot em assembly

* Especificação Multiboot e o GRUB

* Código de boot para Multiboot

\section{- Tópico 2:}

- Primeiro kernel

* setup.ld

* Bootando

* Escrevendo um driver para modo texto 
- Funções básicas da Biblioteca C

* Implementando printf e funções de string

- Linkando o kernel em 3GB

* Configurando a GDT

- Configurando as Interrupções

* Tabela IDT

* Atendimento das interrupções

* Escrevendo um driver para o PIC

- Tópico 3:

- Gerenciamento de Memória

* Gerenciamento de Memória na Arquitetura x86

* Entendendo o gerenciamento de memória do TempOS

* Iniciando as tabelas e diretórios de páginas

* Reconfigurando a GDT

- Projetando o alocador de memória alto nível

- Implementando o alocador de Memória

* Teste do alocador

\section{- Tópico 4:}

- Funções de I/O

- Escrevendo o driver para o controlador de teclado

- Sistema de Cache de Blocos

* Entendendo o sistema de Cache de Blocos do TempOS

* Projetando e implementando o sistema de Cache de Blocos

* Testando o sistema de Cache de Blocos

\section{- Tópico 5:}

- Temporizadores

* Implementando funções de alarmes e delays

- Threads de Kernel

* Entendendo o sistema de threads do TempOS

* Estruturas para threads e processos

* Criação, execução e manipulação de threads de kernel 
* Escalonamento

- Funções wait/wakeup

- Semáforos

- Tópico 6:

- Introdução a Especificação ATA

- Implementando o driver ATA genérico

* Entendendo o driver ATA do TempOS

* Enviando e recebendo comandos

* Atendendo interrupções

* Montando a lista de requisições de blocos

- Tópico 7:

- Introdução a Camada VFS (Sistema de Arquivos Virtual)

* Entendendo a camada VFS do TempOS

* Tabela de Drivers

- Sistema de montagem

* Entendendo o sistema de montagem do TempOS

- Especificação da tabela de partição

* Implementando o parser para a tabela de partições

- Especificação do Sistema de Arquivos EXT2

- Tópico 8:

- Funções do VFS

- Implementando o driver para o EXT2

- Tópico 9:

- Execução de tarefas

* Entendendo o chaveamento de contexto no TempOS

* Implementando o chaveamento para modo de usuário

* Integrando ao escalonador

* Carregando o init

- Tópico 10:

- Chamadas ao sistema 
* Entendendo o mecanismo de chamadas ao sistema no TempOS

* Implementando o mecanismo de chamadas ao sistema

* Executando chamadas ao sistema em modo usuário

* Implementando a chamada ao sistema write 


\section{Capítulo 2}

\section{Tópico de Estudo 1}

- Tópico 1:

- Revisão sobre Sistemas Operacionais

- Apresentando a plataforma

* Arquitetura do kernel

* TempOS

- Ferramentas utilizadas

* gcc, gas, make, qemu, eclipse

* Como utilizar o TempOS

- Introdução a Arquitetura PC

- Introdução a Arquitetura Intel x86

- Prática 1: Sistema de BOOT

* Código de boot em assembly

* Especificação Multiboot e o GRUB

* Código de boot para Multiboot

Este tópico aborda o início do curso. É esperado que os alunos já tenham cursado alguma disciplina de Sistemas Operacionais teórica, e portanto estejam familiarizados com conceitos básicos abordados em clássicos livros texto do assunto, tais como [10], [11] e [9].

O professor deve iniciar o curso com uma breve revisão sobre Sistemas Operacionais citando os tópicos teóricos para situar os alunos e focando principalmente na arquitetura monolítica, que será desenvolvida durante a disciplina. É fundamental que os alunos compreendam as figuras 2.1 e 2.2. Em seguida a Plataforma TempOS deve ser apresentada resumidamente, mostrando os objetivos, composição e a organização da mesma. A arquitetura do kernel (figura 2.3) deve ser explicada abordando-se cada subsistema de maneira geral. O SO TempOS também deve ser apresentado, se possível ilustrando a organização do código de acordo com os subsistemas do kernel. 
Os alunos devem estar cientes de que a arquitetura apresentada é a mesma do kernel Unix, se possível mostrar analogias com o kernel Linux.

O próximo passo compreende na apresentação das ferramentas que serão utilizadas: compiladores gcc e gas, utilitário de compilação make e emulador qemu. Caso o professor opte pelo uso de alguma IDE (recomendando-se neste caso a IDE eclipse), a mesma também deverá ser apresentada. É importante que os alunos saibam ao menos os comandos básicos de cada uma destas ferramentas para estarem aptos a trabalharem em seus códigos ou no código do TempOS, que também deve ser mostrado brevemente.

Este tópico é encerrado com uma prática a respeito do Sistema de Boot. A preparação para esta prática deve ser feita através de um breve resumo das arquiteturas PC e Intel x86. Em seguida um código de boot em Assembly deve ser feito pelo alunos. A prática é finalizada com a apresentação da especificação de Multiboot e com o desenvolvimento de um pequeno código de boot que utilize o GRUB para inicialização.

O conteúdo teórico desde tópico pode ser encontrado em [8], Capítulo 4.

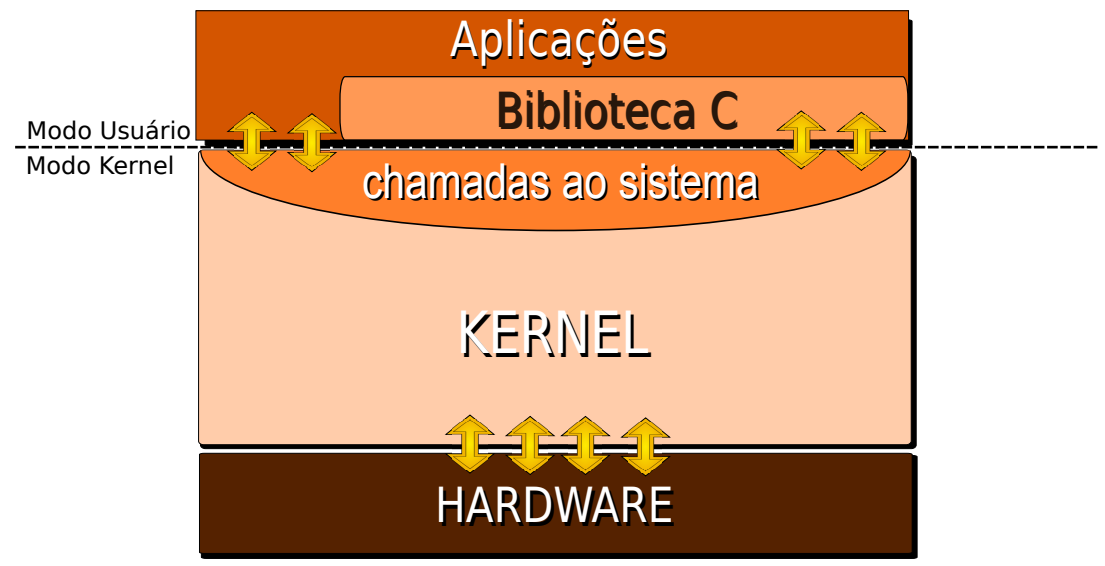

Figura 2.1: Sistema Operacional: Arquitetura Monolítica.

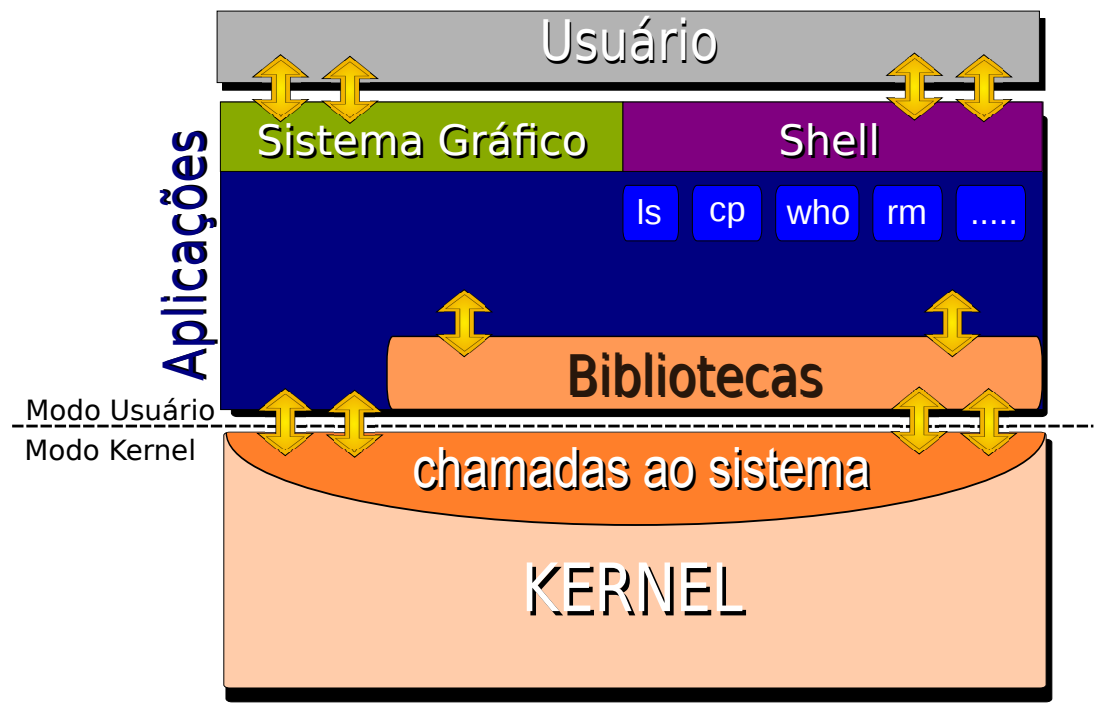

Figura 2.2: Visão geral do SO, mostrando as camadas envolvidas desde o usuário até o kernel. 


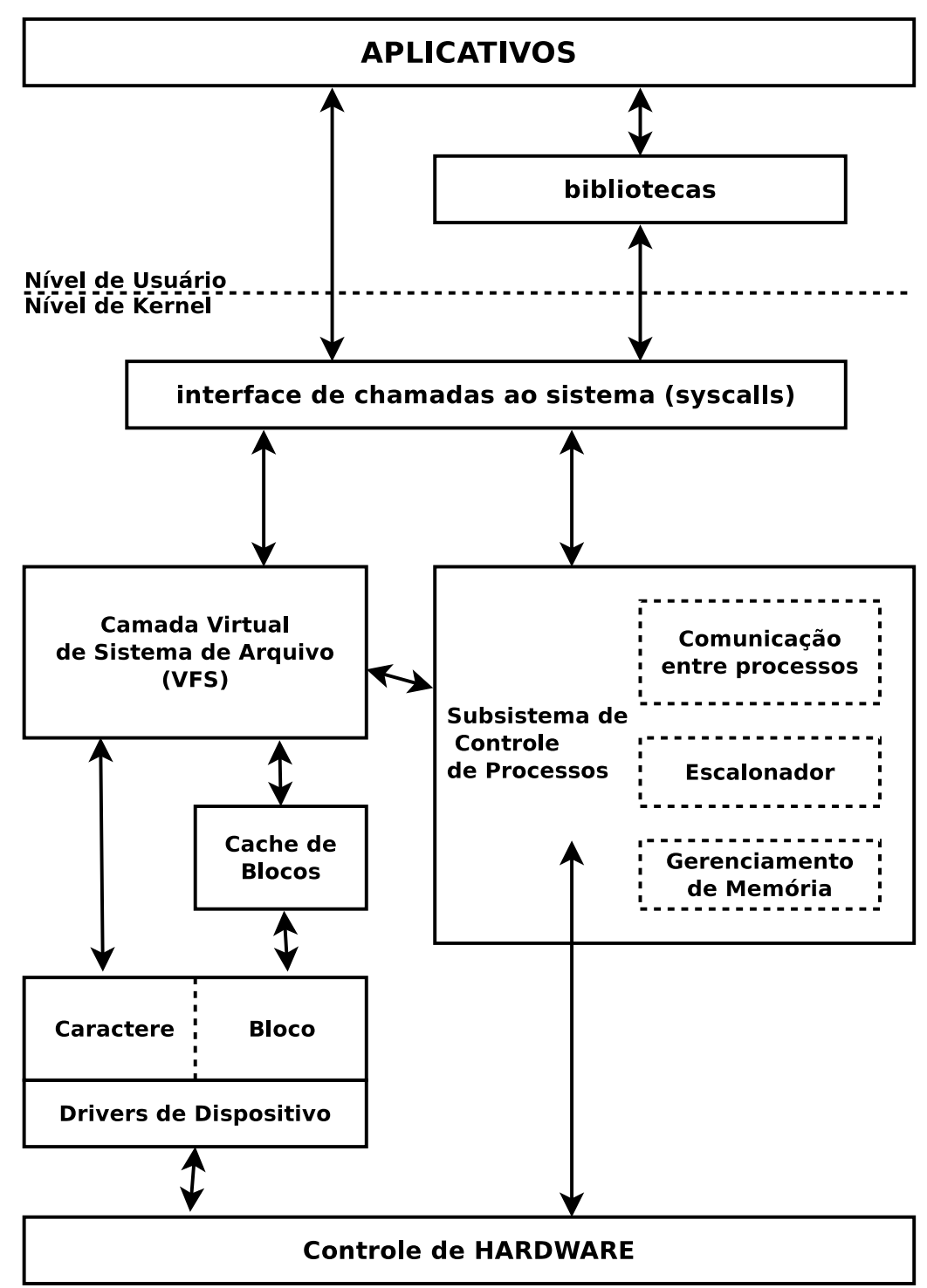

Nível de Kernel. Nívei de Hardware

\section{HARDWARE}

Figura 2.3: Arquitetura do kernel da plataforma TempOS. Figura adaptada de [1]. 


\section{Capítulo 3}

\section{Tópico de Estudo 2}

- Tópico 2:

- Primeiro kernel

* setup.ld

* Bootando

* Escrevendo um driver para modo texto

- Funções básicas da Biblioteca C

* Implementando printf e funções de string

- Linkando o kernel em 3GB

* Configurando a GDT

- Configurando as Interrupções

* Tabela IDT

* Atendimento das interrupções

* Escrevendo um driver para o PIC

O Tópico de Estudo 2 inicia a implementação do kernel a ser desenvolvido durante o curso. Após a introdução teórica e o contato com o código de boot da prática 1 os alunos estarão aptos a iniciar o desenvolvimento de um pequeno kernel em Linguagem C. O professor deve guiar, e se necessário implementar juntamente com os alunos, um pequeno kernel que seja inicializável pelo GRUB utilizando Assembly somente quando estritamente necessário, neste caso, no código Multiboot. É necessário que os alunos entendam a necessidade do arquivo de script do linkador (setup.ld), que descreve o endereçamento do arquivo executável (formato ELF $^{1}$ ). Nesta prática, os alunos também devem implementar um pequeno driver de vídeo modo texto, ou seja, apenas escrever funções que facilitem a escrita de caracteres no console (mapeando o valor ASCII e o atributo do caractere para o endereço correspondente da memória).

\footnotetext{
${ }^{1}$ Executable and Linkable Format
} 
Com o pequeno kernel implementado, os alunos estarão em um ambiente mais confortável para o desenvolvimento de funções básicas da biblioteca $C$. Esta etapa possuí baixo nível de dificuldade em relação as etapas anteriores, permitindo que alunos deficientes na primeira etapa sejam auxiliados pelo professor ou monitores e possam alcançar o restante da turma no conteúdo desenvolvido.

As funções básicas a serem implementadas serão definidas de acordo com o projeto a ser desenvolvido. Se o projeto estiver baseado no TempOS, estas funções podem ser encontradas no diretório lib do código fonte do kernel, compreendendo funções para tratamento de strings, listas encadeadas e conversão numérica. Tipos e estruturas de dados que serão utilizados em todo kernel também podem ser definidos nesta etapa do desenvolvimento.

Com as funções básicas implementadas, o próximo passo é aprofundar as explicações a respeito da Tabela GDT. Se o professor optou por apresentar com detalhes a Tabela GDT no código do boot, então a mesma pode ser diretamente configurada. Entretanto, aconselha-se que o detalhamento da GDT seja apresentado nesta etapa, pois os alunos já possuirão maior maturidade em relação a arquitetura e ao código do kernel. O artifício da GDT para "linkar" o kernel em 3GB antes do gerenciador de páginas da memória estar habilitado deve ficar muito bem claro, pois seu entendimento provavelmente não será trivial aos alunos.

É importante notar que a GDT não será preenchida com os segmentos de código e dados do usuário, apenas do kernel. A configuração completa será feita no Tópico de Estudo 3 (Capítulo 4).

O ultimo passo nesta etapa envolve a configuração da Tabela IDT para o atendimento de interrupções. A Tabela IDT deve ser detalhada aos alunos assim como o modo de funcionamento do PIC e sua ligação em cascata na Arquitetura PC. Uma maneira de testar rapidamente o atendimento das interrupções é através das exceções geradas pelo processador. Uma pequena função (que imprime uma mensagem) pode ser configurada para atender a interrupção 0 (Divisão por Zero), assim uma divisão por zero pode ser forçada no código para que ocorra a exceção e a interrupção seja gerada.

Informações detalhadas sobre o gerenciamento das interrupções podem ser obtidas nos manuais da Arquitetura Intel x86, especificamente o volume 3[7]. O código do TempOS também pode ser utilizado como exemplo. O arquivo $\operatorname{arch} / x 86 /$ idt.c contém toda configuração da IDT em Linguagem $\mathrm{C}$ e com estruturas de dados que representam cada campo da tabela seguindo a mesma nomenclatura dos manuais da Intel. 


\section{Capítulo 4}

\section{Tópico de Estudo 3}

- Tópico 3:

- Gerenciamento de Memória

* Gerenciamento de Memória na Arquitetura x86

* Entendendo o gerenciamento de memória do TempOS

* Iniciando as tabelas e diretórios de páginas

* Reconfigurando a GDT

- Projetando o alocador de memória alto nível

- Implementando o alocador de Memória

* Teste do alocador

O Tópico de Estudo 3 é uma das etapas mais difíceis no desenvolvimento do kernel, por isso, é preciso que os alunos estejam consolidados na disciplina. Antes de iniciar esta etapa o professor pode reservar uma aluna completa (ou parte dela) para sanar dúvidas e problemas provenientes das etapas anteriores.

Este tópico pode ser iniciado com uma breve revisão sobre tabelas de páginas nos Sistemas Operacionais. Entretanto, o foco principal, e que deve ser compreendido pelo alunos, é o mecanismo de tabelas e diretórios de páginas utilizado na Arquitetura Intel x86. O professor deve recomendar aos alunos a leitura pós aula (ou prévia) do Capítulo 3 (Protected-Mode Memory Management) do manual da Arquitetura Intel x86 volume 3[7] para colaborar no entendimento e na implementação do kernel.

Apesar da possibilidade de utilizar o código de diversos Sistemas Operacionais disponíveis como exemplo, recomenda-se fortemente que o professor detalhe o gerenciamento de memória no TempOS, dado a simplicidade do mesmo e o contato direto dos alunos com o código. Neste ponto, compreender pelo menos uma forma de implementação será fundamental ao alunos antes de implementarem seus próprios gerenciadores.

Somente após forte abordagem teórica e com exemplos é que a implementação pode ser iniciada. Os alunos já devem ter projetado seus alocadores de páginas física, inclusive a forma 
com a qual o kernel e as tabelas e diretórios de páginas serão armazenados na memória. Imediatamente após o sistema de paginamento ser iniciado a Tabela GDT deve ser adequadamente reconfigurada, contendo todos descritores de segmentos necessários (segmentos de dados e código do kernel e usuário, e ao menos um descritor TSS - Task State Segment). O arquivo $\operatorname{arch} / x 86 / g d t . c$ do código do TempOS contém a configuração completa da GDT.

Com o alocador de páginas físicas pronto, o próximo passo consiste no projeto e na implementação do alocador alto nível, ou seja, que será responsável por mapear as páginas físicas no espaço de endereço linear. Neste ponto o professor (se desejado) poderá abordar alguns alocadores já existentes, como por exemplo do Linux, FreeBSD ou do TempOS.

Quando finalizado, é imprescindível que o gerenciador de memória seja fortemente testado para que BUGs sejam encontrados e resolvidos, pois poderão afetar diretamente outros subsistemas do kernel durante e após o desenvolvimento, podendo dificultar a depuração do código.

Detalhes sobre a implementação do gerenciador de memória do TempOS podem ser encontrados em [8]. 


\section{Capítulo 5}

\section{Tópico de Estudo 4}

- Tópico 4:

- Funções de I/O

- Escrevendo o driver para o controlador de teclado

- Sistema de Cache de Blocos

* Entendendo o sistema de Cache de Blocos do TempOS

* Projetando e implementando o sistema de Cache de Blocos

* Testando o sistema de Cache de Blocos

Com o gerenciador de memória implementado os alunos terão maior liberdade de programação do kernel, podendo alocar e desalocar memória da mesma forma que um programa $\mathrm{C}$ em espaço de usuário.

Esta etapa possui baixo nível de dificuldade, tendo como objetivo prover um "descanso" e estimular novamente os alunos que tenham apresentado dificuldades na etapa anterior, de alto grau de complexidade. As funções de I/O a serem desenvolvidas consistem apenas em macros para as instruções IN e OUT da Arquitetura x86. O driver para o controlador de teclado é de fácil implementação e permitirá um contato mais direto dos alunos com o hardware, uma vez que o driver poderá ser testado facilmente através do teclado.

Quanto ao Sistema de Cache de Blocos, o professor poderá liberar os alunos para implementarem seus próprios algortimos de cache, entretanto, uma apresentação teórica do Sistemas de Cache do Unix (detalhado em [1]) ou do TempOS é fundamental para orientar os alunos em suas implementações.

Assim como o gerenciador de memória, o Sistema de Cache de Blocos também deve ser fortemente testado afim de não prejudicar o funcionamento da camada VFS, que será desenvolvida posteriormente. 


\section{Capítulo 6}

\section{Tópico de Estudo 5}

- Tópico 5:

- Temporizadores

* Implementando funções de alarmes e delays

- Threads de Kernel

* Entendendo o sistema de threads do TempOS

* Estruturas para threads e processos

* Criação, execução e manipulação de threads de kernel

* Escalonamento

- Funções wait/wakeup

- Semáforos

Nesta etapa os alunos já possuirão parte substancial do kernel implementado. É desejável que a etapa 4 esteja concluída pouco antes ou até a metade do curso, dado que a Camada VFS e o gerenciamento de tarefas (subsistemas complexos) ainda deverão ser implementados.

\subsubsection{Temporizadores}

A primeira parte da etapa 5 é simples e consiste na implementação de temporizadores, ou seja, funções de alarmes e delays. O kernel em desenvolvimento já possuirá suporte completo a interrupções, sendo necessário o desenvolvimento de um driver para o PIT (Programmable Interval Timer), que é de fácil implementação. No TempOS o driver completo para o PIT pode ser encontrado no arquivo $\operatorname{arch} / x 86 /$ kernel/i82C54.c. Após a implementação do driver, a contagem exata do tempo pode ser feita através da IRQ0, onde as interrupções do PIT serão geradas em uma frequência fixa, configurada pelo driver do mesmo.

No TempOS, a cada interrupção IRQ0 a variável global jiffies é incrementada, assim, cada unidade de jiffies representa uma certa quantidade de tempo transcorrido, que pode ser determinada pela frequência do PIT. A macro $H Z$ indica a frequência do PIT em Hertz, logo, se HZ é 
igual a 500, então cada incremento de jiffies ocorre a cada $\frac{1}{500}=0,002$ segundos ( 2 milisegundos).

Muitas vezes a frequência do PIT é considerada alta para a implementação de rotinas de delay. Neste caso, a implementação pode ser feita através de laços de repetição (for, while). $\mathrm{O}$ método consiste em uma "calibração" que irá contar quantas iterações são executadas em um determinado tempo (por exemplo, em uma iteração de jiffies). A partir do número de iterações pode se estimar quanto tempo o processador em que o SO está sendo executado leva para executar uma iteração do laço de repetição. Com base neste valor (denominado de BogoMips ${ }^{1}$ no kernel do Linux) é possível executar delays extremamente baixos, da ordem de microsegundos, por exemplo.

A forma com a qual os alarmes serão implementados (armazenados em listas, árvores, etc) deve ficar livre aos alunos. No TempOS, as funções de delays e alarmes são implementadas nos arquivos kernel/delay.c e kernel/timer.c, respectivamente.

\subsubsection{Threads de Kernel}

O objetivo principal da etapa 5 é o inicio do desenvolvimento do Subsistema de Controle de Processos através da implementação do suporte a threads de kernel. O primeiro passo consiste na definição de todas as estruturas de dados que serão utilizadas para armazenar as informações dos processos. Não é necessário que estas estruturas estejam completas, mas deve ficar claro aos alunos que as threads também serão vistas como processos normais pelo kernel.

É fundamental que uma boa revisão teórica seja feita pelo professor, principalmente nos detalhes de funcionamento das threads de kernel no TempOS. Detalhes da Arquitetura x 86 também devem ser abordados para que os alunos entendam o ambiente necessário para a execução e chaveamento das threads, mesmo que ainda estejam somente no espaço de kernel. Somente após a revisão teórica é o que os alunos implementarão as funções para criação, remoção e chaveamento de threads. Aconselha-se que estas funções sejam implementadas juntamente com o professor (dado a complexidade envolvida), exceto em turmas mais experientes, como por exemplo em cursos de pós-graduação.

Nesta etapa também será desenvolvido o escalonador do kernel. Como threads e processos serão tratados da mesma forma, não será necessário alterar o código do escalonador quando os processo de usuário forem implementados, somente funções dependentes de arquitetura serão alteradas.

Quando as funções para chaveamento de threads estiverem implementadas e testadas, o desenvolvimento do escalonador apresentará menor complexidade. Aconselha-se ao professor que os alunos sejam estimulados a desenvolverem um ou mais algoritmos de escalonamento, permitindo até mesmo que uma comparação entre os mesmos seja executada.

Para o funcionamento completo das threads, as funções de sleep/wakeup deverão ser im-

\footnotetext{
${ }^{1}$ Para maiores informações, consulte http: //en.wikipedia.org/wiki/BogoMips.
} 
plementadas nesta etapa. Maiores detalhes sobre o funcionamento destas funções podem ser obtidos em [8]. A tabela 6.1 contém os arquivos do código fonte do TempOS que implementam o gerenciamento de threads e processos, assim como as funções implementadas por cada um deles.

Tabela 6.1: Arquivos do código fonte do TempOS para o gerenciamento de threads e processos.

\begin{tabular}{|c|c|c|}
\hline Arquivo & Funções & Descrição \\
\hline kernel/thread.c & $\begin{array}{l}\text { kernel_thread_create, } \\
\text { kernel_thread_exit, } \\
\text { kernel_thread_wait }\end{array}$ & $\begin{array}{l}\text { Funções para manipulação das thre- } \\
\text { ads de kernel. }\end{array}$ \\
\hline kernel/sched.c & $\begin{array}{l}\text { init_scheduler, } \\
\text { do_schedule, sche- } \\
\text { dule }\end{array}$ & Escalonador do kernel. \\
\hline $\operatorname{arch} / \mathrm{x} 86 /$ kernel/task.c & $\begin{array}{l}\text { arch_init_scheduler, } \\
\text { setup_task, swtich_to }\end{array}$ & $\begin{array}{l}\text { Funções para configuração das th- } \\
\text { reads e processos. Dependentes de } \\
\text { arquitetura. }\end{array}$ \\
\hline $\operatorname{arch} / \mathrm{x} 86 /$ task.S & $\begin{array}{l}\text { initial_task, } \\
\text { task_switch_to }\end{array}$ & $\begin{array}{l}\text { Funções baixo nível para criação e } \\
\text { chaveamento de processos. }\end{array}$ \\
\hline
\end{tabular}

A etapa 5 é finalizada com a implementação de semáforos. Uma forma simples de implementar a operação dos semáforos é através da desabilitação/habilitação das interrupções. O professor pode explorar métodos mais robustos, entretanto, esta é uma implementação rápida frente ao conteúdo do curso. 


\section{Capítulo 7}

\section{Tópico de Estudo 6}

- Tópico 6:

- Introdução a Especificação ATA

- Implementando o driver ATA genérico

* Entendendo o driver ATA do TempOS

* Enviando e recebendo comandos

* Atendendo interrupções

* Montando a lista de requisições de blocos

Ao alcançarem esta etapa os alunos já possuirão um kernel avançado, com gerenciador de memória, suporte a threads, escalonador e funções de sleep/wakeup e semáforos implementadas. A partir deste ponto, o curso deve partir para a abordagem dos sistemas de arquivos através da camada VFS.

Esta etapa compreende na implementação do driver para dispositivos PATA ${ }^{1}$, especificamente discos rígidos (IDE). Este driver será o responsável pela leitura e escrita dos setores dos discos da máquina, que serão acessados posteriormente pela camada VFS.

O desenvolvimento desta etapa começa com uma descrição teórica da especificação ATA para os alunos. É importante citar as diferenças ATA/ATAPI, os principais pacotes de comandos e principalmente como funciona o modo PIO para acessar as diferentes controladoras PATA presentes nos computadores atuais. O modo PIO será utilizado por ser "genérico", funcionando na grande maioria das controladoras. Entretanto, os alunos devem estar cientes de que problemas de compatibilidade podem ocorrer, sendo assim, testar o driver no emulador (QEMU) é fundamental antes de efetuar testes no hardware real.

Após a introdução teórica a implementação do driver pode ser iniciada. É aconselhado que um estudo no código do driver ATA do TempOS (arquivo drivers/block/ata_generic.c) seja

\footnotetext{
${ }^{1} \mathrm{O}$ professor pode optar pela implementação de um driver SATA (padrão mais moderno, utilizados pelos discos rígidos atuais). Entretanto, este driver é mais complexo em relação ao driver PATA, pois o barramento PCI deverá ser acessado, o que poderá demandar maior tempo de desenvolvimento, prejudicando o restante do curso.
} 
feito para que os alunos possam observar a estrutura do driver e funções que o mesmo deverá implementar.

É muito importante que o driver funcione utilizando interrupções, ou seja, não utilize espera ocupada para aguardar a finalização de uma operação (escrita ou leitura). Apesar da implementação ser muito mais simples, utilizar espera ocupada nesta parte do kernel pode degradar consideravelmente a performance, além de ocultar dos alunos uma implementação real utilizada em praticamente todos os Sistemas Operacionais profissionais.

O tratamento das requisições de leitura/escrita de blocos (setores) no dispositivos pode ser feito nesta camada ou em uma camada superior. O TempOS trata as requisições no próprio driver ATA montando uma lista de requisições que segue o algoritmo FIFO para o atendimento, ou seja, as requisições serão atendidas na ordem de chegada. Algoritmos mais elaborados, como o do Elevador, podem ser implementados pelos alunos. 


\section{Capítulo 8}

\section{Tópico de Estudo 7}

- Tópico 7:

- Introdução a Camada VFS (Sistema de Arquivos Virtual)

* Entendendo a camada VFS do TempOS

* Tabela de Drivers

- Sistema de montagem

* Entendendo o sistema de montagem do TempOS

- Especificação da tabela de partição

* Implementando o parser para a tabela de partições

- Especificação do Sistema de Arquivos EXT2

A camada VFS é o ultimo grande subsistema a ser implementado no curso. Assim como os subsistemas complexos anteriores, uma forte revisão teórica deve ser aplicada antes do início do desenvolvimento. Não só a camada VFS do TempOS, mas também a do Linux podem ser abordadas como exemplo. É importante que os alunos entendam o funcionamento da tabela de drivers e os arquivos de dispositivos, dotados de major e minor numbers, ou números maiores e menores, em tradução literal do inglês. Este entendimento é crucial, pois representa a maior característica dos sistemas Unix, que é a abstração de todo o hardware da máquina em arquivos.

$\mathrm{O}$ sistema de montagem também deve ser detalhado aos alunos. O diretório $f s$ do código fonte do TempOS contém toda camada VFS e o driver para o sistema de arquivos EXT2.

Para acessar os sistemas de arquivos do disco rígido será necessário que o kernel reconheça a tabela de partições do mesmo. O parser da tabela pode ser implementado nesta etapa, antes da implementação das funções do VFS. O parser do TempOS (implementado no arquivo $f_{s} /$ partition.c) reconhece partições primárias e estendidas, entretanto, somente o reconhecimento de partições primárias já é suficiente para o funcionamento da camada VFS, desde que a partição acessada seja primária. 
Esta etapa é finalizada com a apresentação da especificação do sistema de arquivos EXT2. Os alunos podem estudar tanto o código do kernel como de ferramentas como o e2fsprogs ${ }^{1}$.

O intuito desta etapa é fornecer toda a básica teórica necessária para a implementação do VFS, que será feita na próxima etapa. Maiores informações podem ser obtidas em [8].

\footnotetext{
${ }^{1}$ Disponível em http://e2fsprogs. sourceforge.net/ext2 .html
} 


\section{Capítulo 9}

\section{Tópico de Estudo 8}

- Tópico 8:

- Funções do VFS

- Implementando o driver para o EXT2

O Tópico de Estudo 8 constitui a implementação da camada VFS. Toda a teoria necessária, especificações, estruturas, funções, etc devem ser abordados na etapa anterior. O professor pode optar pelo projeto de uma nova camada VFS, porém, é aconselhado que o desenvolvimento seja baseado nas camadas VFS do TempOS ou do Linux, permitindo que os alunos tenham um contato prévio (na etapa anterior) e portanto estejam mais familiarizados com a mesma, além de permitir reutilização de código de drivers de sistemas de arquivos (por exemplo, EXT2) quando não houver tempo hábil no curso para tal implementação.

O sistema de arquivo genérico do VFS definido pelo TempOS é extremamente semelhante ao EXT2, o que facilitará o desenvolvimento do driver para o mesmo. A figura 9.1 apresenta o Superbloco do sistema de arquivo do VFS (TempOS VFS).

A tabela de i-nodes é criada na memória através de uma lista encadeada. A figura 9.2 mostra a estrutura do $i$-node no TempOS VFS. O tamanho da tabela é predefinido no código e determina a quantidade máxima de arquivos abertos ao mesmo tempo, pois quando um arquivo é aberto o VFS chama o driver específico para ler o $i$-node do dispositivo para um $i$-node da tabela. Consequentemente, alterações feitas neste $i$-node deverão ser sincronizadas com o $i$ node presente no sistema de arquivo. 


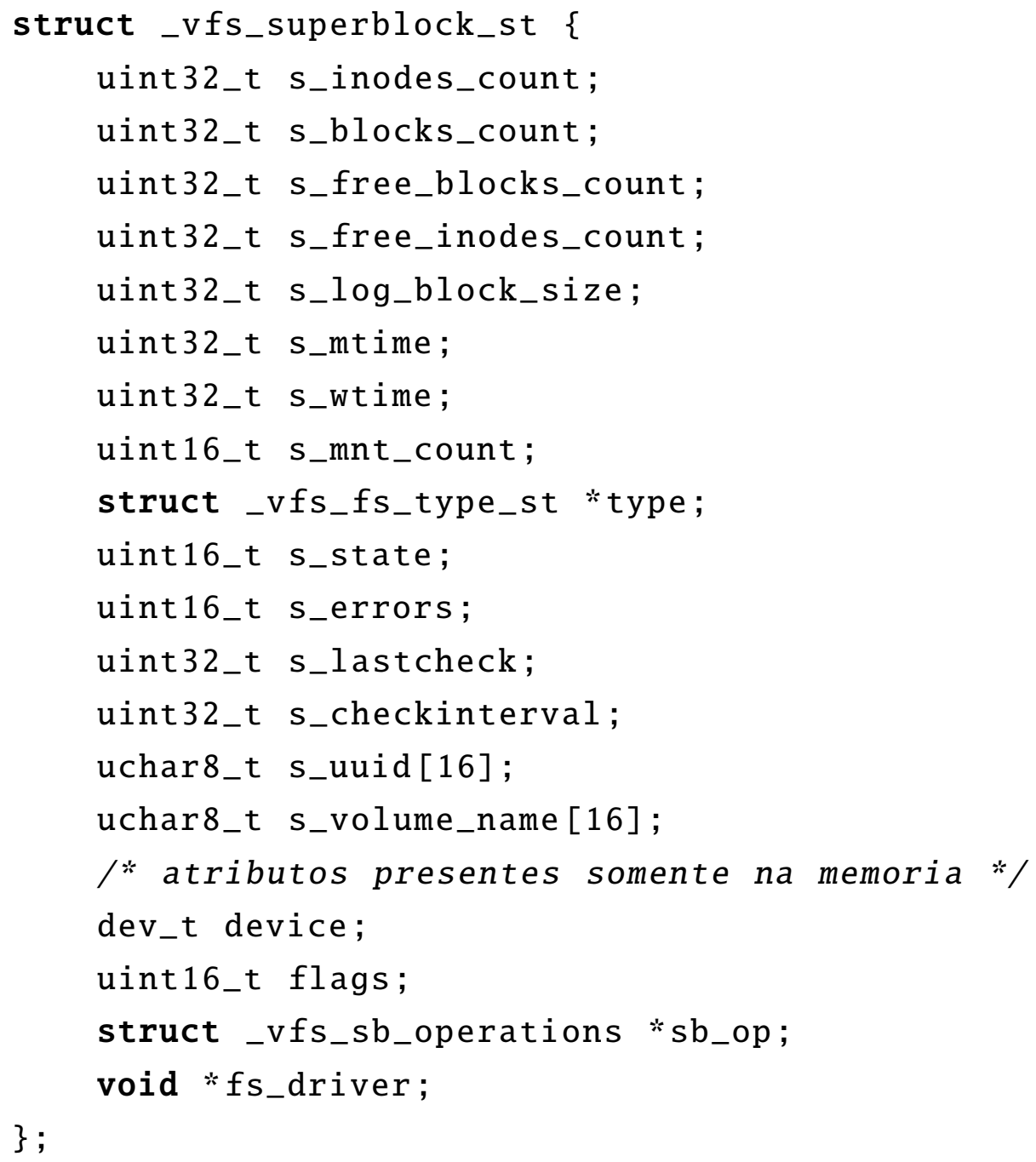

Figura 9.1: TempOS VFS: Estrutura do Superbloco. 


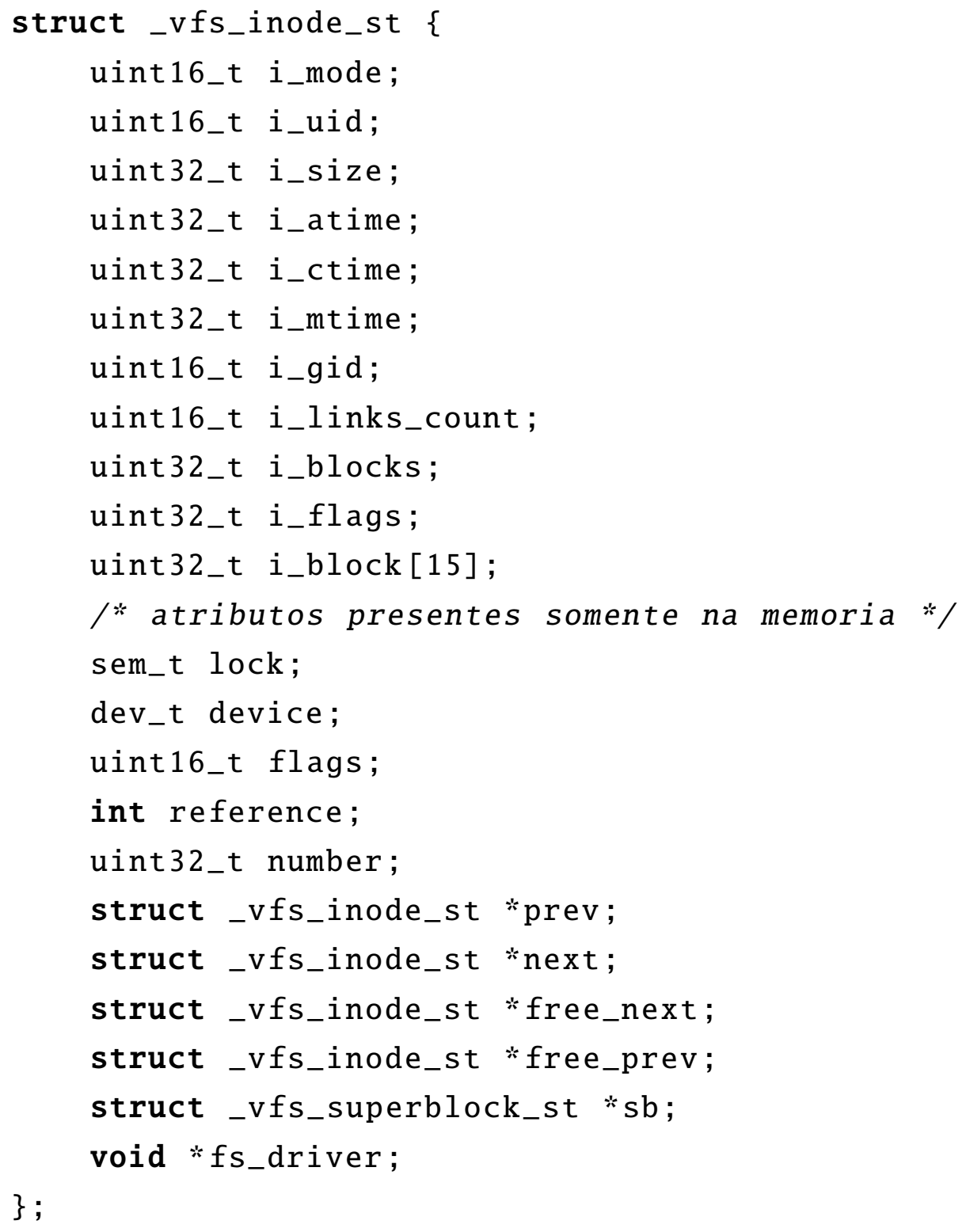

Figura 9.2: TempOS VFS: Estrutura do $i$-node.

A tabela de $i$-nodes possui funcionamento semelhante aos blocos em cache no sistema. Entretanto, sua implementação é mais fácil dado que não há necessidade de um vetor de hash, pois o apontamento ao i-node é direto (a partir da entrada de diretório). Entretanto, o processo de abertura de um arquivo envolve buscar pelo $i$-node do mesmo e verificar se há alguma entrada disponível na tabela de $i$-nodes do sistema para que o mesmo seja carregado para memória. Quando o arquivo é fechado, o $i$-node é gravado de volta no dispositivo (caso tenha sido modificado) e a entrada é liberada.

A figura 9.3 mostra a estrutura de cada entrada na tabela de montagem. 


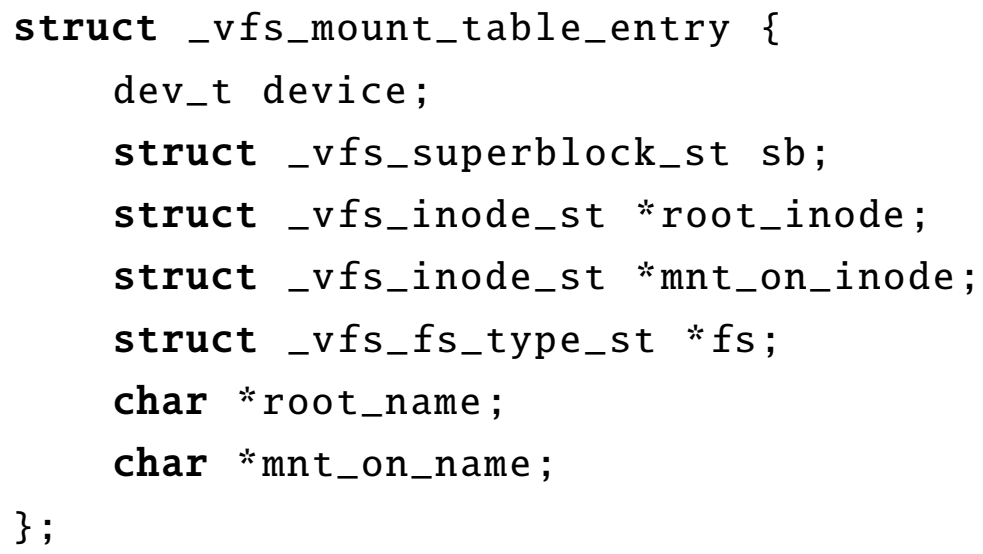

Figura 9.3: TempOS VFS: Estrutura da tabela de montagem.

A tabela 9.1 contém as funções que devem ser implementadas pelo driver.

Tabela 9.1: Funções implementadas por um driver de sistema de arquivo.

\begin{tabular}{|l|l|}
\hline Função & Descrição \\
\hline get_inode & Lê um $i$-node do sistema de arquivo. \\
\hline write_inode & Atualiza o $i$-node no sistema de arquivo. \\
\hline put_inode & Escreve o $i$-node no sistema de arquivo e libera o $i$-node da memória. \\
\hline alloc_inode & Aloca um novo $i$-node. \\
\hline free_inode & $\begin{array}{l}\text { Libera um } i \text {-node e todos os blocos apontados pelo mesmo (utilizado na } \\
\text { remoção de um arquivo ou diretório). }\end{array}$ \\
\hline write_super & Atualiza o Superbloco no sistema de arquivo. \\
\hline get_fs_block & Lê um bloco de dados do sistema de arquivo. \\
\hline check_fs_type & $\begin{array}{l}\text { Responde se o sistema de arquivo fornecido é do tipo implementado pelo } \\
\text { driver. }\end{array}$ \\
\hline get_sb & Lê o Superbloco do sistema de arquivo. \\
\hline
\end{tabular}

A partir das funções implementadas pelos drivers de sistema de arquivo, o VFS implementa funções para o TempOS VFS que consequentemente funcionarão para qualquer sistema de arquivo que tenha o driver correspondente implementado. A tabela 9.2 contém as principais funções, que são fundamentais para a implementação das chamadas ao sistema open(), read(), write() e close(), que manipulam os arquivos. 
Tabela 9.2: Funções implementadas pela camada VFS.

\begin{tabular}{|l|l|}
\hline Função & Descrição \\
\hline vfs_mount_root & $\begin{array}{l}\text { Monta a raiz do sistema a partir do dispositivo fornecido (major e minor } \\
\text { number). }\end{array}$ \\
\hline vfs_mount & Monta um dispositivo em um ponto de montagem (diretório). \\
\hline vfs_iget & Lê um $i$-node do sistema de arquivo e o insere na tabela de $i$-nodes. \\
\hline vfs_bmap & $\begin{array}{l}\text { Converte a posição do conteúdo de um arquivo no bloco de dados em que a } \\
\text { mesma se encontra. }\end{array}$ \\
\hline vfs_namei & $\begin{array}{l}\text { Retorna o } i \text {-node correspondente a partir de um caminho, por exemplo, “/ho- } \\
\text { me/rsp/olamundo.txt” retorna o } i \text {-node do arquivo } \text { olamundo.txt. }\end{array}$ \\
\hline
\end{tabular}




\section{Capítulo 10}

\section{Tópico de Estudo 9}

- Tópico 9:

- Execução de tarefas

* Entendendo o chaveamento de contexto no TempOS

* Implementando o chaveamento para modo de usuário

* Integrando ao escalonador

* Carregando o init

Esta etapa é a fase final do curso. O kernel em desenvolvimento estará próximo de tornar-se funcional, conseguindo carregar um arquivo binário do disco e colocá-lo em execução em espaço de usuário. As principais funcionalidades necessárias já estarão implementadas, como as funções do VFS para carregar o arquivo para memória e o escalonador para chavear os processos. A função para criar o processo inicial (init) deve ser implementada, e será responsável por criar e alocar tabelas e diretórios de páginas e as estruturas do processo. O código do chaveamento de contexto deve ser alterado para que processos de usuário sejam executados em espaço de usuário. Este código é totalmente dependente da Arquitetura x86, portanto, é aconselhado que o professor apresente aos alunos o chaveamento de contexto implementado no TempOS.

O TempOS ainda não reconhece formatos de arquivos executáveis, como $\mathrm{ELF}^{1}$ ou $\mathrm{COFF}^{2}$, possuindo suporte apenas a arquivos executáveis binários puro. Logo, os programas de usuário devem ser compilados com um endereço base pré-definido. No TempOS, o endereço escolhido foi 0xC0000C, ou seja, 12MB + 12 Bytes. Quando um bloco de memória é alocado, o alocador do TempOS preenche os primeiros 12 bytes com informações da alocação, portanto se o bloco de memória que contém o programa executável for alocado no endereço lógico 0xC00000 (12MB), o código binário estará, de fato, no endereço 0xC0000C (12MB +12 bytes), pois o início do bloco conterá informações da alocação.

O primeiro programa de usuário deve ser implementado apenas para testar a execução em espaço de usuário, pois o mecanismo de chamadas ao sistema será implementado somente na

\footnotetext{
${ }^{1}$ http://en.wikipedia.org/wiki/Executable_and_Linkable_Format

${ }^{2}$ http://en.wikipedia.org/wiki/COFF
} 
próxima etapa do desenvolvimento. Como sugestão, os alunos podem implementar o programa da Figura 10.1, cuja função é simplesmente mover o valor 0x85 para o registrador EAX e entrar em um loop infinito.

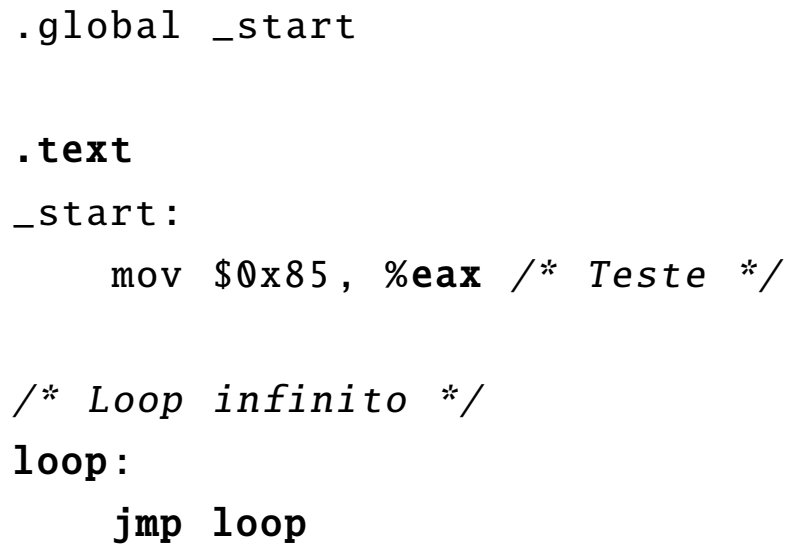

Figura 10.1: Código assembly do programa init para testar execução em espaço de usuário.

A execução correta do programa pode ser verificada através de emulação, depurando-se o valor do registrador EAX (que deve conter 0x85) e dos valores de segmento de código e dados, que devem alternar entre os valores dos segmentos de kernel e usuário juntamente com os respectivos níveis de privilégio. Assim, os valores dos registradores CS e DS devem ser 0x08 e 0x10 para kernel e 0x1B e 0x23 para usuário.

O código da Figura 10.1 pode ser compilado através dos comandos:

\# as --32 init.s -o init.o

\# ld init.o -melf_i386 -Ttext=C0000C --oformat=binary -o init 


\section{Capítulo 11}

\section{Tópico de Estudo 10}

\section{- Tópico 10:}

- Chamadas ao sistema

* Entendendo o mecanismo de chamadas ao sistema no TempOS

* Implementando o mecanismo de chamadas ao sistema

* Executando chamadas ao sistema em modo usuário

* Implementando a chamada ao sistema write

Esta etapa marca o fim do curso. Os alunos que obtiverem êxito até a etapa anterior terão implementado um kernel simples, mas que abrange os principais subsistemas de um Sistema Operacional Unix, e apesar da simplicidade em termos de funcionalidade, o kernel estará apto a executar as tarefas básicas de um SO, inclusive ler arquivos do disco e executar programas em espaço de usuário, gerenciando o hardware básico da máquina e provendo um ambiente aos aplicativos.

O Tópico de Estudo 10 implementa o mecanismo de chamadas ao sistema e ao menos uma chamada que pode ser executada pelos aplicativos. O intuito é fechar o desenvolvimento permitindo a execução de chamadas ao sistema pelos aplicativos de usuário. Ficará a critério do professor definir quantas e quais chamadas serão implementadas. Aconselha-se que ao menos a chamada write seja implementada parcialmente para que os alunos possam testa-lá diretamente a partir dos programas de usuário. Cursos mais extensos, especialmente de pós-graduação, poderão abordar a implementação de mais chamadas e até o port da biblioteca $\mathrm{C}$ para o kernel desenvolvido.

O mecanismo de chamada ao sistema pode funcionar através de instruções especiais do processador ou através de interrupções. Este último é o mecanismo clássico, e se possível, que deve ser abordado no curso.

O TempOS utiliza a interrupção 0x85 para chamadas ao sistema. Assim como no Linux, o registrador EAX deve conter o número da chamada a ser efetuada e os registradores EBX, ECX e EDX devem conter os argumentos da mesma. O arquivo arch/x86/kernel/sys_enter.S 
implementa este mecanismo e as chamadas desenvolvidas estão contidas no diretório kernel. A chamada write foi parcialmente implementada, a string passada como parâmetro é impressa no console.

Nesta etapa a implementação do mecanismo pode ser guiada pelo professor, entretanto, é esperado que os alunos já estejam aptos a implementarem sozinhos esta ultima funcionalidade. Como prática final, uma ou mais chamadas ao sistema devem ser implementadas e testadas a partir dos aplicativos executados em espaço de usuário. 


\section{Capítulo 12}

\section{Notas finais}

Os dez tópicos de estudos apresentados abrangem todos os subsistemas descritos pela arquitetura da Plataforma TempOS. Os alunos que completarem com êxito todas as etapas do desenvolvimento possuirão uma sólida base de conhecimento que facilitará o contato com códigos de Sistemas Operacionais modernos baseados no Unix, como o Linux ou FreeBSD, por exemplo. Além do contato direto com o hardware básico da Arquitetura PC, a experiência de implementação de drivers de dispositivos poderá ser agregada a implementações mais complexas, que exijam conhecimento mais especializado.

Extensões da Plataforma TempOS também podem ser trabalhadas, como o desenvolvimento de mais drivers de dispositivos, pilhas de Rede, USB, implementação de mais chamadas ao sistema (do padrão POSIX) assim port de bibliotecas, utilitários e do próprio kernel, para outras arquiteturas. 


\section{Bibliografia}

[1] Maurice J. Bach. The design of the Unix Operating System. Prentice-Hall, 1986.

[2] Creative Commons. http://creativecommons.org/. Último acesso em 14 de Agosto de 2012.

[3] Filesystem Hierarchy Standard Group. Filesystem Hierarchy Standard, 2004.

[4] GNU General Public License, version 2. http://www.gnu.org/licenses/old-licenses/gpl2.0.html. Último acesso em 14 de Agosto de 2012.

[5] The Open Group IEEE. IEEE Std 1003.1-2001, 2004.

[6] Intel. Intel Architecture Software Developer's Manual V1, 1999.

[7] Intel. Intel Architecture Software Developer's Manual V3, 1999.

[8] Renê de Souza Pinto. Uma plataforma para ensino e treinamento em desenvolvimento de sistemas operacionais. Master's thesis, Instituto de Ciências Matemáticas e de Computação, ICMC-USP, 2012.

[9] W. Stallings and G.K. Paul. Operating systems: internals and design principles, volume 148. Prentice Hall, 1998.

[10] Andrew S. Tanenbaum. Sistemas Operacionais: projeto e implementação. Bookman, 2000.

[11] A.S. Tanenbaum. Modern operating systems, volume 2. Prentice Hall New Jersey, 1992. 


\section{TempOS}

0.1

Generated by Doxygen 1.7.6.1

Fri Aug 242012 10:45:12 


\section{Contents}

1 Todo List 2

2 Data Structure Index 2

2.1 Data Structures . . . . . . . . . . . . . . . . . . . . 2

3 File Index 2

3.1 File List . . . . . . . . . . . . . . . . . . . . . . . 2

4 Data Structure Documentation 3

$4.1 \quad$ c_llist Struct Reference . . . . . . . . . . . . . . . . . . . 3

4.1 .1 Detailed Description . . . . . . . . . . . . . . . 4

4.1 .2 Field Documentation . . . . . . . . . . . . . . . . . 4

4.2 _llist Struct Reference . . . . . . . . . . . . . . . . . . . . . . . 4

4.2.1 Detailed Description . . . . . . . . . . . . . . 5

4.2 .2 Field Documentation . . . . . . . . . . . . . . 5

5 File Documentation 5

5.1 bhash.c File Reference . . . . . . . . . . . . . . . . . . . 5

5.1 .1 Function Documentation . . . . . . . . . . . . . . . 6

5.2 binfmt_elf32.c File Reference . . . . . . . . . . . . . . . . . . . 12

5.3 clinkedl.c File Reference . . . . . . . . . . . . . . . . . . . . 13

5.3.1 Function Documentation . . . . . . . . . . . . . . . . . 14

5.4 cmdline.c File Reference . . . . . . . . . . . . . . . . . . . . . . . 16

5.4 .1 Define Documentation . . . . . . . . . . . . . 17

5.4.2 Function Documentation . . . . . . . . . . . . . . 17

5.4 .3 Variable Documentation . . . . . . . . . . . . . 18

5.5 config.h File Reference . . . . . . . . . . . . . . . . . . . . . . 19

5.5 .1 Define Documentation . . . . . . . . . . . . . . . . 19

5.6 ctype.c File Reference . . . . . . . . . . . . . . . . . . . . . . . . . . . 20

5.6.1 Function Documentation ................. 20

5.7 ctype.h File Reference . . . . . . . . . . . . . . . . . . . . . . 22

5.7.1 Function Documentation . . . . . . . . . . . . . . . . 23

5.8 delay.c File Reference . . . . . . . . . . . . . . . . . . . . . . . . . 25

5.8.1 Function Documentation . . . . . . . . . . . . . . . . 25 
5.8 .2 Variable Documentation . . . . . . . . . . . . . . . . 26

5.9 devices.c File Reference . . . . . . . . . . . . . . . . . 27

5.9 .1 Function Documentation $\ldots \ldots \ldots$

5.9 .2 Variable Documentation . . . . . . . . . . . . . . . . . 28

5.10 execve.c File Reference . . . . . . . . . . . . . . . . . . . 28

5.10 .1 Function Documentation . . . . . . . . . . . . . . . . . . . 29

5.11 exit.c File Reference . . . . . . . . . . . . . . . . . . . . . . . 29

5.11 .1 Function Documentation . . . . . . . . . . . . . . . 30

5.12 fork.c File Reference . . . . . . . . . . . . . . . . . . . 30

5.12 .1 Function Documentation . . . . . . . . . . . . . . . . . 31

5.12 .2 Variable Documentation . . . . . . . . . . . . . . . 33

5.13 kernel.c File Reference . . . . . . . . . . . . . . . . . . . . . . 33

5.13.1 Function Documentation . . . . . . . . . . . . . . . . . 33

5.13 .2 Variable Documentation . . . . . . . . . . . . . . . 37

5.14 linkedl.c File Reference . . . . . . . . . . . . . . . . . . . 37

5.14.1 Function Documentation . . . . . . . . . . . . . . . . 38

5.15 linkedl.h File Reference . . . . . . . . . . . . . . . . . . . . . 39

5.15 .1 Define Documentation . . . . . . . . . . . . . . . . . 41

5.15 .2 Typedef Documentation . . . . . . . . . . . . . . . . . . . 41

5.15 .3 Function Documentation . . . . . . . . . . . . . . . . 41

5.15 .4 Variable Documentation . . . . . . . . . . . . . . 43

5.16 mount.c File Reference . . . . . . . . . . . . . . . . . . . . 43

5.16 .1 Function Documentation . . . . . . . . . . . . . . 43

5.17 namei.c File Reference . . . . . . . . . . . . . . . . . . . 44

5.17 .1 Function Documentation . . . . . . . . . . . . . . . . 45

5.18 partition.c File Reference . . . . . . . . . . . . . . . . . . 47

5.18 .1 Function Documentation $\ldots \ldots \ldots$. . . . . . . . . 47

5.19 printf.c File Reference . . . . . . . . . . . . . . . . . . . . . . 49

5.19 .1 Define Documentation . . . . . . . . . . . . . . . . . . 50

5.19 .2 Function Documentation . . . . . . . . . . . . . . . 50

5.20 read.c File Reference . . . . . . . . . . . . . . . . . . 53

5.20 .1 Function Documentation . . . . . . . . . . . . . . . . . 53

5.21 sched.c File Reference . . . . . . . . . . . . . . . . . . . . 53

5.21 .1 Function Documentation . . . . . . . . . . . . . . . . . 54 
5.21 .2 Variable Documentation . . . . . . . . . . . . . . . 55

5.22 semaphore.c File Reference $\ldots \ldots \ldots \ldots$

5.22 .1 Function Documentation . . . . . . . . . . . . . . 56

5.23 semaphore.h File Reference . . . . . . . . . . . . . . . . . 58

5.23 .1 Typedef Documentation . . . . . . . . . . . . . . . . . . 59

5.23 .2 Function Documentation . . . . . . . . . . . . . . . . . 59

5.24 stdlib.c File Reference . . . . . . . . . . . . . . . . . . . . . . 60

5.24 .1 Function Documentation . . . . . . . . . . . . . 60

5.25 stdlib.h File Reference . . . . . . . . . . . . . . . . . . . . . 61

5.25 .1 Define Documentation . . . . . . . . . . . . . . . . . 62

5.25 .2 Function Documentation . . . . . . . . . . . . . . . . . 62

5.26 string.c File Reference . . . . . . . . . . . . . . . 63

5.26 .1 Function Documentation . . . . . . . . . . . . . . . 64

5.27 string.h File Reference . . . . . . . . . . . . . . . . . 65

5.27 .1 Function Documentation . . . . . . . . . . . . . . 66

5.28 syscall.c File Reference . . . . . . . . . . . . . . . . . . 67

5.28 .1 Variable Documentation . . . . . . . . . . . . . . . . 67

5.29 thread.c File Reference . . . . . . . . . . . . . . . . . 68

5.29 .1 Function Documentation . . . . . . . . . . . . . . . 69

5.30 timer.c File Reference . . . . . . . . . . . . . . . . . . 70

5.30 .1 Function Documentation $\ldots \ldots \ldots$. . . . . . . 71

5.30 .2 Variable Documentation . . . . . . . . . . . . . . . . . 72

5.31 unistd.h File Reference . . . . . . . . . . . . . . . . . 73

5.31 .1 Typedef Documentation . . . . . . . . . . . . . . . . 74

5.32 vfs.c File Reference . . . . . . . . . . . . . . . . . . . . . . . 74

5.32 .1 Function Documentation . . . . . . . . . . . . . . . . . . 75

5.32 .2 Variable Documentation . . . . . . . . . . . . . . 78

5.33 wait.c File Reference . . . . . . . . . . . . . . . . . . . . 79

5.33 .1 Function Documentation . . . . . . . . . . . . . . . . . 79

5.33 .2 Variable Documentation . . . . . . . . . . . . . . . . 81

5.34 write.c File Reference . . . . . . . . . . . . . . . . . . . . 81

5.34.1 Function Documentation . . . . . . . . . . . . . . . . . . 82 


\section{Todo List}

Global kprintf (const char $*$ format,...)

Implement "TYPE" of messages.

\section{Data Structure Index}

\subsection{Data Structures}

Here are the data structures with brief descriptions:

C_Ilist 3

_llist

\section{File Index}

\subsection{File List}

Here is a list of all files with brief descriptions:

$\begin{array}{ll}\text { bhash.c } & 5\end{array}$

binfmt_elf32.c 12

$\begin{array}{lr}\text { clinkedl.c } & 13\end{array}$

$\begin{array}{lr}\text { cmdline.c } & 16\end{array}$

$\begin{array}{lr}\text { config.h } & 19\end{array}$

$\begin{array}{lr}\text { ctype.c } & 20\end{array}$

$\begin{array}{ll}\text { ctype.h } & 22\end{array}$

$\begin{array}{ll}\text { delay.c } & 25\end{array}$

$\begin{array}{lr}\text { devices.c } & 27\end{array}$

$\begin{array}{ll}\text { execve.c } & 28\end{array}$

$\begin{array}{lr}\text { exit.c } & 29\end{array}$

$\begin{array}{ll}\text { fork.c } & \mathbf{3 0}\end{array}$

kernel.c

$\begin{array}{ll}\text { linkedl.c } & 37\end{array}$ 
$\begin{array}{ll}\text { linkedl.h } & 39\end{array}$

$\begin{array}{ll}\text { mount.c } & 43\end{array}$

namei.c 44

$\begin{array}{ll}\text { partition.c } & 47\end{array}$

$\begin{array}{lr}\text { printf.c } & 49\end{array}$

read.c 53

sched.c

semaphore.c 55

$\begin{array}{ll}\text { semaphore.h } & 58\end{array}$

$\begin{array}{ll}\text { stdlib.c } & 60\end{array}$

stdlib.h $\quad 61$

$\begin{array}{ll}\text { string.c } & 63\end{array}$

$\begin{array}{ll}\text { string.h } & 65\end{array}$

$\begin{array}{ll}\text { syscall.c } & 67\end{array}$

$\begin{array}{ll}\text { thread.c } & 68\end{array}$

$\begin{array}{ll}\text { timer.c } & 70\end{array}$

$\begin{array}{ll}\text { unistd.h } & 73\end{array}$

$\begin{array}{ll}\text { vfs.c } & 74\end{array}$

$\begin{array}{ll}\text { wait.c } & 79\end{array}$

$\begin{array}{lc}\text { write.c } & 81\end{array}$

4 Data Structure Documentation

4.1_C_llist Struct Reference

\#include <linkedl.h> 
Collaboration diagram for_c_llist:

$$
\text { c_llist } 1 \text { prev }
$$

Data Fields

- void $*$ element

- struct_c_llist $*$ prev

- struct_c_llist $*$ next

\subsubsection{Detailed Description}

Circular-linked list

\subsubsection{Field Documentation}

4.1.2.1 void*_c_llist::element

4.1.2.2 struct_c_llist $*$ c_llist::next

4.1.2.3 struct_c_Ilist*_c_llist::prev

The documentation for this struct was generated from the following file:

- linkedl.h

\subsection{Ilist Struct Reference}

\#include <linkedl.h> 
Collaboration diagram for_llist:

llist 1 next

Data Fields

- void $*$ element

- struct_llist $*$ next

4.2.1 Detailed Description

Singly-linked list

4.2.2 Field Documentation

4.2.2.1 void*_Ilist::element

4.2.2.2 struct_Ilist $*$ Illist::next

The documentation for this struct was generated from the following file:

- linkedl.h

\section{File Documentation}

\section{1 bhash.c File Reference}

\#include <fs/bhash.h $\rangle$ \#include $\langle$ fs/device.h $\rangle$ \#include <tempos/wait.h> \#include <arch/io.h> Include dependency graph 
for bhash.c:

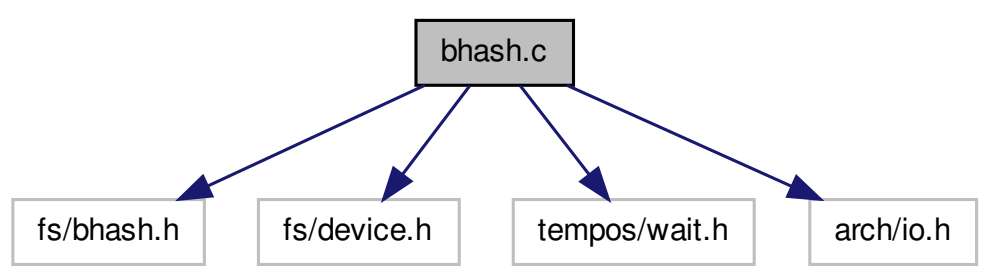

Functions

- static buff_header_t $*$ search_blk (buff_hashq_t $*$ queue, int device, uint64_t blocknum)

- static void blk_remove_from_freelist (buff_hashq_t $*$ queue, int device, uint64_t blocknum)

- static buff_header_t $*$ get_free_blk (buff_hashq_t $*$ queue, int device, uint64_t blocknum)

- static void add_to_buff_queue (buff_hashq_t $*$ queue, buff_header_t $*$ buff, int device, uint64_t blocknum)

- static buff_header_t $*$ getblk (int major, int device, uint64_t blocknum)

- buff_hashq_t $*$ create_hash_queue (uint64_t size)

- void brelse (int major, int device, buff_header_t $*$ buff)

- buff_header_t $*$ bread (int major, int device, uint64_t blocknum)

- buff_header_t $*$ breada (int major, int device, uint64_t blocknum1, uint64_t blocknum2)

- int bwrite (int major, int device, buff_header_t $*$ buff, char type)

\subsubsection{Function Documentation}

5.1.1.1 static void add_to_buff_queue ( buff_hashq_t $*$ queue, buff_header_t $*$ buff, int device, uint64_t blocknum ) [static]

Remove buffer from old hash queue and insert onto new hash queue

Parameters

\begin{tabular}{|r|l|}
\hline queue & The new hash queue. \\
\hline buff & The Buffer. \\
\hline device & Device number. \\
\hline blocknum & New block number. \\
\hline
\end{tabular}


Here is the call graph for this function:

$$
\text { add_to_buff_queue } \longrightarrow \text { search_blk }
$$

5.1.1.2 static void blk_remove_from_freelist ( buff_hashq_t $*$ queue, int device, uint64_t blocknum ) [static]

Remove a block from free list

Parameters

\begin{tabular}{|r|l|}
\hline queue & The hash queue. \\
\hline blocknum & Block number. \\
\hline device & Device number. \\
\hline
\end{tabular}

Returns

buff_header_t The block (if was found), NULL otherwise.

5.1.1.3 buff_header_t $*$ bread ( int major, int device, uint64_t blocknum )

Read a specific block from device (handling the cache).

Parameters

\begin{tabular}{|r|l|}
\hline major & Major number of the device \\
\hline device & Minor number (device number) \\
\hline blocknum & Block number (address) \\
\hline
\end{tabular}


Returns

buff_header_t* Buffer on read success, NULL otherwise.

Here is the call graph for this function:

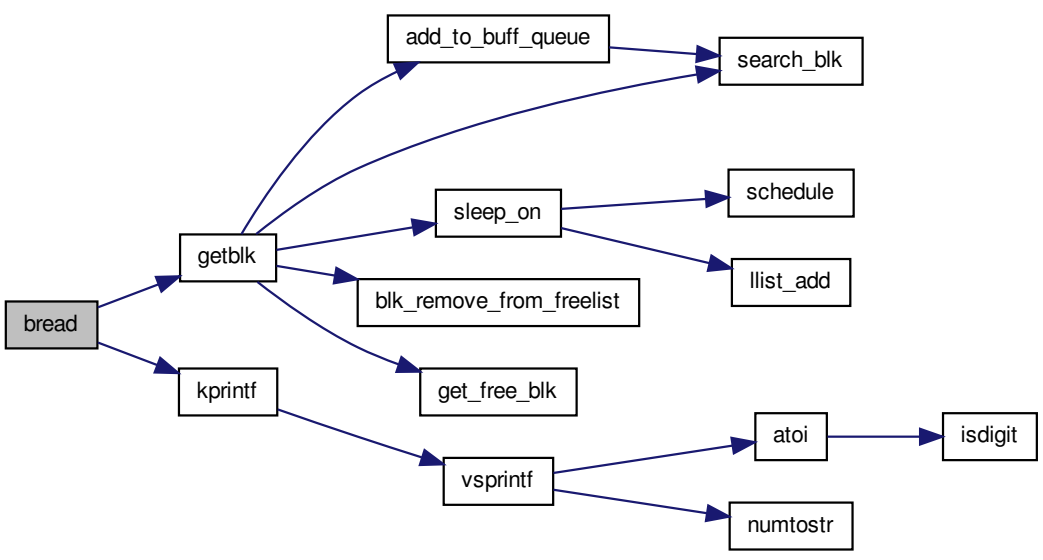

5.1.1.4 buff_header_t $*$ breada ( int major, int device, uint64_t blocknum1, uint64_t blocknum2 )

Read a specific block from device (handling the cache), and put the second block to be read to improve sequential reads.

Parameters

\begin{tabular}{|r|l|}
\hline major & Major number of the device \\
\hline device & Minor number (device number) \\
\hline blocknum1 & Block number (address) of immediate read. \\
\hline blocknum2 & Block number (address) of second block. \\
\hline
\end{tabular}


Returns

buff_header_t* Buffer on read success, NULL otherwise.

First, we read block 1

Now, we check for second block and if not in cache, start a asynchronous read.

Here is the call graph for this function:

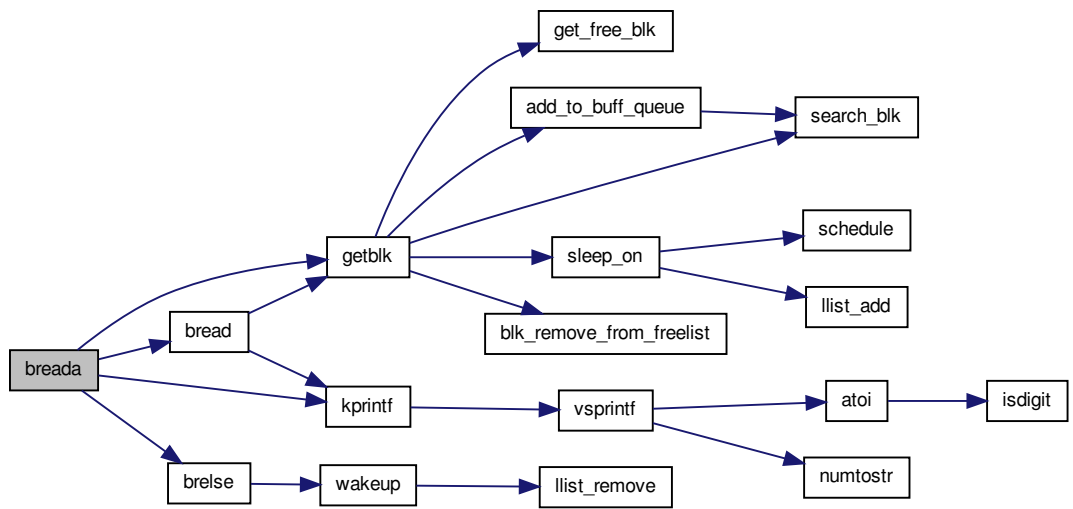

5.1.1.5 void brelse ( int major, int device, buff_header_t $*$ buff )

Release a locked buffer.

Parameters

\begin{tabular}{|r|l|}
\hline major & Major number of the device \\
\hline device & Minor number (device number) \\
\hline buff & The buffer to be released. \\
\hline
\end{tabular}

Here is the call graph for this function:

brelse $\rightarrow$ wakeup $\rightarrow$ Ilist_remove


5.1.1.6 int bwrite ( int major, int device, buff_header_t $*$ buff, char type )

Write block back to device.

Parameters

\begin{tabular}{|r|l|}
\hline major & Major number of the device \\
\hline device & Minor number (device number) \\
\hline buff & The buffer to be write. \\
\hline type & $\begin{array}{l}\text { Type of write operation: BWRITE_SYNC (synchronously), BWRITE_A- } \\
\text { SYNC (asynchrounously) or BWRITE_DELAYED (for delayed write). }\end{array}$ \\
\hline
\end{tabular}

Returns

1 on success, 0 otherwise.

\subsubsection{7 buff_hashq_t $*$ create_hash_queue ( uint64_t size )}

Creates a buffer queue (cache of blocks) to a specific disk.

Parameters

size $\quad$ The size (in sectors) of the device.

Returns

int -1 on error. Otherwise the number of the queue.

Note

The returned number should be used as argument to cache block functions (getblk, etc).

Here is the call graph for this function:

$$
\text { create_hash_queue } \longrightarrow \text { memset }
$$

5.1.1.8 static buff_header_t $*$ get_free_blk ( buff_hashq_t $*$ queue, int device, uint64_t blocknum ) [static]

Search and get a free block from free list. 
Parameters

\begin{tabular}{|r|l|}
\hline queue & The hash queue. \\
\hline device & Device number. \\
\hline blocknum & Try to find (and retrieve) a particular block (blocknum) on the list. \\
\hline
\end{tabular}

\subsubsection{9 static buff_header_t $*$ getblk ( int major, int device, uint64_t blocknum ) [static]}

Each disk has a buffer queue of blocks. This function will search for a specific block in the disk's buffer queue.

\section{Parameters}

\begin{tabular}{|r|l|}
\hline major & Major number of the device \\
\hline device & Minor number (device number) \\
\hline blocknum & Block number (address) \\
\hline
\end{tabular}

Returns

buff_header_t* Pointer to the block

Here is the call graph for this function:

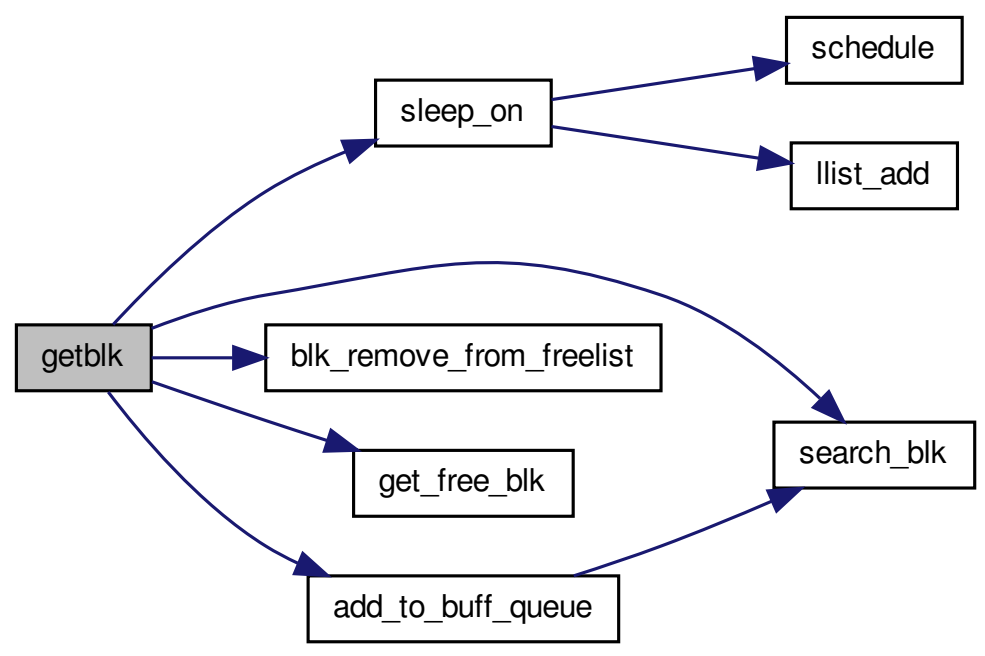


5.1.1.10 static buff_header_t $*$ search_blk ( buff_hashq_t $*$ queue, int device, uint64_t blocknum ) [static]

Search for a block on hash queue.

Parameters

\begin{tabular}{|r|l|}
\hline queue & The hash queue. \\
\hline blocknum & Block number. \\
\hline device & Device number. \\
\hline
\end{tabular}

Returns

buff_header_t The block (if was found), NULL otherwise.

\section{2 binfmt_elf32.c File Reference}

\#include <fs/elf32.h> Include dependency graph for binfmt_elf32.c:

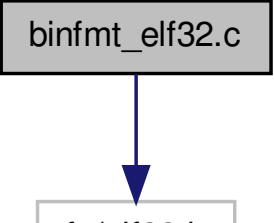

fs/elf32.h 


\section{3 clinkedl.c File Reference}

\#include <linkedl.h> Include dependency graph for clinkedl.c:

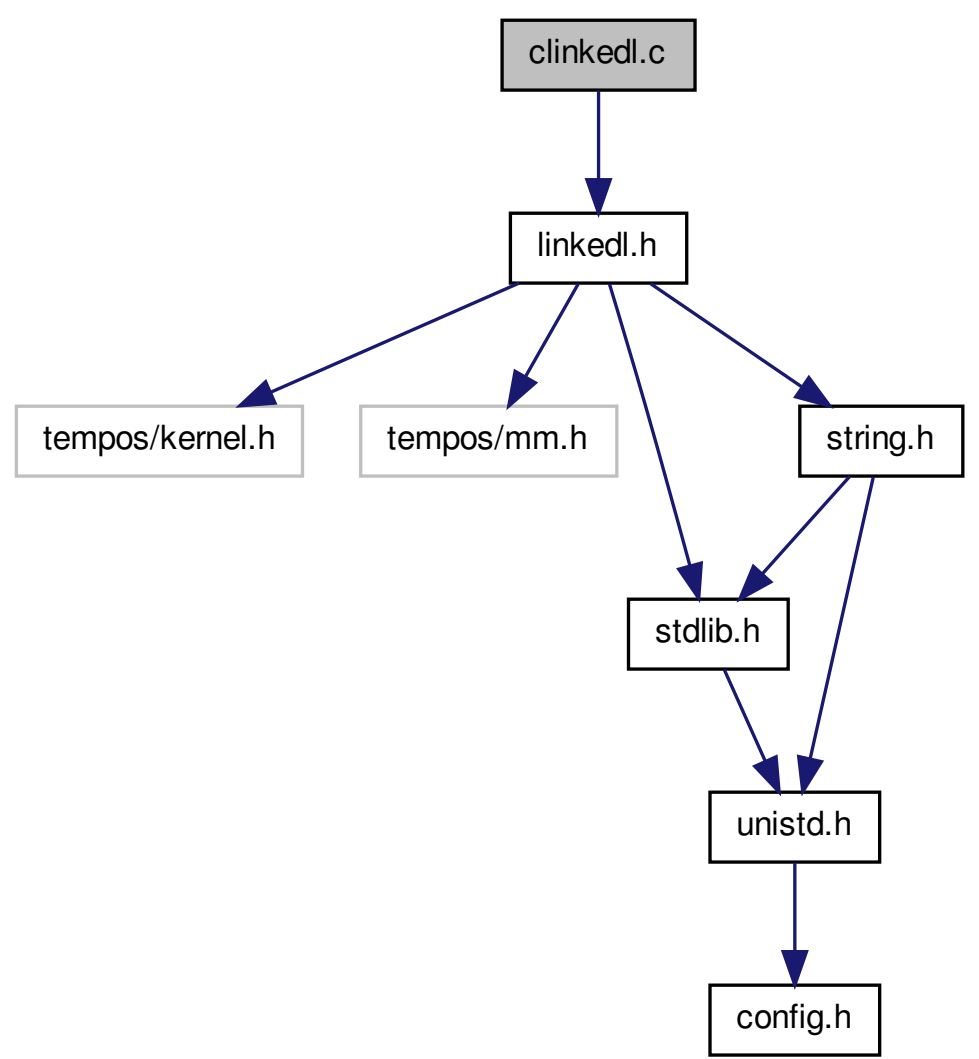

Functions

- int C llist create (c llist $* *$ list)

- int c_llist_destroy (c_llist $* *$ list)

- int C_llist_add (c_llist $* *$ list, void $*$ element)

- int C_llist_remove_nth (c_llist $* *$ list, uint32_t pos)

- int C llist remove (c llist $* *$ list, void $*$ element)

- void $*$ c_llist_nth (c_llist $*$ list, uint32_t index)

- int32_t c_llist_index (c_llist $*$ list, void $*$ element)

- int32_t c_llist_length (c_llist $*$ list) 


\subsubsection{Function Documentation}

5.3.1.1 int C_Ilist_add ( c_Ilist $* *$ list, void $*$ element )

Add a element into the list

Parameters

\begin{tabular}{|r|l|}
\hline list & List. \\
\hline element & Element to be inserted. \\
\hline
\end{tabular}

5.3.1.2 int C_llist_create ( c_llist $* *$ list )

Create a circular linked list

5.3.1.3 int C_Ilist_destroy ( c_llist $* *$ list )

Destroy (free memory) a list.

5.3.1.4 int32_t c_llist_index ( c_Ilist $*$ list, void $*$ element )

Return the index of a element in the list

Parameters

\begin{tabular}{|r|l|}
\hline list & List. \\
\hline element & Element to find the index. \\
\hline
\end{tabular}

Returns

-1 if element was not found, the index otherwise.

5.3.1.5 int32_t c_llist_length ( c_llist $*$ list )

Return the length of a circular linked list

Parameters

\begin{tabular}{|l|l|}
\hline list & List \\
\hline
\end{tabular}

5.3.1.6 void $*$ c_Ilist_nth ( c_Ilist $*$ list, uint32_t index )

Return the element at nth position in the list

Parameters

\begin{tabular}{|r|l|}
\hline list & List. \\
\hline index & Element position. \\
\hline
\end{tabular}


Returns

The element or NULL if not found.

5.3.1.7 int c_Ilist_remove ( c_Ilist $* *$ list, void $*$ element )

Remove a element from the list

Parameters

\begin{tabular}{|r|l|}
\hline list & List. \\
\hline element & Element to remove. \\
\hline
\end{tabular}

5.3.1.8 int c_llist_remove_nth ( c_llist $* *$ list, uint32_t pos )

Remove the nth element from the list

Parameters

\begin{tabular}{|r|l|}
\hline list & List. \\
\hline pos & Element position. \\
\hline
\end{tabular}




\section{4 cmdline.c File Reference}

\#include <tempos/kernel.h> \#include <string.h> Include dependency graph for cmdline.c:

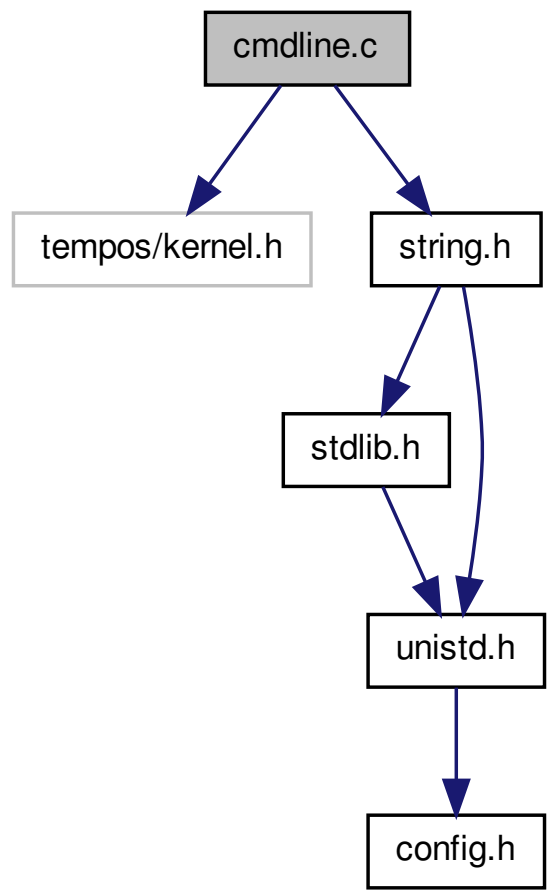

Defines

- \#define CMDLINE MAX ARGS 50

Functions

- int parse_cmdline (char $*$ cmdline)

- char $*$ cmdline_get_value (char $*$ key)

\section{Variables}

- cmdline_arg_t cmdline_args [CMDLINE_MAX_ARGS]

- char cmdline_str [CMDLINE_MAX] 
- int cmdline_argc $=0$

\subsubsection{Define Documentation}

\subsubsection{1 \#define CMDLINE_MAX_ARGS 50}

Maximum command line arguments

\subsubsection{Function Documentation}

5.4.2.1 char $*$ cmdline_get_value ( char $*$ key )

Return key value of command line argument

Parameters

\begin{tabular}{l|l} 
key & to get its value
\end{tabular}

Returns

Key value

Here is the call graph for this function:

cmoline_get_value $\rightarrow$ strcmp

5.4.2.2 int parse_cmdline ( char $*$ cmdline )

Parse command line

Parameters

cmdline Command line (string) 
Returns

Number of arguments found.

Here is the call graph for this function:

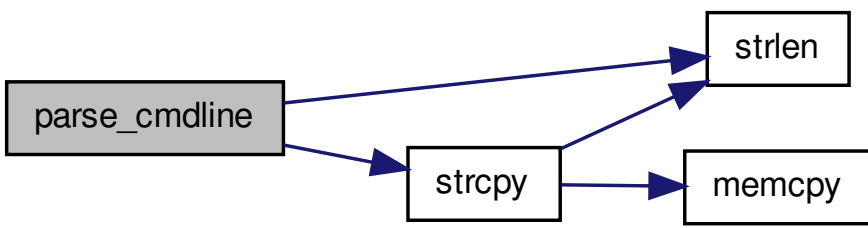

5.4.3 Variable Documentation

5.4.3.1 int cmdline_argc $=0$

Number of valid arguments parsed

5.4.3.2 cmdline_arg_t cmdline_args[CMDLINE_MAX_ARGS]

command line arguments

5.4.3.3 char cmdline_str[CMDLINE_MAX]

copy of the whole command line string 


\section{5 config.h File Reference}

This graph shows which files directly or indirectly include this file:

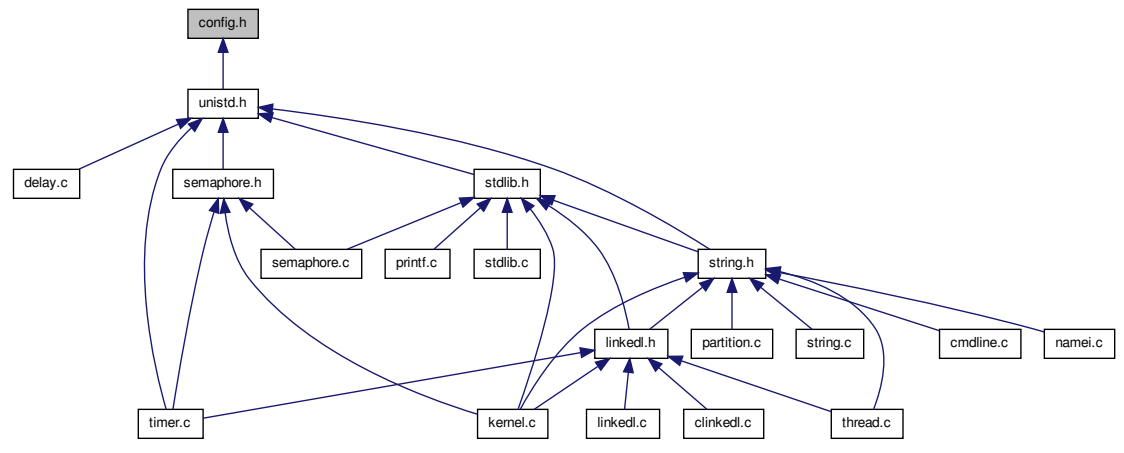

Defines

- \#define CONFIG_ARCH_X86 y

- \#define CONFIG_X86_MAKEFILE "arch/x86/build/Makefile"

- \#define CONFIG_SYSTEM_HZ 250

- \#define CONFIG_BUFFER_QUEUE_SIZE 1024

- \#define CONFIG_FS_EXT2 y

\subsubsection{Define Documentation}

5.5.1.1 \#define CONFIG_ARCH_X86 y

5.5.1.2 \#define CONFIG_BUFFER_QUEUE_SIZE 1024

5.5.1.3 \#define CONFIG_FS_EXT2 y

5.5.1.4 \#define CONFIG_SYSTEM_HZ 250

5.5.1.5 \#define CONFIG_X86_MAKEFILE "arch/X86/build/Makefile" 


\section{6 ctype.c File Reference}

\# include <ctype.h> Include dependency graph for ctype.c:

\section{ctype.c}

Functions

- int isalnum (int c)

- int isalpha (int c)

- int isascii (int c)

- int isblank (int c)

- int iscntrl (int c)

- int isdigit (int c)

- int isgraph (int c)

- int islower (int c)

- int isprint (int c)

- int ispunct (int c)

- int isspace (int c)

- int isupper (int c)

- int isxdigit (int c)

5.6.1 Function Documentation 
5.6.1.1 int isalnum ( int $c$ )

Here is the call graph for this function:

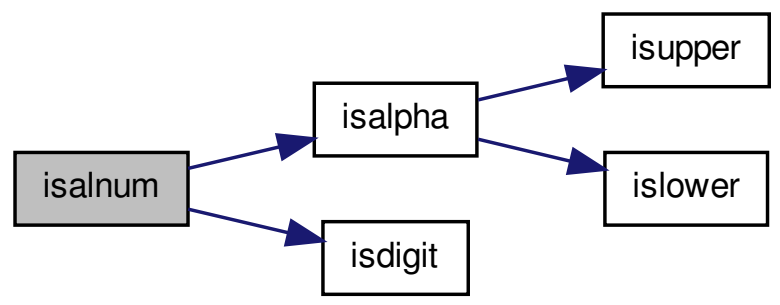

5.6.1.2 int isalpha ( int $c$ )

Here is the call graph for this function:

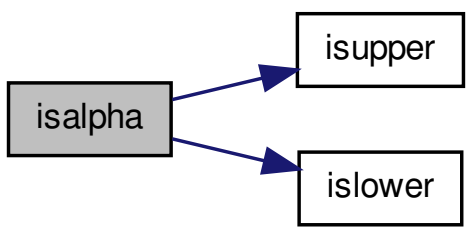

\footnotetext{
5.6.1.3 int isascii ( int c )

5.6.1.4 int isblank ( int $c$ )

5.6.1.5 int iscntrl ( int $c$ )

5.6.1.6 int isdigit ( int $c$ )

5.6.1.7 int isgraph ( int $c$ )

5.6.1.8 int islower ( int $c$ )
} 
5.6.1.9 int isprint ( int $c$ )

5.6.1.10 int ispunct ( int $c$ )

Here is the call graph for this function:

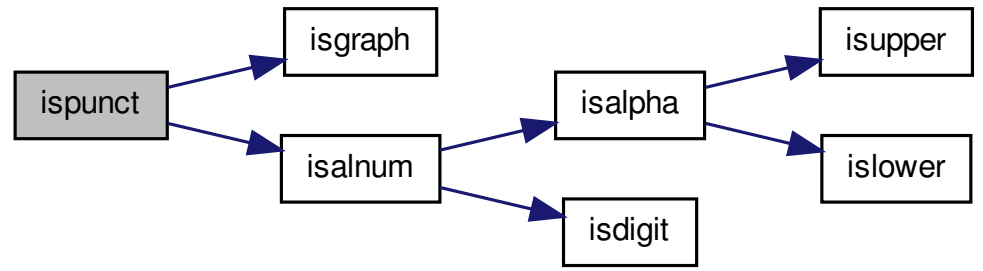

5.6.1.11 int isspace ( int $c$ )

5.6.1.12 int isupper ( int $c$ )

5.6.1.13 int isxdigit ( int $c$ )

\section{7 ctype.h File Reference}

This graph shows which files directly or indirectly include this file:

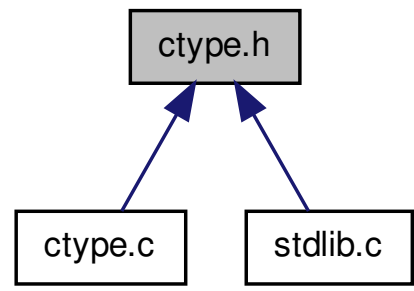

Functions

- int isalnum (int c) 
- int isalpha (int c)

- int isascii (int c)

- int isblank (int c)

- int iscntrl (int C)

- int isdigit (int c)

- int isgraph (int c)

- int islower (int c)

- int isprint (int c)

- int ispunct (int c)

- int isspace (int c)

- int isupper (int c)

- int isxdigit (int c)

\subsubsection{Function Documentation}

5.7.1.1 int isalnum ( int $c$ )

Here is the call graph for this function:

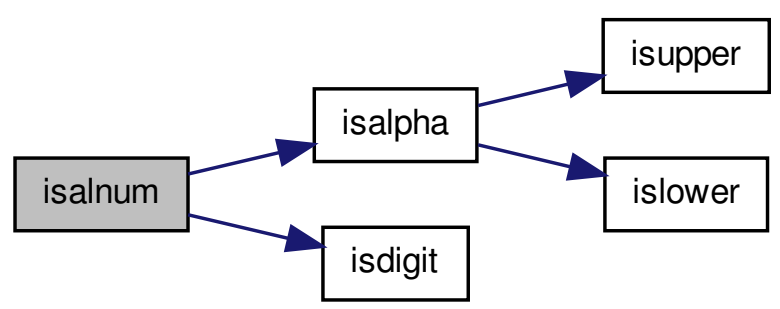




\subsubsection{2 int isalpha ( int $c$ )}

Here is the call graph for this function:

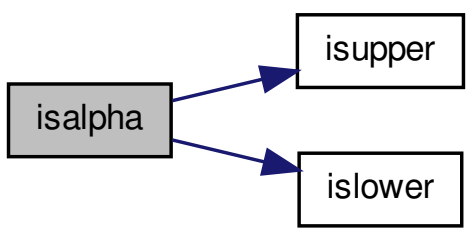

5.7.1.3 int isascii ( int c )

5.7.1.4 int isblank ( int $c$ )

5.7.1.5 int iscntrl ( int $c$ )

5.7.1.6 int isdigit ( int $c$ )

5.7.1.7 int isgraph ( int $c$ )

5.7.1.8 int islower ( int $c$ )

5.7.1.9 int isprint ( int c )

5.7.1.10 int ispunct ( int $c$ )

Here is the call graph for this function:

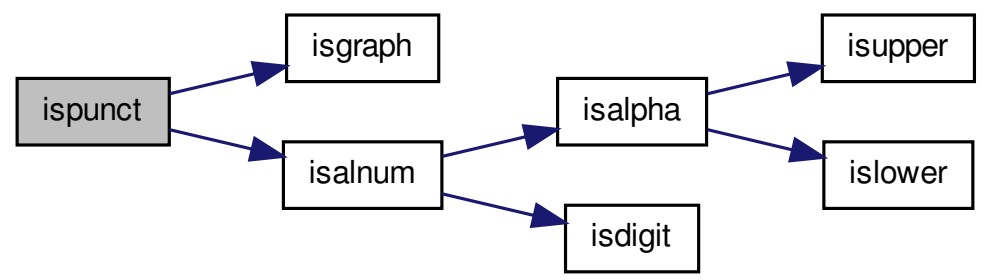


5.7.1.11 int isspace ( int $c$ )
5.7.1.12 int isupper ( int $c$ )
5.7.1.13 int isxdigit ( int $c$ )

\section{8 delay.c File Reference}
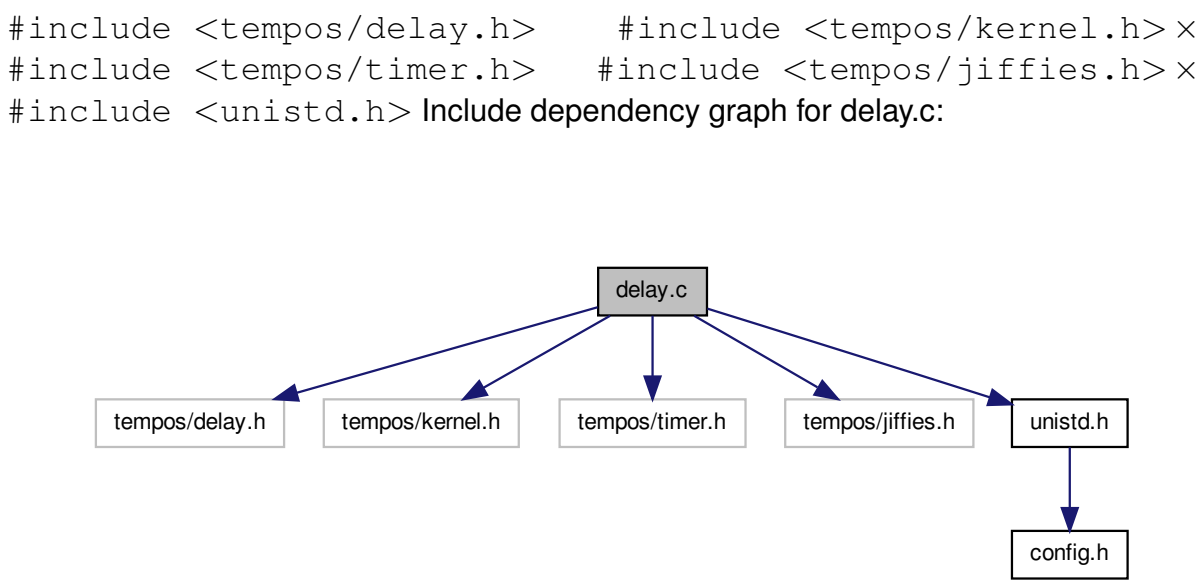

Functions

- void calibrate_delay (void)

- void udelay (uint32_t usecs)

- void mdelay (uint32_t msecs)

Variables

- uint32_t bogomips

\subsubsection{Function Documentation}

5.8.1.1 void calibrate_delay ( void )

Calibrate delay (calculate BogoMIPS) 
Here is the call graph for this function:

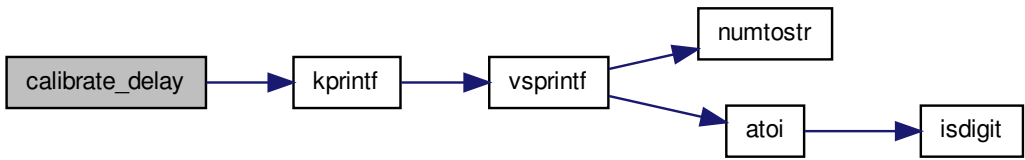

5.8.1.2 void mdelay ( uint32_t msecs )

Delay in milliseconds

Parameters

msecs Miliseconds to wait

Here is the call graph for this function:

mdelay $\longrightarrow$ udelay

5.8.1.3 void udelay ( uint32_t usecs )

Delay in microseconds

Parameters

usecs Microseconds to wait

5.8.2 Variable Documentation

5.8.2.1 uint32_t bogomips

BogoMIPS calculated at system startup 


\section{9 devices.c File Reference}

\#include <tempos/kernel.h> \#include <fs/vfs.h> \#include $<$ fs / device.h> Include dependency graph for devices.c:

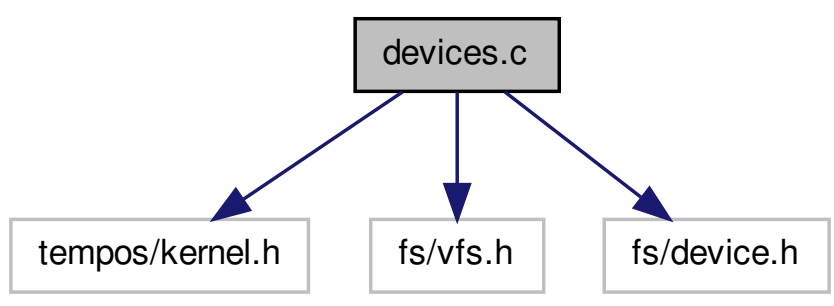

Functions

- void init_drivers_interface (void)

- int register_block_driver (dev_blk_driver_t $*$ driver)

Variables

- dev_char_driver_t $*$ char_dev_drivers [MAX_DEVCHAR_DRIVERS]

- dev_blk_driver_t $*$ block_dev_drivers [MAX_DEVBLOCK_DRIVERS]

\subsubsection{Function Documentation}

5.9.1.1 void init_drivers_interface ( void )

Initialize drivers interface.

5.9.1.2 int register_block_driver ( dev_blk_driver_t $*$ driver )

Register a block device driver.

Parameters

driver Block driver structure.

See also

fs/device.h 
Returns

int 0 on Success, -1 otherwise.

Here is the call graph for this function:

register_block_driver $\rightarrow$ create_hash_queue $\longrightarrow$ memset

5.9.2 Variable Documentation

5.9.2.1 dev_blk_driver_t* block_dev_drivers[MAX_DEVBLOCK_DRIVERS]

Table of device drivers for block devices

5.9.2.2 dev_char_driver_t $*$ char_dev_drivers[MAX_DEVCHAR_DRIVERS]

Table of device drivers for character devices

\subsection{0 execve.c File Reference}

\#include <tempos/syscall.h> \#include <tempos/kernel.h>x Include dependency graph for execve.c:

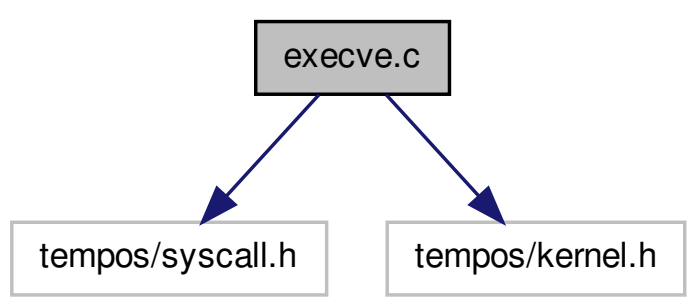


Functions

- _pushargs int sys_execve (const char $*$ filename, char $*$ const argv[], char $*$ const envp[])

5.10.1 Function Documentation

5.10.1.1_pushargs int sys_execve ( const char $*$ filename, char $*$ const argv [], char $*$ const envp[] )

Here is the call graph for this function:

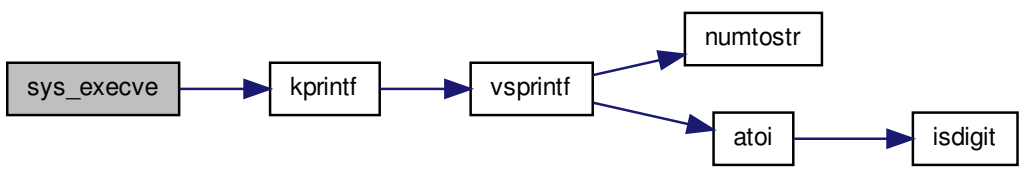

\subsection{1 exit.c File Reference}

\#include <tempos/syscall.h> \#include <tempos/error.h>x \#include <tempos/kernel.h> Include dependency graph for exit.c:

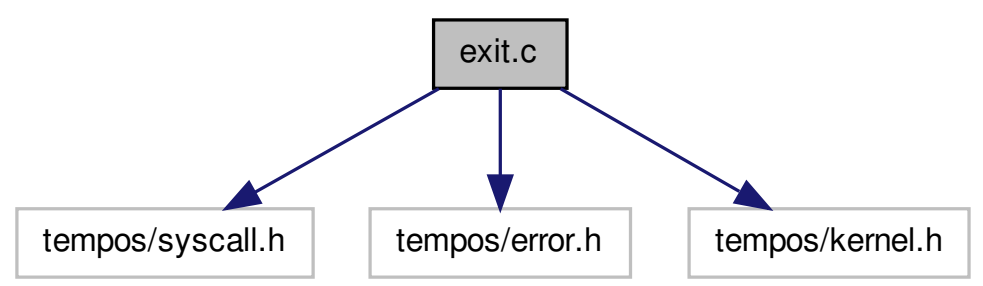

Functions

- _pushargs int sys_exit (int status) 


\subsubsection{Function Documentation}

\subsubsection{1_pushargs int sys_exit ( int status )}

Here is the call graph for this function:

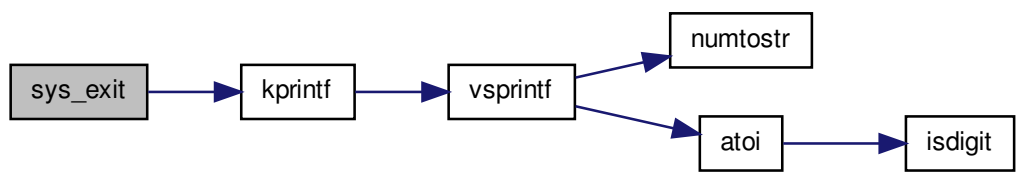

\subsection{2 fork.c File Reference}

\#include <tempos/kernel.h> \#include <tempos/syscall.h>x \#include <tempos/sched.h> \#include <arch/io.h> \#include $<\mathrm{x} 86 / \mathrm{x} 86 . \mathrm{h}>$ Include dependency graph for fork.c:

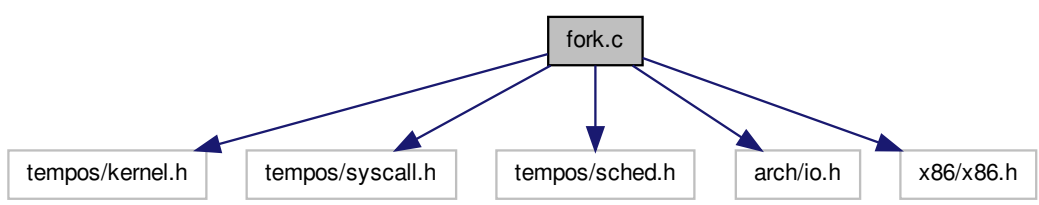

Functions

- void initial_task2 (task_t $*$ task)

- _pushargs void sys_fork (void)

- static uint32_t get_phy_addr (void $*$ ptr)

- void_exec_init (char $*$ init_data)

- pid t fork (task_t $*$ thread)

- pid_t get_new_pid (void)

- void release_pid (pid_t pid)

- void init_pids (void) 
Variables

- static pid_t pid_stack [MAX_NUM_PROCESS]

- static uint32_t pid_st_top

5.12.1 Function Documentation

5.12.1.1 void_exec_init ( char $*$ init_data )

Here is the call graph for this function:

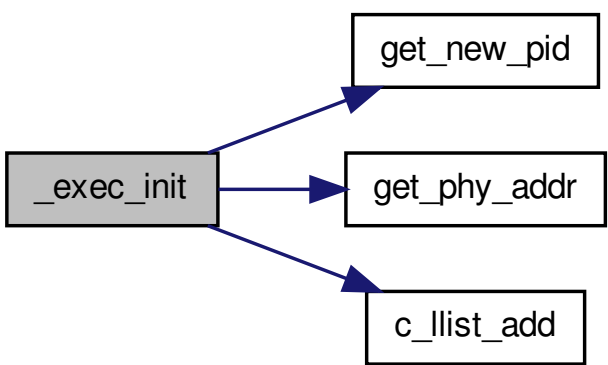

5.12.1.2 pid_t_fork ( task_t $*$ thread )

Fork a thread (process).

Parameters

thread The thread to fork. 
Here is the call graph for this function:

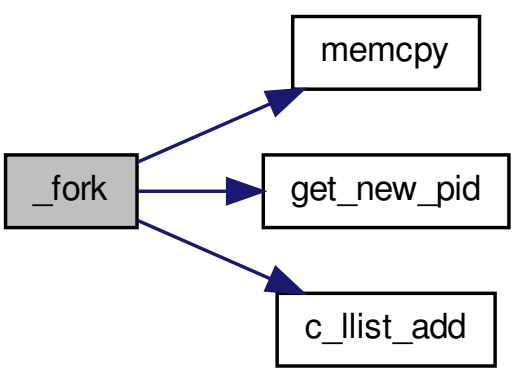

5.12.1.3 pid_t get_new_pid ( void )

Retrieve a new PID.

Returns

pid_t New PID.

5.12.1.4 static uint32_tget_phy_addr ( void $*$ ptr ) [stat ic ]

This is just for test

5.12.1.5 void init_pids ( void )

Initialize stack of PIDs numbers.

5.12.1.6 void initial_task2 ( task $\mathrm{t} *$ task )

5.12.1.7 void release_pid ( pid_t pid )

Release a allocated PID.

Parameters

pid PID.

5.12.1.8 pushargs void sys_fork ( void )

Fork system call. 
5.12.2 Variable Documentation

5.12.2.1 uint32_tpid_st_top [static]

PID's stack top

5.12.2.2 pid_t pid_stack[MAX_NUM_PROCESS] [static ]

Stack of PIDs numbers

\subsection{3 kernel.c File Reference}

\#include <tempos/kernel.h>\#include <tempos/mm.h>\#include $<$ tempos/timer.h> \#include <tempos/jiffies.h> \#include <tempos/delay.h>\#include <tempos/sched.h>\#include <tempos/wait.h> \#include <drv/i8042.h> \#include <drv/ata_generic.h> \#include $\langle$ fs/vfs.h $\rangle$ \#include $\langle f s /$ device.h $\rangle$ \#include <string.h> \#include <stdlib.h> \#include <linkedl.h $>$ x \#include <semaphore.h> Include dependency graph for kernel.c:

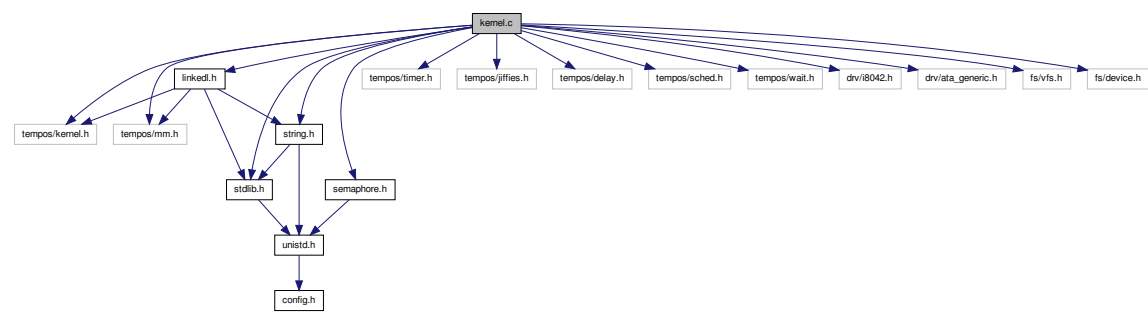

Functions

- void kernel_main_thread (void $*$ arg)

- void idle_thread (void $*$ arg)

- void tempos_main (karch_t kinf)

- void thread1 (void $*$ arg)

- void panic (const char $*$ format,...)

Variables

- karch_t kinfo

- static int thread_done $=0$

5.13.1 Function Documentation 


\subsubsection{1 void idle thread ( void $*$ arg )}

idle thread

This function does nothing.

Note

This function will run as a kernel thread just to keep another process running when the main kernel thread goes to sleep at system initialization, when there is no user process running yet.

Parameters

\begin{tabular}{l|l}
$\arg$ & Not used.
\end{tabular}

Here is the call graph for this function:

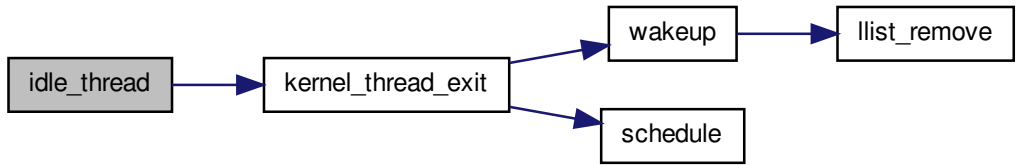

5.13.1.2 void kernel_main_thread ( void $*$ arg )

kernel main thread

This is the main kernel thread. When TempOS initializes his scheduler the kernel process becomes a kernel thread (running this function). So this thread executes all functions after scheduler initialization.

Parameters

$\arg$ Not used.

We are done. User process "init" is running, now idle_thread can go away... 
Here is the call graph for this function:

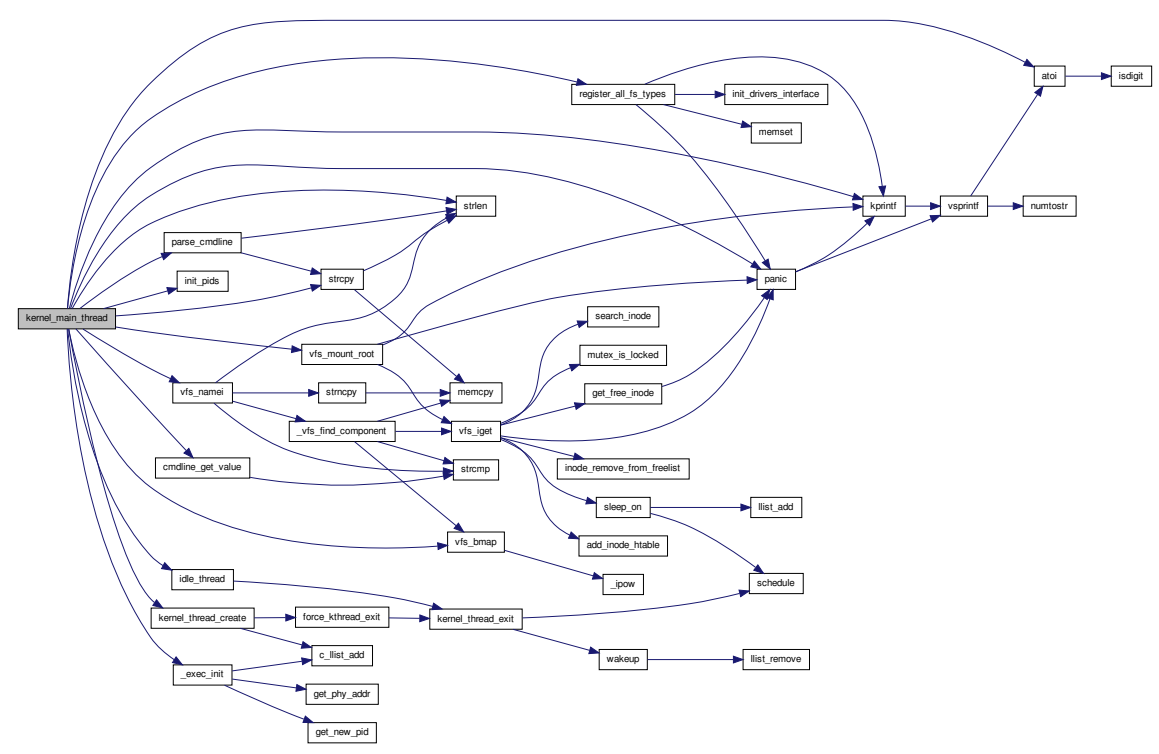

5.13.1.3 void panic ( const char $*$ format, ... )

Show error message and dump halt CPU. This function should be used when something goes really wrong. System will hang out without any chance of recovery.

Parameters

format Error message (formated).

Here is the call graph for this function:

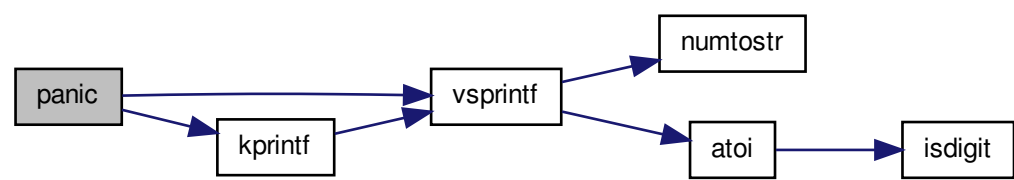

5.13.1.4 void tempos_main ( $k a r c h \_t$ kinf )

tempos_main : Second stage 
This is the function called when first stage is done, which means that all dependent machine boot code was executed. See $\mathrm{arch} / \$ \mathrm{ARCH} / \mathrm{boot} / \mathrm{karch} . \mathrm{c}$

Here is the call graph for this function:

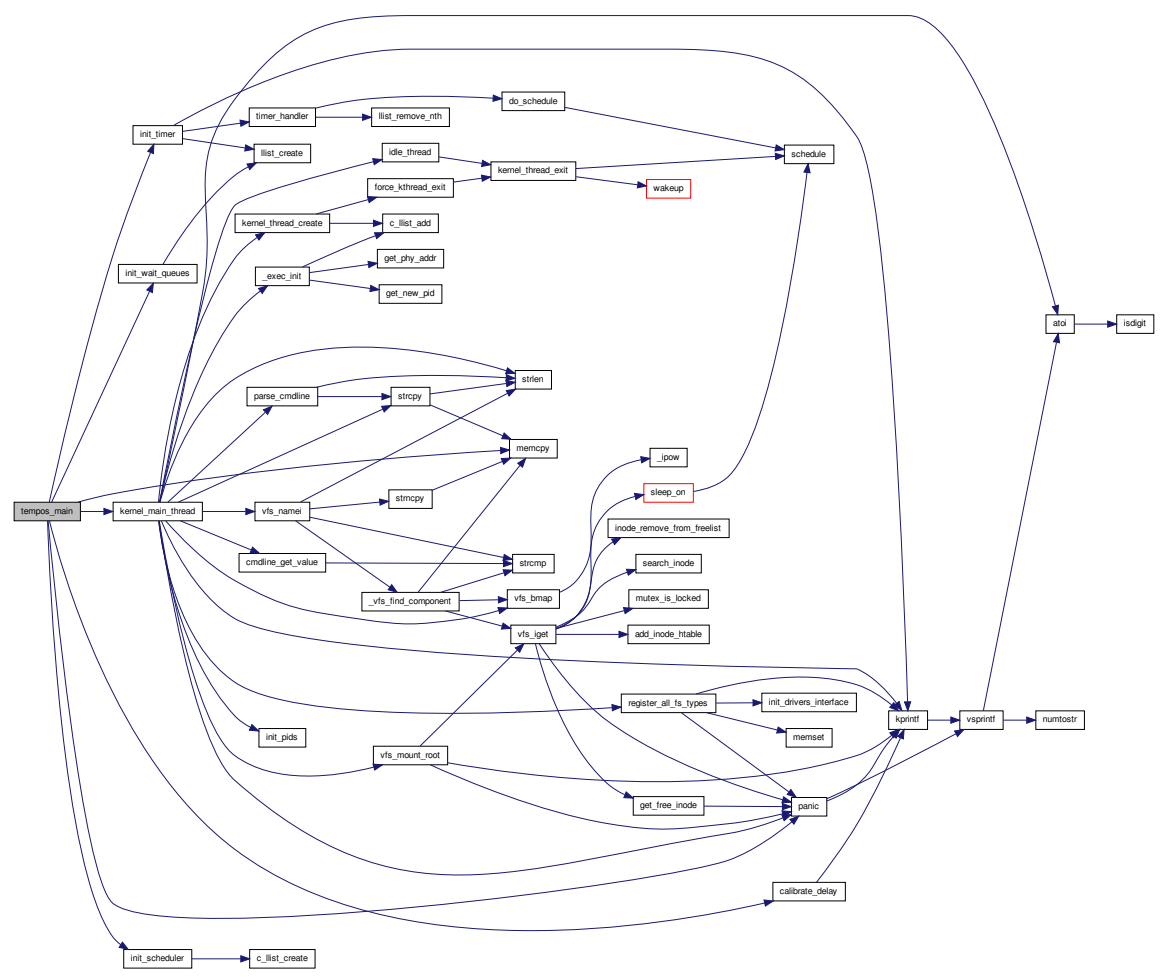

5.13.1.5 void thread1 ( void $* \arg$ )

Here is the call graph for this function:

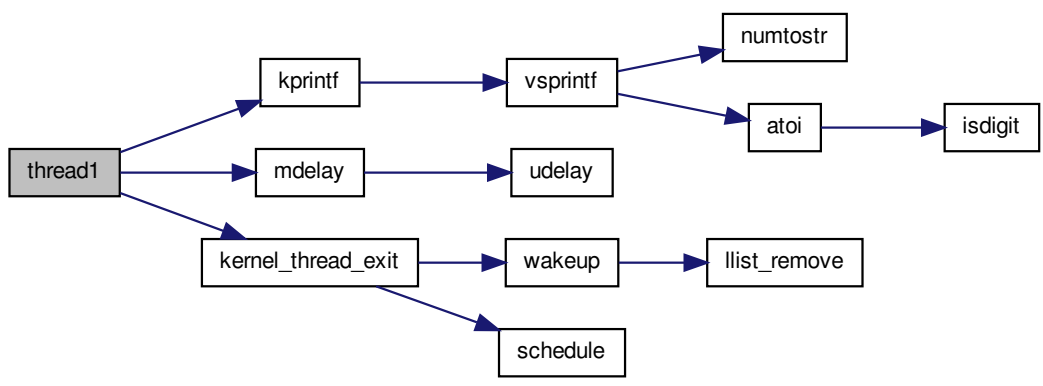


5.13.2 Variable Documentation

5.13.2.1 karch_t kinfo

information passed from first stage

5.13.2.2 int thread_done $=0 \quad$ [static $]$

indicates when idle_thread should exit

\subsection{4 linkedl.c File Reference}

\# include <linkedl.h> Include dependency graph for linkedl.c:

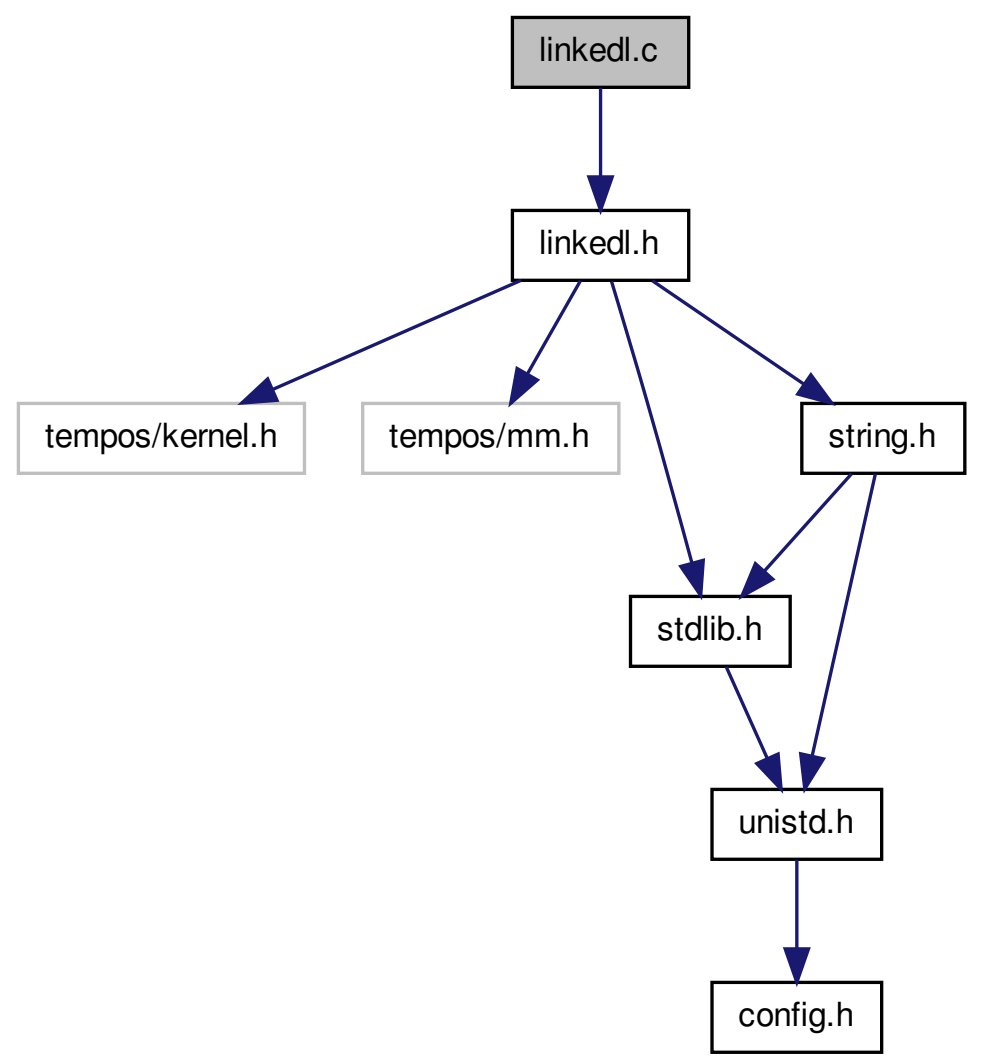


Functions

- int llist_create (llist $* *$ list)

- int llist_destroy (Ilist $* *$ list)

- int llist_add (llist $* *$ list, void $*$ element)

- int llist_remove_nth (llist $* *$ list, uint32_t pos)

- int llist_remove (llist $* *$ list, void $*$ element)

- void $*$ llist_nth (llist $*$ list, uint32_t index)

- int32_t llist_index (llist $*$ list, void $*$ element)

- int32_t llist_length (Ilist $*$ list)

5.14.1 Function Documentation

5.14.1.1 int llist_add ( Ilist $* *$ list, void $*$ element )

5.14.1.2 int Ilist_create ( Ilist $* *$ list )

Create a new linked list

Parameters

list New list

Returns

int Always return true

5.14.1.3 int Ilist_destroy ( Ilist $* *$ list )

5.14.1.4 int32_t llist_index ( Ilist $*$ list, void $*$ element )

5.14.1.5 int32_t llist_length ( Ilist $*$ list )

5.14.1.6 void $*$ Ilist_nth ( Ilist $*$ list, uint32_t index )

5.14.1.7 int llist_remove ( Ilist $* *$ list, void $*$ element )

5.14.1.8 int llist_remove_nth ( Ilist $* *$ list, uint32_t pos ) 


\subsection{5 linkedl.h File Reference}

\#include <tempos/kernel.h>\#include <tempos/mm.h>\#include <stdlib.h>\#include <string.h> Include dependency graph for linkedl.h:

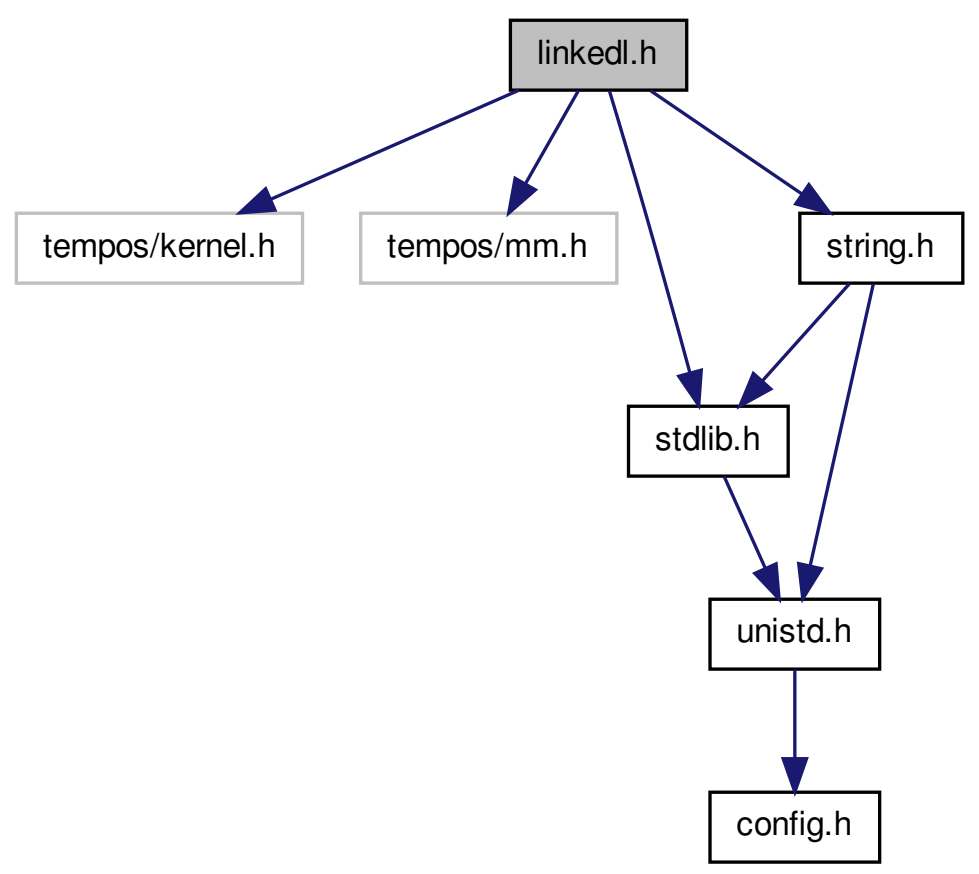

This graph shows which files directly or indirectly include this file:

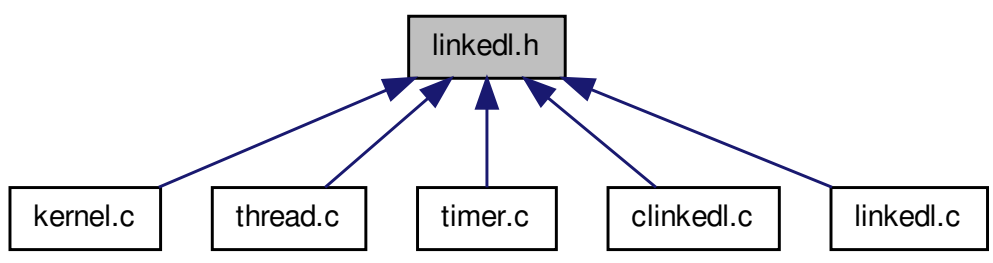


Data Structures

- struct_llist

- struct_c_llist

Defines

- \#define foreach(list, tmp) for(tmp = list; tmp != NULL; tmp = tmp- $>$ next $)$

Typedefs

- typedef struct_Ilist llist

- typedef struct_c_llist C_llist

Functions

- struct_llist_attribute__((packed))

- int llist_create (llist $* *$ list)

- int llist_destroy (Ilist $* *$ list)

- int llist_add (llist $* *$ list, void $*$ element)

- int llist_remove_nth (Ilist $* *$ list, uint32_t pos)

- int llist_remove (llist $* *$ list, void $*$ element)

- void $*$ llist_nth (llist $*$ list, uint32_t index)

- int32_t llist_index (llist $*$ list, void $*$ element)

- int32_t llist_length (llist $*$ list)

- int C_llist_create (c_llist $* *$ list)

- int C_llist_destroy (c_llist $* *$ list)

- int c_llist_add (c_llist $* *$ list, void $*$ element)

- int c_llist_remove_nth (c_llist $* *$ list, uint32_t pos)

- int C_llist_remove (c_llist $* *$ list, void $*$ element)

- void $*$ c_llist_nth (c_llist $*$ list, uint32_t index)

- int32_t c_llist_index (c_llist $*$ list, void $*$ element)

- int32_t c_llist_length (c_llist $*$ list)

Variables

- void $*$ element

- struct_llist $*$ next

- struct_c_llist $*$ prev 


\subsubsection{Define Documentation}

5.15.1.1 \#define foreach( list, $t m p$ ) for(tmp = list; tmp != NULL; tmp = tmp- $>$ next)

5.15.2 Typedef Documentation

5.15.2.1 typedef struct_c_llist c_Ilist

5.15.2.2 typedef struct_Ilist Ilist

5.15.3 Function Documentation

5.15.3.1 struct_c_Ilist_attribute_( (packed) )

5.15.3.2 int C_llist_add ( c_llist $* *$ list, void $*$ element )

Add a element into the list

Parameters

\begin{tabular}{|r|l|}
\hline list & List. \\
\hline element & Element to be inserted. \\
\hline
\end{tabular}

5.15.3.3 int C_Ilist_create ( c_llist $* *$ list )

Create a circular linked list

5.15.3.4 int C_Ilist_destroy ( c_llist $* *$ list )

Destroy (free memory) a list.

5.15.3.5 int32_t c_llist_index ( c_llist $*$ list, void $*$ element $)$

Return the index of a element in the list

Parameters

\begin{tabular}{|r|l|}
\hline list & List. \\
\hline element & Element to find the index. \\
\hline
\end{tabular}

Returns

-1 if element was not found, the index otherwise.

5.15.3.6 int32_t c_llist_length ( c_llist $*$ list )

Return the length of a circular linked list

Parameters

list List 
5.15.3.7 void $*$ C_Ilist_nth ( c_Ilist $*$ list, uint32_t index )

Return the element at nth position in the list

Parameters

\begin{tabular}{|r|l|}
\hline list & List. \\
\hline index & Element position. \\
\hline
\end{tabular}

Returns

The element or NULL if not found.

5.15.3.8 int c_llist_remove ( c_llist $* *$ list, void $*$ element )

Remove a element from the list

Parameters

\begin{tabular}{|r|l|}
\hline list & List. \\
\hline element & Element to remove. \\
\hline
\end{tabular}

5.15.3.9 int c_llist_remove_nth ( c_Ilist $* *$ list, uint32_t pos )

Remove the nth element from the list

Parameters

\begin{tabular}{|r|l|}
\hline list & List. \\
\hline pos & Element position. \\
\hline
\end{tabular}

5.15.3.10 int llist_add ( Ilist $* *$ list, void $*$ element )

5.15.3.11 int Ilist_create ( Ilist $* *$ list )

Create a new linked list

Parameters list New list

Returns

int Always return true

5.15.3.12 int llist_destroy ( Ilist $* *$ list )

5.15.3.13 int32_t llist_index ( Ilist $*$ list, void $*$ element )

5.15.3.14 int32_t llist_length ( Ilist $*$ list ) 
5.15.3.15 void $*$ Ilist_nth ( Ilist $*$ list, uint32_t index )

5.15.3.16 int Ilist_remove ( Ilist $* *$ list, void $*$ element )

5.15.3.17 int Ilist_remove_nth ( Ilist $* *$ list, uint32_t pos )

5.15.4 Variable Documentation

5.15.4.1 void $*$ element

5.15.4.2 struct_c_llist $*$ next

5.15.4.3 struct_c_Ilist $*$ prev

\subsection{6 mount.c File Reference}

\#include <tempos/kernel.h> \#include <tempos/wait.h>x \#include <tempos/sched.h> \#include <fs/vfs.h> \#include $<$ fs/device.h $>$ Include dependency graph for mount.c:

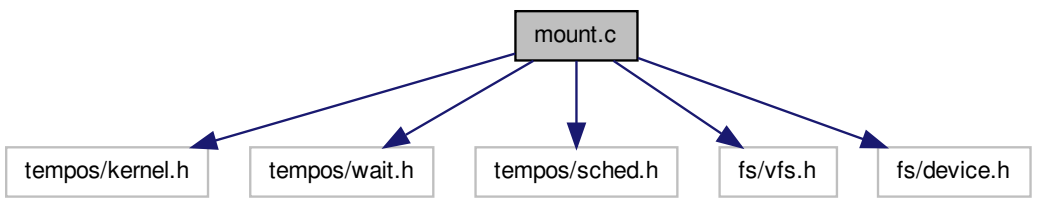

Functions

- int vfs_mount_root (dev_t device)

5.16.1 Function Documentation

5.16.1.1 int vfs_mount_root ( dev_t device )

Mount root file system

Parameters device Root device. 
Returns

1 on success, 0 otherwise.

Here is the call graph for this function:

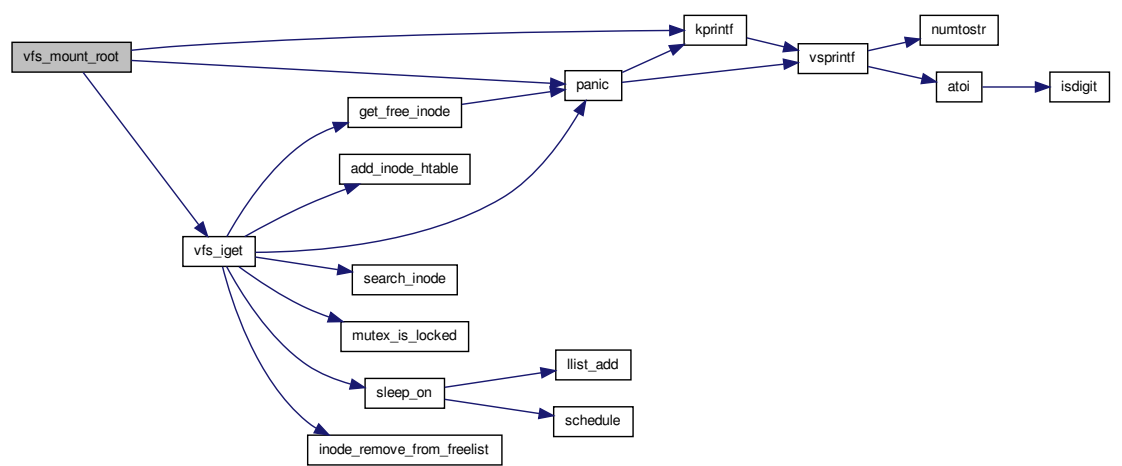

\subsection{7 namei.c File Reference}

\#include <tempos/kernel.h> \#include <tempos/sched.h>x \#include <fs/vfs.h>\#include <string.h> Include dependency graph 
for namei.c:

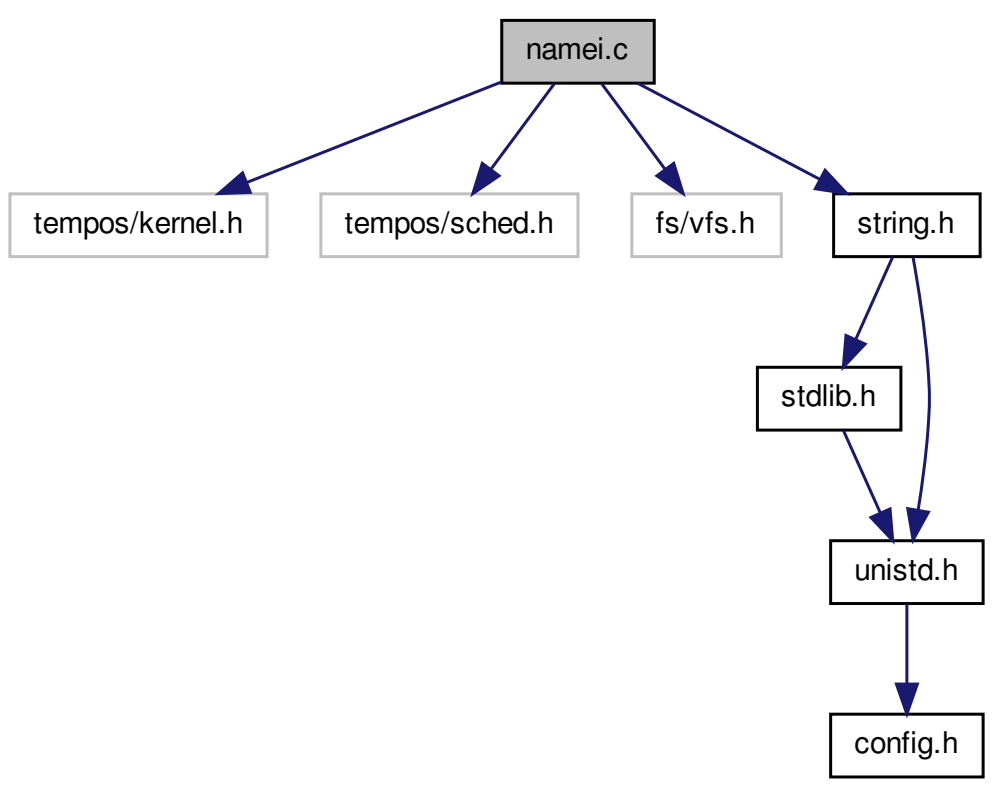

Functions

- static vfs_inode $*$ _vfs_find_component (vfs_inode $*$ inode, char $*$ component)

- vfs_inode $*$ vfs_namei (const char $*$ pathname)

\subsubsection{Function Documentation}

5.17.1.1 static vfs_inode $*$ _vfs_find_component ( vfs_inode $*$ inode, char $*$ component ) [static]

Find component directory entry in i-node.

Parameters

inode Direcroty i-node to search.

component Component name. 
Returns

Component i-node (if was found), or NULL otherwise.

Here is the call graph for this function:

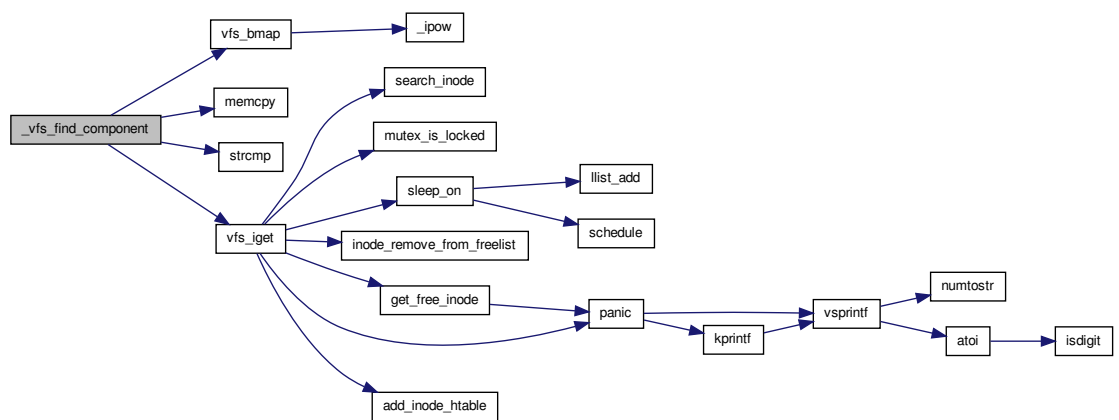

5.17.1.2 vfs_inode $*$ vfs_namei ( const char $*$ pathname )

Convert path name to i-node.

Parameters

pathname Path name.

Returns

NULL if path name is invalid, or the i-node (locked) otherwise.

Here is the call graph for this function:

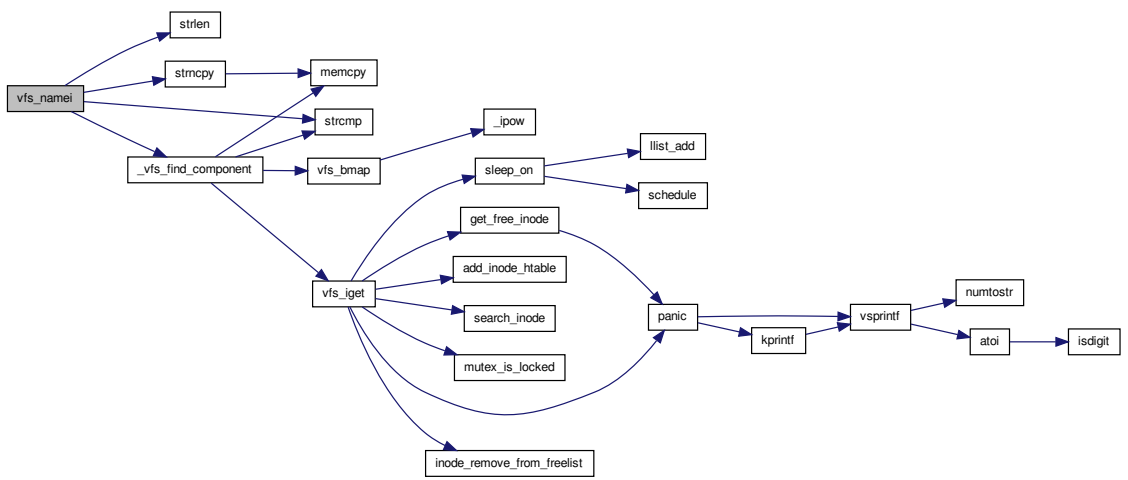

Generated on Fri Aug 242012 10:45:12 for TempOS by Doxygen 


\subsection{8 partition.c File Reference}

\#include <string.h> \#include <tempos/kernel.h> \#include $<$ fs/vfs.h> \#include <fs/partition.h> Include dependency graph for partition.c:

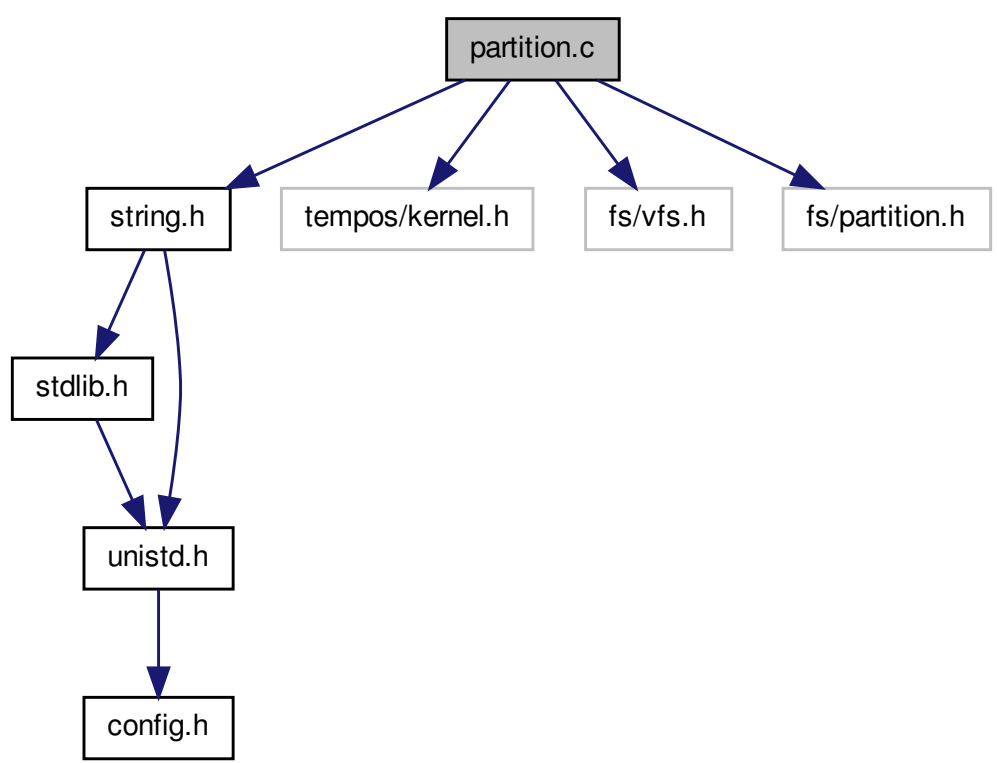

Functions

- part_table_st $*$ parse_mbr (dev_blk_driver_t blk_drv, int device)

- void print_partition_table (part_table_st $*$ ptable, char $*$ devstr)

- int translate_part_address (uint64_t $*$ diskaddr, part_table_st $*$ ptable, uint32_t pnumber, uint64_t paddress)

\subsubsection{Function Documentation}

5.18.1.1 part_table_st $*$ parse_mbr ( dev_blk_driver_t blk_drv, int device )

Parses the MBR table from block device.

Parameters

\begin{tabular}{|r|l|}
\hline blk_drv & Driver structure of block device. \\
\hline device & Device number. \\
\hline
\end{tabular}


Returns

The partition table (

See also

fs/partition.h)

Here is the call graph for this function:

parse_mbr $\rightarrow$ memcpy

5.18.1.2 void print_partition_table ( part_table_st $*$ ptable, char $*$ devstr )

Print partition numbers from partition table.

Parameters

\begin{tabular}{|l|l|}
\hline ptable & Partition table. \\
\hline devstr & $\begin{array}{l}\text { String to precede the number (i.e. sdaX, hdaX, ..., where } \mathrm{X} \text { is the parti- } \\
\text { tion number). }\end{array}$ \\
\hline
\end{tabular}

Here is the call graph for this function:

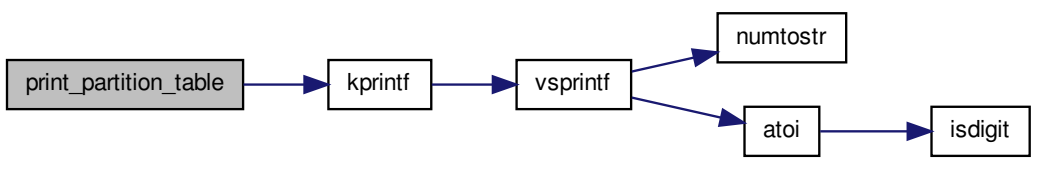

5.18.1.3 int translate_part_address ( uint64_t $*$ diskaddr, part_table_st $*$ ptable, uint32_t pnumber, uint64_t paddress )

Translate partition block address to disk sector address. 
Parameters

\begin{tabular}{|r|l|}
\hline diskaddr & Disk address (sector number converted from partition address). \\
\hline ptable & Partition table. \\
\hline pnumber & Partition number. \\
\hline paddress & Partition address. \\
\hline
\end{tabular}

Returns

0 on success (it's a valid partition address), -1 otherwise.

\subsection{9 printf.c File Reference}

\#include <tempos/kernel.h> \#include <stdlib.h> Include dependency graph for printf.c:

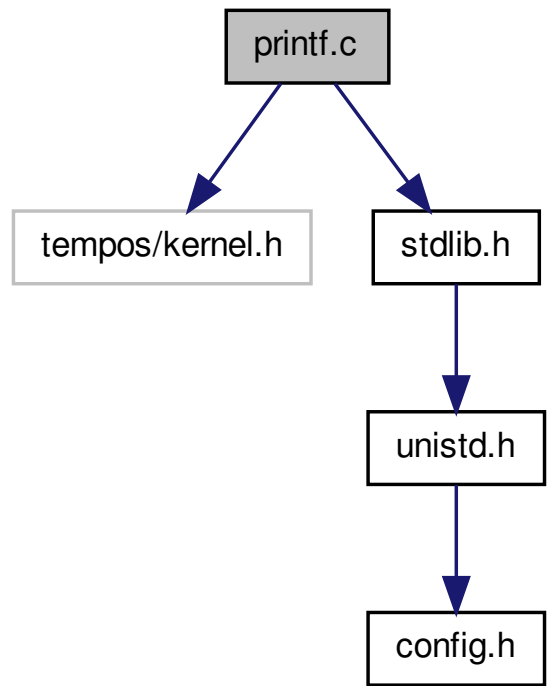

Defines

- \#define MAXDIG 20

- \#define FLAG_ALT 0x00

- \#define FLAG_ZPAD 0x01

- \#define FLAG_FB 0x02

- \#define FLAG SPACE 0x03 
- \#define FLAG_PLUS 0x04

- \#define SIGNED 1

- \#define UNSIGNED 0

Functions

- static void numtostr (char $* *$ dest, char flags, long int value, int base, int prec, char sig)

- int vsprintf (char $*$ str, const char $*$ format, va_list ap)

- int sprintf (char $*$ str, const char $*$ format,...)

- int kprintf (const char $*$ format,...)

5.19.1 Define Documentation

5.19.1.1 \#define FLAG_ALT 0x00

5.19.1.2 \#define FLAG FB 0x02

5.19.1.3 \#define FLAG_PLUS 0x04

5.19.1.4 \#define FLAG_SPACE $0 \times 03$

5.19.1.5 \#define FLAG ZPAD 0x01

5.19.1.6 \#define MAXDIG 20

5.19.1.7 \#define SIGNED 1

Signed conversion

5.19.1.8 \#define UNSIGNED 0

Unsigned conversion

5.19.2 Function Documentation

5.19.2.1 int kprintf ( const char $*$ format, $\quad$... )

Write formated messages (like printf).

Todo Implement "TYPE" of messages. 
Here is the call graph for this function:

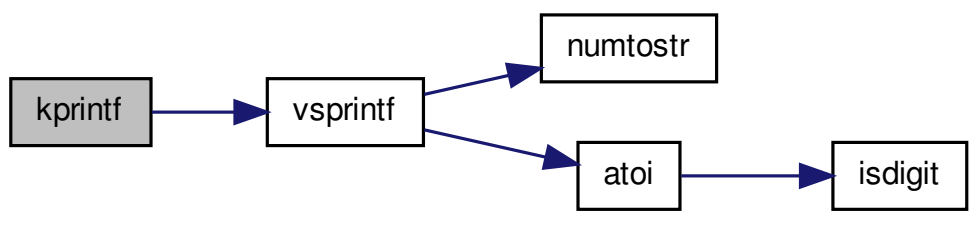

5.19.2.2 static void numtostr ( char $* *$ dest, char flags, long int value, int base, int prec, char sig ) [static]

Convert number to string (in specific base)

Parameters

\begin{tabular}{|r|l|}
\hline dest & Destination of converted string \\
\hline flags & Flags \\
\hline value & Numeric value \\
\hline base & The base $(2=$ binary $/ 10=$ decimal $/ 16=$ hexa $)$ \\
\hline prec & Precision \\
\hline sig & Signed conversion $(0=$ unsigned $)$ \\
\hline
\end{tabular}

5.19.2.3 int sprintf ( char $*$ str, const char $*$ format, $\quad$... )

Formatted output conversion

Parameters

\begin{tabular}{|r|l|}
\hline str & Destination string \\
\hline format & Format \\
\hline$\ldots$ & \\
\hline
\end{tabular}


Here is the call graph for this function:

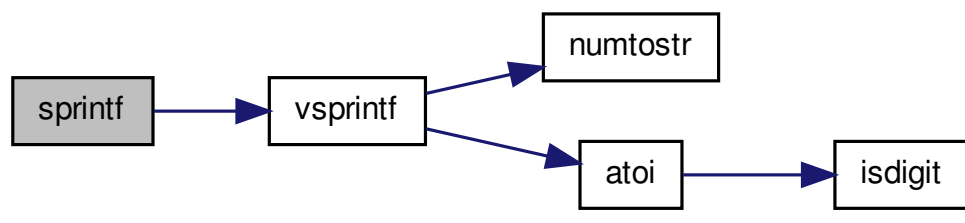

5.19.2.4 int vsprintf ( char $*$ str, const char $*$ format, va_list ap )

Formatted output conversion

Parameters

\begin{tabular}{|r|l|}
\hline str & Destination string \\
\hline format & Format \\
\hline$a p$ & Variable arguments list \\
\hline
\end{tabular}

Here is the call graph for this function:

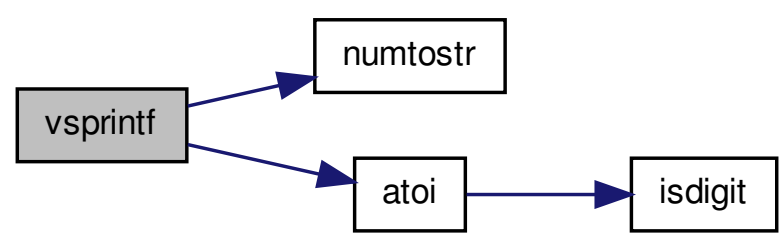




\subsection{0 read.c File Reference}

\#include <tempos/syscall.h> \#include <tempos/kernel.h>x Include dependency graph for read.c:

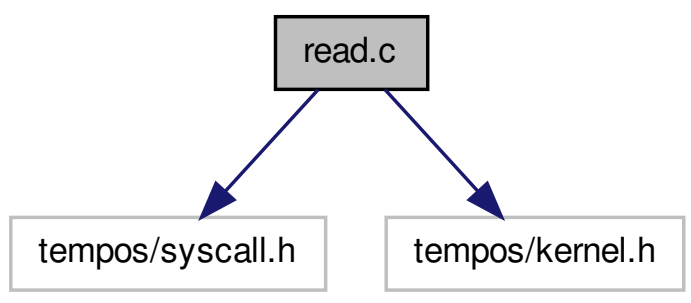

Functions

- _pushargs ssize_t sys_read (int fd, void $*$ buf, size_t count)

5.20.1 Function Documentation

5.20.1.1 _pushargs ssize_t sys_read ( int $f d$, void $*$ buf, size_t count )

Here is the call graph for this function:

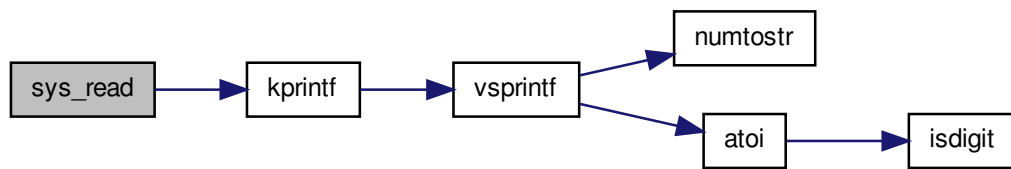

\subsection{1 sched.c File Reference}

\#include <tempos/sched.h> \#include <tempos/kernel.h>x
\#include <tempos/timer.h> \#include <tempos/jiffies.h>x 
Include dependency graph for sched.c:

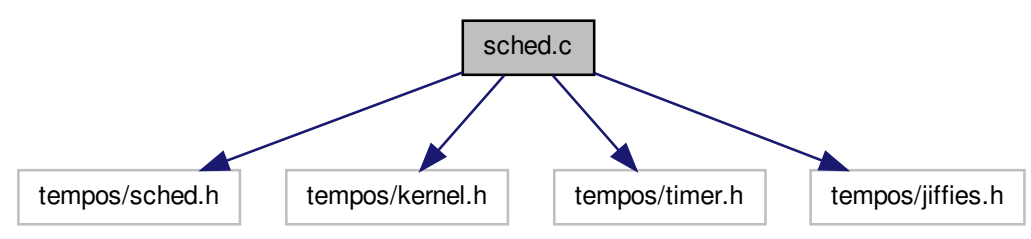

Functions

- void init_scheduler (void $(*$ start_routine $)($ void $*))$

- void do_schedule (pt_regs $*$ regs)

- void schedule (void)

\section{Variables}

- static uint32_t scheduler_quantum $=(\mathrm{HZ} / 100)$

- static size_t sched_cnt

- c_llist $*$ tasks = NULL

- c_llist $*$ cur_task $=$ NULL

5.21.1 Function Documentation

5.21.1.1 void do_schedule ( pt_regs $*$ regs )

Check if scheduler quantum is expired and make a context switch if necessary.

Note

This function is executed on each IRQ0 interrupt.

Here is the call graph for this function:

do_schedule $\rightarrow$ schedule


5.21.1.2 void init_scheduler ( void $(*)($ void $*)$ start_routine )

Initialize the scheduler. This function creates the circular linked list and call architecture specific code to initialize the scheduler.

Here is the call graph for this function:

$$
\text { init_scheduler } \rightarrow \text { c_llist_create }
$$

5.21.1.3 void schedule ( void )

Decides what task to run and make the task switch.

TempOS scheduler uses a round robin policy.

5.21.2 Variable Documentation

5.21.2.1 c_llist $*$ cur_task $=$ NULL

Element of list that points to current task

5.21.2.2 size_tsched_cnt [static]

Scheduler time counter

5.21.2.3 uint32_t scheduler_quantum $=(\mathrm{HZ} / \mathbf{1 0 0}) \quad$ [ s t at $\mathrm{i}$ c ]

Scheduler Quantum

5.21.2.4 c_Ilist $*$ tasks $=$ NULL

Linked list of all tasks

\subsection{2 semaphore.c File Reference}

\#include <semaphore.h>\#include <stdlib.h>\#include <arch/io.$\mathrm{h}>$ \#include <arch/atomic.h> Include dependency graph for semaphore.c: 


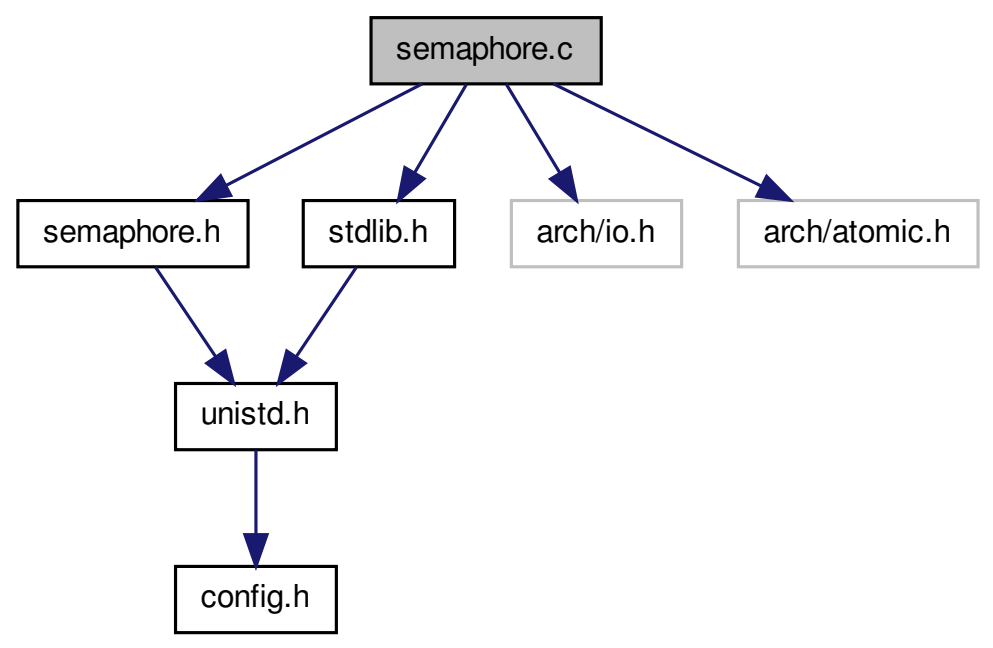

Functions

- int mutex_init (sem_t $*$ mutex)

- int mutex_is_locked (sem_t mutex)

- void mutex_spin_down (sem_t $*$ mutex)

- void mutex_up (sem_t $*$ mutex)

5.22.1 Function Documentation

5.22.1.1 int mutex_init ( sem_t $*$ mutex )

Init a mutex semaphore.

Parameters

mutex Pointer to sem_t mutex.

Returns

int 0 if mutex was started, -1 otherwise.

5.22.1.2 int mutex_is_locked ( sem_t mutex )

Get the state of a mutex 
Parameters

mutex

Returns

int 1 if mutex is locked, 0 otherwise.

5.22.1.3 void mutex_spin_down ( $\operatorname{sem}$ _t $*$ mutex )

Make a down operation on the mutex. This function works by first check the value of mutex, if mutex is greater than 0 , the value is decremented and the function returns. On the other hand, if mutex is 0 , the function will wait in a loop (busy wait) until mutex is locked.

Parameters

mutex Mutex

5.22.1.4 void mutex_up ( sem_t $*$ mutex )

Make an UP operation on mutex. This function just increments the value of mutex.

Parameters

mutex Mutex to "unlock". 


\subsection{3 semaphore.h File Reference}

\#include <unistd.h> Include dependency graph for semaphore.h:

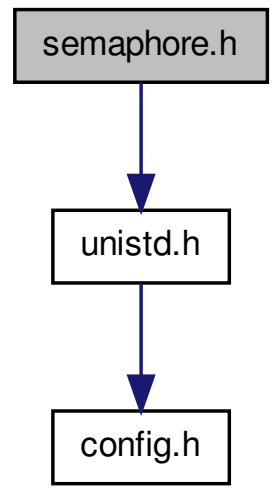

This graph shows which files directly or indirectly include this file:

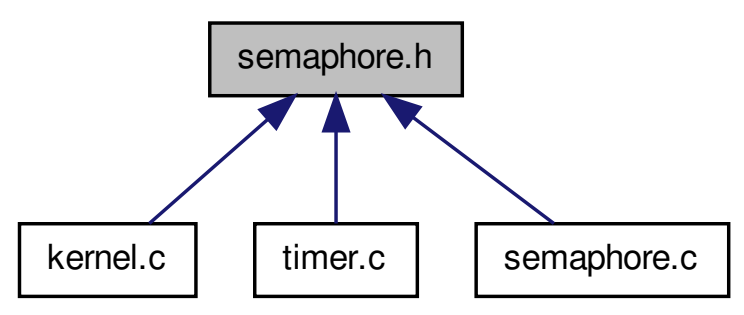

Typedefs

- typedef uint32_t sem_t

Functions

- int mutex_init (sem_t $*$ mutex) 
- int mutex_is_locked (sem_t mutex)

- void mutex_spin_down (sem_t $*$ mutex)

- void mutex_up (sem_t $*$ mutex)

5.23.1 Typedef Documentation

5.23.1.1 typedef uint32_t sem_t

Semaphore structure

5.23.2 Function Documentation

5.23.2.1 int mutex_init ( sem_t $*$ mutex )

Init a mutex semaphore.

Parameters

mutex Pointer to sem_t mutex.

Returns

int 0 if mutex was started, -1 otherwise.

5.23.2.2 int mutex_is_locked ( sem_t mutex )

Get the state of a mutex

Parameters

mutex

Returns

int 1 if mutex is locked, 0 otherwise.

5.23.2.3 void mutex_spin_down ( $\operatorname{sem} \_t$ t $*$ mutex )

Make a down operation on the mutex. This function works by first check the value of mutex, if mutex is greater than 0 , the value is decremented and the function returns. On the other hand, if mutex is 0 , the function will wait in a loop (busy wait) until mutex is locked.

Parameters

mutex Mutex 
5.23.2.4 void mutex_up ( sem_t $*$ mutex )

Make an UP operation on mutex. This function just increments the value of mutex.

Parameters

mutex Mutex to "unlock".

\subsection{4 stdlib.c File Reference}

\#include <stdlib.h> \#include <ctype.h> Include dependency graph for stdlib.c:

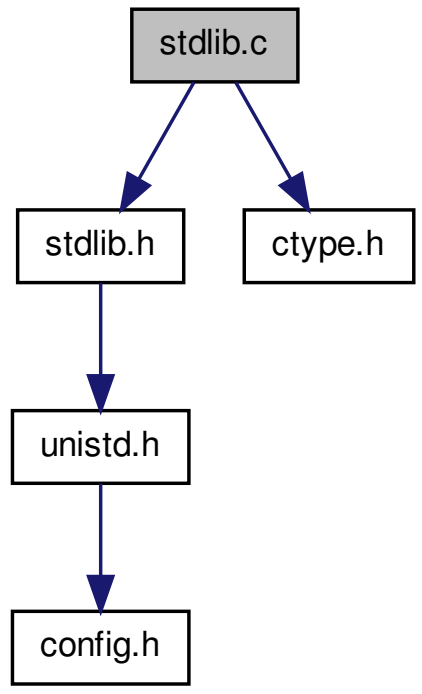

Functions

- int atoi (const char $*$ nptr)

5.24.1 Function Documentation 
5.24.1.1 int atoi ( const char $*$ nptr )

Here is the call graph for this function:

atoi $\rightarrow$ isdigit

\subsection{5 stdlib.h File Reference}

\#include <unistd.h> Include dependency graph for stdlib.h:

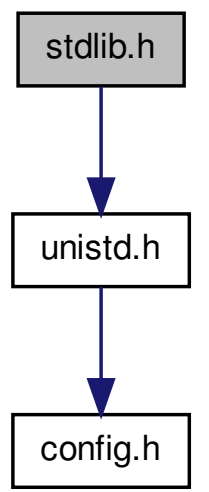


This graph shows which files directly or indirectly include this file:

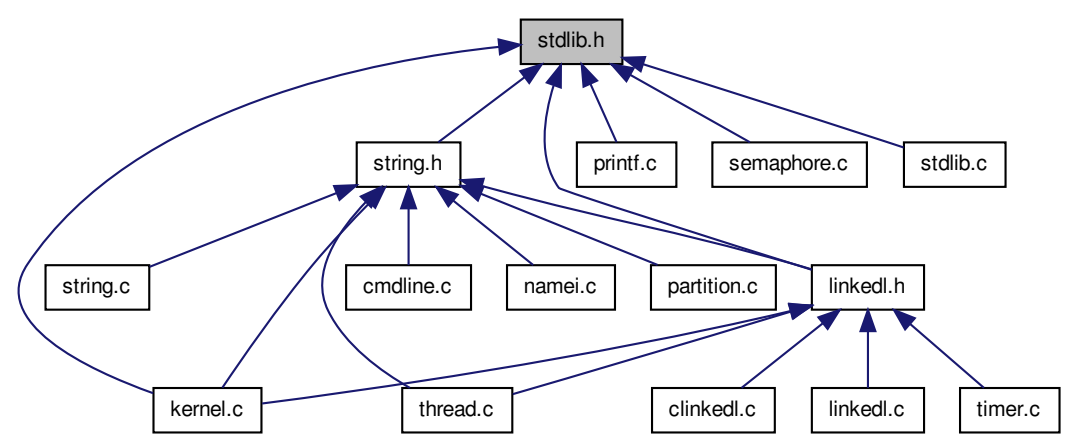

Defines

- \#define NULL ((void *)0)

Functions

- int atoi (const char $*$ nptr)

\subsubsection{Define Documentation}

5.25.1.1 \#define NULL ((void $*) 0)$

5.25.2 Function Documentation

5.25.2.1 int atoi ( const char $*$ nptr )

Here is the call graph for this function:

atoi $\longrightarrow$ isdigit




\subsection{6 string.c File Reference}

\#include < string.h> Include dependency graph for string.c:

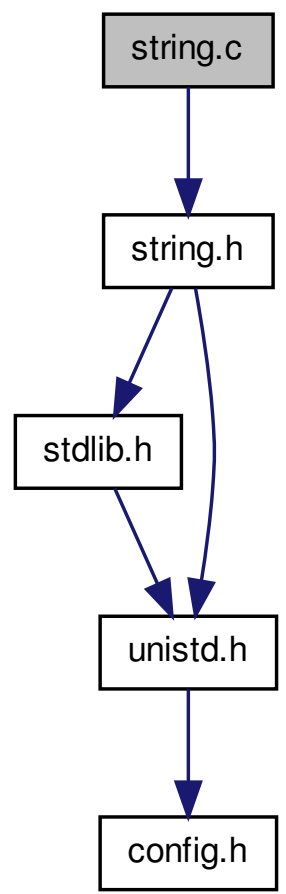

Functions

- char $*$ strcat (char $*$ dest, const char $* \operatorname{src})$

- int strcmp (const char $* \mathrm{~s} 1$, const char $* \mathrm{~s} 2$ )

- char $* \operatorname{strcpy}$ (char $*$ dest, const char $* \mathrm{src}$ )

- size_t strlen (const char $* \mathrm{~s}$ )

- char $*$ strncat (char $*$ dest, const char $*$ src, size_t $n$ )

- int strncmp (const char $* s 1$, const char $* s 2$, size_t n)

- char $*$ strncpy (char $*$ dest, const char $*$ src, size_t $\mathrm{n}$ )

- char $* \operatorname{strstr}$ (const char $*$ haystack, const char $*$ needle)

- void $*$ memcpy (void $*$ dest, const void $*$ src, size_t $\mathrm{n}$ )

- void $*$ memset (void $* \mathrm{~s}$, int c, size_t $\mathrm{n}$ ) 
5.26.1 Function Documentation

5.26.1.1 void $*$ memcpy ( void $*$ dest, const void $*$ src, size_t $n$ )

5.26.1.2 void $*$ memset ( void $* s$, int $c$, size_t $n$ )

5.26.1.3 char $*$ strcat ( char $*$ dest, const char $*$ src )

5.26.1.4 int $\operatorname{strcmp~(~const~char~} * s 1$, const char $* s 2$ )

5.26.1.5 char $*$ strcpy ( char $*$ dest, const char $*$ src )

Here is the call graph for this function:

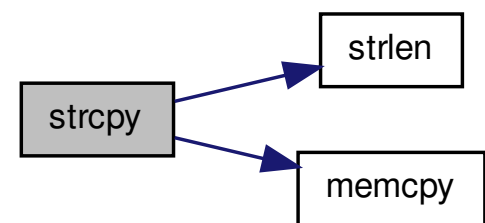

5.26.1.6 size_t strlen ( const char $* s$ )

5.26.1.7 char $*$ strncat ( char $*$ dest, const char $*$ src, size_t $n$ )

5.26.1.8 int strncmp ( const char $* s 1$, const char $* s 2$, size_t $n$ )

5.26.1.9 char $*$ strncpy ( char $*$ dest, const char $*$ src, size_t $n$ )

Here is the call graph for this function:

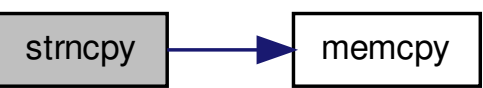

5.26.1.10 char $*$ strstr ( const char $*$ haystack, const char $*$ needle ) 


\subsection{7 string.h File Reference}

\#include <stdlib.h>\#include <unistd.h> Include dependency graph for string.h:

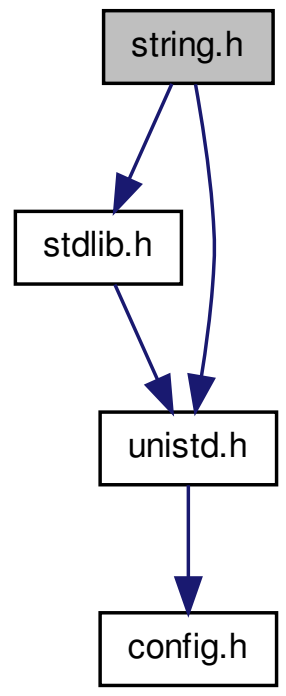

This graph shows which files directly or indirectly include this file:

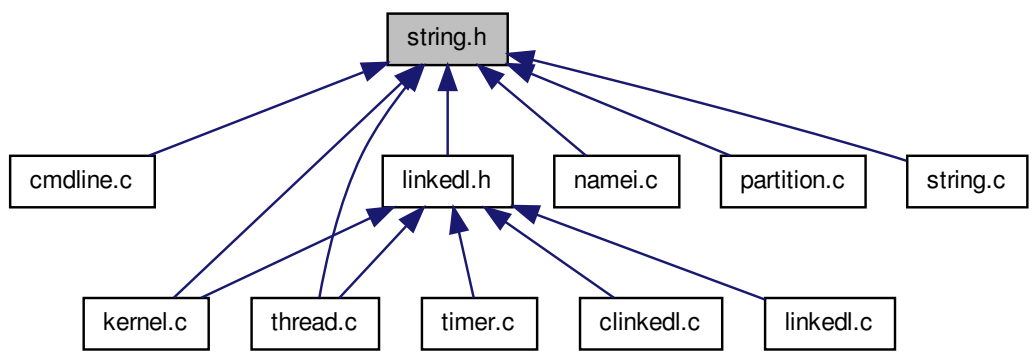


Functions

- char $* \operatorname{strcat}$ (char $*$ dest, const char $* \operatorname{src}$ )

- int strcmp (const char $* \mathrm{~s} 1$, const char $* \mathrm{~s} 2$ )

- char $*$ strcpy (char $*$ dest, const char $*$ src)

- size_t strlen (const char $*$ s)

- char $*$ strncat (char $*$ dest, const char $*$ src, size_t n)

- int strncmp (const char $* s 1$, const char $* s 2$, size_t n)

- char $* \operatorname{strncpy}($ char $*$ dest, const char $*$ src, size_t n)

- char $* \operatorname{strstr}$ (const char $*$ haystack, const char $*$ needle)

- void $*$ memcpy (void $*$ dest, const void $*$ src, size_t $\mathrm{n}$ )

- void $*$ memset (void $*$ s, int c, size_t $\mathrm{n}$ )

\subsubsection{Function Documentation}

5.27.1.1 void $*$ memcpy ( void $*$ dest, const void $*$ src, size_t $\boldsymbol{n}$ )

5.27.1.2 void $*$ memset ( void $* s$, int $c$, size_t $n$ )

5.27.1.3 char $*$ strcat ( char $*$ dest, const char $*$ src )

5.27.1.4 int $\operatorname{strcmp}$ ( const char $* s 1$, const char $* s 2$ )

5.27.1.5 char $*$ strcpy ( char $*$ dest, const char $*$ src )

Here is the call graph for this function:

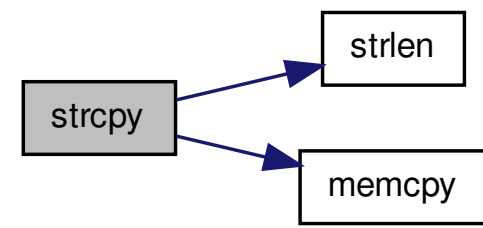

\footnotetext{
5.27.1.6 size_t strlen ( const char $* s$ )

5.27.1.7 char $*$ strncat ( $\operatorname{char} *$ dest, const char $*$ src, size_t $n$ )

5.27.1.8 int strncmp ( const char $* s 1$, const char $* s 2$, size_t $n$ )
} 
5.27.1.9 char $*$ strncpy ( char $*$ dest, const char $*$ src, size_t $n$ )

Here is the call graph for this function:

$$
\text { strncpy } \longrightarrow \text { memcpy }
$$

5.27.1.10 char $*$ strstr ( const char $*$ haystack, const char $*$ needle )

\subsection{8 syscall.c File Reference}

\#include <tempos/syscall.h> Include dependency graph for syscall.c:

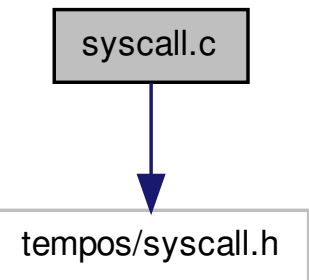

Variables

- void $*$ syscall_table []

5.28.1 Variable Documentation

5.28.1.1 void $*$ syscall_table[]

Initial value: 


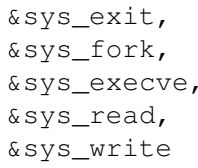

TempOS system calls table

\subsection{9 thread.c File Reference}

\#include <tempos/sched.h> \#include <tempos/kernel.h>x \#include <tempos/wait.h> \#include <tempos/mm.h> \#include <arch/io.h> \#include <linkedl.h> \#include <string.h> $\times$ Include dependency graph for thread.c:

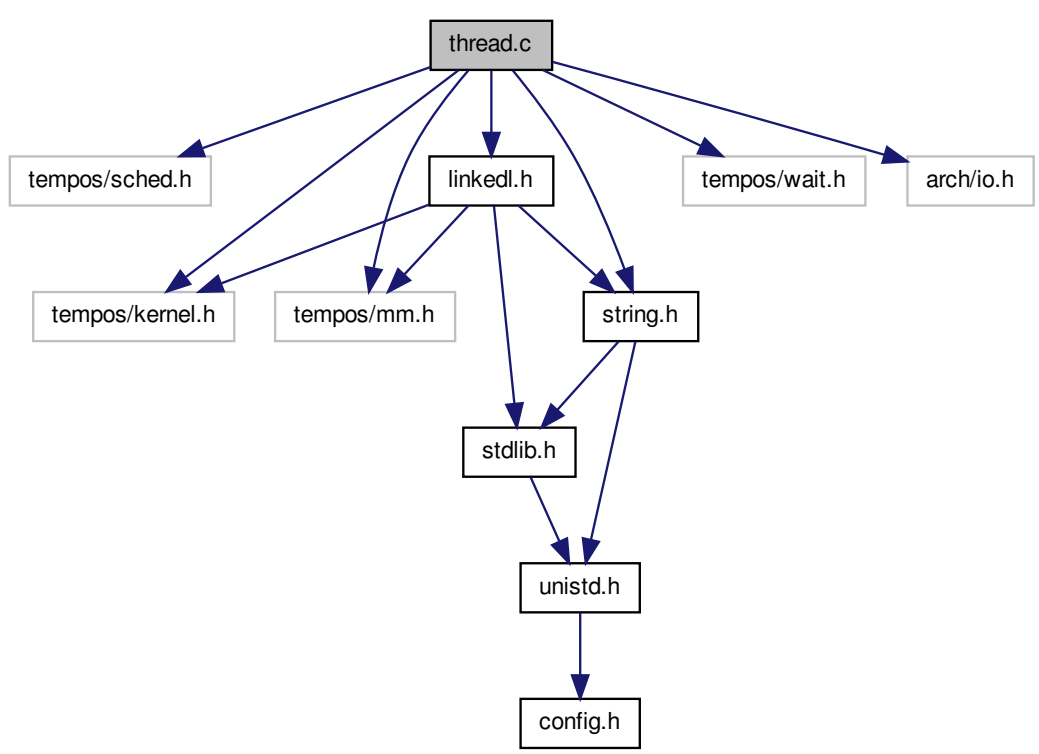

Functions

- void force_kthread_exit (void)

- task_t $*$ kernel_thread_create (int priority, void( $*$ start_routine)(void $*)$, void $*$ arg)

- void kernel_thread_exit (int return_code)

- int kernel_thread_wait (task_t $*$ th) 
5.29.1 Function Documentation

5.29.1.1 void force_kthread_exit ( void )

Here is the call graph for this function:

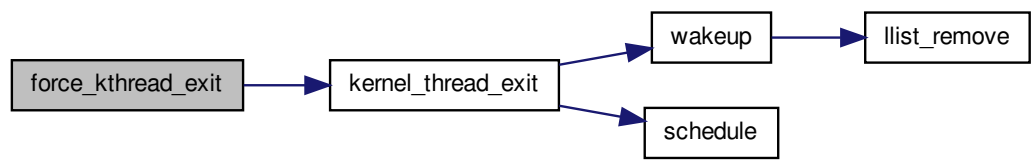

5.29.1.2 task_t $*$ kernel_thread_create ( int priority, void $(*)($ void $*)$ start_routine, void $*$ arg )

Here is the call graph for this function:

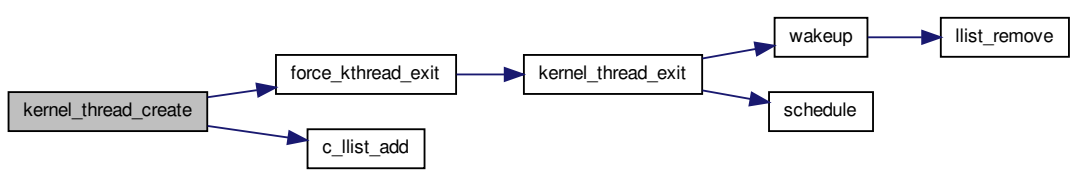

5.29.1.3 void kernel_thread_exit ( int return_code )

Here is the call graph for this function:

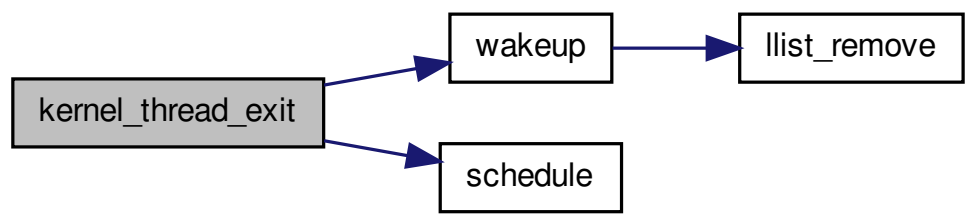


5.29.1.4 int kernel_thread_wait ( task_t $*$ th )

Here is the call graph for this function:

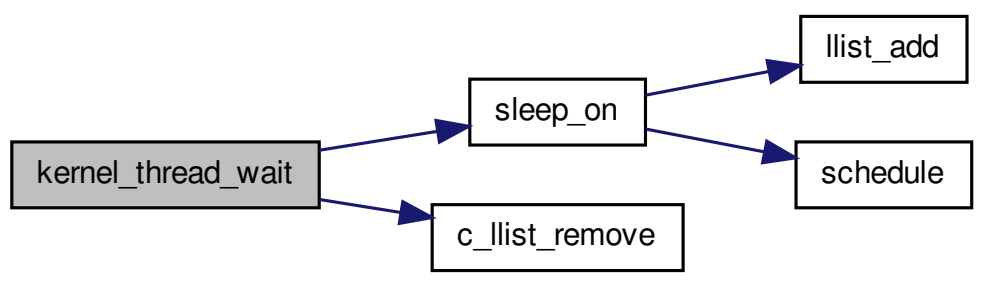

\subsection{0 timer.c File Reference}

\#include <tempos/timer.h> \#include <tempos/jiffies.h>x \#include <tempos/sched.h> \#include <linkedl.h> \#include <semaphore.h> \#include <unistd.h> \#include <arch/irq.h> \#include <arch/io.h> Include dependency graph for timer.c:

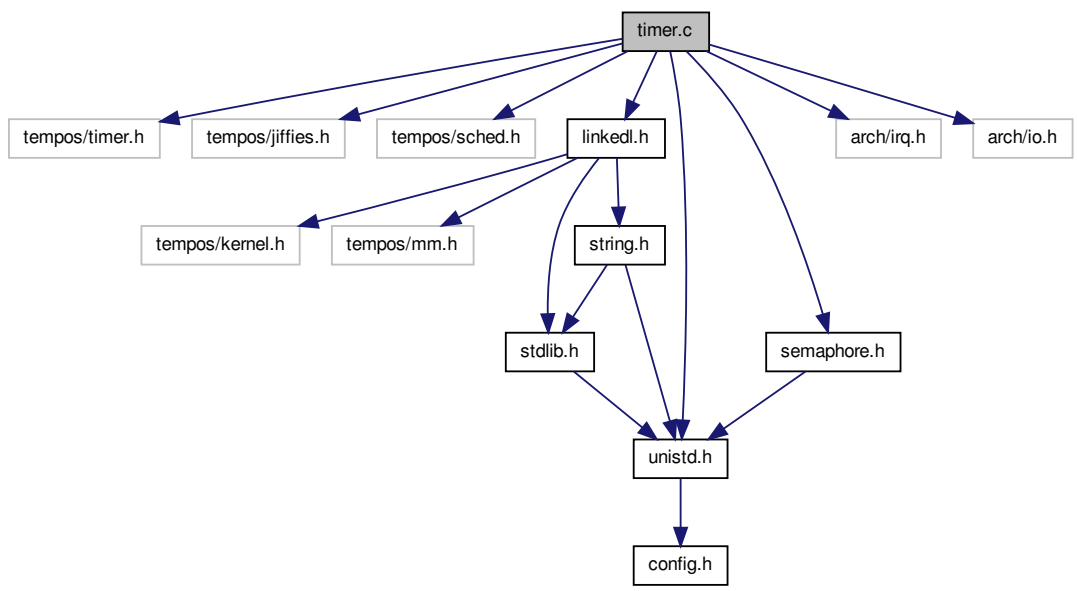

Functions

- _pushargs void timer_handler (int i, pt_regs $*$ regs) 
- void init_timer (void)

- int new_alarm (uint32_t expires, void $(*$ handler) (pt_regs $*$, void $*$ ), void $*$ arg)

Variables

- llist $*$ alarm_queue

- volatile uint32_t jiffies

5.30.1 Function Documentation

5.30.1.1 void init_timer ( void )

Initialize time system

Here is the call graph for this function:

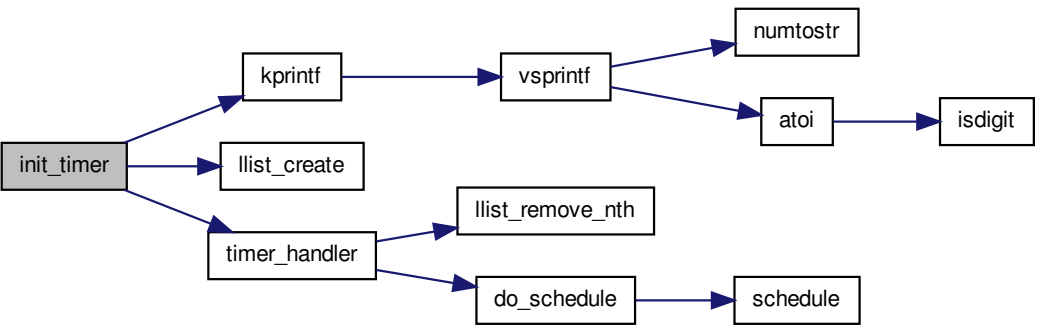

5.30.1.2 int new_alarm ( uint32_t expires, void $(*)($ pt_regs $*$, void $*)$ handler, void $* \arg$ )

Create a new alarm

Parameters

\begin{tabular}{|r|l|}
\hline expires & When alarm will expire (expressed in jiffies) \\
\hline handler & The function to be executed when alarm expires. \\
\hline$a r g$ & Argument to be passed to handler function. \\
\hline
\end{tabular}


Here is the call graph for this function:

new_alarm $\rightarrow$ llist_add

5.30.1.3 _pushargs void timer_handler ( int $i$, pt_regs $*$ regs )

Interrupt handler

Here is the call graph for this function:

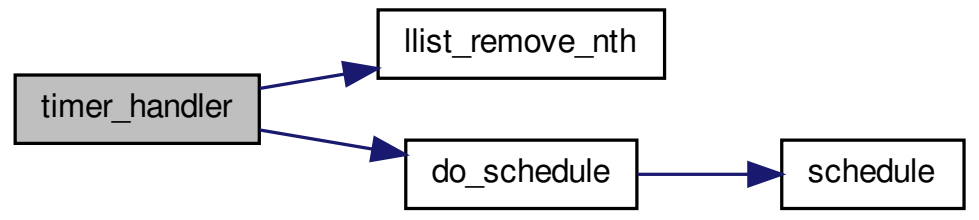

5.30.2 Variable Documentation

5.30.2.1 Ilist $*$ alarm_queue

Queue of alarms

5.30.2.2 volatile uint32_t jiffies

Contains the number of system clock ticks

Note

System frequency is expressed in hertz by $\mathrm{HZ}$ defined at compilation.

See also

tempos/timer.h 


\subsection{1 unistd.h File Reference}

\#include <config.h> Include dependency graph for unistd.h:

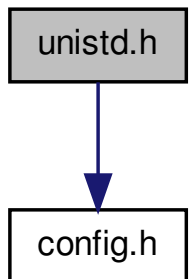

This graph shows which files directly or indirectly include this file:

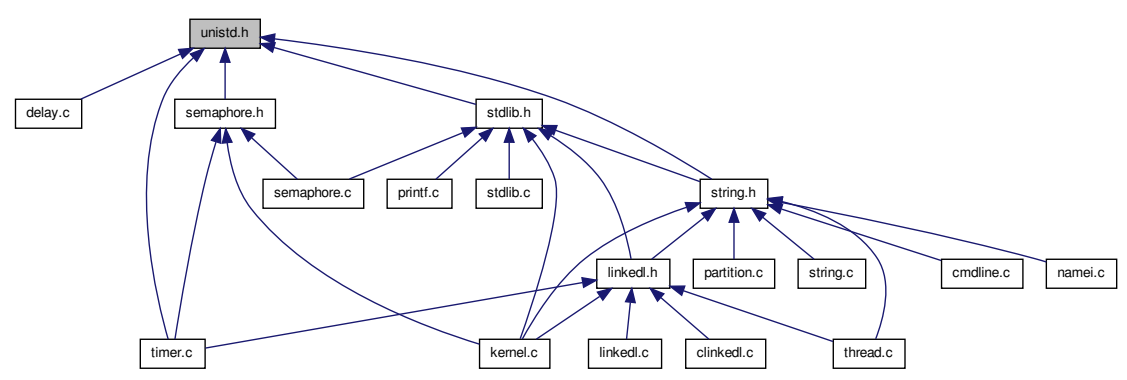

Typedefs

- typedef char char8_t

- typedef unsigned char uchar8_t

- typedef short int16_t

- typedef unsigned short uint16_t

- typedef int int32_t

- typedef unsigned int uint32_t

- typedef long long int64_t

- typedef unsigned long long uint64_t

- typedef unsigned long size_t

- typedef long ssize_t 
5.31.1 Typedef Documentation

5.31.1.1 typedef char char8_t

5.31.1.2 typedef short int16_t

5.31.1.3 typedef int int32_t

5.31.1.4 typedef long long int64_t

5.31.1.5 typedef unsigned long size_t

5.31.1.6 typedef long ssize_t

5.31.1.7 typedef unsigned char uchar8_t

5.31.1.8 typedef unsigned short uint16_t

5.31.1.9 typedef unsigned int uint32_t

5.31.1.10 typedef unsigned long long uint 64 _t

\subsection{2 vfs.c File Reference}

\#include <tempos/kernel.h> \#include <tempos/wait.h>x

\#include <fs/vfs.h>\#include <fs/device.h>\#include <arch/io.$\mathrm{h}>$ Include dependency graph for vfs.c:

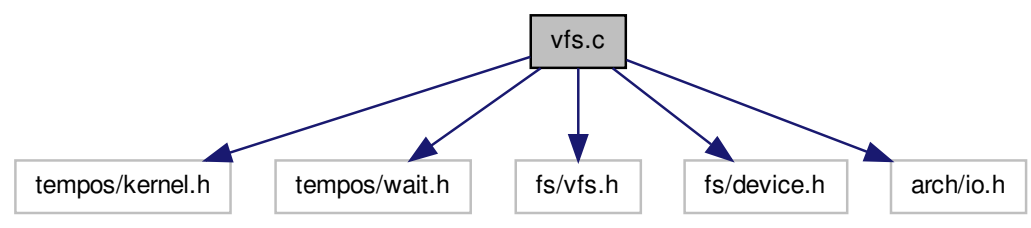

Functions

- static uint32_t_ipow (uint32_t x, uint32_t y)

- static vfs_inode $*$ search_inode (dev_t device, uint32_t number)

- static void inode_remove_from_freelist (vfs_inode $*$ inode)

- static void add_inode_htable (vfs_inode $*$ inode)

- static vfs_inode $*$ get_free_inode (vfs_superblock $*$ sb, uint32_t number)

- void register_all_fs_types (void)

- void register_fs_type (vfs_fs_type $*$ type)

- vfs_inode $*$ vfs_iget (vfs_superblock $*$ sb, uint32_t number) 
- vfs_bmap_t vfs_bmap (vfs_inode $*$ inode, uint32_t offset)

Variables

- vfs_inode $* *$ inode_hash_table

- vfs_inode $*$ free_inodes

- vfs_inode $*$ free_inodes_head

- vfs_file $*$ file_table

-vfs_mount_table mount_table [VFS_MAX_MOUNTED_FS]

- vfs_fs_type $*$ vfs_filesystems [VFS_SUPPORTED_FS]

- static int vfs_reg_types $=0$

5.32.1 Function Documentation

5.32.1.1 static uint32_t_ipow ( uint32_t $x$, uint32_t $y$ ) [static]

Integer power function.

Parameters

\begin{tabular}{|r|l|}
\hline$x$ & Operand. \\
\hline$y$ & Operand. \\
\hline
\end{tabular}

Returns

uint32_t Value $x$ raised to the power $y$.

Note

Be coherent with values $=:$ )

5.32.1.2 static void add_inode_htable ( vfs_inode $*$ inode ) $\quad$ [static ]

Remove i-node from old hash queue and inser onto new hash queue.

Parameters

inode $\mathrm{i}$-node.

5.32.1.3 static vfs_inode $*$ get_free_inode (vfs_superblock $* s b$, uint32_t number )

[static]

Get new i-node from free list and initialize it.

Parameters

$s b$ Super block associated with i-node. number i-node number. 
Returns

The new i-node.

Here is the call graph for this function:

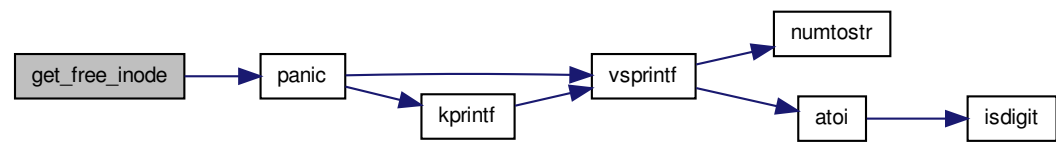

5.32.1.4 static void inode_remove_from_freelist ( vfs_inode $*$ inode ) [stat ic ]

Remove i-node from free list.

Parameters

inode $\mathrm{i}$-node.

5.32.1.5 void register_all_fs_types ( void )

This function initializes all File System types recognized by TempOS.

Note

If you are going to implement a new File System type for TempOS, your init function should be called from here.

Here is the call graph for this function:

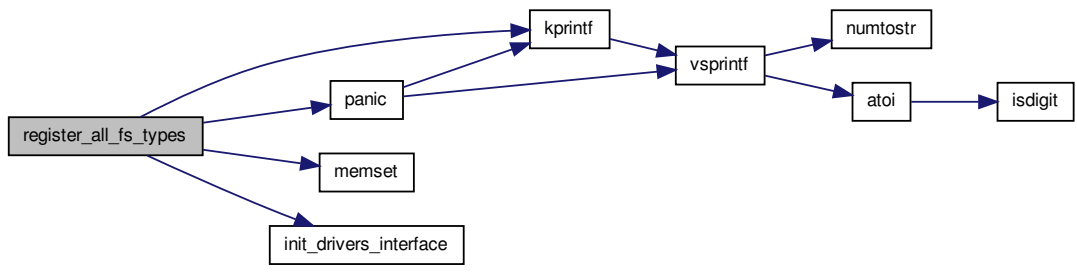

5.32.1.6 void register_fs_type ( vfs_fs_type $*$ type )

Register a file system type to VFS. 
Here is the call graph for this function:

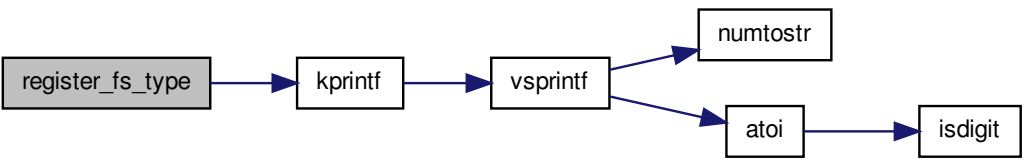

5.32.1.7 static vfs_inode $*$ search_inode ( dev_t device, uint32_t number ) [stat ic ]

Search for an i-node on i-nodes queue

Parameters

device Device which i-node belong. number i-node number

Returns

vfs_inode The i-node (if was found), NULL otherwise.

5.32.1.8 vfs_bmap_t vfs_bmap ( vfs_inode $*$ inode, uint32_t offset )

Translate file byte offset into file system block number, block offset, etc.

Parameters

\begin{tabular}{|r|l|}
\hline inode & File i-node. \\
\hline offset & File byte offset. \\
\hline
\end{tabular}

Returns

vfs_bmap_t Structure with converted numbers.

Here is the call graph for this function:

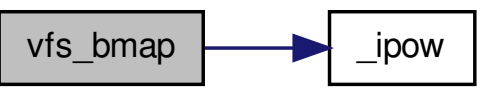


5.32.1.9 vfs_inode $*$ vfs_iget ( vfs_superblock $* s b$, uint32_t number )

Get i-node from hash table. Read from disk if i-node it's not at memory.

Parameters

\begin{tabular}{|r|l|}
\hline$s b$ & Super block of associated file system. \\
\hline number & i-node number. \\
\hline
\end{tabular}

Here is the call graph for this function:

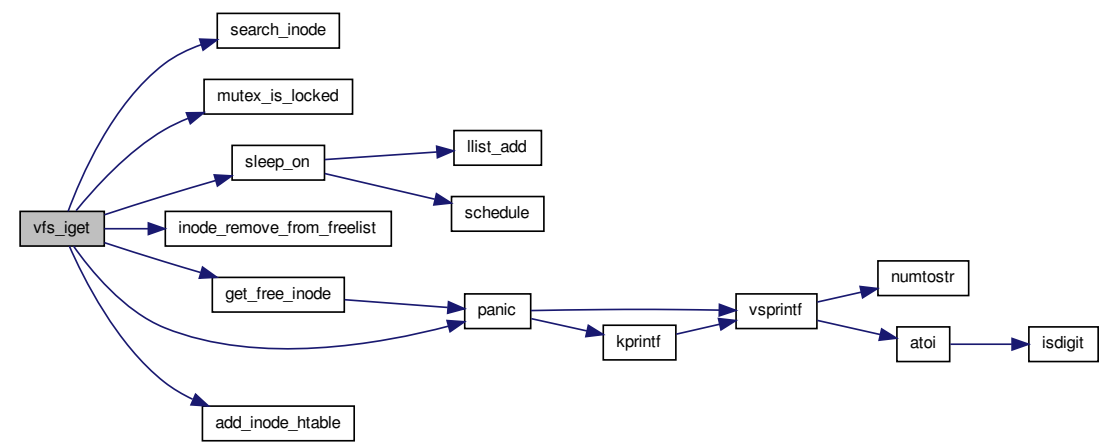

5.32.2 Variable Documentation

5.32.2.1 vfs_file $*$ file_table

Global system file table

5.32.2.2 vfs_inode $*$ free_inodes

Global list of free i-nodes

5.32.2.3 vfs_inode $*$ free_inodes_head

Head of the free i-nodes list

5.32.2.4 vfs_inode $* *$ inode_hash_table

I-nodes hash queue

5.32.2.5 vfs_mount_table mount_table[VFS_MAX_MOUNTED_FS]

Global mount table 
5.32.2.6 vfs_fs_type $*$ vfs_filesystems[VFS_SUPPORTED_FS]

Registered file system types

5.32.2.7 int vfs_reg_types $=0 \quad$ [stat i c ]

Number of file system type already registered

\subsection{3 wait.c File Reference}

\#include <tempos/wait.h> \#include <arch/io.h> Include dependency graph for wait.c:

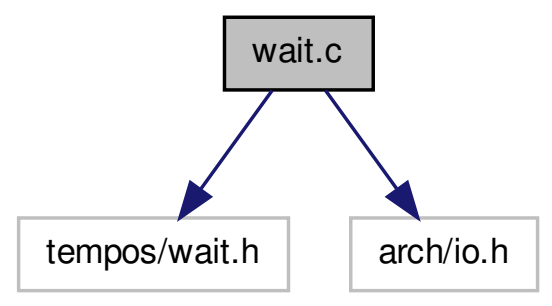

Functions

- void init_wait_queues (void)

- void sleep_on (int sleep_addr)

- void wakeup (int sleep_addr)

Variables

- Ilist $*$ wait_queues [WAIT_ADDRESS_SIZE]

5.33.1 Function Documentation

5.33.1.1 void init_wait_queues ( void )

This functions initializes the wait queues. 
Here is the call graph for this function:

init_wait_queues $\rightarrow$ llist_create

\subsubsection{2 void sleep_on ( int sleep_addr )}

This function puts the process that called it to sleep until the event represented by sleep_addr become available.

Parameters

sleep_addr The event that process should wait for.

Here is the call graph for this function:

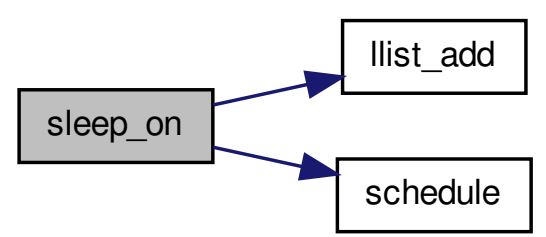

\subsubsection{3 void wakeup ( int sleep_addr )}

Wake up all process sleeping waiting for sleep_addr resource(s).

Parameters

sleep_addr Slepe address. 
Note

All process waiting for sleep_addr will be put in TASK_READY_TO_RUN state.

Here is the call graph for this function:

wakeup $\rightarrow$ Ilist_remove

5.33.2 Variable Documentation

5.33.2.1 Ilist $*$ wait_queues[WAIT_ADDRESS_SIZE]

List of wait addresses. Each position represents a wait address

\subsection{4 write.c File Reference}

\#include <tempos/syscall.h> \#include <tempos/kernel.h>x \#include <tempos/sched.h> Include dependency graph for write.c:

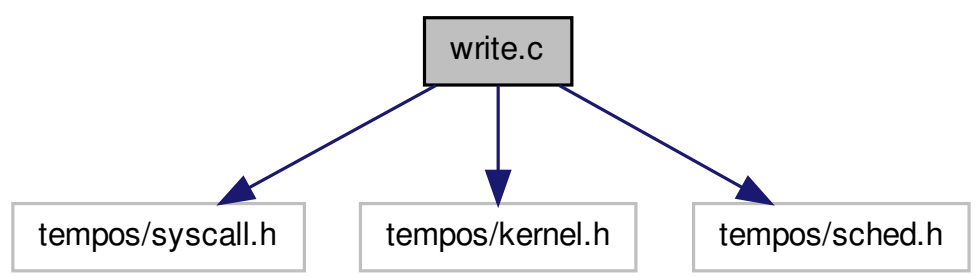

Functions

- _pushargs ssize_t sys_write (int fd, const void $*$ buf, size_t count) 


\subsubsection{Function Documentation}

5.34.1.1 _pushargs ssize_t sys_write ( int $f d$, const void $*$ buf, size_t count )

Here is the call graph for this function:

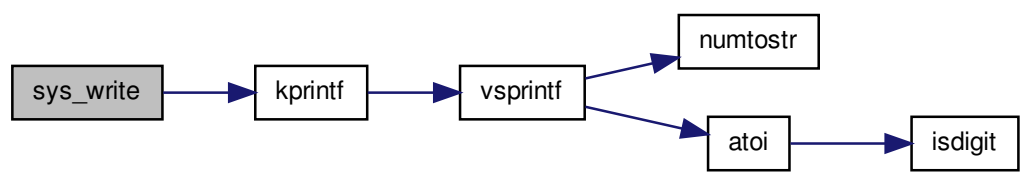

